


\section{DISCLAIMER}

This report was prepared as an account of work sponsored by an agency of the United States Government. Neither the United States Government nor any agency Thereof, nor any of their employees, makes any warranty, express or implied, or assumes any legal liability or responsibility for the accuracy, completeness, or usefulness of any information, apparatus, product, or process disclosed, or represents that its use would not infringe privately owned rights. Reference herein to any specific commercial product, process, or service by trade name, trademark, manufacturer, or otherwise does not necessarily constitute or imply its endorsement, recommendation, or favoring by the United States Government or any agency thereof. The views and opinions of authors expressed herein do not necessarily state or reflect those of the United States Government or any agency thereof. 


\section{DISCLAIMER}

Portions of this document may be illegible in electronic image products. Images are produced from the best available original document. 
IMPROVEMENT ON METHODS OF DETERMINING SEASONAL

PERFORMANCE CHARACTERISTICS OF UNITARY AIR

CONDITIONERS AND HEAT PUMPS

DOE Contract No. DE-AC02-80CS 23337

(PRF No. 0141-55-12885)

A STUDY OF THE TEST METHOD FOR PREDICTION

OF AIR CONDITIONING EQUIPMENT

SEASONAL PERFORMANCE

$$
\begin{gathered}
\text { Sponsored by } \\
\text { DOE/ARI }
\end{gathered}
$$

Report No. I

HL $80-15$

submitted by:

Steven B. Thomas, Graduate Research Assistant David R. Tree, Principal Investigator

Victor W. Goldschmidt, Principal Investigator ARI-Project

Approved by:

Raymond Cohen, Director

Ray W. Herrick Laboratories

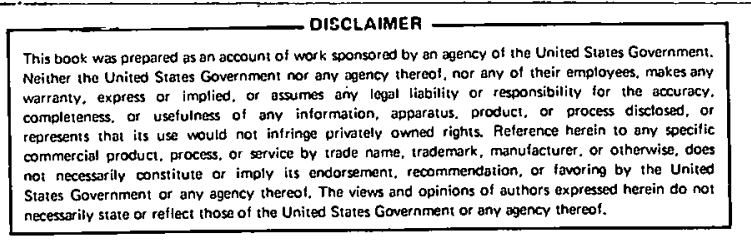

This book was prepared as an account of work sponsored by an agency of the United States Government.

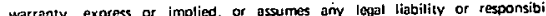
completeness. or usefulness of any information, apparatus. product, or process dischesed, or commercial produch, process, or service by trode name, trademark, manufacturer, or otherwise, does

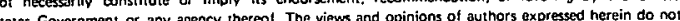
necessarily state or reflect those of the United States Government or any agency thereot. 


\title{
STUDY OF THE TEST METHOD FOR PREDICTION OF AIK CONDITIONING EOUIPMENT SEASONAL PERFORMANCE
}

\author{
A Thesis \\ Submitted to the Faculty \\ of \\ Purdue University \\ by \\ Steven Bruce Thomas \\ In Partial Fulfillment of the \\ Requirements for the Degree. \\ of \\ Master of Science \\ May 1980
}


$\therefore$

Part of the information in this report was obtained under the sponsorship of the Air-Conditioning and Refrigeration Institute as a complementary project to the Department of Energy project.

By mutual consent of DOE and ARI, that information has been included in this report and has been made available to both sponsors. 


\section{ACKNOWLEDGEMENTS}

The author is deeply grateful to his major professors, Dr. David R. Tree and Dr. Victor W. Goldschmidt for the time, patience and guidance devoted to the research which led to this thesis. A note of appreciation is extended to the graduate students of the Ray $W$. Herrick Laboratories and especially to Mr. William E. Murphy and Mr. Frederic Laville for their many ideas, positive attitude and encouragement. 
TABLE OF CONTENTS

Page

LIST OF TABLES . . . . . . . . . . . . . . . . . . . . . vi

LIST OF FIGURES. . . . . . . . . . . . . . . . . . . . viii

NOMENCLATURE . . . . . . . . . . . . . . . . . . . . . . xi

ABSTRACT . . . . . . . . . . . . . . . . . . . . . . .xviii

CHAPTER I INTRODUCTION AND LITERATURE SURVEY. . . . . . 1

A) Introduction . . . . . . . . . . . . . . . . . . . 1

B) Rating Method for the Central Air

Conditioner and Heat Pump in Cooling Mode. . . . . 3

C) Proposed DOE Test Method . . . . . . . . . . . . . 7

D) Scope of Work. . . . . . . . . . . . . . . . . . 9

E) Literature Survey of Non-Steady Performance. . . . 10

CHAPTER 2 INITIAL STUDY AND EXPERIMENTAL DATA. . . . . I4

A) Initial Study. . . . . . . . . . . . . . . . . . . 14

1. Collection of Cyclic Data. . . . . . . . . . . 14

2. Visitation and Questionnaire....... . . 15

B) Problems Reported in Obtaining Data.. . . . . . . 20

1. Duration of Tests. . . . . . . . . . . . . . . 20

2. Air Flow Modifications . . . . . . . . . . . . 20

3. Temperature Readings . . . . . . . . . . . . . 23

4. Coil Conditions. . . . . . . . . . . . . . . 24

5. Maintaining Room Conditions. . . . . . . . . 25

6. Sampling . . . . . . . . . . . . . . . . . 25

C) Experimental Data. . . . . . . . . . . . 26

1. Data Analysis. . . . . . . . . . . . . . . 26

CHAPTER 3 ANALYSIS OF TRANSIEINT RESPONSE BASED ON SEMI-EMPIRICAL FORMULA. . . . . . . . . . . . . . . . 39

A) Assumptions Used in Semi-Empirical Study . . . . . 39

B) Derivation of Semi-Empirical Equarions. . . . . . 41 1. Cooling Load Factor. . . . . . . . . . . . . . 41 2. Degradation Coefficient and Fart-Load . . . . 43

C) Semi-Empiricai Analysis With Thermostat Model. 
Page

CHAPTER 4 SENI-EMPIRICAL ANALYSIS OF

EER RATIOS. . . . . . . . . . . . . 63

A) Semi-Empirical Analysis of Steady State . . . . . . . . . . . . . . . . . 3

B) Semi-Empirical Analysis of Cyclic . . . . . . . . . . . . . . . . . . . . . . . . 74

CHAPTER 5 ERROR ANALYSIS. . . . . . . . . . . . . . . . . . . . 81

A) Introduction . . . . . . . . . . . . . . . . . . . . . . 81

B) Propagation of Allowable Measured Errors . . . . 81

C) Probable Error . . . . . . . . . . . . . . . . . 91

D) Error Resulting from Room Dependence . . . . . . 92

CHAPTER 6 DIFFERENT METHODS OF COMPUTING.

SEASONAI ENERGY EFFICIENCY RATIO
FOR TESTS A;B,C AND D. . . . . . . . . . . . . . 95

A) Introduction and Methods Used. . . . . . . . . . 95

B) Results from SEER Comparisons. . . . . . . . . . 100

CHAPTER 7 CONCLUSIONS AIND RECOMMENDATIONS . . . . . 194

A) Conclusions. . . . . . . . . . . . . . . . . 104

B) Recommendations. . . . . . . . . . . . . . . . 105

BIBLIOGRAPHY . . . . . . . . . . . . . . . . . 107

APPEINDICES

APPENDIX A CONPANIES IN ART UNITARY AIR-

APPEINDIX B QUESTIONINAIRE

DOE TESTS FOR CENTRAL AIR CONDITION-

APPENDIX C TEST ROOM CONFIĊURATIÓNS F́ROM $\cdot \cdot \cdot \cdot \cdot 113$

ASHRAE STANDARD 37-69. . . . . . . . . 116

APPENDIX D EXPERIMENTAL DATA. . . . ......... . . 121

APPENDIX E DERIVATION OF LEAST SQUARES METHOD

FOR THE DEGRADATION COEFFICIENT

APPENDIX F RESULTS OF SEER AND DEVA ANATYSIS

FOR $166^{\circ}$ UNITS. 
1-1 Possible Test Methods for Estimating Seasonal Energy Usage. . . . . . . . . . . . 6

1-2 Method Response to Effects Taken into Consideration. . . . . . . . . . . . . . . . . 6

1-3 Summary of Test and Rating Requirements; Indoor and Outdoor Entering Air Temperature and Mode of Operation, From Ref. 20 .

2-1 Summary of Available Data as of October 3i, 1979 . . . . . . . . . . . . . . . 15

2-2 Summary of Information Obtained From Questionnaire (Summer 1978) . . . . . . . 18

3-1 Summary of Results When Using Thermostat Demand Cycle... . . . . . . . . . . 60

3-2 Slope of Line at the Same Percent On-Time. . . . . . . . . . . 61

3-3 Results of Least Squares Method. . . . . . . . 61

5-1 Test Operating Tolerances for Steady State Wet and Dry-Coil Tests A,B \& C (20). . . 82

5-2 Test Operating Tolerances for Cyclic Dry-Coil Test D (20)......... . . 83

5-3 Percent Deviation of $\mathrm{CPLF}^{1}$ with Variation of Thermocouple Response Rate. . . . . . . . : 84

5-4 Accuracy of Instruments (20) . . . . . . . . 90

5-5 Sumnary of Error Analysis. . . . . . . . . . . . 94

D-I Experimental Data. . . . . . . . . . . . 32 ?

F-1 Power Consuription Ratio. . . . . . . . . . . . . 132 
vii

Table

Page

F-2 Seasonal Energy Efficiency Ratio

$$
\begin{aligned}
& \text { Calculated Using } \dot{E}_{C} / \dot{E}_{D} \neq 1 \text { for all } \\
& \text { Percent on -Times. . . . . . . . . . . . . . . . . . } 139
\end{aligned}
$$

F-3 Deviations of the Different Methods

$$
\text { from SEER(BLD) when Using } \dot{E}_{C} / \overline{\dot{E}}_{D} \neq 1 . . . .14 \epsilon
$$

F-4 Seasonal Energy Efficiency Ratio Calculation

$$
\text { Using } \dot{\mathrm{E}}_{\mathrm{C}} / \dot{\mathrm{E}}_{\mathrm{D}}=1 \text { for all Percent On-Times. . . . } 153
$$

F-5 Deviations of the Different Methods from

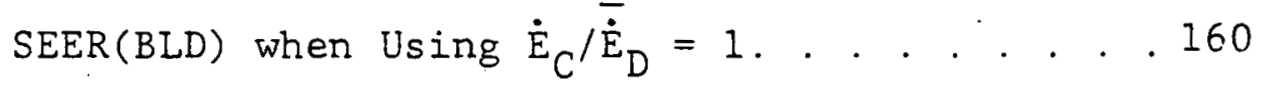




\section{LIST OF FIGURES}

Figure

Page

2-1 Temperature Difference Across Evaporator

Coil as a Function of On-Time....... . . 22

2-2 $\operatorname{EER}_{\mathrm{B}}$ vs. $\mathrm{EER}_{\mathrm{A}}$. . . . . . . . . . . . . . . . . . . . 27

2-3 $\operatorname{EER}_{C}$ vs. $\operatorname{EER}_{A} \cdot$. . . . . . . . . . . . . . . . . . . . . 28

$2-4 \operatorname{EER}_{\mathrm{D}}$ vs. $\mathrm{EER}_{\mathrm{A}}$. . . . . . . . . . . . . . . . . . 29

$2-5 C_{D}$ vs. $E_{A}$. . . . . . . . . . . . . . . . . . . 30

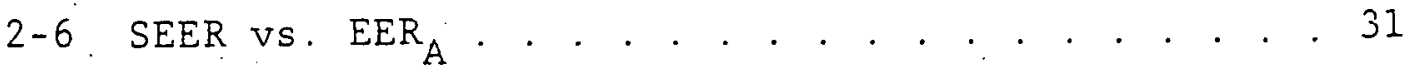

2-7 C C VS. SEER . . . . . . . . . . . . . . . . . . . 32

2-8 $\mathrm{EER}_{\mathrm{D}} / \mathrm{EER}_{\mathrm{C}}$ vs. $\mathrm{EER}_{\mathrm{A}} / \mathrm{EER}_{\mathrm{B}}$. . . . . . . . . . . . . 34

2-9 Temperature Drop Across the Evaporator Coil as a Function of Time, $\Delta \mathrm{T}_{\mathrm{O}}=0 . . . .35$

2-10 Temperature Drop Across the Evaporator Coil as a Function of Time, $\Delta \mathrm{T}_{0} \neq 0 . . \cdot . \cdot . \cdot . \cdot . \cdot 36$

2-11. Another Plot of the Temperature Drop Across the Evaporator Coil as a Function of

Time, $\Delta \mathrm{T}_{0}=0 .$. . . . . . . . . . . . . . . 37

3-1 The General Response Curve as a Result of
an Ideal Thermostat Response. . . . . 46

3-2 Cycle-Time vs. On-Time as Determined from the Thermostat Demand Cycle at Different. Maximum $\mathrm{CPH}$. . . . . . . . . . . . . . . 49

3-3 Cycle-Time vs. Percent On-Time as Determined from the Thermostat Demand Cycle at Different Maximum $\mathrm{CPH}$. . . . . . . . . . . 50

3-4 On-Time vs. Percent On-Time as Determined from Thermostat Demand Cycle at Different Maximum $\mathrm{CPH}$. 
Figure

Page

3-5. Cooling Load Factor vs. On-Time at Different Maximum CPH, with a Variable Cycle-Time Determined from Thermostat Demand Cycle. . . . 52

3-6 Cooling Load Factor vs. Cycle-Time at Different Maximum $\mathrm{CPH}$, with a Variable On-Time Determined from Thermostat Demand Cycle. . . . . 53

3-7 Cooling Load Factor as a Function of Percent On-Time at Different Maximum CPH . . . 54

3-8 Part-Load Factor vs. On-Time at Different Maximum CPH, with a Variable Cycle-Time Determined from Thermostat Demand Cycle. . . . 56

3-9 Part-Load. Factor vs. Cycle-Time at Different Maximum CPH, with a Variable On-Time Determined from Thermostat Demand Cycle. . . 57

3-10 Part-Load Factor as a Function of Percent On-Time at Different Maximum $\mathrm{CPH}$. . . . . . . 58

3-11 Part-Load Factor vs. Cooling Load Factor at Different Maximum $\mathrm{CPH}$, with On-Time and Cycle-Time Determined from Thermostat Demand Cycle. . . . . . . . . . . . . . 59

4-1 Schematic of the Basic Vapor Compression Cooling System. . . . . . . . . . . . . . . 64

4-2 Temperature - Entropy Diagram of an Ideal Vapor Compression Cooling Cycle... . . . 65

4-3 Pressure - Enthalpy Diagram of an Ideal Vapor Compression Cooling Cycle... . . . : . 65

4-4 Detailed Look at Temperature - Entropy Diagram for Basic Vapor Compression System. . . . . . . . . . . . . . . 68

4-5 Typical Response of Condensing Temperature to Ambient Temperature (9). :. . . . . . . . . . 72

4-6 Evaporator Temperature vs. Ambient Temperature. . . . . . . . . . . . . . . 72

4-7 Typical Performance of Most Central Air Conditioners (Steady State Conditions). . . . . 73 
Figure

Page

4-8 Total Power Input for the Same Ambient Conditions for Test C vs. Test D. . . . . . . . 77

4-9 Ideal Response of $\Delta T$ Across Evaporator Coil as. a Function of Time. . . . . . . . . . . . 78

6-1 Heat Pump in Cooling Mode (8) . . . . . . . . . . 98

6-2 Percent Deviation of SEER(EMP) from SEER(BLD) when the Power Consumption Ratio is Unity for all Percent On-Times. . . . . . . .103

C-1 Reproduction of Figure 1 from ASHRAE Standard 37-69. . . . . . . . . . . . . . . . 117 .

C-2 Reproduction of Figure 2 from ASHRAE Standard 37-69... . . . . . . . . . . . . . 118

C-3 Reproduction of Figure 3 from ASHRAE Standard 37-69. . . . . . . . . . . . . . . . 119

C-4 Reproduction of Figure 4 from ASHRAE Standard 37-69. . ... . . . . . . . . . . . . 120 


\section{NOMENCLATURE}

\section{$A_{n}$}

Btu

C

C

$\mathrm{C}_{1}$

$\mathrm{C}_{\mathrm{D}}$

$\mathrm{C}_{\mathrm{pa}}$

CAC

CLF

COP

CORCOEF

COOLING

COOLING

CONT.ING:

$\mathrm{CPH}$
Area of nozzle $\left[f t^{2}\right]$.

British thermal unit.

Coefficient of discharge at nozzle.

Portion of cooling delivered from ideal vapor compression cycle.

Constant defined in Eqn. 4-28.

Degradation factor for cyclic operation, defined by Eqn. 3-11.

Specific heat at constant pressure of air-water mixture per pound of dry air, $\left[\mathrm{Btu} / 1 \mathrm{~b}-{ }^{\circ} \mathrm{F}\right]$.

Central air conditioner.

Cooling load factor, defined as the ratio of the total cyclic cooling done in a.complete cycle of specified period consisting of an "on"-time and "off"-time to the steady-state cooling done over the same time period at constant ambient conditions.

Coefficient of performance.

Correlation coefficient.

Cooling resulting from ideal vapor compression cycle, [Btu/h].

Cooling resulting from ideal vapor compression cycle, [Btu/h]

Purtion of cooling resulting from ideal vapor compression cycle, $B t u / h]$

Cycle per hour, $[1 / \mathrm{h}]$. 
CPLF

$\mathrm{CR}$

$\mathrm{CR}(50)$

DEVA (EX, CL)

$\operatorname{DEVA}(E X, E M)$

DEVA (DOE)

$\operatorname{DEVA}(20)$

DEVA (50)

DEVA2 (50)

$\operatorname{DEVA}(E M P)$

DEVA (2DOE)

$E\left(T_{j}\right)$

$\dot{\mathrm{E}}$

$\dot{\mathrm{E}}_{C}(20)$

$\overline{\dot{E}}_{D}(20)$

EER

EER $_{\text {A }}$
Cooling part-load factor.

Cycle rate, $[1 / \mathrm{h}]$.

Cycle rate at $50 \%$ on-time, [I/h] .

Deviation between experimental PLF and cooling PLF.

Deviation between experimental PLF and empirical PLF.

Deviation between SEER(BLD) and $\operatorname{SEER}(D O E)$.

Deviation between SEER(BLD) and SEER(20).

Deviation between SEER(BID) and SEER(50).

Deviation between SEER(BLD) and SEER2 (50).

Deviation between SEER(BLD) and $\operatorname{SEER}($ EMP).

Deviation between SEER(DOE) and $\operatorname{SEER}(20)$

Energy usage in temperature bin $j$, [Btu].

Rate of total seasonal electrical energy usage [Watt].

Power consumption of test C at $20 \%$ on-time [Watt].

Average power consumption of test $D$ at $20 \%$ on-time [Watt]

Energy efficiency ratio, defined as the ratio of total capacity of the unit to the total power input at specified indoor and oudoor ambient conditions, [Btu/W-h] .

The energy efficiency ratio based on Test A, $[B t u / W-h]$. 


\begin{tabular}{|c|c|}
\hline$E_{E} R_{B}$ & $\begin{array}{l}\text { The energy efficiency ratio based on } \\
\text { Test } B,[B t u / W-h] \text {. }\end{array}$ \\
\hline${ }^{E E R} \mathrm{C}$ & $\begin{array}{l}\text { The energy efficiency ratio based on } \\
\text { Test } C,[B t u / W-h]\end{array}$ \\
\hline $\mathrm{EER}_{\mathrm{D}}$ & $\begin{array}{l}\text { The energy efficiency ratio based on } \\
\text { Test } \mathrm{D} ;[\mathrm{Btu} / \mathrm{W}-\mathrm{h}] \text {. }\end{array}$ \\
\hline$e_{x}$ & $\begin{array}{l}\text { The per unit error in } x \text {, where } x \text { is a } \\
\text { variable. }\end{array}$ \\
\hline $\mathrm{h}$ & Hour \\
\hline$h_{i}$ & $\begin{array}{l}\text { Enthalpy of refrigerant at point } \\
i=1 \text { to } 4 \text {. }\end{array}$ \\
\hline $\mathrm{k}$ & Kilo \\
\hline $\mathrm{K}$ & Constant defined by Eqn. 3-6. \\
\hline $\mathrm{N}$ & Total number of temperature bin hours. \\
\hline $\mathrm{N}$ & Total number of cycles. \\
\hline $\mathrm{p}$ & Probable error defined by Eqn. $5-28$. \\
\hline P.v & $\begin{array}{l}\text { Velocity pressure at nozzle throat } \\
\text { or static pressure difference across } \\
\left.\text { nozzle [in. } \mathrm{H}_{2} \mathrm{O}\right]\end{array}$ \\
\hline$P_{n}$ & $\begin{array}{l}\text { Pressure at nozzle throat Iin. Hg } \\
\text { absolute]. }\end{array}$ \\
\hline PLF & $\begin{array}{l}\text { Part-load factor, deined as the ra- } \\
\text { tio of the cyciic energy-efficiency } \\
\text { ratio to tine steady state efficiency } \\
\text { ratio, see Fquation } 3=15 \text {. }\end{array}$ \\
\hline $\operatorname{PLF}(C L G)$ & $\begin{array}{l}\text { Part-load facior determined with } \\
\dot{\mathrm{E}}_{\mathrm{C}} / \dot{\mathrm{E}}_{\mathrm{D}}=1: 0\end{array}$ \\
\hline $\operatorname{PLF}(E M P)$ & $\begin{array}{l}\text { Part-load factor determined empiri- } \\
\text { cally. }\end{array}$ \\
\hline PLF $(E X P)$ & $\begin{array}{l}\text { Part-load factor determined experi- } \\
\text { mentally. }\end{array}$ \\
\hline $\operatorname{PLF}(0.5)$ & Part-load factor at $50 \%$ on-time. \\
\hline & Percent on-time. \\
\hline
\end{tabular}




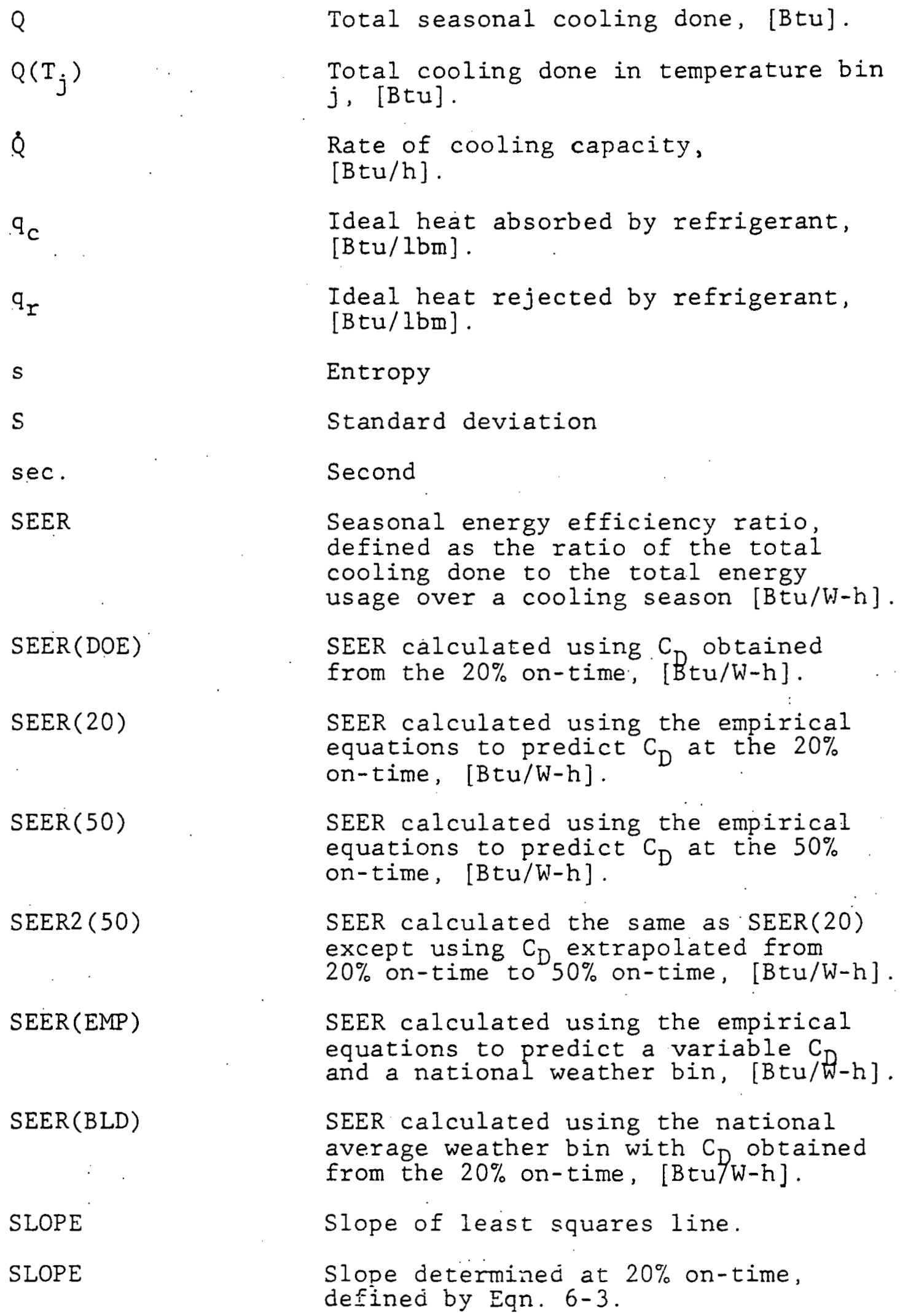

Seasonal energy efficiency ratio, defined as the ratio of the total cooling done to the total energy usage over a cooling season $[\mathrm{Btu} / \mathrm{W}-\mathrm{h}]$ ].

SEER calculated using $C_{D}$ obtained from the $20 \%$ on-time, [Btu/W-h] .

SEER calculated using the empirical equations to predict $C_{D}$ at the $20 \%$ on-time, [Btu/W-h].

SEER calculated using the empirical equations to predict $C_{D}$ at the $50 \%$ on-time, [Btu/W-h] .

SEER calculated the same as $\operatorname{SEER}(20)$ except using $C_{D}$ extrapolated from $20 \%$ on-time to $50 \%$ on-time, [Btu/W-h] .

SEER calculated using the empirical equations to predict a variable $C_{A}$ and a national weather bin, [Btu/h-h] .

SEER calculated using the national average weather bin with $C_{D}$ obtained from the $20 \%$ on-time, [Btu/w-h] .

Slope of least squares line.

Slope determined at $20 \%$ on-time, defined by Eqn. 6-3. 


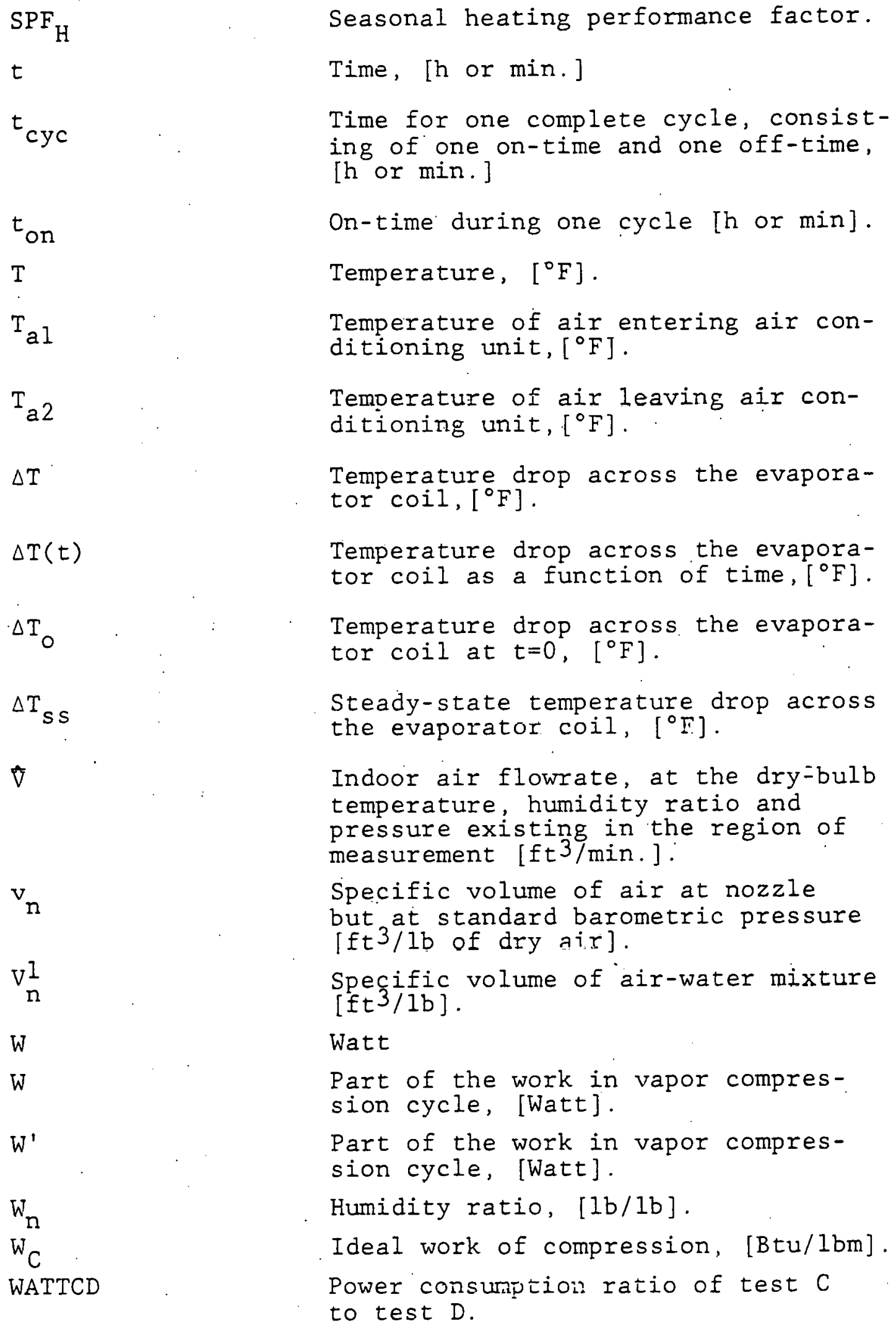


WORK

WORK'

WORK*

$\mathrm{y}$

$\mathrm{Y}-\mathrm{INCPT}$

$\alpha$

$\alpha$

B

I

$\bar{\tau}$

$\mathrm{AMB}$

A

B

C

D

c
Work required in ideal vapor compression cycle, [Watt].

Work required in ideal vapor compression cycle, [Watt].

Portion of work required, [Watt].

Year

Intersection point on the $\mathrm{y}$-axis.

Greek Symbols

Time Constant of thermostat defined in Eqn. 1-1.

Ratio less than one defined in Eqn. 4-12.

Ratio less than one defined in Eqn. 4-12.

Defined by Eqn. 3-5 as the integral with respect to time of the temperature drop across the evaporator coil during the cycling tests [ ${ }^{\circ} \mathrm{F}$-min. ] .

Time constant of air-conditioning unit [min.].

Average time constant of all airconditioning units analyzed [min.].

\section{Subscripts}

Ambient

Test A

Test B

Test C

Test D

Cooling 


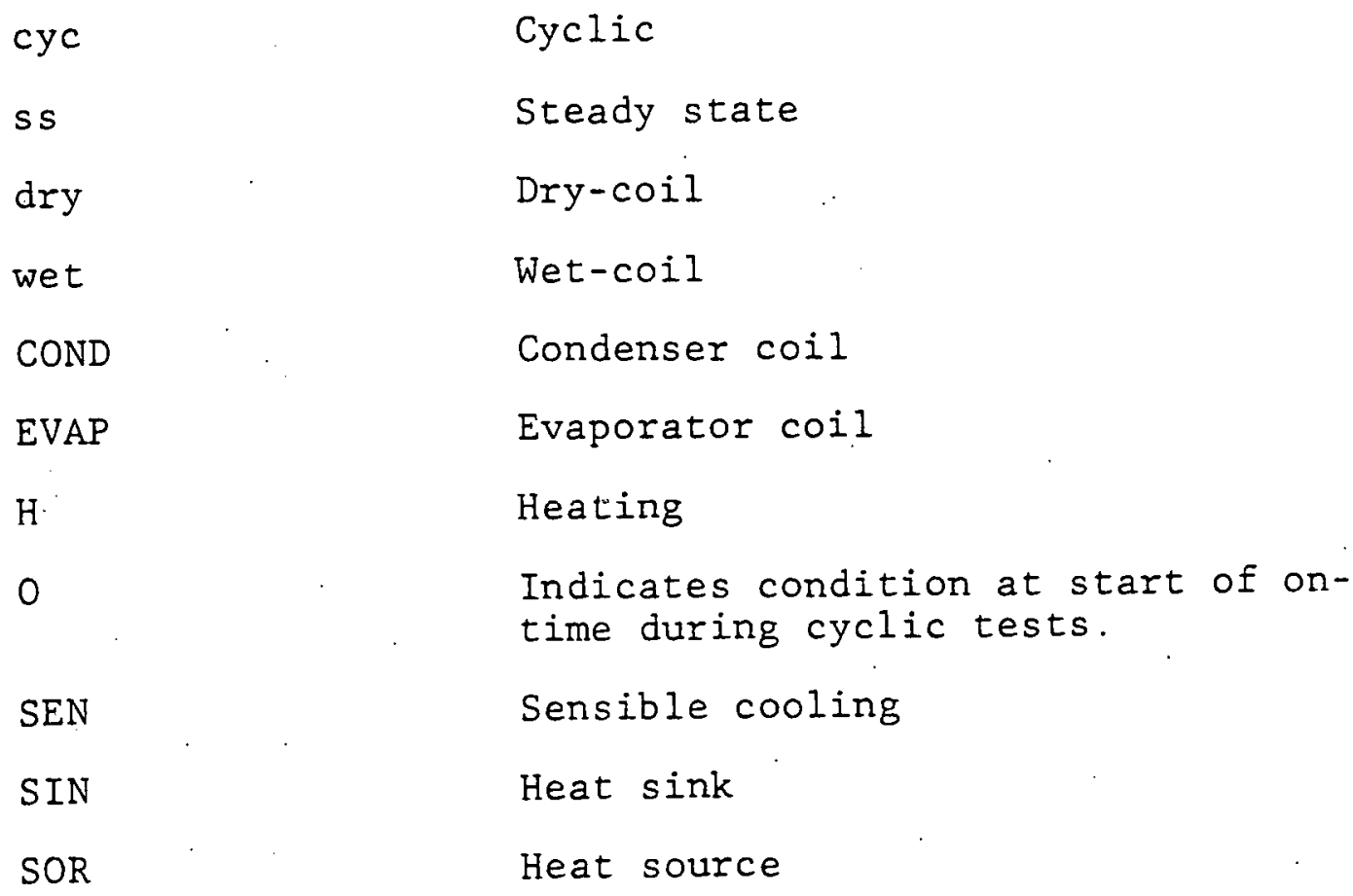




\section{ABSTRACT}

Thomas, Steven Bruce. M.S., Purdue University, May 1980. Study of the Test Method for Prediction of Air Conditioning Equipment Seasonal Performance. Co-Major Professors:

David R. Tree and Victor $W$. Goldschmidt.

The test procedure, Method of Testing, Rating and Estimating the Seasonal Performance of Central Air-Conditioners and Heat Pumps Operating in the Cooling Mode, has been analyzed. The analysis of the test procedure incorporated two main functions: 1) to determine the validity of the test procedure and, 2) to determine if there are other alternate methods of obtaining the same results with less testing burden.

Data was collected from industry and analyzed for any significant trends. Certain conclusions are drawn about the energy efficiency ratios, degradation coefficients and seasonal energy efficiency ratios.

An error analysis was performed on the test procedure to determine the approximate amount of error when using this procedure.

A semi-empirical model assuming a first order system response was developed to determine the factors that affect the part-load and cooling-load factors. The corresponding transient characteristics are then determined in terms of a single time constant. A thermostat demand cycle is used to determine the relationship between on-time and cycle-time.

Recommendations are made regarding an alternate method being used to determine the seasonal energy efficiency ratio. 
CHAPTER 1

INTRODUCTION AND LITERATURE SURVEY

\section{A) Introduction}

For many years it has been obvious to many people that the world in general and the United States in particular could not continue to use energy at ever increasing rates and, in many cases, wasting large amounts of energy. The North American people have a tremendous amount of energy at their disposal, with great quantities of it being used for heating and cooling. Approximately $20 \%$ of the United. States' total energy demand is consumed in heating and cooling ( 5$)$. Something must be done to reduce or at least slow down the rate of increased energy usage and to stop any wasting of energy.

One result of the political pressure due to an increasing awareness of energy waste and consumption was the passage of the Energy Policy and Conservation Act (PL 94385 ) by the United States government. Part of this bill was a requirement that certain energy using devices be labeled with a seasonal energy usage number. These labels were intended to inform the consumer how much energy on a seasonal basis the equipment would use under normal operating conditions. The thinking behind such labels was that consumers would tend to buy the most efficient (from an energy usage standpoint) units. This in turn would be an incentive for manufacturers to build more efficient units and rid the market place of the lesser efficient units.

*Numbers in parentheses refer to references listed in Bibliography. 
Air conditioners with capacities under $65000 \mathrm{Btu} / \mathrm{h}$ $(19 \mathrm{~kW})$ are energy using devices to be labeled. Estimates have been made on potential savings derived from improvements in such units. A $30 \%$ improvement in efficiency is expected to produce energy savings of approximately 1400-1500 kWh/y per central air conditioner and 4000$5000 \mathrm{kWh} / \mathrm{y}$ per heat pump (29). For an assumed 1980 annual sales level of 1.5 million central air conditioners and 0.5 million heat pumps, one year's sales could save approximately 4100 million $\mathrm{kWh}$ or 2.5 million barrels of oil (29). It should be noted that heat pump sales are increasing at a very rapid rate (approximately 50\% annually from 1974-1976), thus the estimated annual increase in conservation of 2.5 million barrels of oil is a conservative estimate for 1980 and later sales levels.

The United States Department of Energy (DOE) was given the task of developing the test procedures to provide the necessary data to go on the seasonal usage labels for various types of equipment. Central air conditioners and heat pumps" in the cooling mode are one type of equipment to be labeled. With technical input from the National Bureau of Standards (NBS), DOE published its final test procedures for central air conditioners in the Federal Register of November 25, 1977, pages 60150-60157. In recent Lilles, DOE has propnsed to amend the test procedures for central air conditioners to include testing procedures for heat pumps. DOE published its most recent proposed test procedures for central air conditioners and heat pumps in the Federal Register of April 19, 1979, pages $23468-23506$.

*Hereafter in this work the term air conditioners will also refer to heat pumps in their cooling mode. 
Air conditioning systems have a significant impact on energy demands. With an ever increasing energy demand it is logical that substantial research be given to seasonal energy efficiency of central air conditioning units.

B) Rating Method for the Central Air Conditioner and Heat Pump in Cooling Mode

Many problems exist in developing an energy rating method for this type of equipment. Associated problems include: 1) There is no single normal operating condition. 2) Outdoor weather conditions vary greatly throughout the United States. 3) The end use of the equipment and its interaction with the building can and does generally affect the energy used by the cooling system. 4) Very little data exists that shows the effect of cycling on energy usage.

When developing a rating program which truly represents the energy consumed on a seasonal basis at least the following effects of energy usage should be considered: a) outdoor temperature and humidity, b) relationship of capacity to load as seen by cycling and percentages of running time, c) indoor temperature and humidity and d) building-equipment interaction.

To fully consider all possible effects of just those items listed, an energy rating and test program would have to be developed that would be so complex that it would be virtually impossible to conduct. On the other hand a very simple energy rating method could be developed by neglecting all such effects, but the rating number would have little or no meaning with respect to. the actual seasonal energy used.

In order to develop any estimate of yearly consumption or efficiency, certain basic considerations are needed. These relate to: a) the transient behavior of the 
equipment, b) the weather causing a cooling demand, c) the sizing of the equipment, d) the thermal lag of the building and other interactions of building and equipment, and e) the thermostat characteristics.

Based on the extent to which the above considerations are accounted for, a rating procedure of more or less complexity can be derived. In essence then the assumptions made will determine the seasonal rating procedure. A partial list of possible seasonal rating schemes is given below. They are listed in increasing order of expected complexity and accuracy.

1. Assuming equivalency between the seasonal efficiency and the steady state efficiency at $80^{\circ} \mathrm{F}$ indoor, $95 \circ \mathrm{F}$ outdoor (the pre-1979. rating conditions). Under this rating procedure the effects of cycling, outdoor temperature variations and average value, building interaction, equipment to load matching and thermostat characteristics are all neglected. It is in essence assumed that the increased outdoor temperature offsets the effect of cycling and that the temperature of air returning to the evaporator remains constant.

2. Assuming equivalency between the seasonal efficiency and the steady state efficiency at $80^{\circ} \mathrm{F}$ indoor, $82^{\circ} \mathrm{F}$ outdoor (referred to as the average U.S. temperature during the cooling period). Under this rating procedure the effect of cycling, outdoor temperature variations, building interaction equipment to load matching and thermostat characteristics are all neglected.

3. Assuming equivalency between the seasonal efficiency and that determined neglecting cyclic effects using steady state data at different outdoor conditions. This data is then used with a weather bin or hour-byhour weather data to determine seasonal energy usage. This rating procedure takes into account the effects 
of outdoor conditions, but neglects the effects of cycling and all other effects (such as building interaction, load matching and thermostat characteristics).

4. Assuming equivalency between the seasonal efficiency and that determined from a specific laboratory test while cycling at a fixed load, say $50 \%$, and at a specific outdoor temperature, say $82^{\circ} \mathrm{F}$. This procedure takes into partial account the cycling effects but neglects the effects of outdoor conditions, building interactions load matching and, to a large extent, the thermostat characteristics.

5. Assuming equivalency between seasonal efficiency and that determined based on a cyclic test and a dependence of cyclic efficiency on outside temperature. The outside weather temperature variation is best accounted for via some weather bin data. This method can also include some assumptions about the matching of the unit with the building. It generally assumes a design point and a given oversize. It can also take into account a limited thermostat effect. It neglects thermal $\mathrm{lag}$ and other building effects. It also assumes that all buildings are designed at the same fixed point and over-sizing.

6. Measuring the effects of cycling, varying weather conditions and varying design points and oversizing. The method neglects only the thermal lag of the building and a realistic thermostat model.

The list could go on, but the testing effort required to do number 6 would be tremendous. In reference (30) a comparison of methods 1 through 5 is given. Table 1-1 summarizes the corresponding six methods and the accompanying testing where one of these is to be utilized for estimating seasonal efficiencies. Table 1-2 summarizes the method response to the effects under consideration. 
Table 1-1. Possible Test Methods for Estimating Seasonal Energy Usage.

\begin{tabular}{|c|c|c|c|}
\hline Method & Testing Required & $\begin{array}{l}\text { Outdoor Test } \\
\text { Conditions }\end{array}$ & Comments \\
\hline 1 & Steady State. & $95^{\circ} \mathrm{F} *$ & \\
\hline 2 & Steady State & $82^{\circ} \mathrm{F} *$ & \\
\hline 3 & Steady State & $82^{\circ} \mathrm{F} \& 95^{\circ} \mathrm{F}$ & $\begin{array}{l}\text { Use with } \\
\text { Weather Bin }\end{array}$ \\
\hline 4 & $\begin{array}{l}\text { Steady State \& } \\
\text { Cycling }\end{array}$ & $82^{\circ} \mathrm{F}$ & $\begin{array}{l}\text { Fixed Load, } \\
50 \%\end{array}$ \\
\hline 5 & $\begin{array}{l}\text { Steady State } \& \\
\text { Cycling }\end{array}$ & $82^{\circ} \mathrm{F} \& 95^{\circ} \mathrm{F}$ & $\begin{array}{l}\text { Use with } \\
\text { Weather Bin }\end{array}$ \\
\hline 6 & $\begin{array}{l}\text { Steady State \& } \\
\text { Cycling }\end{array}$ & Varying & \\
\hline
\end{tabular}

Table 1-2 Method Response to Effects Taken into Consideration.

Effects Taken Into Consideration

Method

1. Is transient behavior of equipment accounted for. fully?

\begin{tabular}{cccccc}
1 & 2 & 3 & 4 & 5 & 6 \\
\hline No & No & No & Yes & Ýes & Yes
\end{tabular}

2. Are variations in weather accounted for fully?

No Part Yes Part Yes Yes

3. Is the equipment matching lu luad accounted for fully? No No No No Part Yee

4. Is the thermal lag of the
building accounted for fully? No No no No No No

5. Are the thermostat characteristics accounted for fully?

No No No No Part Part

$* 95^{\circ} \mathrm{F}\left(35^{\circ} \mathrm{C}\right) \quad 82^{\circ} \mathrm{F} \quad\left(27.8^{\circ} \mathrm{C}\right)$ 
C) Proposed DOE Test Method

Method five was chosen by DOE to determine the seasonal efficiency. The DOE test procedure calls for the conducting of two steady state wet coil tests ( $A \& B$ ), which determine the influence of outdoor temperature on energy consumption and cooling performance and, either conducting two other dry coil tests, one steady state (test $\mathrm{C}$ ), the other cyclic (test $\mathrm{D}$ ), to determine the effects of cycling on energy consumption or using a fixed degradation coefficient of 0.25 (the default value). The conditions of each test are summarized in Table 1-3.

. The part-load factor (PLF) which determines the effect of cycling on performance defined as

$P L F=\frac{E E R_{D}}{\overline{E E R}_{C}}$

and the cooling-load factor (CLF) defined as

CLF $=\frac{\dot{Q}_{D}}{\dot{Q}_{C}} \frac{t_{\text {on }}}{t_{\text {cyc }}}$

are used to determine the degradation coefficient $\left(C_{D}\right)$ defined as

$C_{D}=\frac{1-P L F}{1-C L F}$

The degradation coefficient is used to determine the seasonal energy efficiency ratio (SEER) defined as either

SEER $=\frac{\sum \frac{Q\left(T_{j}\right)}{N}}{\sum \frac{E\left(T_{j}\right)}{N}}$

where

$$
\begin{aligned}
& Q\left(T_{j}\right)=\text { Total cooling done in temperature bin } j,[B t u] . \\
& E\left(T_{j}\right)=\text { Energy usage in temperature bin } j,[W-h] .
\end{aligned}
$$


Table 1-3 Summary of Test and Rating Requirements; Indoor and Cutdoor Entering Air Temperature and Mode of Operation, From Ref. 20.

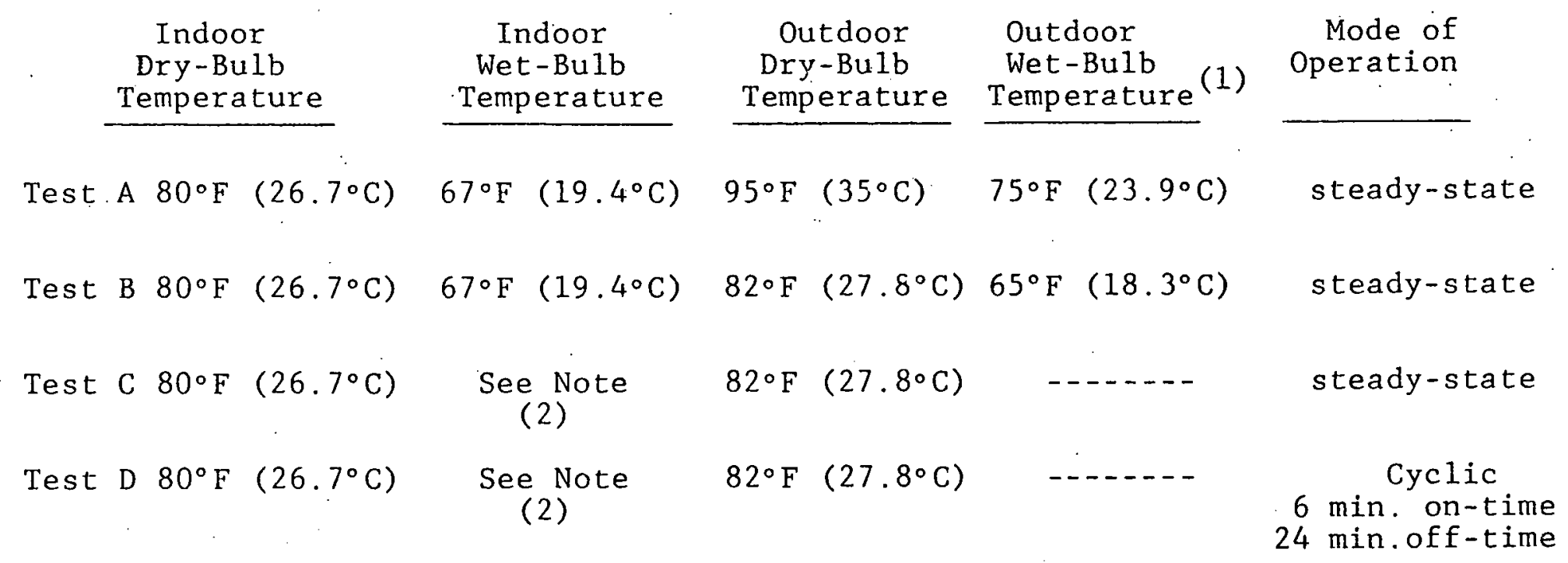

(1) Applies only to those units which reject condensate to the outdoor coil.

(2) Shall at no time exceed that value of the wet-bulb temperature which results in the production of condensate by the indoor coil at the dry-bulb temperatures existing for the air entering the indoor portion of the unit. 
$N=$ Total number of temperature bin hours.

or for the shorter method (used for units employing singlespeed compressors and single-speed condenser fans)

$\operatorname{SEER}=\operatorname{PLF}(0.5) * \operatorname{EER}_{B}$

where

$\operatorname{PLF}(0.5)=1-C_{D}(1-0.5)$

A fuller explanation of the test procedure can be found in reference (20) or in the Federal Register of April 19, 1979. DOE found the calculation procedure could be simplified when considering the average national weather, which essentially simplifies to method four.

As part of an ARI certification program, industry has been conducting steady state tests similar to tests $A$ and $B$ for many years, although the present DOE test procedures require different tolerances (1). Thus it appears that for all practical purposes necessary facilities, equipment and experience are available to conduct tests $A \& B$. Prior to the issuing of these DOE rules, the industry as a whole, had not had any experience in conducting type $C$ and $D$ tests. Test $C$ and $D$ add two additional requirements: 1) dry coil testing and 2) cyclic testing.

\section{D) Scope of Work}

The purpose of the DOE test and calculation procedures is to provide an estimate for the expected seasonal performance including the seasonal cost of operation for central air conditioners. Compared to previous tests being conducted by the industry, these new tests require considerable more testing. With their present test facilties some companies can not conduct tests $C$ and D. 
The goals of this work and location of analysis are:

1) Evaluate the applicability of the DOE test procedure and determine the most important parameters, Chp. $2 \& 3$.

2) Perform an error analysis on the test procedure, Chp. 5.

3) Analyze data available on the transient test for seasonal energy efficiency ratio for a number of central air conditioners, Chp. 2.

4) Investigate alternate methods (empirical) of determining the seasonal energy efficiency ratio, Chp. 6.

5) Compare alternate methods with the present DOE test procedure, Chp. 6.

E) Literature Survey of Non-Steady Performance

As a result of the 1973 oil embargo there has been an increased awareness in energy conservation. Resulting from this energy conservation has been an increased analysis of energy usage of appliances on a seasonal basis. Since 1974 the analysis on central air conditioners (CAC) has followed the same path. Hence, this literature survey is concerned with the seasonal performance of central air conditioners.

Cohen, Hamilton and Pearson (9) looked at possible energy conservation in CAC through the use of variable capacity compressors. It was shown that residential small commercial air cooled air conditioning systems can provide savings from $28 \%$ to $35 \%$ of the usual seasonal energy requirements by using variable capacity compressors.

With the increased scrutiny of CAC it is logical to expect all pertinent areas to be considered. Hamilton and Pearson (16) looked at typical performance characteristics of the basic vapor compression cooling system. The purpose of the study was to indicate desirable goals for increased performance by comparing typical performance characteristics of currently manufactured cooling systems with corresponding performance of ideal systems. 
In a different study, Kelly and Bean (19) began their field study on a heat pump in the summer of 1974 and the 1974-5 heating season. They were one of the first to look into the dynamic performance of residential air-to-air heat pumps. In their study they looked at the effect of part-load operation on the heat pump's "cooling" and "heating" coefficients of performance (COP). On the particular unit which was tested, the results showed that partload operation was worst in the cooling mode than the heating mode. In a later study Parken, Beausoliel and Kelly (26) looked at the factors that affect the performance of a residential air-to-air heat pump over a broad range of operating conditions. With the heat pump in the cooling mode their results indicated a decrease in the cyclic cooling $C O P$ and load as the cycle frequency. increased for each of the percent-on-times. Kelly and Bean felt (19) that an improvement in the part load performance might result from continuous operation of the indoor fan. Bullock and Reedy (8) showed for the system they investigated that a continuously running fan actually decreased the part load performance. Also, the losses were greatest at very light loads and least under heavy load (high run time percentage) conditions. These losses are due primarily to the transient start-up period when the output capacity comes up to steady state slower than does the input power. Cyclic losses can also be aggravated by other system factors, including:

1. Thermostats with high cycling rates;

2. Continuously running indoor fans, especially on cooling;

3. Poorly insulated or leaky supply ducts outside of the conditioned space.

These are only a few possible effects that deserve consideration. 
In conjunction with the increase of field studies empirical models were developed to correlate the seasonal performance of CAC. It was found that an exponential function provides a reasonably accurate mathematical model for the variation of heat output rate with time $(16,33)$. Wildin et al. (33) used these empirical equations to help predict seasonal heating performance factors $\left(S P F_{H}\right)$ for a heat pump in heating mode in an arid climate. The semiempirical equations predicted for two different users, a $S P F_{H}$ of 1.83 for user 1 and 1.61 for user 2 . They agreed well with the actual measured values of 1.88 and 1.64 respectively obtained from the electrical energy use and part-load values based on experimental data for users 1 and 2. Bonne and Patani (7) looked into the influence of balance temperature on seasonal (heating) COP for various heat pumps simulated with a very simple model characterized by linear functions of outdoor temperature with average COP, average heat pump output (without auxiliary heat) and building energy demand. In another study Kelnhofer (21) tested $6 \mathrm{CAC}$ and 6 heat pumps in cooling mode. He compared actual energy usage with that predicted by the BIN method. It showed an error of $\pm 25 \%$, suggesting the need for a better method to predict seasonal energy usage. In more recent times Goldschmidt, Hart and Reiner (I2) showed for the heat pump which they tested that the degradation coefficient (defined by Eqn. 1-3). differed for the cooling and heating modes. This suggests that the transient response is not a simple function of the thermal mass of the coils. Their analysis also suggested that the transient response could be sufficiently described by an effective time constant.

In another study Goldschmidt and Murphy (13) noted that the losses in performance due to transient effects are most likely attributed to refrigerant dynamics rather than the thermal mass of the heat exchanger coils. They 
also note that the losses due to duct leakage may overshadow any losses due to transient effects. In an additional study Murphy and Goldschmidt (24) calculated the degradation coefficient for a self-contained 3-ton air conditioner field-tested in a mobile home. They concluded that the degradation coefficient is not a unique value but depends on air conditioner transient response under a fixed test. Alternatively, it depends on the combination of the thermostat setting, deadband, thermal mass of the buildings, as well as the anticipator design. It is interesting to note that they determined from their experimental data the following relationship:

$\frac{t_{\text {on }}}{t_{\text {cyc }}}=1-\frac{\alpha}{t_{\text {on }}}$

where $\alpha=5.3 \mathrm{~min}$. for that particular mobile home. They say $\alpha$ depends on the thermostat deadband, thermal mass of the building and the cooling capacity.

With respect to the thermal mass of the building Hopkins, Gross and Ellifritt (18) showed from computer simulation that thermal mass can play a measurable role in controlling the thermal performance of a building. However, they also show that the overall energy consumption of the building is not greatly affected by thermal mass alone - the difference in energy consumption due to light and heavy constructions being only a few percent: Rudoy and Dougall (27) obtained similar results using the computer program NBSLD developed by the National Bureau of Standards with minor revisions.

In conclusion, one can see that many factors which affect seasonal performance have been examined. The preceding survey covers only recent studies in seasonal performance of central air conditioners. 
CHAPTER 2

INITIAL STUDY AND EXPERIMENTAL DATA

\begin{abstract}
A) Initial Study
1. Collection of Cyclic Data

This research work which was conducted at the
\end{abstract}

Ray W. Herrick Laboratories, Purdue University, started with the compilation of cyclic test data for central air conditioners (CAC) supplied by industry in response to the 1979 rating program (31). The research was sponsored by the Unitary Division of the Air Conditioning and Refrigeration Institute (ARI) and the National Bureau of Standards (NBS). A list of companies in the Unitary Division is given in Appendix A. Experimental test data pertaining to the DOE test procedures was requested from the companies in the Unitary Division. Table $2-1$ is a summary of the response as of October 31, 1979.

Although data were available on many units tested under the ARI certification program which has the same temperature and humidity conditions as test $A$, and data at other outdoor temperatures including $82^{\circ} \mathrm{F}\left(27.8^{\circ} \mathrm{C}\right.$ ) (test $\mathrm{B}$ conditions) is also available from specification and sales sheets, only data obtained from companies making their best effort to follow the DOE test procedure were used in this work. 
Table 2-1 Summary of Available Data as of October 31, 1979.

\begin{tabular}{ccc} 
TEST & $\begin{array}{c}\text { NUMBER OF UNITS } \\
\text { TESTED }\end{array}$ & $\begin{array}{c}\text { NUMBER } \\
\text { SUP COMPANIES }\end{array}$ \\
\hline A & 485 & 12 \\
B & 427 & 12 \\
C & 180 & 8 \\
D & 166 & 7
\end{tabular}

2. Visitation and Questionnaire

In order to try to determine capabilities, expectations and problems that industry was having in conducting these tests, personal visits were made by several members of the research group to at least 11 different companies. In these visits the facilities were inspected and test procedures, equipment, problems and results were discussed with those people conducting the tests.

In addition, during the summer of 1978 a questionnaire was developed and sent to each company. A copy of the questionnaire appears in Appendix B.

It was observed that all companies had some problems in conducting these tests. In general, the problems fell into two areas: 1) interpretation and understanding of how to conduct $C$ and $D$ type tests and 2) lack of adequate facilities, equipment and manpower to conduct $C$ and $D$ type tests.

The results of the questionnaire are outlined below.

1) Companies receiving questionnaire-

The questionnaire was sent to all forty-one manufacturers listed in the Unitary Air-Conditioning Division of ARI. It should be pointed out that in several 
cases two or more manufacturers belong to the same parent company. In these cases some companies responded as one parent company while others responded as individual manufacturing units.

2) Response to questionnaireTwenty-nine questionnaires were returned. However, two manufacturers indicated that for various reasons they did not wish to participate in the program and did not complete the questionnaire. Of the twentyseven completed questionnaires some manufacturers did not answer some questions.

3) Tests $A \& B$ Of the twenty-seven manufacturers responding all can conduct tests $A \& B$ without difficulty.

4) Test C-

Twenty of the twenty-seven manufacturers ( $74.1 \%$ ) have tried to do test $C$. Twelve of twenty-sever (44.4\%) believe that they can conduct test $C$ for at least part of the year. Because of the low humidity requirements of tests $C \& D$, some facilities are able to conduct these tests only during certain periods of the year. Eight companies supplied test C data.

5) Test DEighteen of the twenty-seven manufacturers (66.7\%) have tried to conduct test $D$. Only nine of the twenty-seven (33.3\%) believe their facilities and equipment are good enough to conduct at any time of the year test $D$. Seven companies have supplied test $D$ data.

6) Facilities -

Fourteen companies thought that their present facilities could be modified so that test $D$ could be conducted. However, only nine indicated plans to do so. Seven companies indicated that they intended to 
construct new facilities. Most of these new facilities, are believed to be adequate at least during part of the year to conduct all tests.

If all companies modify present facilities and construct new facilities as reported on the questionnaire by late 1979 or early 1980, eleven additional manufacturers will be able to conduct all four tests. This will bring the total number of manufacturers who can conduct all four tests at least during part of the year to twenty or $74.1 \%$ of those companies returning the questionnaire.

7) Calculation of SEERAt the time of the survey, only six of the twentyseven manufacturers $(22.2 \%)$ intended to make $C$ and $D$ measurements to determine SEER.

Seventeen of the twenty-seven $(63.0 \%)$ intend to make only $A$ and $B$ measurements and use $C_{D}=0.25$. Three of the twenty-seven (11.1\%) will make $C$ and $D$ measurements on some units and use $C_{D}=0.25$ for all other units.

One of the twenty-seven $(3.7 \%)$ did not know what they would do.

The results of the information obtained from the questionnaire are summarized in Table 2-2.

The questionnaire asked manufacturers to report problems in conducting tests $C$ and $D$. Those problems in order of greatest number to least times reported are listed below:

. Cannot obtain the required humidity: (to keep evaporator dry)

. Cannot obtain set pnint conditions . During cycling test the temperature and humidity cannot be held within tolerances 
Table 2-2 Summary of Information Obtained

From Questionnaire (Summer. 1978)

Questionnaire Sent to

Returned Questionnaire

Completed Questionnaire

Tests $A \& B$

Can Conduct

Supplied Data

Test $\mathrm{C}$

Tried to Conduct

Can Conduct

Supplied Data

Test D

Tried to Conduct

Can Conduct

Supplied Data

Facilities

Present Facilities can be Modified

to Conduct all Tests

Plan to Modify Present Facilities

Plan to Construct New Facilities

Calculation of SEER

Conduct Tests $A, B, C \& D$

Conduct Tests A\& $B$ Use $C_{D}=0.25$

Combination of Both Methods

Undecided

$\begin{array}{cc}\begin{array}{c}\text { Number of } \\ \text { Companies }\end{array} & \frac{\text { Percentage }}{41} \\ 29 & 100^{1} \\ 27 & 70.7^{1} \\ 65.9^{1}\end{array}$

27

12

$100^{2}$

$29.3^{1}$

20

12

$74.1^{2}$

8

$44.4^{2}$

$19.5^{1}$

18

$66.7^{2}$

9

$33.3^{2}$

7.

$17.1^{1}$

14

$51.9^{2}$

9

$33.3^{2}$

7

$25.9^{2}$

6

17

$22.2^{2}$

$63.0^{2}$.

3

$11.1^{2}$

1

1 Percentage based on 41 manufacturers in the Unitary Division of ARI.

2 Percentage based on 27 questionnaires completed. 
. Test chambers have too much leakage, therefore, when outdoor humidity is high tests $C \& D$ cannot be conducted

. Do not have temperature measuring and recording equipment that will respond with the desired accuracy

. Shortage of skilled people to run test.

One problem that was not reported, but which was expressed many times in conversation with many companies was how to interpret the DOE test procedure with.respect to control of air flow across the evaporative coil during the off-time and at start of on-time. As was expressed by many people and as will be pointed out later in this work, this could have an effect on SEER.

To determine what effect the new DOE test procedure was having on development of newer and more energy efficient units, a survey was conducted among a small select group. The results were surprising. The industry is divided into two groups 1) a large majority who are making an effort to understand and conduct tests as outlined in the DOE test procedure, and 2) a few who were taking a waitand-see attitude and are really not trying to make any tests beyond test $A$.

The effect on development of new products of the first group has been tremendous, ranging from about $90 \%$ loss of effort to $50 \%$ for 1978 and 1979. The new tests to date have had little effect on the second group's development program. These results are based on a small sample and because of the surprisingly high effect on development on new products reported it should be investigated in more detail. With so much effort going into the testing procedure, the increase in consumer product cost with $\mathrm{nn}$ increase in energy efficiency should be investigated. It appears that the test procedure could be very inflationary. 
B) Problems Reported in Obtaining Data

1. Duration of Tests

The time necessary to set-up, obtain test conditions, and run the test, varies according to the sophistication of the facilities and expertise of the personnel.

When asked to estimate total test time (including set-up, etc., for all tests, $A, B, C \& D$ ) the values reported were 50 hours maximum, 10 hours minimum, and a mean of around 24 hours. This may greatly change as companies become more familiar with these tests.

2. Air Flow Modifications

Two common configurations for test rooms are noted in Figures 2 and 4 of ASHRAE Standard 37-69. For convenience these figures are reproduced in Appendix $C$. In them, the metered air flow through the indoor coil is conditioned and returned to the room at the desired temperatures. The major method for controlling the room temperature is through the return conditioned air. Obviously, a major problem does arise in tests calling for no flow over the evaporator coil since control of the indoor test room conditions is lost. Rooms equipped in this manner have required extensive modifications in order to provide two independent air loops, one for the conditioning of the test room air, the other for the metering and treating of the flow over the evaporator coil.

Alternative configurations for testing which show an additional complication are shown in Figures 1 and 3 of ASHRAE Standard 37-69 (the latter being quite uncommon). These figures are also reproduced in Appendix $C$. The measurement of the inlet air is accomplished after sufficient mixing of the air with a thermocouple grid. (Obviously a sampling tube will be difficult for transient measurements). Invariably, there is a section of duct between 
the coil and inlet section. When testing under steady state conditions the inlet section does not cause any complications, however, when performing $D$ type tests considerable time and effort - in some cases unsuccessful has been given to the problems of a) not trapping cold air during the off-time making it hard to readily return to an $80^{\circ} \mathrm{F}$ inlet during the off-time while b) having a proper inlet section to measure inlet temperatures with a thermocouple grid. Early it was believed that this cooler trapped air would have a significant effect on the results. Recent proprietary data reveals that the cooler trapped air has a small effect if any on test $D$ results.

With a little insight it can be readily explained why this cooler trapped air has a small effect.

Figure 2-1 shows the temperature difference across the evaporator-coil versus time for two cases: an idealized first order response and a typical response as measured for some cases. The shaded excess cooling could be attributed to trapped air in the indoor section. If such were the case the cooler trapped air in the duct could cause a finite $\Delta T_{0}$ at the initial start-up time. As the central air conditioner begins to operate, the cooler air, then the warmer air surrounding the duct, would be pulled past the thermocouple grid and evaporator-coil. Thus the temperature difference would drop for a short period of time. At the same time cooler air is being supplied to the surroundings through another duct. Hence, with the addition of cooler air the temperature difference will gradually begin to increase with time. Therefore, in general if $\Delta T_{0}$ is not very large and the time to get $\Delta \mathrm{T}$ : to increase with time is short, there will be relatively small errors introduced into test $D$ results from the resulting offset temperature-difference. (The dip in the curve could also be 
22

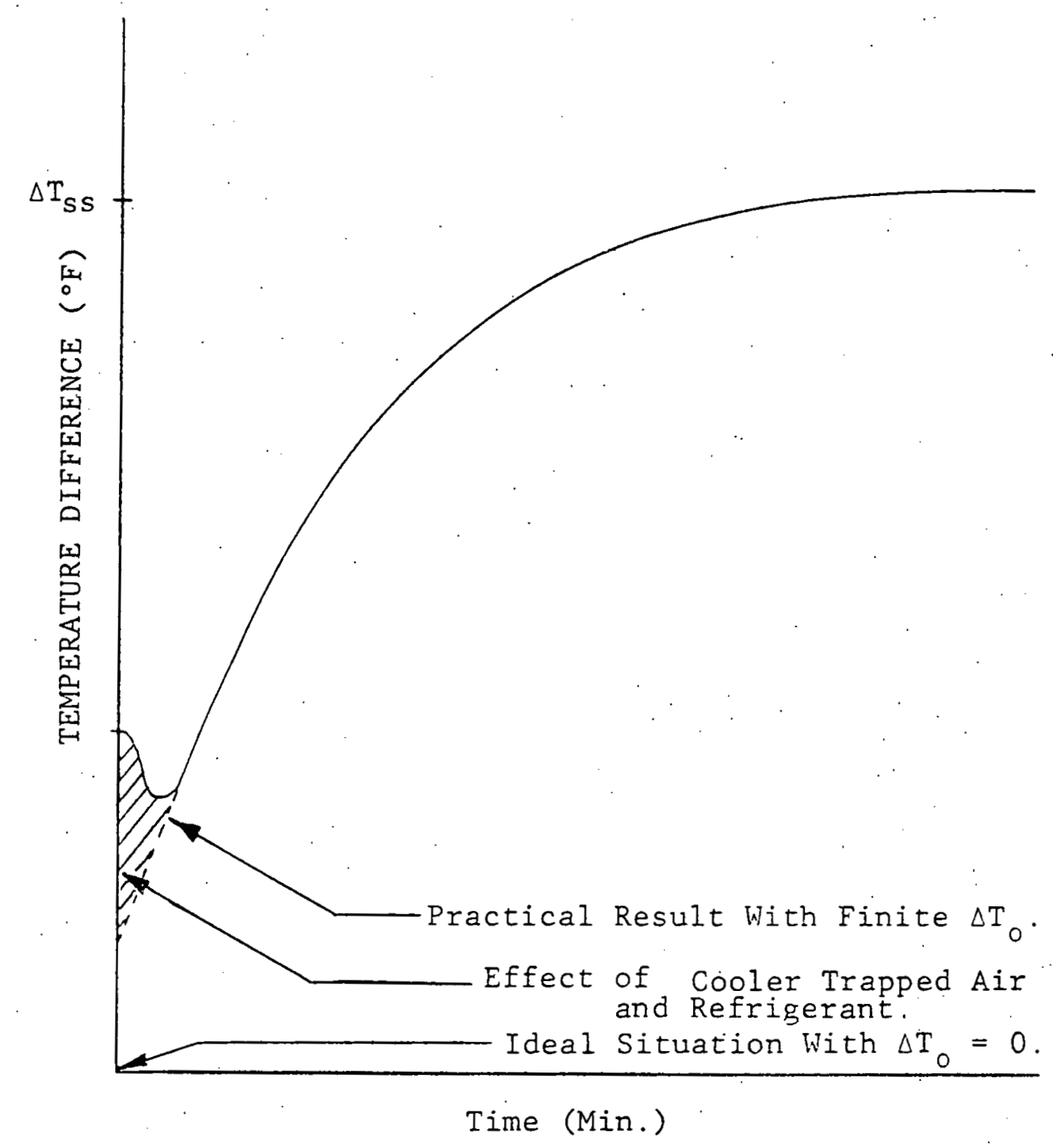

Figure 2-1 Temperature Difference Across Evaporator Coil as a Function of On-Time. 
attributed to start-up conditions with liquid refrigerant in the evaporator coil. However, this is only postulated at this time.)

Most manufacturers faced a third major problem area while modifying facilities for $D$ tests. The no-flow conditions called for during the off-time usually required the use of dampers downstream of the evaporator coil. (Activation of these dampers is usually manual, thus adding to manpower needs). The major problem for most manufacturers lies in the fact that the location of these dampers as well as their tightness will affect the amount of air trapped and hence, the starting conditions at the beginning of the "on" part of the cycle.

3. Temperature Readings

A basic concern appears to be with the accuracy of the temperature readings during test $D$. Many manufacturers are accustomed to using calibrated mercury-in-glass thermometers for temperature measurements which are indeed adequate for steady state tests. These manufacturers felt. uneasy with the required thermocouples (or equivalent devices) for making temperature measurements during transient tests. In some instances this was due to lack of instrumentation, such as high speed chart type recorders or digital data recorders. That lack is certainly easy to overcome. In other cases it is a mistrust of the accuracy of the thermocouples (or alternative sensors) and recording equipment - both in magnitude and frequency response. That concern is valid. Without calibration, thermocouples are expected to have an accuracy of $\pm 1^{\circ} \mathrm{F}$ (see ASTM Standard E230-72). That, by itself, equals the allowable error allowed by the DOE test procedures for indoor and outdoor temperatures, and is more than twice the allowable error 
in the measured temperature differences across the coil. A thermocouple grid with a number of thermocouples will reduce the uncertainty (see ASHRAE Standard 41.1) and may be within the required $\pm 0.3^{\circ} \mathrm{F}$. However, questioning the accuracy of the temperature measuring and readings equipment is still proper.

The fact remains that, even with the reduced error from grids, thermocouple response time, the location of the grid, non-uniformity of the flow field, and the inherent inaccuracy in thermocouples (or similar sensors) all place considerable question on the expected accuracy of the temperature readings.

The problem here is created because the DOE test procedure in this area follows the tolerances suggested in ASHRAE Standards 37 and 41. Both standards were developed for steady state testing. An updated ASHRAE Standard could solve this problem.

\section{Coil Conditions}

Tests $C \& D$ require dry-coil conditions. In order to accomplish such conditions the relative humidity in the indoor-side test room has to be reduced considerably below that for tests A\& B. The great majority of test facilities were designed for test $A$. To adapt them for test $C \& D$ two concerns have to be addressed: 1) increasing the capacity of the conditioning equipment in order to adequately lower the wet bulb in the room and, 2) reducing the moisture transport into the room through its walls, doors and cracks. Practical limitations in space, cost and time have made it extremely hard for some manufacturers to reach the desired dry coil conditions. Twenty-five out of the twenty-seven manufacturers reported having some trouble obtaining the low relative humidity required by tests $C$ and $D$. Because of the cycling condition required in test $D$, the problem in reaching dry coil conditions under test $C$ becomes even more difficult and complex under test $D$. 


\section{Maintaining Room Conditions}

The added room requirements of test $C$ and $D$ especially the cyclic conditions of test $D$, have caused consilerable problems for most manufacturers. Twenty-four of the twentyseven manufacturers reporting (three did not answer) had trouble maintaining temperature and twenty-three had trouble holding the set point conditions (one did not answer).

The schemes for maintaining test conditions are a combination of some of the following: having a test room capacity much larger than that of the test unit, having resistance heaters in the test rooms to phase in and out as the test unit cycles, anticipating the cycling effects of the test unit and preadjusting the conditioning equipment.

The first option is generally unacceptable due to space and cost practicalities. Most manufacturers find it necessary instead to have their operators provide constant attention to make adjustments in anticipation of the cycling effects. The technician becomes, in essence, the feedback element sensing the lag in response of the conditioning equipment, the mass effect of the humidification and dehumidifying elements, the cycling loads due to the test unit, etc.

It is amazing how ingenious and patient some manufacturers have been in performing these tests in their test chambers which originally had not been designed to conduct tests $C$ and $D$.

6. Sampling

One area of considerable concern on the part of manufacturers is the sampling program. DOE is proposing that. among all basic models using a single condensing unit, only units of the condenser-evaporator-coil combination expected to have the largest volume of retail sales need be tested. 
Also, DOE is reproposing that there be at least $90 \%$ confidence that the true mean of any measure of energy consumption of condenser-evaporator-coil combination lies within $5 \%$ of the mean of such measure of the sample. In essence, this means that more than one unit must be tested.

\section{C) Experimental Data}

Table D-1 reported in Appendix D summarizes the data received. Only 166 units for which the manufacturers had conducted all four tests are included in Table D-1. The data are presented as supplied by the companies. Approximately three-fourths of the data came from 3 companies.

1. Data Analysis

During the course of the research the experimental test data were checked to see if any relationship could be observed between various functions. As a base point $E E R_{A}$ was plotted against $E E R_{B}, E E R_{C}, E E R_{D}$, SEER and $C_{D}$. (see Figure 2-2 through 2-6).

Figures 2-2 through 2-4 exhibit a possible linear relationship between the various EER values. Equations of the form

$\mathrm{EER}_{\mathrm{B}} \doteqdot 1.13 * \mathrm{EER}_{\mathrm{A}}$

${ }^{E E R} \mathrm{C} \doteqdot 1.02 * \mathrm{EER}_{\mathrm{A}}$

$\mathrm{EER}_{\mathrm{D}} \doteqdot 0.90 * \mathrm{EER}_{\mathrm{A}}$

approximately follow the data.

Figure 2-5 implies for this preliminary data set, no obvious and simple relationship between the steady state measurement $E_{A}$ and $C_{D}$, whereas Fig. 2-6 shows that the data may be approximated by

$\mathrm{SEER} \doteqdot 1.05 * \mathrm{EER}_{\mathrm{A}}$ 


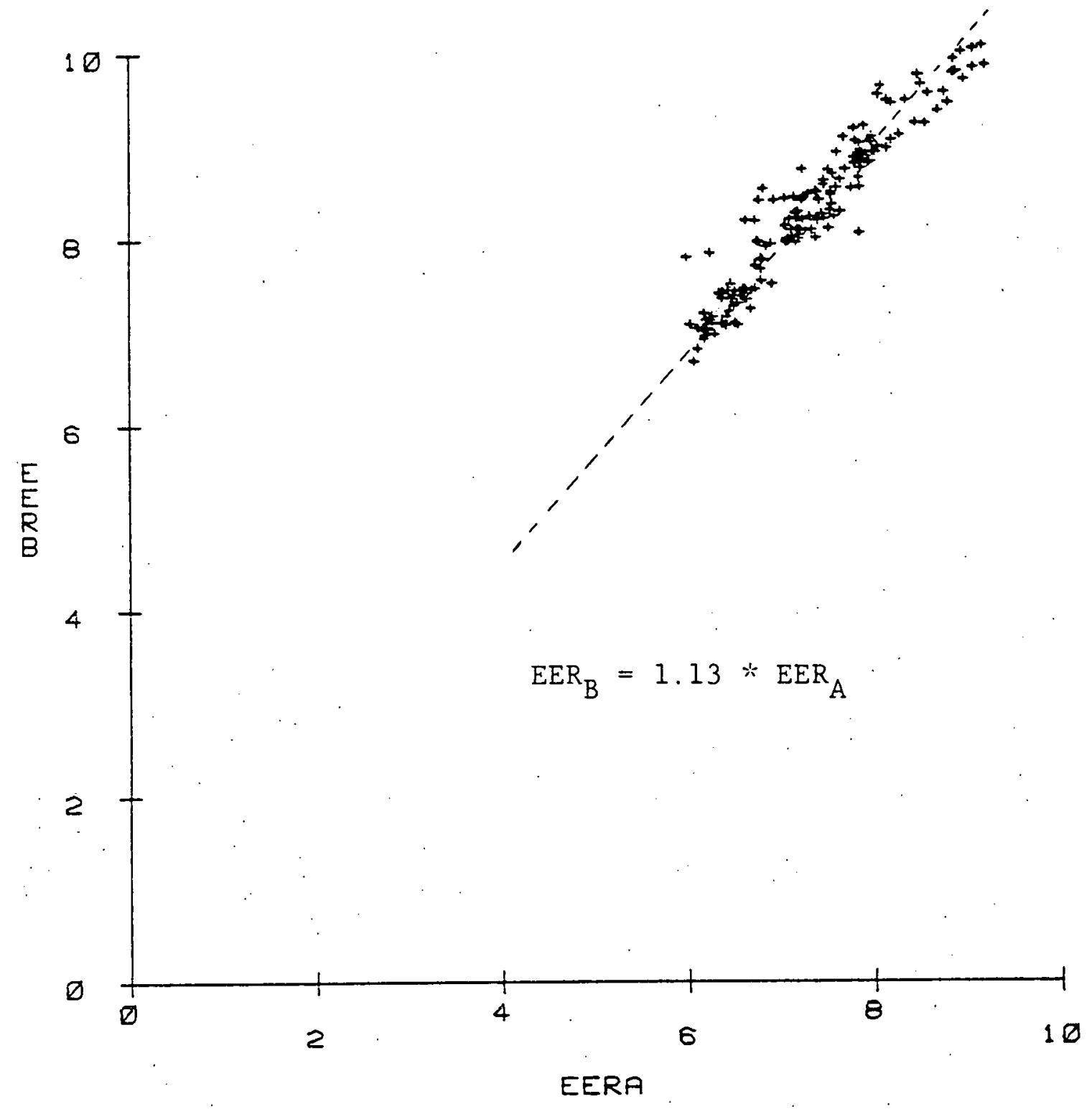

Figure 2-2 $E_{B}$ vs. $\operatorname{EER}_{A}$ 


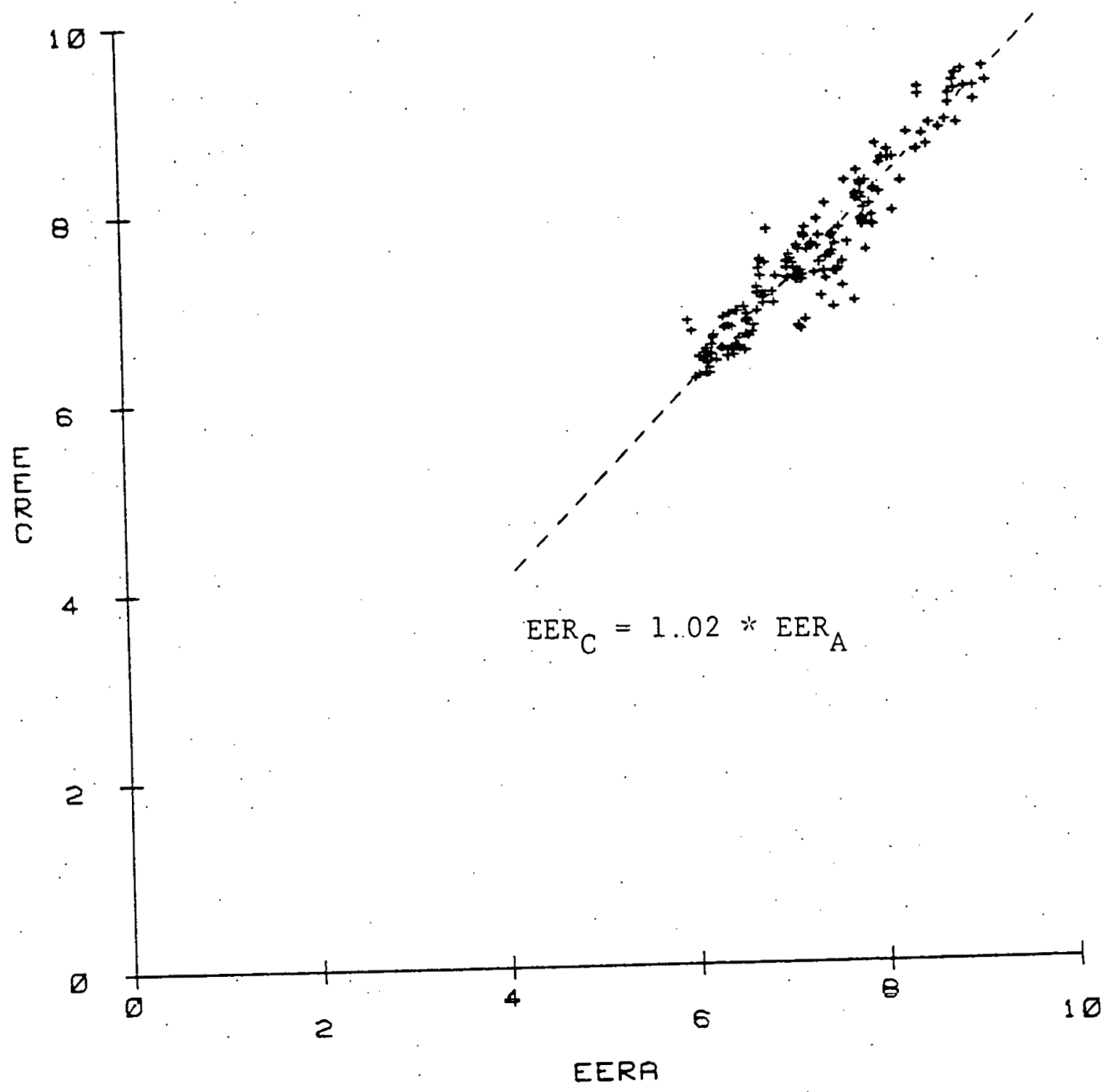

Figure 2-3 EER $_{C}$ vs. ${ }^{E E R_{A}}$ 


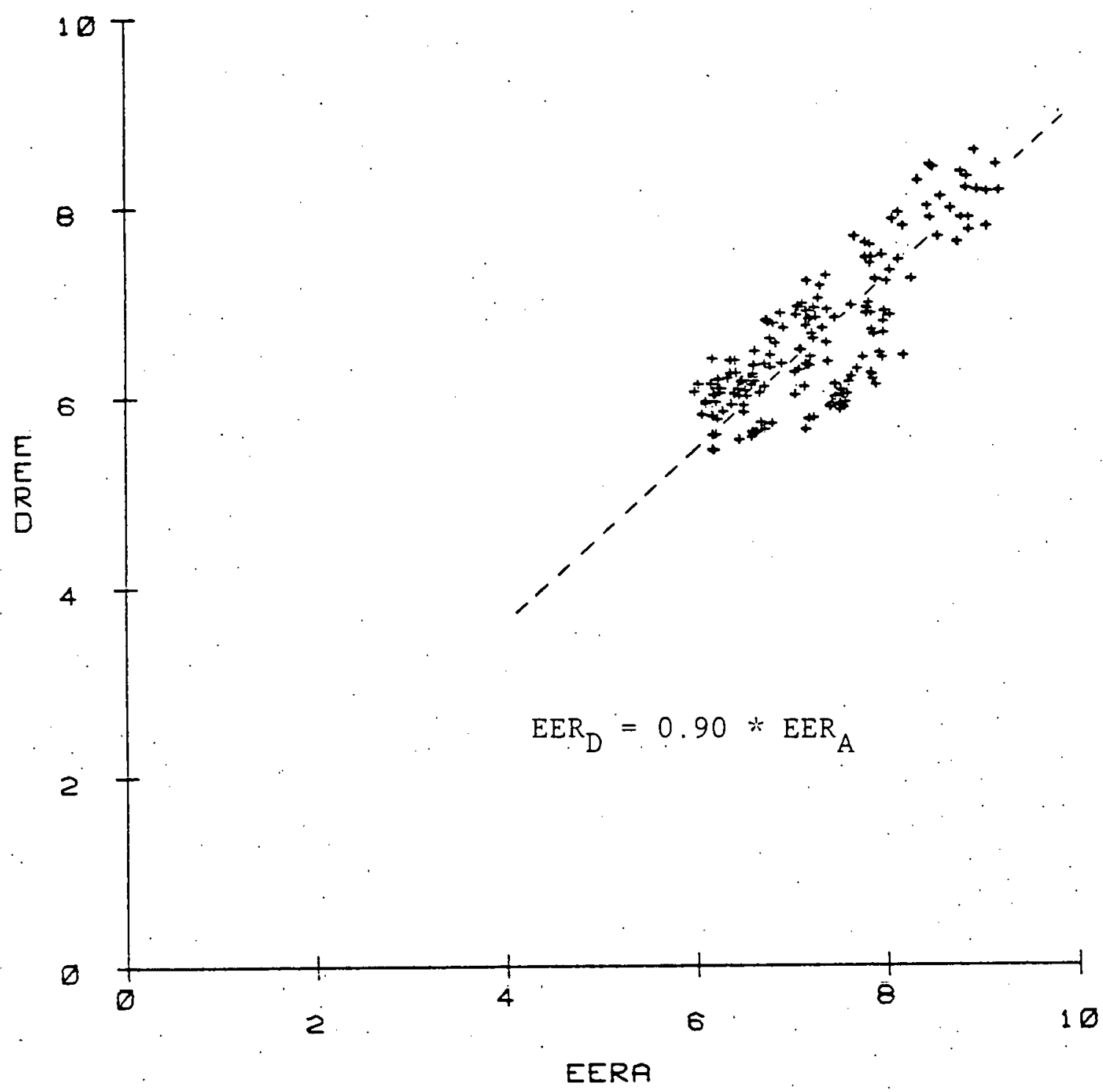

Figure 2-4 EER $R_{D}$ vs. EER 




Figure 2-5 $C_{D}$ vs. $\operatorname{EER}_{A}$ 


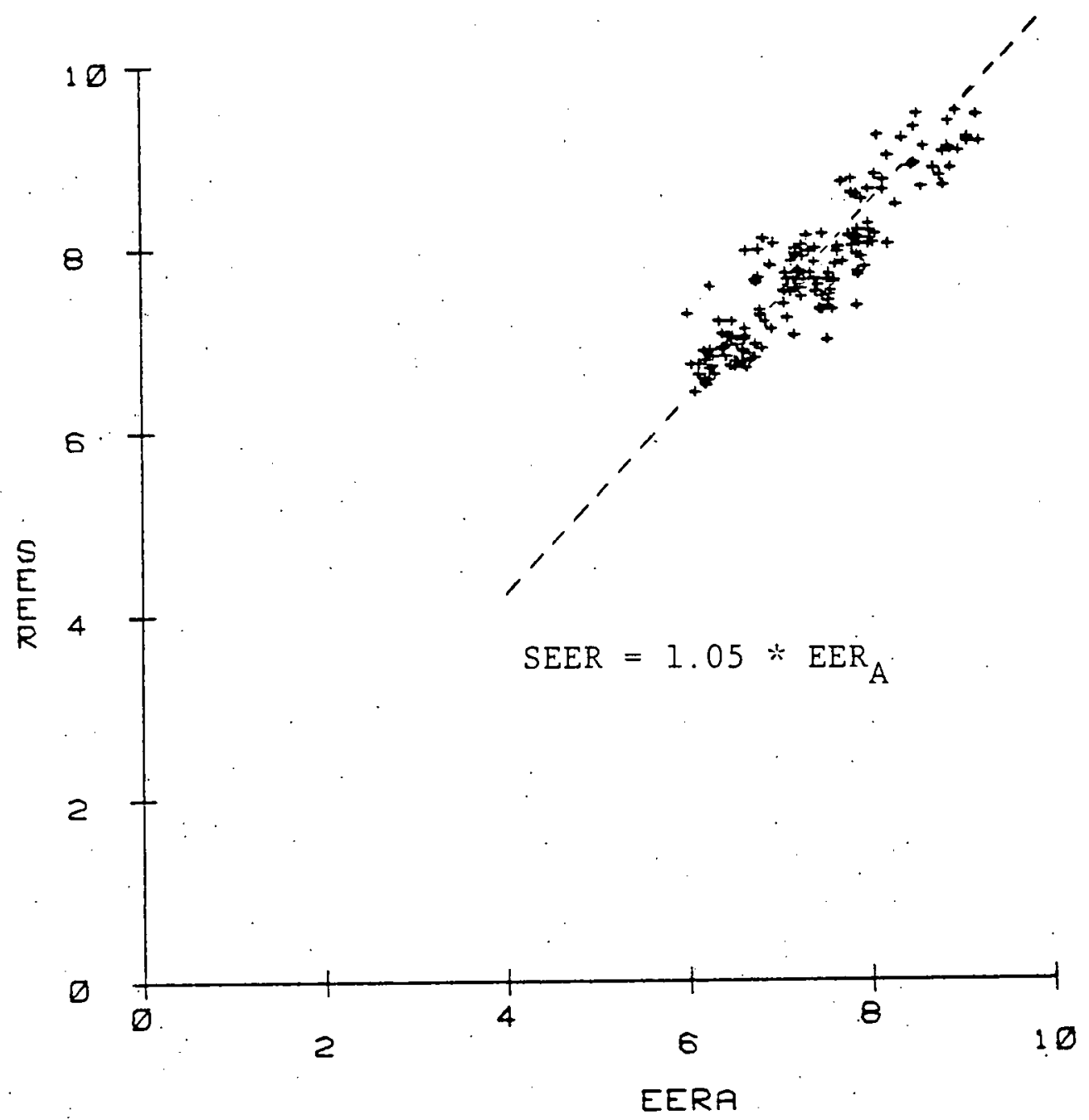

Figure 2-6 SEER vs. EER A 


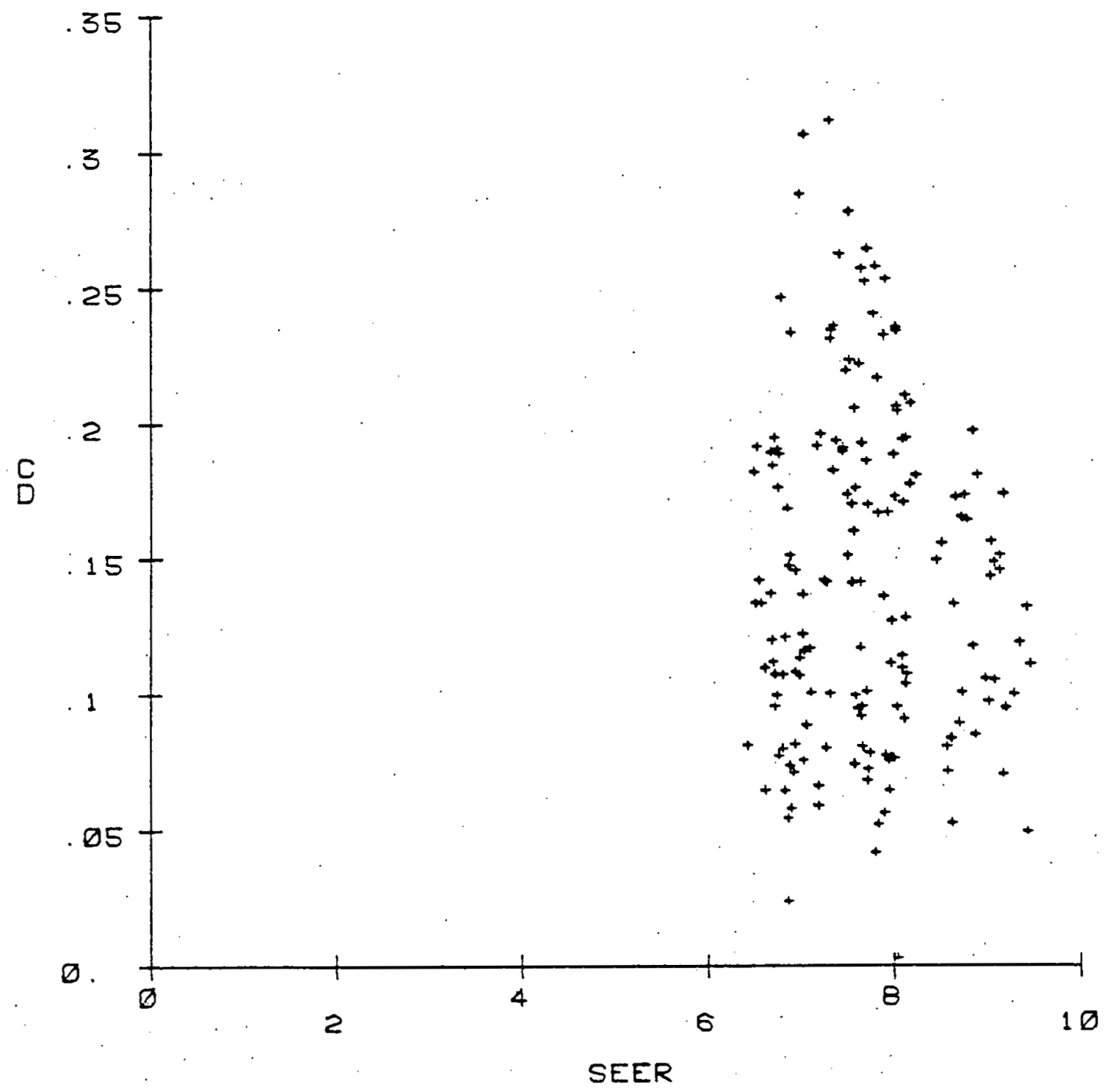

Figure 2-7 $C_{D}$ vs. SEER 
Figure 2-7 shows a plot of $C_{D}$ versus SEER and it appears that no simple relationship exists. This may be surprising at first impression, but is easily explained. There are three things that can have an influence on SEER: 1) the steady state EER as a function of outdoor temperature,. 2) the temperature drop across the evaporator coil at the start of the on-time and 3) cyclic effects. The part-load factor is by definition the indicator of the effect of cycling on energy usage.

In trying various functional relationships, many other plots were made. A plot of $E E R_{D} / E E R_{C}$ versus $E E R_{A} / E E R_{B}$ has a cluster of points at approximately $(0.9$, 0.9 ) (see Fig. 2-8). (This is also a consequence of Eqns. 2-1. through 2-3, from which $\mathrm{EER}_{\mathrm{A}} / \mathrm{EER}_{\mathrm{B}} \doteqdot 0.38 ; \mathrm{EER}_{\mathrm{D}} / \mathrm{EER}_{\mathrm{C}} \doteqdot$ 0.88.) Chapter 4 will address this topic from a general physical analysis. It should be stressed that this relationship is dependent on the validity of the available data and its universality. Since industry has had considerable difficulty in performing these tests, there is a possibility that the data could change as industry gains more experience in conducting these tests. There is some evidence to indicate that not all data points obtained are correct. One suspect example is the extremely low value of 0.0015 reported for the degradation factor of one unit (not reported nor used in this work).

It should also be pointed out that this relationship may only be a consequence of present design and may change as companies change their design. At the present time units are designed to give high steady state EERs. This is generally done by increasing the heat exchanger size which also reduces the back pressure on the compressor. The larger heat exchanger increases the steady state EER and at the same time increases the cyclic effect. Thus $E E R_{B}$ increases while $E E R_{D}$ decreases keeping the $E E R_{D} / E E R_{C}$ vs. $E E R_{A} / E E R_{B}$ relationship constant. 


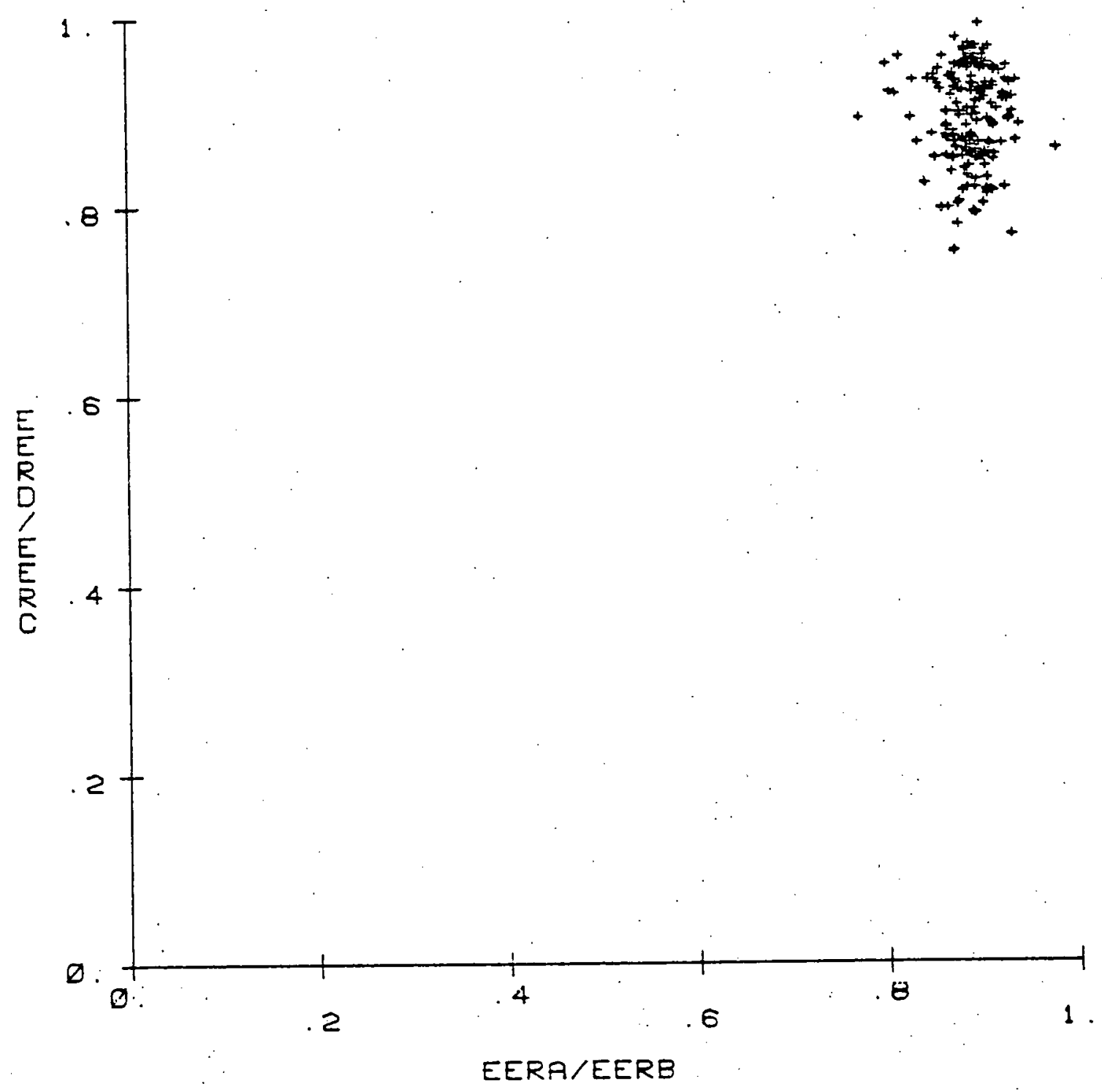

Figure 2-8 $E_{D E R_{D}} /{ }^{E E R_{C}}$ vs. $E E R_{A} / E E R_{B}$ 


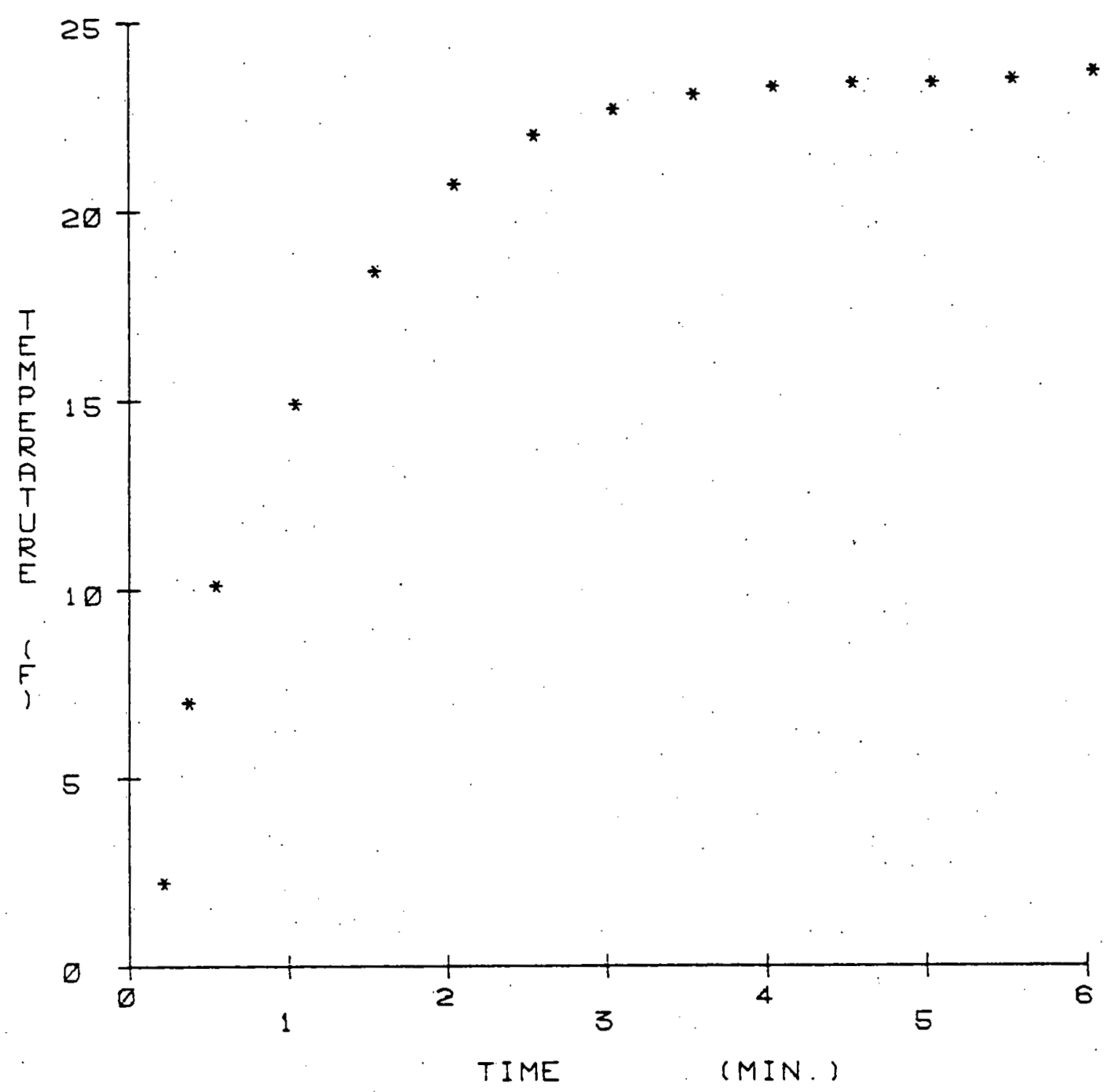

Figure 2-9. Temperature Drop Across the Evaporator Coil as."a Function of Time, $\Delta \mathrm{T}_{0}=0$. 


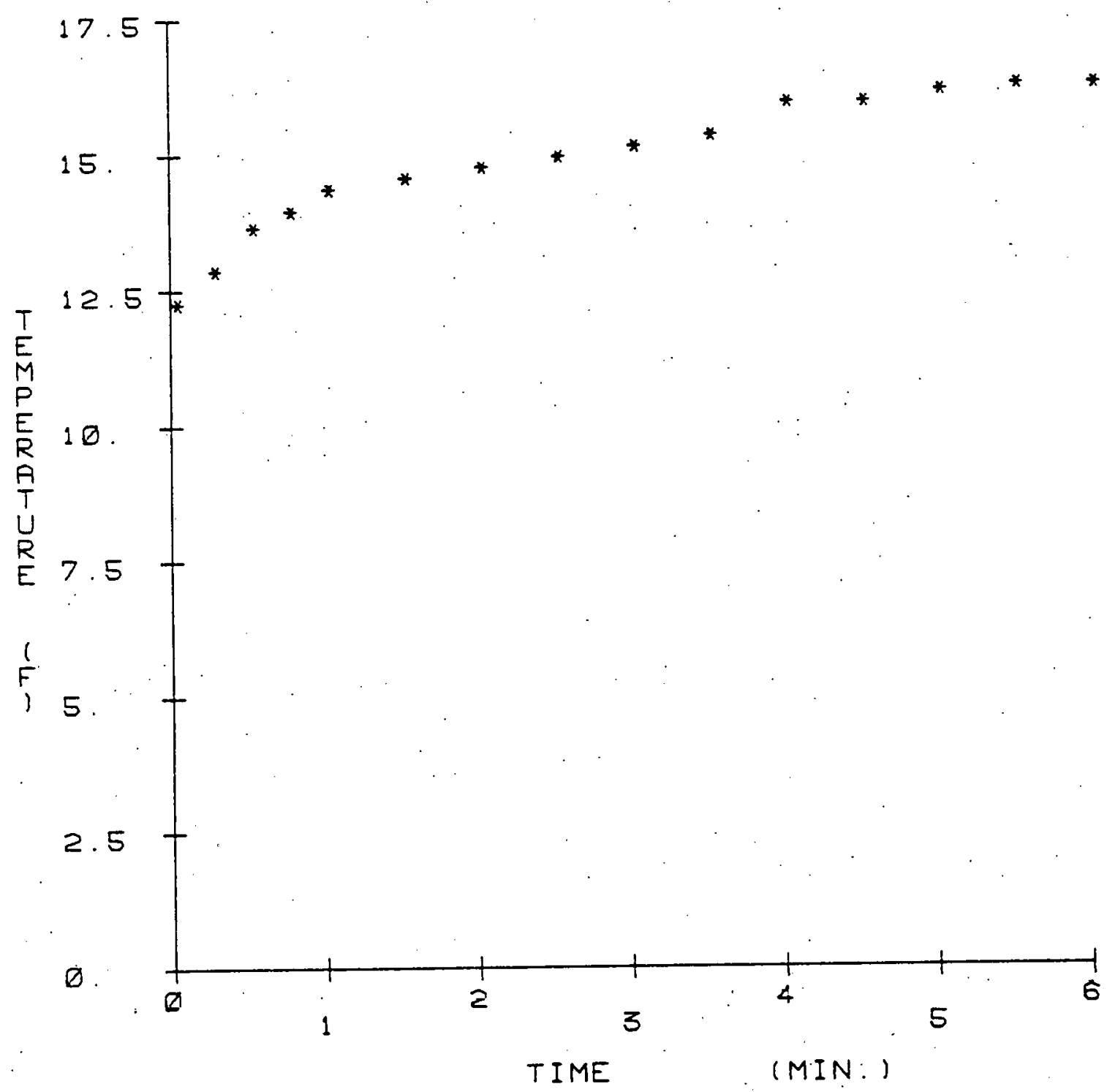

Figure 2-10 Temperature Drop Across the Evaporator Coil as a Function of Time, $\Delta \mathrm{T}_{0} \neq 0$. 


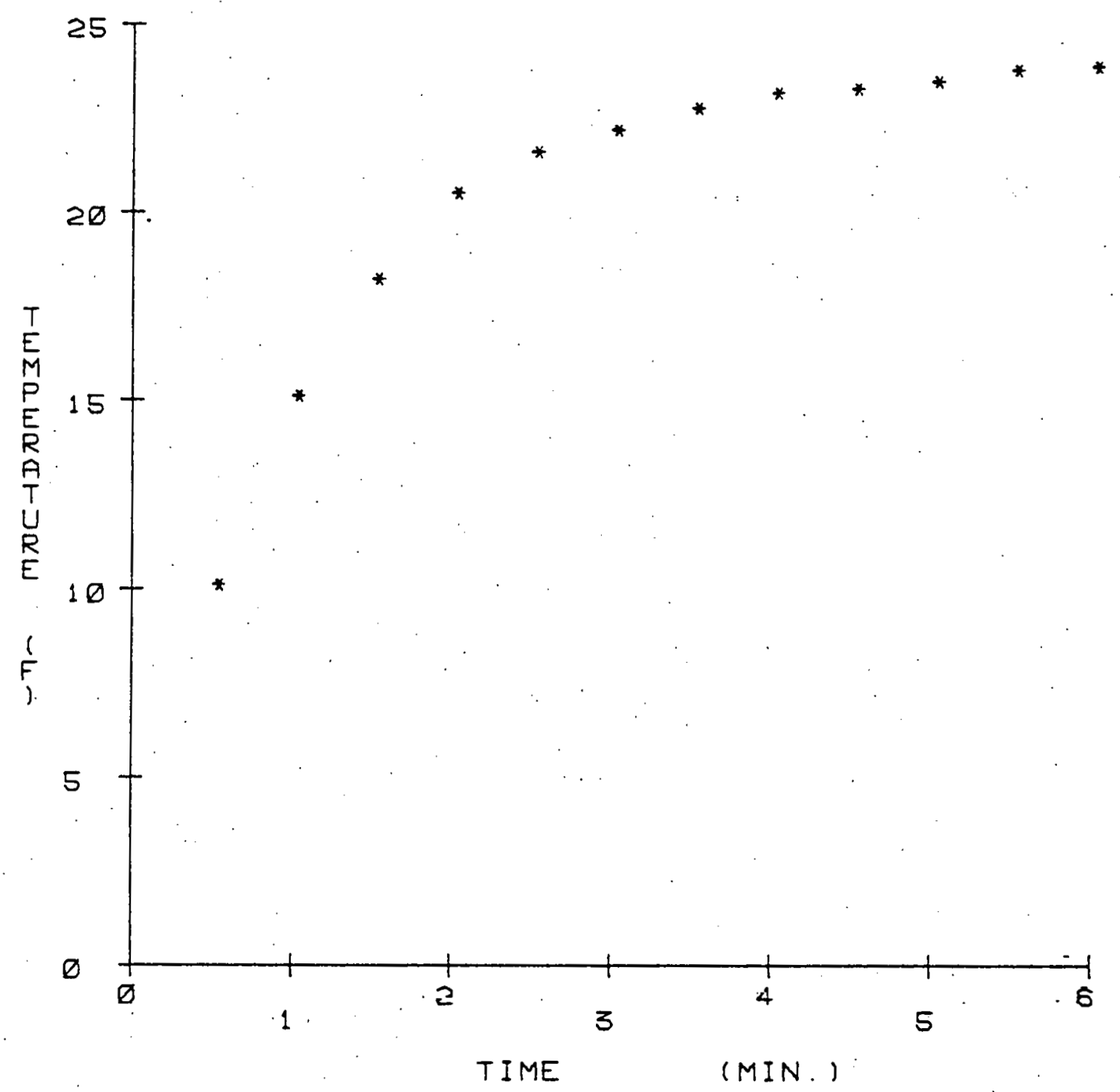

Figure 2-11 Another Plot of the Temperature Drop Across the Evaporator Coil as a Function of Time, $\Delta T_{0}=0$. 
Nevertheless, this relationship deserves further study. Further data may indicate that this relationship does not hold for all possible units, but for example, may only hold for a class or classes of units from a given company. Even if only the latter proved true it might mean a great reduction in the experimental tests needed.

A few manufacturers supplied evaporator coil temperature vs. time data. The data for three units are plotted in Figs. 2-9, 2-10 and 2-11. These plots along with all other time-temperature plots observed show two interesting and important things: 1) in general, the form of the curve is exponential, and 2) the temperature drop across the coil at the start of the on-time is not always zero. The temperature off-set at the start of the on-time may be a function of how the test chambers have been modified to conduct test $D$ and could vary greatly from test chamber to test chamber and even from run to run. It was shown in reference (30) that if this temperature offset exists, it could affect the reported SEER. This may be one explanation for some of the scatter in the present data.

It should be noted here that the analysis in reference (30) assumed that there were three indeperident variables: 1) the time constant of the unit, 2) the on-time, and 3) the cycle-time. Reference (30) used a constant cycle-time of 30 minutes. This assumption led to some conditions that cannot exist in a real unit: One such condition is an incorrect prediction of the degradation coefficient as the $100 \%$ on-time is approached. See Chapter 3 for additional comments. 


\section{CHAPTER 3 \\ ANALYSIS OF TRANSIENT RESPONSE BASED ON SEMI-EMPIRICAL FORMULA}

A) Assumptions Used In Semi-Empirical Study

In order to make some further comparisons and to give more insight into the present DOE test method a semiempirical model will be developed. This model is developed by making the three assumptions listed below. Those assumptions which are not the same as those made in the DOE test procedure (20) were obtained from trends in the data. The assumptions are:

1. The volumetric flow rate $(\dot{\bar{V}})$ of air across the evaporator coil is a step function of time or

$$
\begin{aligned}
& \dot{\bar{V}}=\dot{\bar{V}} \text { Steady State for all on-time } \\
& \dot{\bar{V}}=0 \text { for all off-time }
\end{aligned}
$$

This same assumption is made in the DOE regulations.

2. The rate of energy consumed in tests $C$ and $D$ by the air conditioning system is a function of percent ontime or

$$
\begin{aligned}
& \frac{\overline{\mathrm{E}}_{\mathrm{D}}}{\dot{\mathrm{E}}_{\mathrm{C}}}=f\left(t_{o n} / t_{c y c}\right) \text { as a } \\
& \dot{E}=0 \text { for all off-time }
\end{aligned}
$$

Experimental data shows that there appears to be a large spike of very small duration at the beginning of the on-cycle and then the energy consumption drops a little below steady state and rises very rapidly to steady state. Hence, this assumption is relaxed at times. 
3. The temperature drop across the evaporator coil $\Delta T(t)$ can be represented by a first order system or

$$
\Delta T(t)=\Delta T_{S S}[1-\exp (-t / \tau)]+\Delta T_{0}[\exp (-t / T)]
$$

where

$$
\begin{aligned}
\Delta \mathrm{T}_{S S}= & \text { steady state temperature drop across coil } \\
\Delta \mathrm{T}_{0}= & \text { temperature drop across the coil at time } \\
& \text { equal to } 0 \\
t= & \text { time since start of cycle } \\
\mathrm{T}= & \text { time constant }
\end{aligned}
$$

Experimental results show that $\Delta \mathrm{T}_{0}$ does not always equal zero, as noted in Figure 2-10.

of the three assumptions the last two need more investigation. There is less experimental support and thus a need for further research.

Since all of the data collected for this work was on single compressor constant speed units, only this type of unit will be considered.

An evaluation of the DOE test method is made using the assumptions outlined previously. The DOE test method is evaluated by following reference (20). Under this test procedure four tests must be conducted. These tests are summarized in Table $1-3$. Tests $C \& D$ are needed to determine the effect of transient conditions. It should be noted that tests $C \& D$ are conducted under dry indoor conditions. Everyone agrees that for a large fraction of the cooling season, air conditioning units operate cyçlically and with a wet evaporator coil. It would appear that tests should be performed under these conditions. Kelly and Parken (20) found from laboratory tests that constant room ambient conditions are difficult to maintain and errors associated with measuring the dry-bulb and wetbulb temperature can lead to large uncertainties in the cyclic sensible and latent capacities. However, they state that they can replace the wet-coil tests with a simpler and more accurate dry coil test. A major assumption 
made by NBS and DOE states that

$\frac{E E R_{c y c}, \text { dry }}{E E R_{\text {ss }, \text { dry }}}=\frac{E E R_{\text {cyc }} \text {, wet }}{E E R_{\text {ss }} \text {, wet }}$

at the same cooling load factor (CLF).

Throughout the duration of this work no data was

supplied to the author to either support or contradict this assumption.

B) Derivation of Semi-Empirical Equations

1. Cooling Load Factor

The cooling load factor (CLF) is defined as the ratio

of the total cooling during cycling conditions to the total cooling for steady state conditionsor

$$
\begin{aligned}
C L F & =\frac{Q_{c y c, d r y}}{\dot{Q}_{s s, d r y} \cdot n \cdot t_{c y c}} \\
& =\frac{\dot{Q}_{c y c, d r y} t_{\text {on }}}{\dot{Q}_{s s, d r y} t_{c y c}}
\end{aligned}
$$

Both tests run at the same indoor and outdoor conditions, where

$$
\begin{aligned}
& Q_{\text {cyc, dry }}=\text { Total cyclic cooling. (sensible) done } \\
& \text { by unit in time } n \cdot t_{\text {cyc }} \\
& t_{\text {cyc }}=\text { Time for one complete cycle consisting of } \\
& \text { one on-time, one off-time } \\
& \mathrm{n}=\text { Number of cycles } \\
& t_{\text {on }}=\text { on-time during one cycle } \\
& \dot{Q}_{\text {SS, dry }}=\text { Steady state total cooling capacity } \\
& \dot{Q}_{c y c, d r y}=\text { Average cycling cooling capacity during } \\
& \text { on-time }=Q_{\text {cyc }, d r y} / n \cdot t_{\text {on }}
\end{aligned}
$$


but

$$
Q_{c y c, d r y}=\frac{60 \dot{\bar{V}} c_{p a} \Gamma}{v_{n}^{1}\left(1+w_{n}\right)}
$$

where

$$
\begin{aligned}
\dot{\bar{V}} & =\text { indoor air flow rate } \\
C_{p a} & =\text { specific heat of air at constant pressure } \\
V_{n}^{I} & =\text { specific volume of air-water mixture at } \\
\text { indoor conditions } & \\
W_{n} & =\text { humidity } \\
I=\int_{0}^{t} \text { on } & \Delta T(t) d t \\
\Delta T(t) & =\text { temperature drop across coil } \\
t & =\text { time }
\end{aligned}
$$

In order to gain more insight into the cooling load factor the assumptions of Section $\mathrm{A}$ will be used. It should again be stressed that this analysis is based on semi-empirical results and its intention is to give in-. sight into the DOE test method.

Beginning with assumption 1 (i.e., $\dot{\bar{V}}=$ constant) the following is obtained for both the cyclic test and the steady state tests

$\frac{60 \dot{\nabla} c_{p a}}{v_{n}^{1}\left(1+w_{n}\right)}=K$

where $K=$ constant, with units of $B t u / h-{ }^{\circ} F$.

Integrating Eqn. 3-5, the following results,

$$
\Gamma=\Delta T_{S S} t_{o n}+\left[1-\exp \left(-t_{o n} / \tau\right)\right]\left[\Delta T_{0}-\Delta T_{S S}\right] \tau
$$


and for $\Delta T_{0}=0$

$\Gamma=\Delta T_{S S}\left(t_{\text {on }}-\tau\right)+\left[\Delta T_{S S} \exp \left(-t_{\text {on }} / \tau\right)\right] \tau$

putting both of these results into Eqn. 3-2 gives

$\mathrm{CLF}=\frac{t_{o n}}{t_{c y c}}+\frac{\tau}{t_{c y c}}\left(\frac{\Delta T_{o}}{\Delta T_{s s}}-1\right) \quad\left[1-\exp \left(-t_{o n} / \tau\right)\right]$

if $\Delta T_{0}=0$

CLF $=\frac{t_{\text {on }}}{t_{c y c}}-\frac{\tau}{t_{c y c}}\left[1-\exp \left(-t_{\text {on }} / \tau\right)\right]$

Equation 3-10 will be used in section $C$ to determine how CLF varies when combined with a thermostat model. Reference (30) analyzed Eqn. 3-9 by varying the variables. In a real system the thermostat will determine how the on-time and cycle-time vary (i.e., they are not independent).

2. Degradation Coefficient and Part-Load Factor The degradation coefficient $C_{D}$ is defined as

$C_{D}=\frac{1-\frac{E E R_{C y C}, d r y}{E E R_{S S, d r y}}}{1-C L F}$

but

$E E R_{c y c}, d r y=\frac{K}{\dot{E}_{D}}\left[\Delta T_{s S}+\left(\Delta T_{0}-\Delta T_{S S}\right)\left(1-\exp \left(-t_{o n} / \tau\right)\right) \tau / t_{o n}\right]$

where $\overline{\dot{E}}_{D}=\frac{1}{t_{\text {on }}} \int_{0}^{t}$ on $\dot{E}_{D}(t) d t$ and

$\mathrm{EER}_{S S, \mathrm{dry}}=\frac{\mathrm{K}}{\dot{\mathrm{E}}_{\mathrm{C}}} \Delta \mathrm{T}_{S S}$ 
dividing Eqn: $3-12$ by Eqn. 3-13 gives

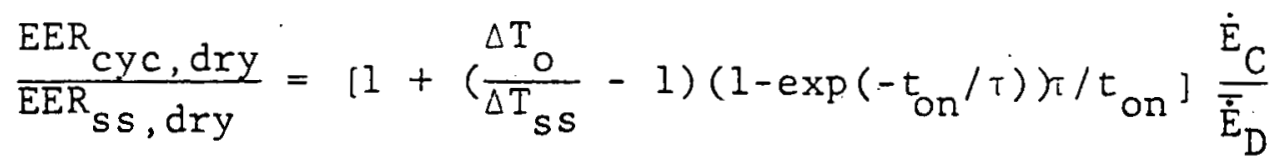

but

$\frac{\text { EER cyc, dry }}{\text { EER }_{S S, d r y}}=$ part-load factor (PLF)

The part-load factor is more important than the degradation coefficient in determining the effects of cycling on the energy usage of a unit. Substituting Eqn. 3-9 and 3-14 into Eqn. 3-11 gives

$C_{D}=\frac{1-\left\{1+\left(\frac{\Delta T_{0}}{\Delta \mathrm{T}_{S}}-1\right)\left[1-\exp \left(-t_{o n} / \tau\right)\right] \tau / t_{o n}\right\} \cdot \frac{\dot{\mathrm{E}}_{C}}{\dot{\mathrm{E}}_{D}}}{1-\left\{\frac{\mathrm{t}_{\text {on }}}{\mathrm{t}_{c y c}}+\frac{\tau}{\mathrm{t}_{c y c}}\left(\frac{\Delta \mathrm{T}_{0}}{\Delta \mathrm{T}_{S}}-1\right)\left[1-\exp \left(-t_{o n} / \tau\right)\right]\right\}}$

or with $\frac{\dot{E}_{\mathrm{C}}}{\dot{\mathrm{E}}_{\mathrm{D}}}=1$, then

$C_{D}=\frac{\left(1-\frac{\Delta T_{O}}{\Delta T_{S}}\right)\left[1-\exp \left(-t_{o n} / \tau\right)\right] \tau / t_{\text {on }}}{1-\frac{t_{o n}}{t_{c y c}}+\left(1-\frac{\Delta T_{O}}{\Delta T_{S}}\right)\left[1-\exp \left(t_{o n} / \tau\right)\right] \frac{\tau}{t_{c y c}}}$ 
Equation 3-17 shows that the degradation coefficient is a function of the initial temperature drop across the evaporator coil. This indicates one problem that needs further attention in clarification of these test procedures. As the test procedure now stands it is possible to perform tests according to the test procedure but change the way air is blocked from flowing over the indoor coil. This could change the $\Delta T_{0}$ value and give a different $C_{D}$ and $P L F$ for the same unit. These semi-empirical equations will.be used in further investigations with the on-time and cycletime (both varying) determined from ideal thermostat responses.

C) Semi-Empirical Analysis With Thermostat Model

In a similar analysis in reference (30), the study was conducted with a constant cycle time (i.e., $t_{\text {cyc }}=$ $30 \mathrm{~min}$.$) . The following analysis will have both the on-$ time and cycle-time varying throughout the study. The logical choice to determine how the on-time and cycle-time varies is to consider the thermostat demand cycle. Present day thermostats force these two variables to be related. In this model the percent on-time (i.e., $t_{\text {on }} / t_{c y c}$ ) is determined from a curve fit to the ideal thermostat response as determined by National Electrical Manufactures Association (NEMA) test for low-voltage room thermostats (DC3-1978) (25). Figure 3-1 shows the ideal. thermostat response. The equation for the parabola is given by

$C R=\frac{-C R(50)}{2500}(\%-50)^{2}+C R(50)$

where

$\mathrm{CR} \quad=$ cycle rate $(\mathrm{CPH})$

$\mathrm{CR}(50)=$ cyclie rate at $50 \%$ on-time

$\% \quad=$ percent on-time $\left(t_{\text {on }} / t_{\text {cyc }} \times 100\right)$ 


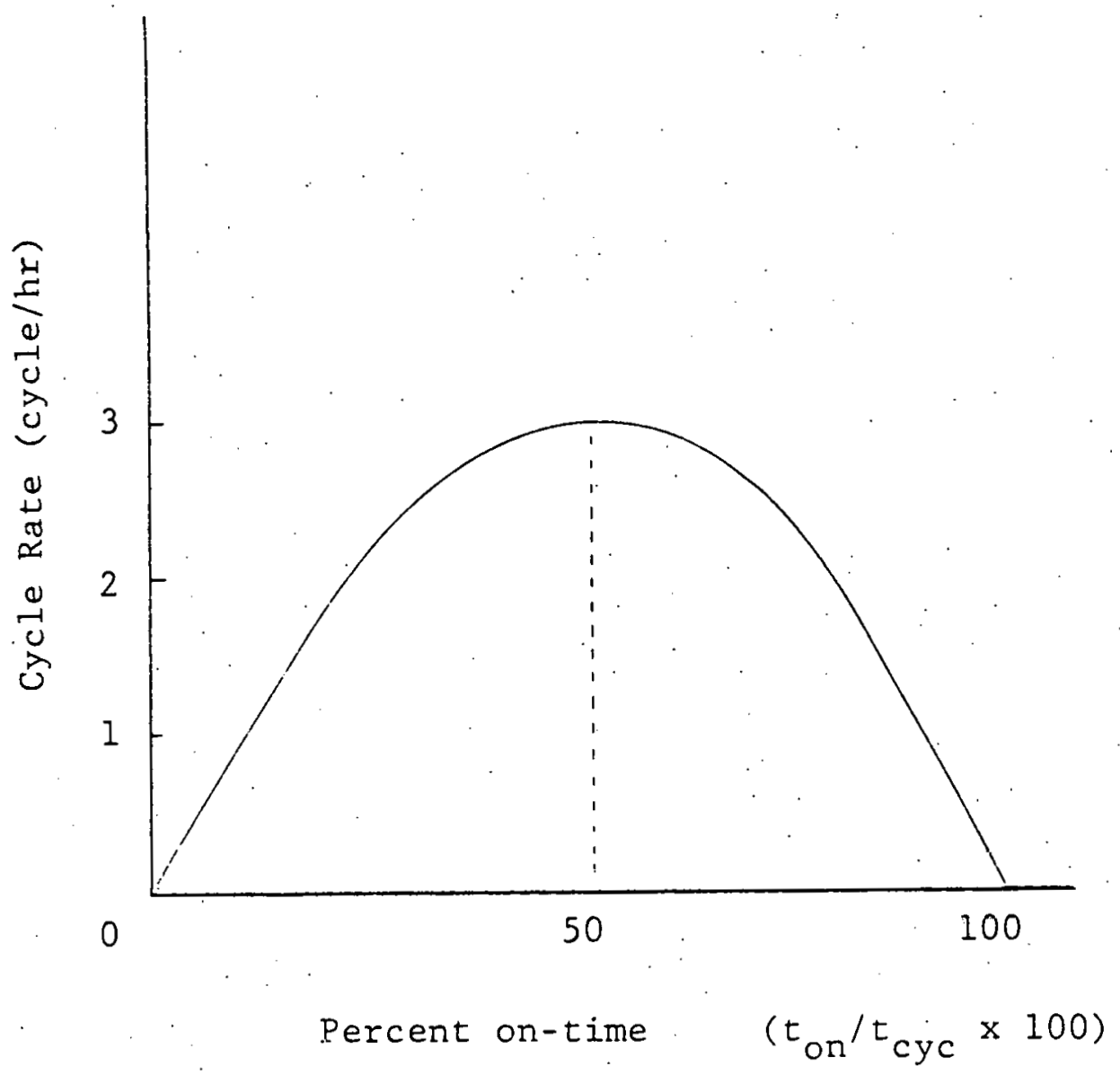

Figure 3-1 The General Response Curve as a Result of an Ideal Thermostat Response. 
In the ideal case $\mathrm{CR}(50)$ is equal to $3 \mathrm{CYH}$. To determine the relationship for the on-time and cycle-time, note the following:

1. The cycle rate (CR) is equal to one cycle divided by the cycle time or

$C R=\frac{1 \text { cycle }}{t_{\text {cyc }}}$

2. The percent on-time is equal to the on-time divided by the cycle-time or

$\%=t_{\text {on }} / t_{\text {cyc }} x \cdot(100)$

substituting Eqns. 3-19 and 3-20 into Eqn. 3-18 we obtain the following general equation

$\left(\frac{t_{\text {on }}}{t_{c y c}}\right)^{2}-\frac{t_{\text {on }}}{t_{c y c}}+\frac{15}{t_{c y c} \times \text { CR(50) }}=0$

or

$t_{\text {on }}=\frac{t_{c y c} \pm\left\{t_{c y c}{ }^{2}-60 \times t_{c y c} / C R(50)\right\}^{1 / 2}}{2}$

where the unit of time is minutes.

Equation 3-21 could have been written in the following form with the specific case where $C R(50)$ is equal to 3

$\frac{t_{\text {on }}}{t_{\text {cyc }}}=1-\frac{5}{t_{\text {on }}}$

A similar experimental result (see Eqn. 1-7) was found in reference (24). 
By following the thermostat demand cycle it can be shown that the on-time is a function of the cycle-time and maximum cycling rate. Actually the maximum cycling rate determines the minimum cycle-time and on-time. Figure 3-2 shows how $t_{\text {on }}$ varies with $t_{c y c}$ for maximum cycling rates of 3 and $6 \mathrm{CPH}$. In general as the on-time and cycletime both increase above the minimum cycle-time they will each approach the same value (ie. the percent on-time goes to 1). Also, as the on-time approaches the minimum ontime allowed by the thermostat the cycle-time will increase asymptotically to this asymptote. Thus, there will be two asymptotes, one at the minimum on-time and the other at ontime equal to cycle-time. From Eqn. 3-2l or from Figure 3-3 one can see that cycle-time versus percent on-time forms a parabola with the minimum cycle-time as the vertex and the axis of symmetry going through this point. Looking at Figure $3-4$ or Eqn. $3-23$ it is observed that due to the thermostat there is a finite on-time at zero percent ontime. A similar experimental result was obtained in Murphy and Goldschmidt's study (24) of a 3-ton field-tested air conditioner. Also, it should be noted that by increasing the maximum cycling rate, the minimum cycle and on-time are reduced and the percent on-time is increased for corresponding on-times (see Figures $3-3$ and 3-4).

This model can be used to examine how CLF and PLF are functions of on-time, cycle-time. cycle rate and percent on-time as well as the time constant. Figure 3-5 shows how CLF varies for different on-times. The CLF is most sensitive to on-times up to 30 minutes. Also, the CLF is most sensitive to cycle-time in the first 10-20 minutes past the minimum cycle-time (see Figure 3-6). Taking the ratio of on-time to cycle-time, Figure 3-7, shows that by changing the maximum cycle rate there is less of an effect on CLF for the same percent on-time. Thus, CLF is responsive to percent on-time, but varies little with the change in maximum cycle rate: 


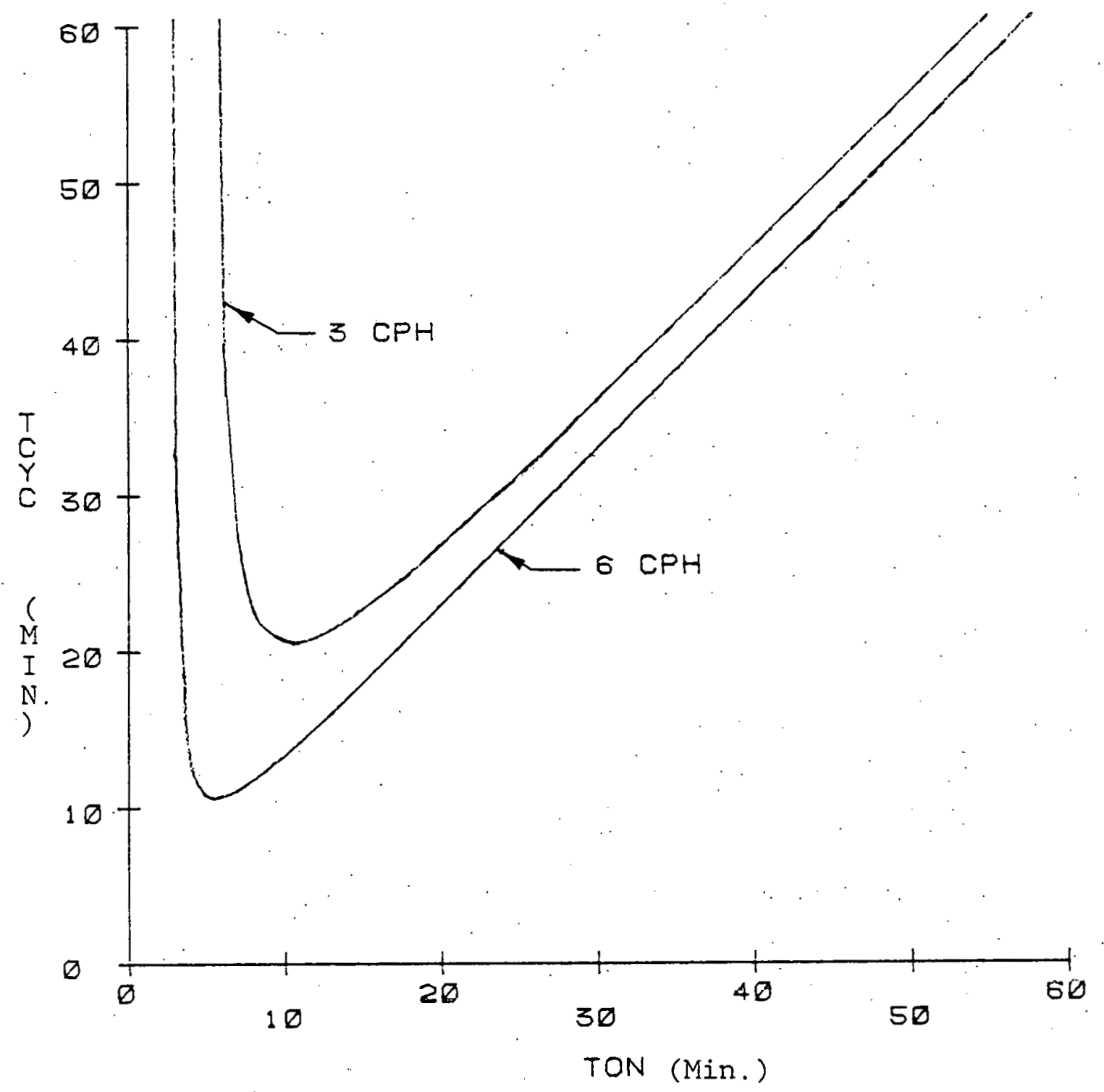

Figure 3-2 Cycle-Time vs. On-Time as Determined from the Thermostat Demand Cycle at Different Maximum $\mathrm{CPH}$. 


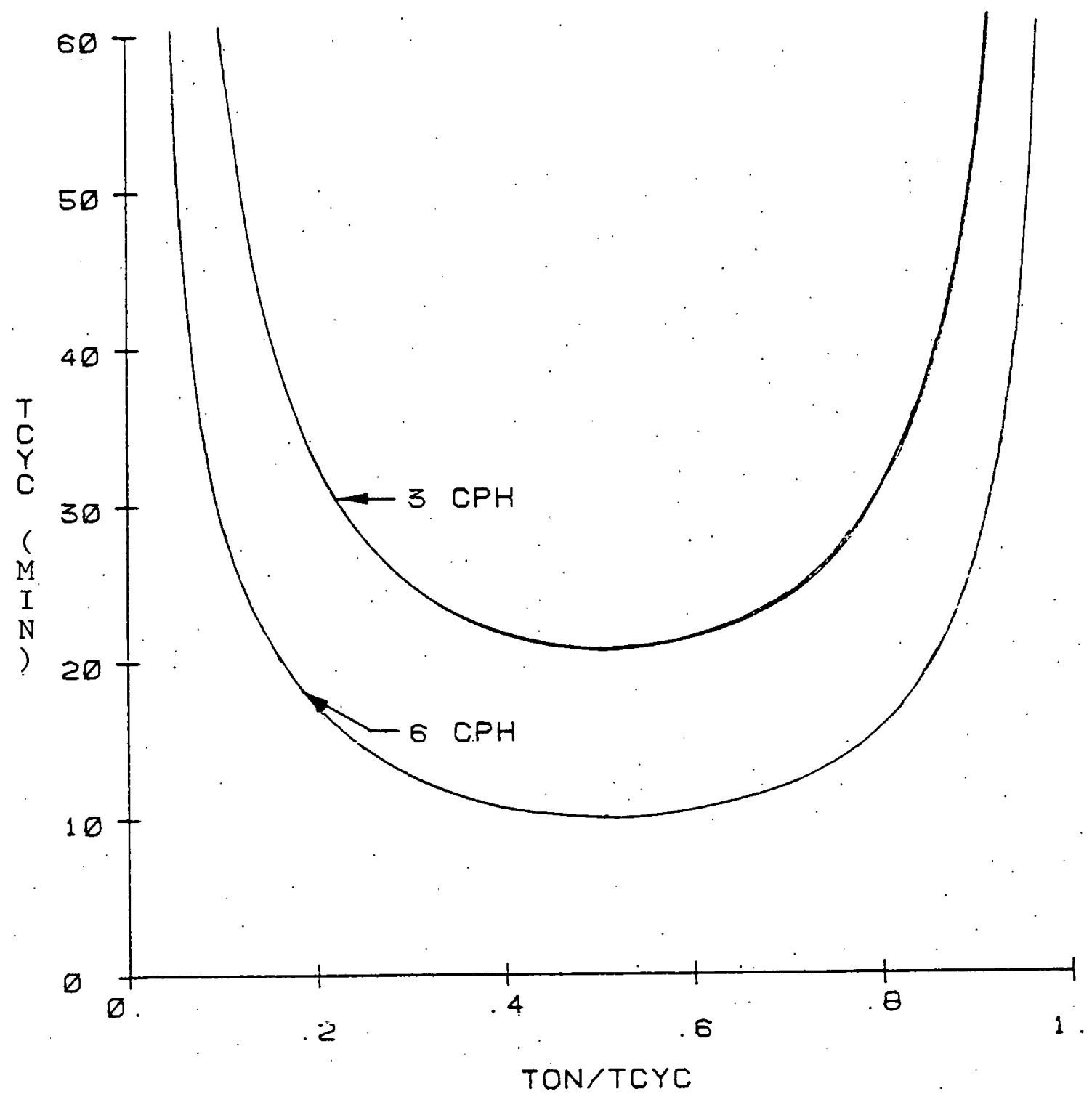

Figure 3-3 Cycle-Time vs. Percent On-Time as Determined from the Thermostat Demand Cycle at Different Maximum $\mathrm{CPH}$. 


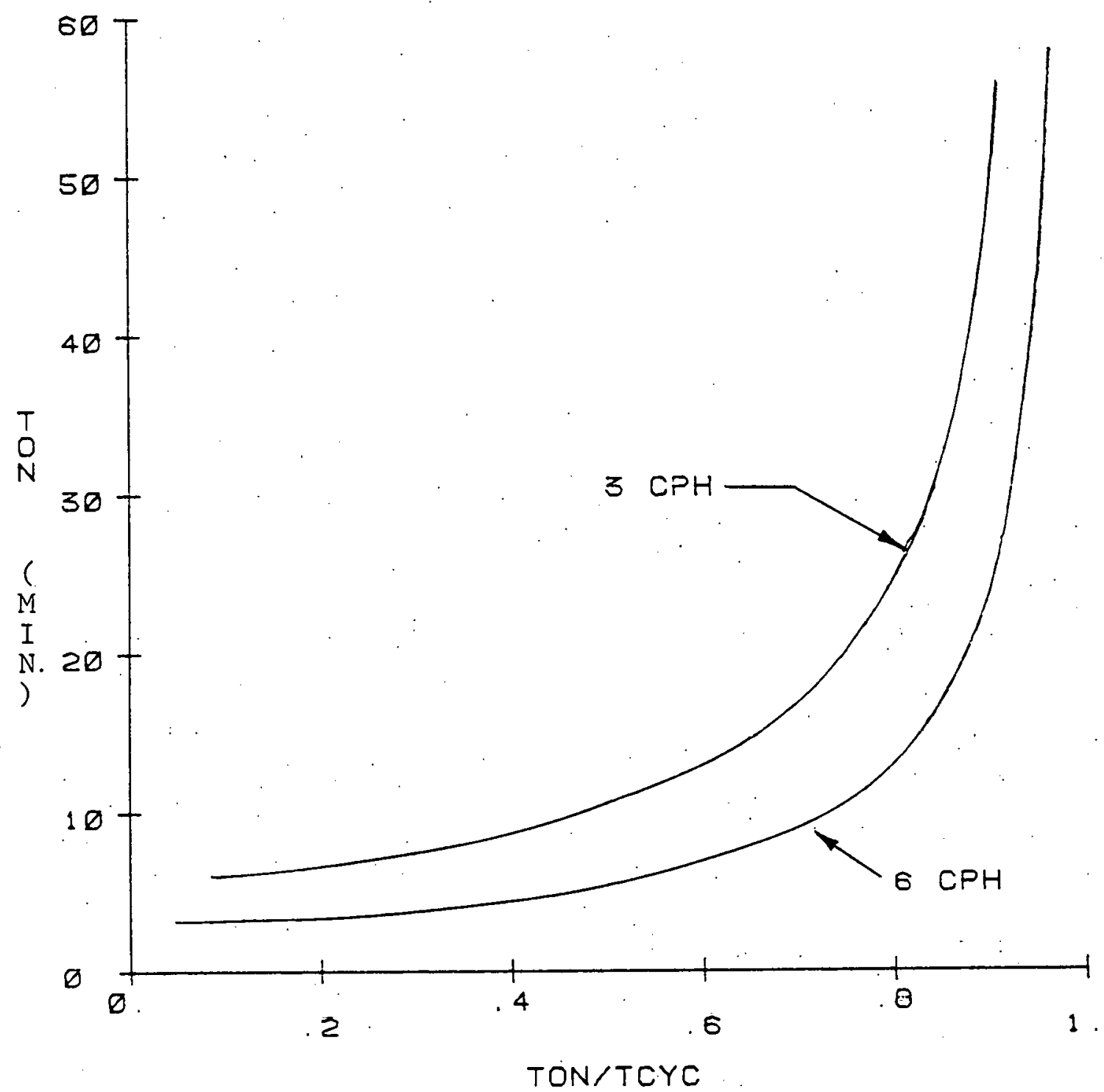

Figure 3-4 On-Time vs. Percent On-Time as Determined from Thermostat Demand Cycle at Different Maximum $\mathrm{CPH}$. 


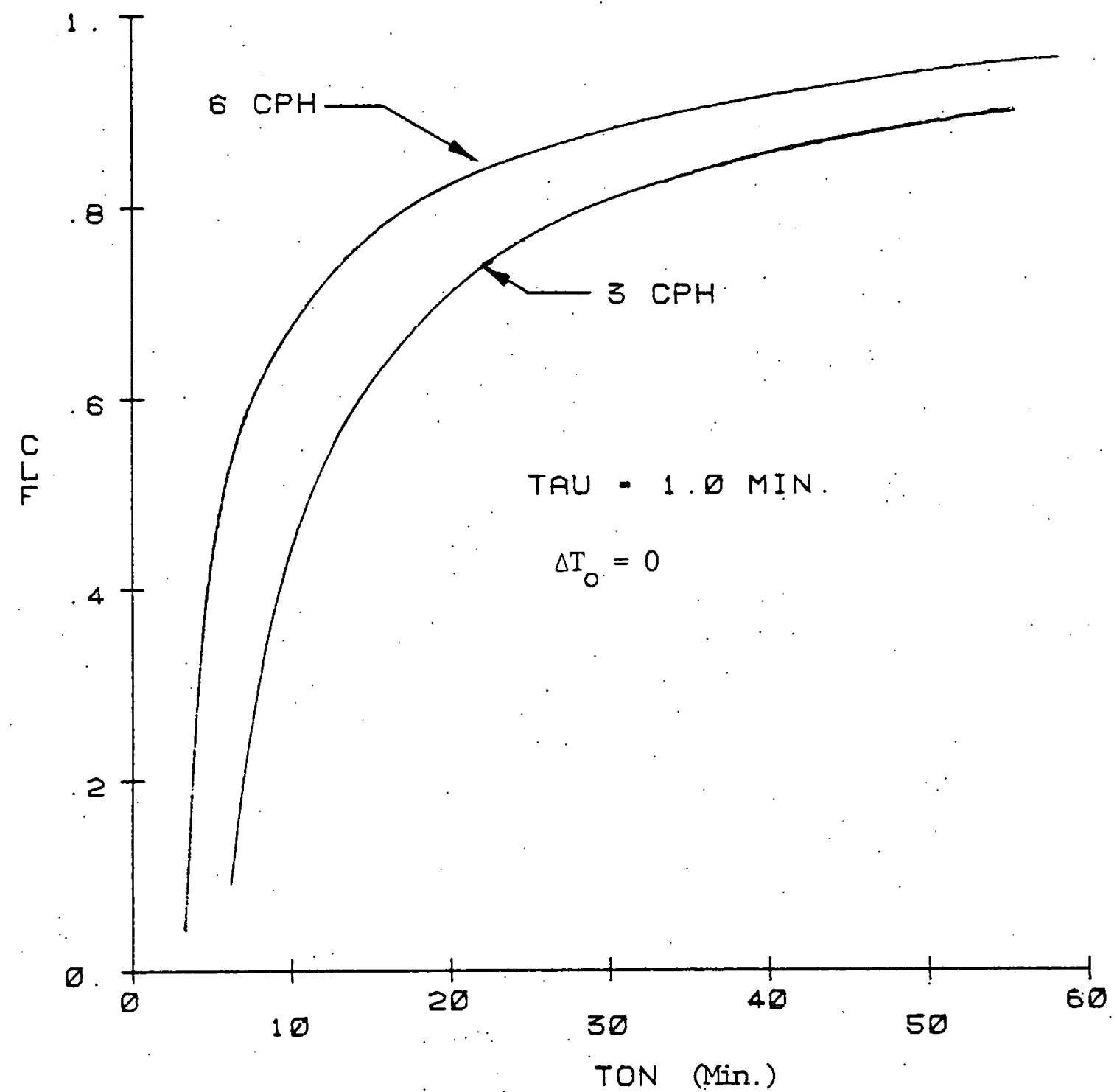

Figure 3-5 Cooling Load Factor vs. On-Time at Different Maximum CPH, with a Variable Cycle-Time Determined from Thermostat Demand Cycle. 


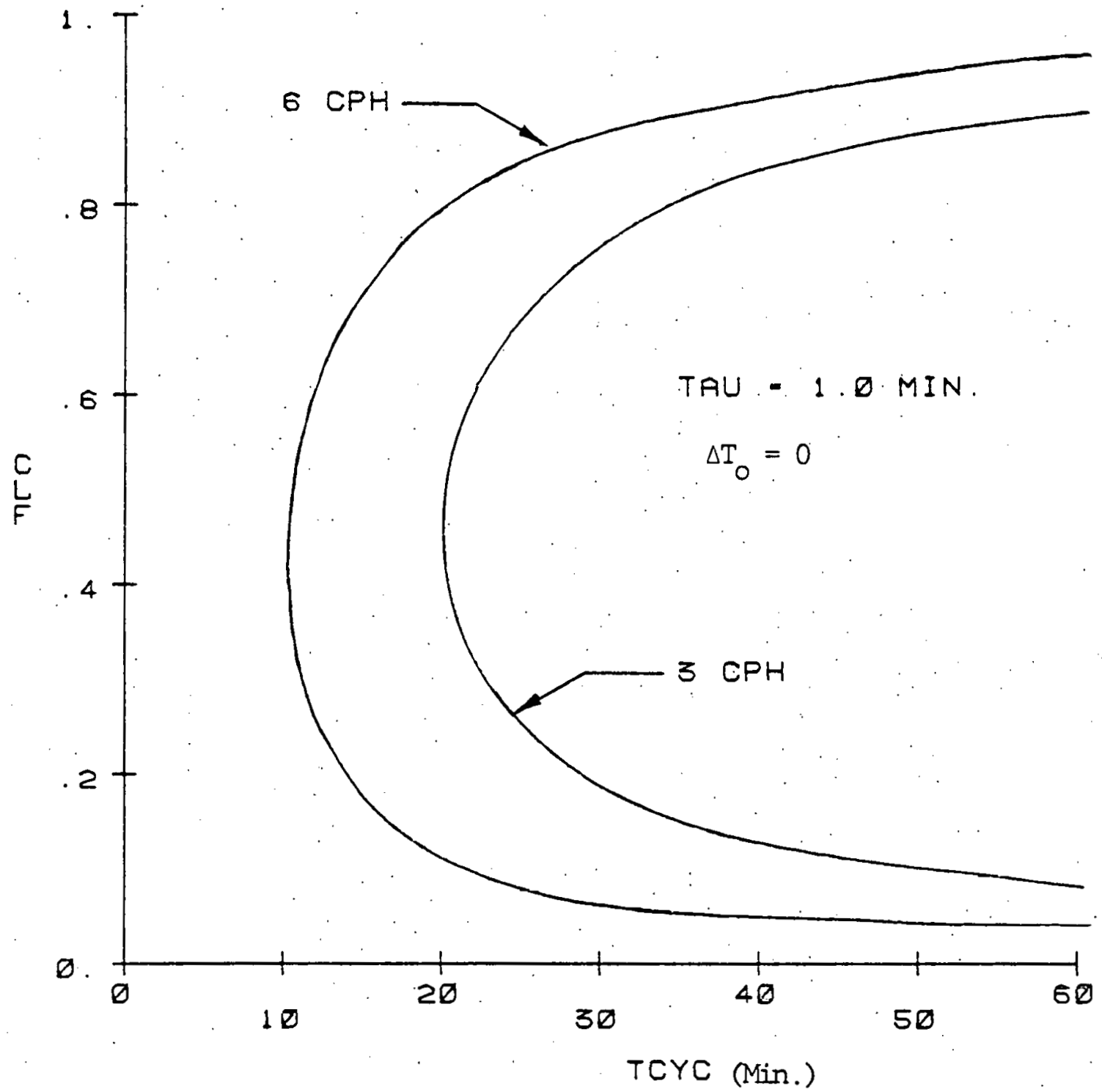

Figure 3-6 Cooling. Load Factor vs. Cycle-Time at Different Maximum CPH, with a Variable On-Time Determined from Thermostat Demand Cycle. 


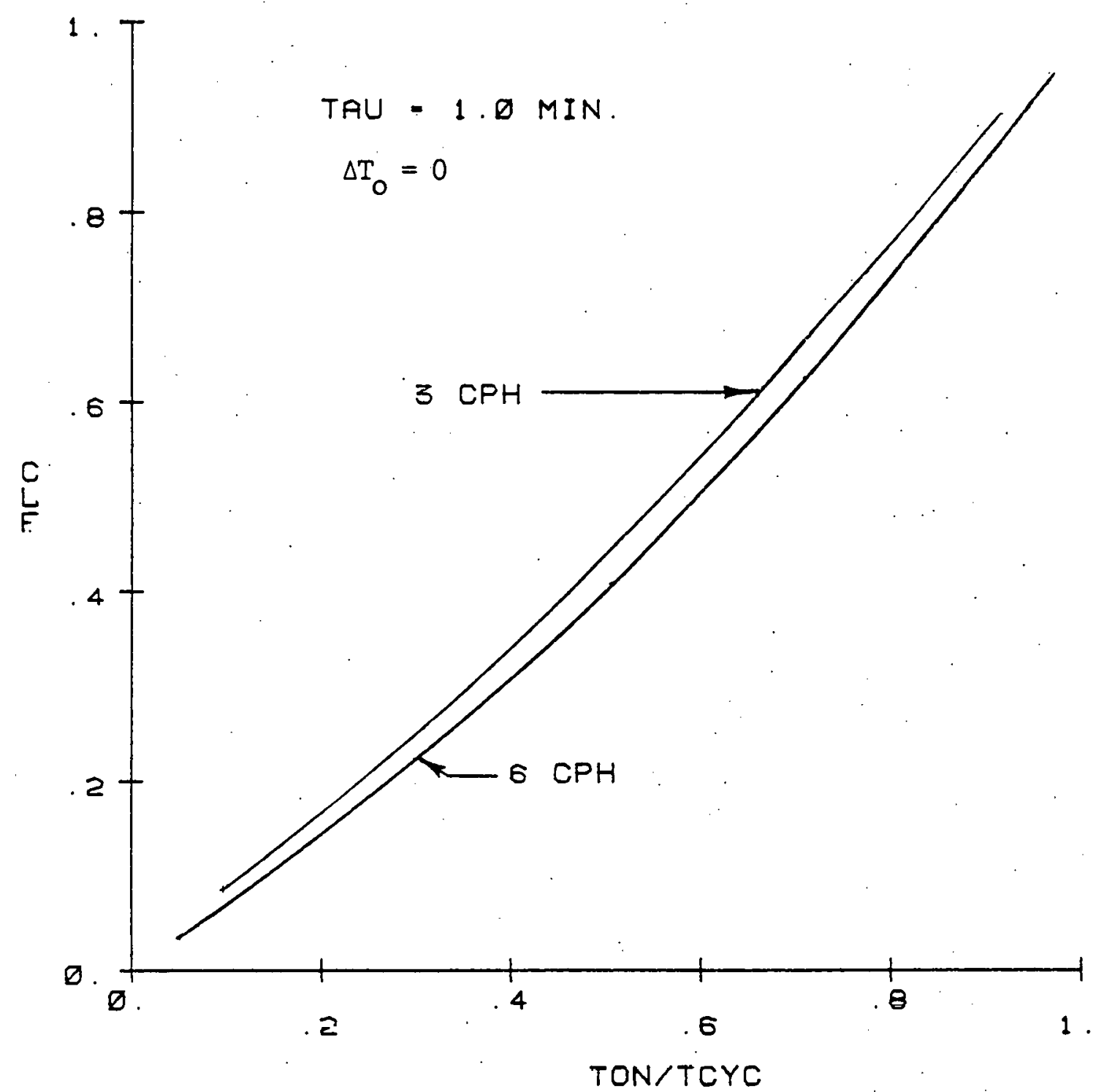

Figure 3-7 Cooling Load Factor as a Function of Percent On-Time at Different Maximum $\mathrm{CPH}$. 
From Figure 3-8 it is noted that PLF is most sensitive to on-times up to 15-20 minutes long. Additionally the change in PLF with respect to the cycle-time is the greatest in the first 5-10 minutes past the minimum cycletime. Figure 3-9 displays these characteristics of PLF and cycle-time. From this figure it can be observed that increasing the maximum cycle rate will broaden the range of PLFs for the same cycle-time. In Figure 3-10 PLF is observed to vary with changes in maximum cycle rate and percent on-time. With an increase of cycle rate the PLF is more sensitive to percent on-time. This can be explained since PLF measures the degradation of performance. With an increase of cycle rate there will be more transient start-up periods in the same amount of time. Thus, PLF will be smaller at higher cycle rates than at lower cycle rates when compared at the same percent on-time. Actually, CLF and PLF are both stronger functions of percent on-time than of cycling rate. Parken et al. (26) obtained similar experimental results. Figure $3-11$ shows PLF versus CLF at different cycling rates. The results indicate $a$ decrease in the cyclic cooling EER and load as the-cycle frequency increases for each of the percent on-times. Table 3-1 gives a summary of the results when using the semi-empirical equations and thermostat demand cycle. Table 3-2 shows the general trend in the slope when drawing a line through the same percent on-time at the different cycle rates. At smaller percent on-times, the change in cycle rate has the greatest effect on PLF. As the percent on-time increases there is little change in PLF at the different cycle rates.

It is interesting to note that in Figure 3-11, PLF versus CLF almost forms a straight line. The method of least squares is applied to determine the "best fit" by following two approaches: 


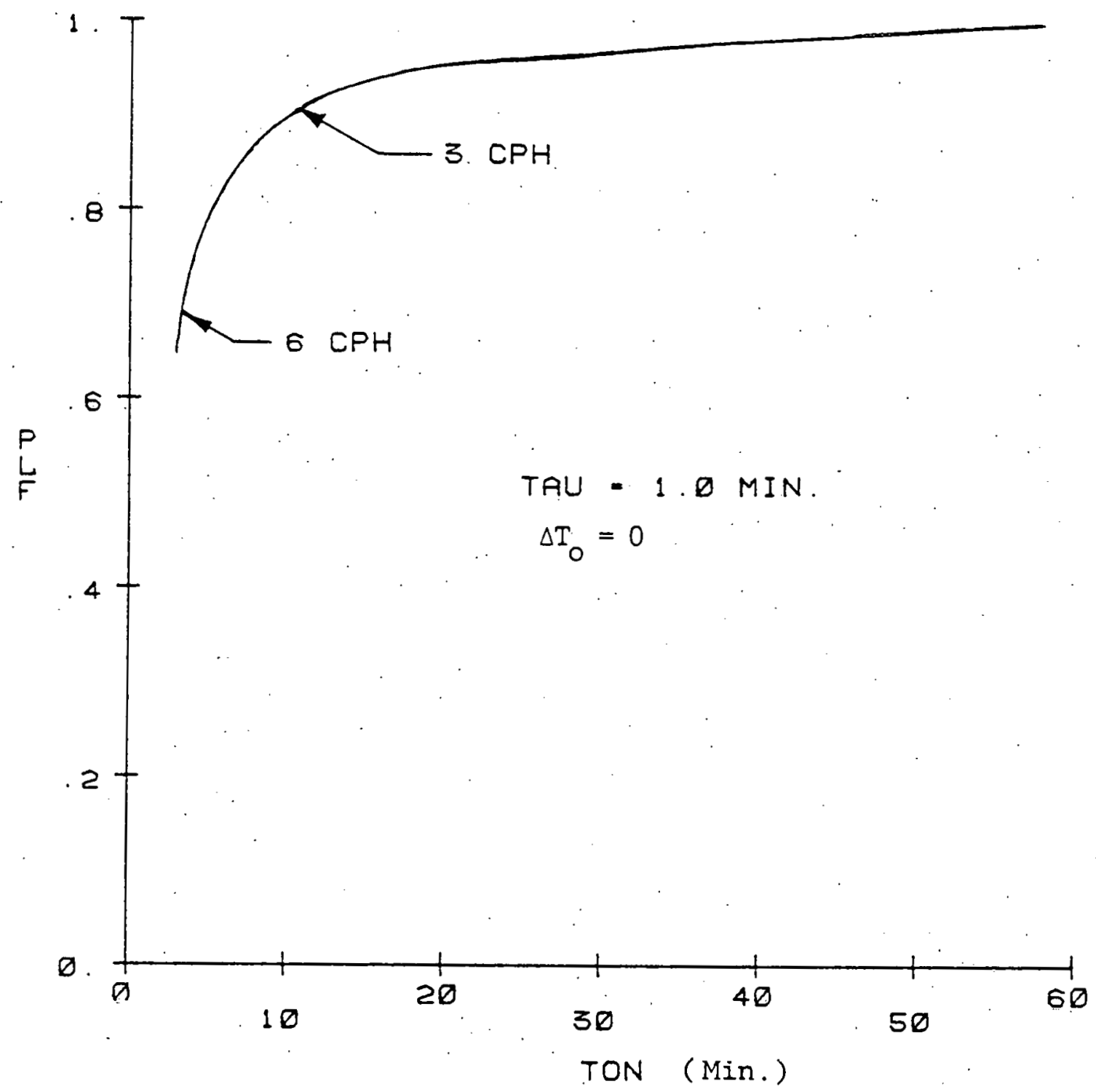

Figure 3-8 Part-Load Factor vs. On-Time at Different Maximum $\mathrm{CPH}$, with a Variable Cycle-Time Determined from Thermostat Demand Cycle. 


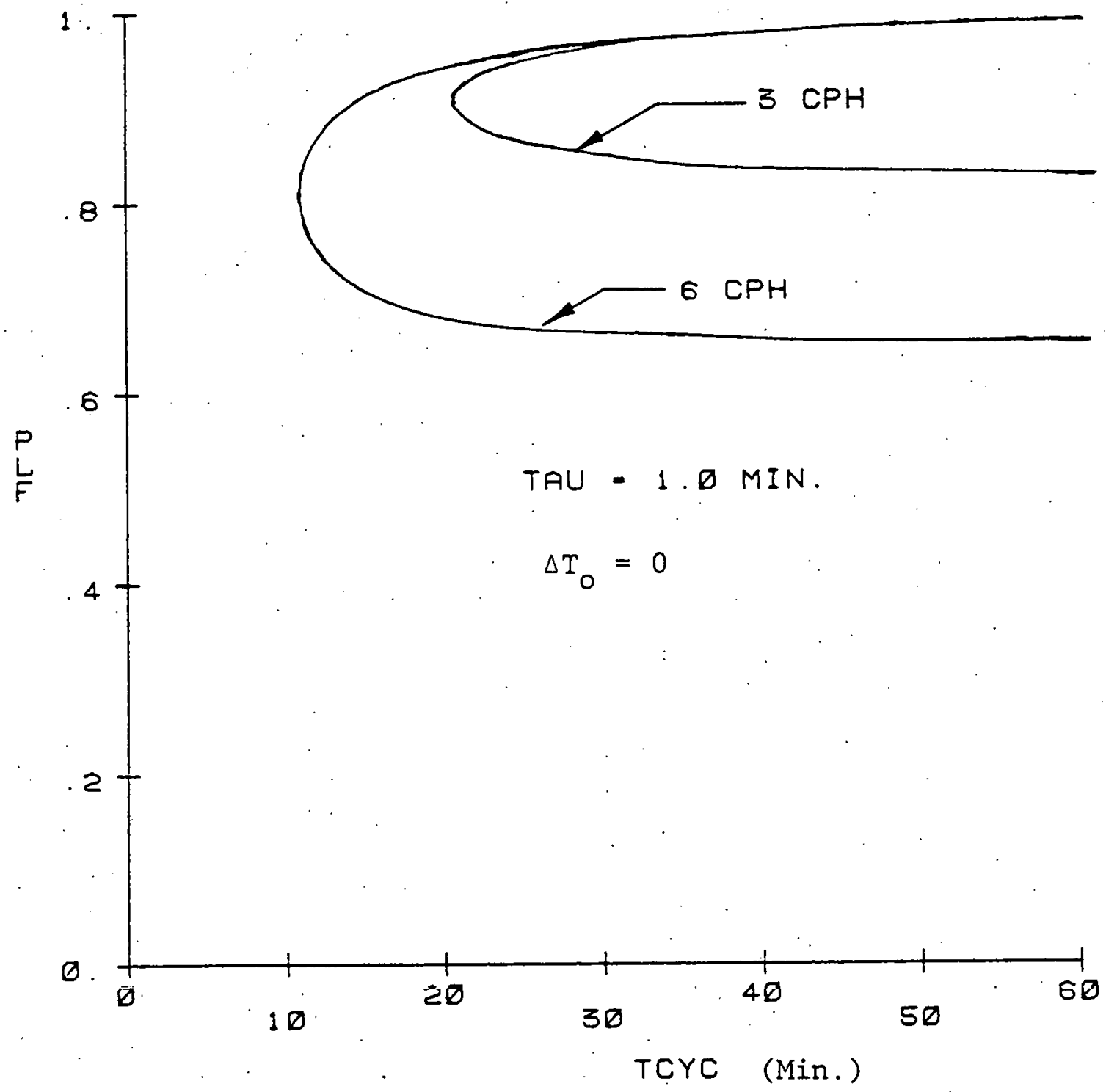

Figure 3-9 Part-Load Factor vs. Cycle-Time at Different Maximum $\mathrm{CPH}$, with a Variable on-Time Determined from Thermostat Demand Cycle. 


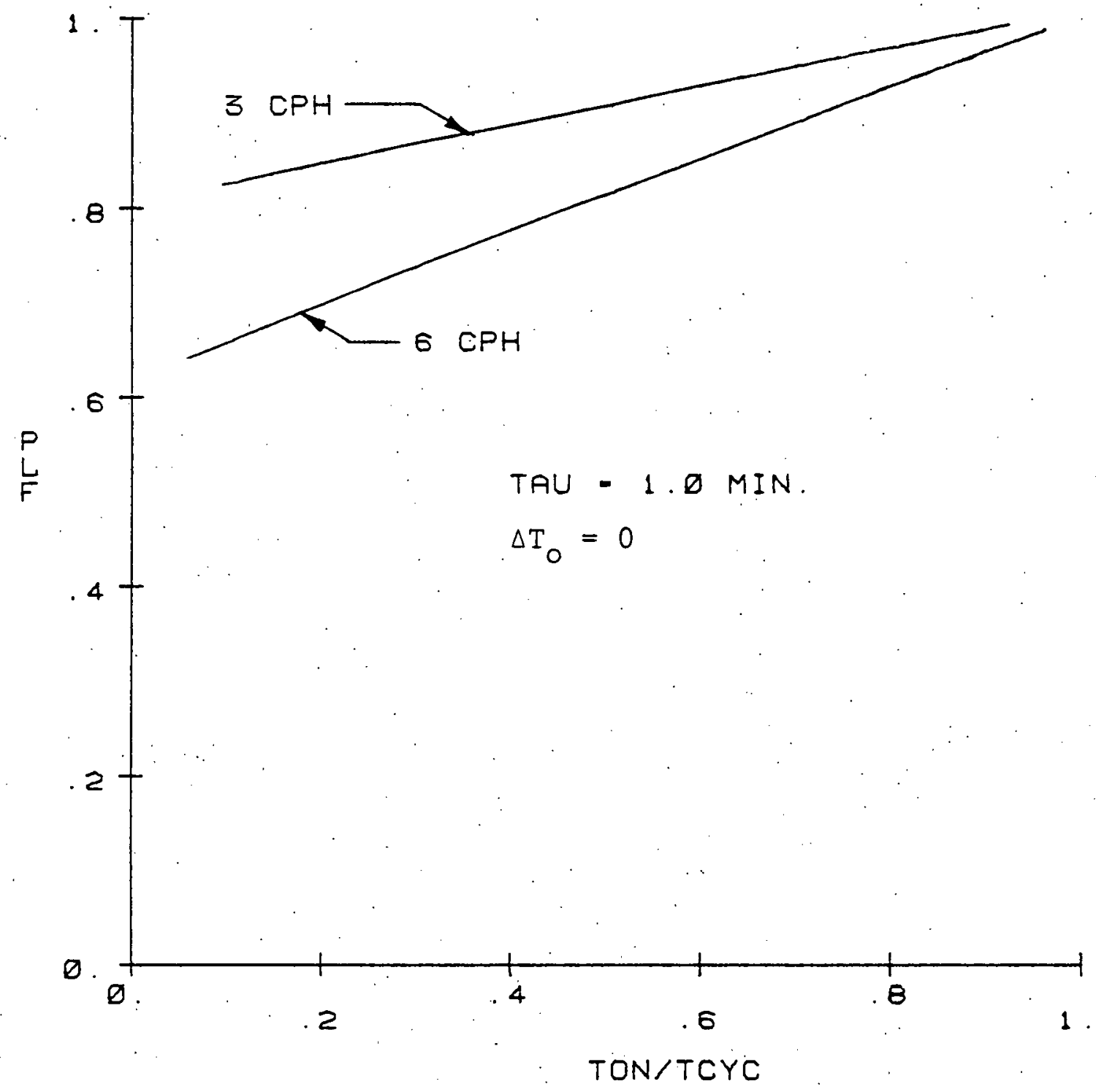

Figure 3-10 Part-Load Factior as a Function of Percent On-Time at Different Maximum $\mathrm{CPH}$. 


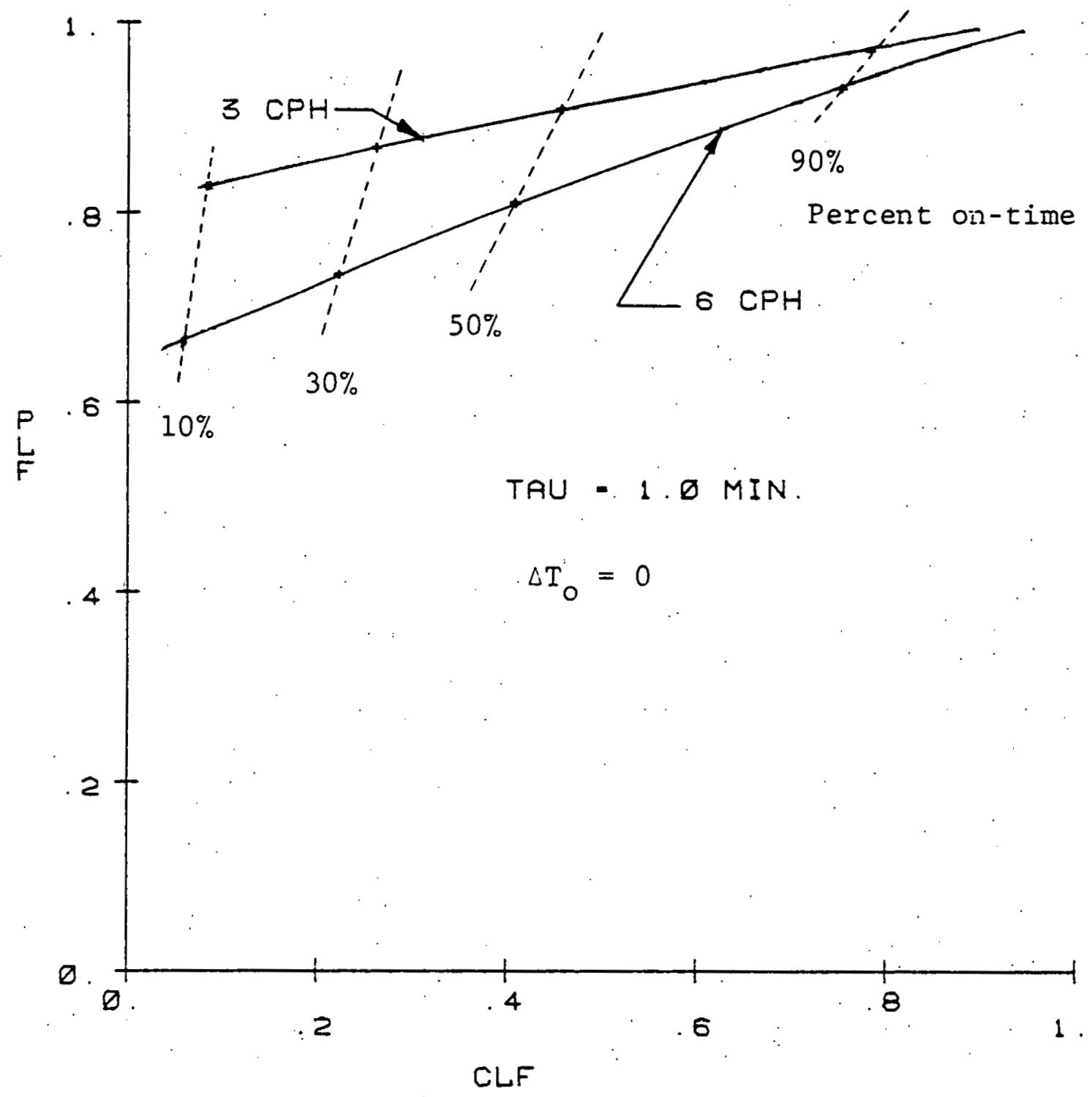

Figure 3-11 Part-Load Factor vs. Cooling Load Factor at Different Maximum $\mathrm{CPH}$, with On-Time and Cycle-Time Determined from Thermostat Demand cycle. 
Table'3-1 Summary of Results When Using Thermostat Demand Cycle.

\begin{tabular}{cccccc} 
For $\tau=1.0$ Min., a Maximum of $3 \mathrm{CPH}$ and $\Delta \mathrm{T}_{\mathrm{O}}=0$. \\
\hline \begin{tabular}{c}
$\%$ on-Time \\
\hline 9.91
\end{tabular} & $\frac{t_{\text {on }}}{5.55}$ & $\frac{t_{c y c}}{56}$ & $\frac{\mathrm{CLF}}{.0813}$ & $\frac{\mathrm{PLF}}{.8205}$ \\
20.2 & 6.267 & 31 & .1700 & .8407 \\
29.6 & 7.101 & 24 & .2542 & .8593 \\
39.09 & 8.209 & 21 & .3433 & .8782 \\
50.00 & 10.00 & 20 & .4500 & .9000 \\
60.9 & 12.791 & 21 & .5615 & .9218 \\
70.41 & 16.899 & 24 & .6625 & .9408 \\
79.78 & 24.733 & 31 & .7656 & .9596 \\
90.09 & 50.45 & 5.6 & .8830 & .9802
\end{tabular}

For Same $\tau$ and $6 \mathrm{CPH}$.

\begin{tabular}{|c|c|c|c|c|}
\hline 9.91 & 2.775 & 38 & .0656 & .6621 \\
\hline 19.38 & 3.101 & 16 & .1341 & .6920 \\
\hline 29.59 & $3.55 i$ & 12 & .2149 & .7264 \\
\hline 34.93 & 3.842 & 11 & .2603 & .7453 \\
\hline 50.0 & 5.0 & 10 & .4007 & .8013 \\
\hline 65.07 & 7.158 & 11 & .5599 & .8604 \\
\hline $70 . \wedge 1$ & $8.1 / 19$ & 12 & .6208 & .8817 \\
\hline 80.62 & 12.899 & 16 & .7437 & .9225 \\
\hline 90.09 & 25.225 & 28 & .8652 & .9604 \\
\hline
\end{tabular}


Table 3-2 Slope of Line at the Same Percent On-Time.

\begin{tabular}{|c|c|c|}
\hline Percent On-Time & Slope of Line & Connected at Different \\
\hline 9.91 & & 10.09 \\
\hline 29.6 . & & 3.38 \\
\hline 50.0 & & 2.0 \\
\hline 90.09 & & 1.11 \\
\hline
\end{tabular}

Table 3-3 Results of Least Squares Method

\begin{tabular}{|c|c|c|c|c|c|}
\hline \multirow{2}{*}{$\begin{array}{l}\text { Maximum } \\
\text { Cycle Rate } \\
\tau=1.0 \mathrm{~min})\end{array}$} & Straigh & Line Through $(1,1)$ & \multirow[b]{2}{*}{ SLOPE } & Straight Line & \\
\hline & $C_{D}$ & Y-INCPT. $\left(1-C_{D}\right)$ & & Y-INCPT. & CORCOEF. \\
\hline $3 \cdot \mathrm{CPH}$ & 0.1957 & 0.8043 & 0.1989 & 0.8038 & 0.9998 \\
\hline $6 \mathrm{CPH}$ & 0.3637 & 0.6363 & 0.3692 & 0.6358 & 0.9997 \\
\hline
\end{tabular}


1. Fit the best possible line through the points with no restrictions.

2. Fit the best possible line through the points and force it to go through $(1,1)$.

Table 3-3 gives the results when applying the method of least squares developed in Appendix $E$. for these two methods. From the table, it is noted that changing the cycle rate by a factor of two also changes the degradation coefficient $\left(C_{D}\right)$ by approximately two. Since the correlation coefficient is nearly 1 , then it is reasonable to assume that the degradation coefficient is constant. This is exactly what Kelly and Parken (20) had stated earlier. They said "Laboratory tests indicated that $C_{D}$ is constant for cooling load factors ranging from approximately 0.1 to $i$ and is also independent of ambient conditions". Thus, using the semi-empirical equations and a thermostat demand cycle, results can be predicted similar to experimental ones. It is important to note that in this analysis both the ontime and cycle-time vary. They are not independent because they are determined from the thermostat demand cycle. Since the thermostat regulates when the air conditioning system is operating it is logical that it be included in the analysis of performance.

In conclusion, the thermostat demand cycle will determine how the on-time and cycle-time will vary. With these variable times, the variation in slope $\left(C_{D}\right)$ for PLF versus CLF is very small and the slope $\left(C_{D}\right)$ can be considered constant without introducing large errors. 
CHAPTER 4

SEMI-EMPIRICAL ANALYSIS

OF EER RATIOS

\section{A) Semi-Empirical Analysis of Steady State EER Ratio}

The general performance of a central air conditioner can be explained by looking at the thermodynamics of the system. This analysis will only include the ideal performance to give insight into the steady state EER ratio (i.e., $\left.E E R_{A} / E E R_{B}\right)$. The analysis will include the examination of temperature vs. entropy and pressure vs. enthalpy plots for an ideal response.

The general equipment employed in the basic vapor compression cooling system is illustrated in Figure 4-1. The basic system consists of a compressor, a condenser, an expansion valve (throttling device) and an evaporator. "The refrigerant flowing in the system may be assumed to follow an ideal cycle as shown in the temperature-entropy diagram of Figure 4-2 or the pressure-enthalpy diagram of Figure 4-3. It has been assumed throughout the cycle that the constant flow process occurs with negligible kinetic, potential and viscous energy changes. The cycle consists of a reversible adiabatic (constant entropy) compression process (1-2), a reversible constant pressure, desuperheating and condensation process (2-3), an irreversible adiabatic (constant enthalpy) expansion process (3-4), and a reversible constant pressure evaporation process (4-1).

For a general description see (15) or (32). 


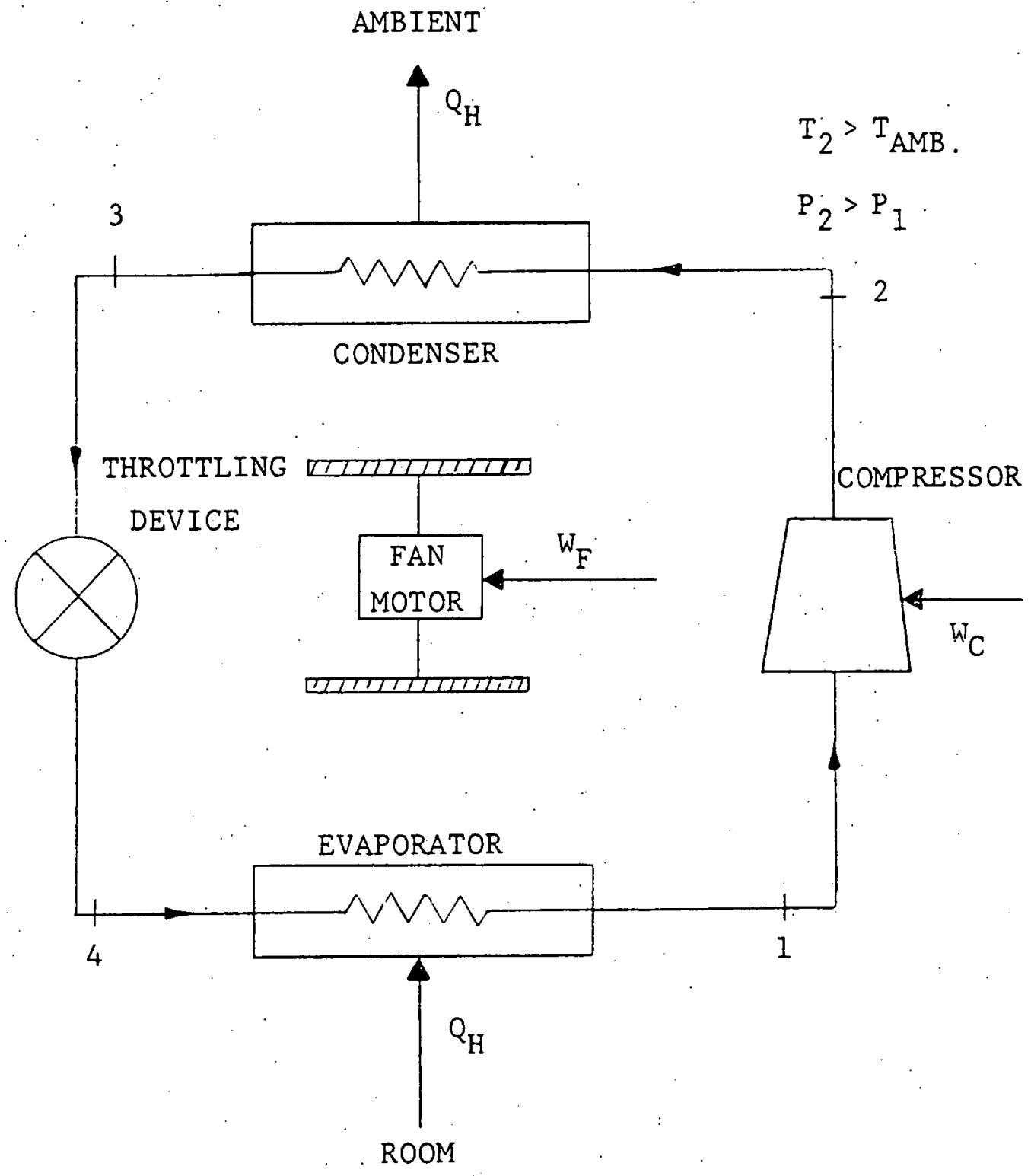

Figure 4-1 Schematic of the Basic Vapor Compression Cooling System. 


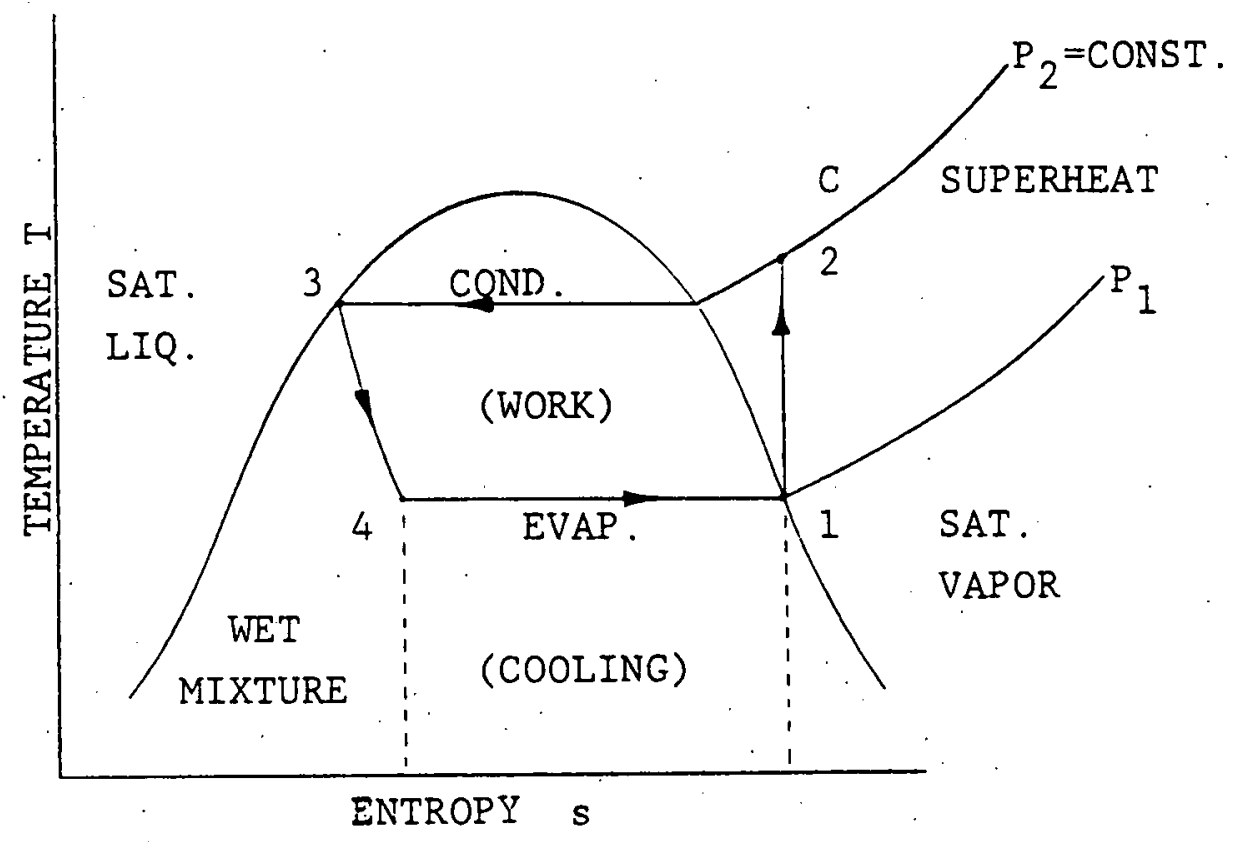

Figure 4-2 Temperature - Entropy Diagram of an Ideal Vapor Compression Cooling Cycle.

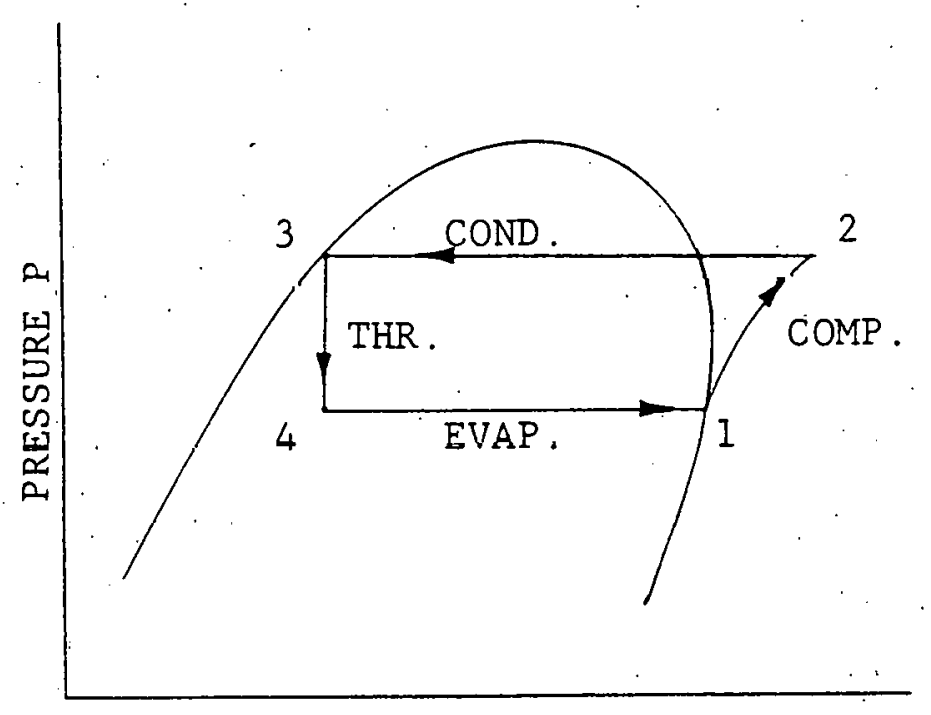

ENTHALFY h

Figure 4-3 Pressure - Enthalpy Diagram of an Ideal Vapor Compression Cooling Cycle. 
From Fig. 4-3, the amount of heat removed from the cooled space/lbm of refrigerant flowing is

$\mathrm{q}_{c}=\mathrm{h}_{1}-\mathrm{h}_{4}$

where

$\mathrm{q}_{c}=$ Ideal heat absorbed by refrigerant, $\mathrm{Btu} / \mathrm{lbm}$

$h_{1}=$ Enthalpy of refrigerant at point l, Btu/lbm

$\mathrm{h}_{4}=$ Enthalpy of refrigerant at point $4, \mathrm{Btu} / \mathrm{lbm}$

while the work of compression/lbm. of refrigerant flowing is

$\mathrm{w}_{\mathrm{c}}=\mathrm{h}_{2}-\mathrm{h}_{1}$

where

$W_{c}=$ Ideal work of compression, $B t u / 1 b m$

$h_{2}=$ Enthalpy of refrigerant at point 2, Btu/lbm

$h_{1}=$ Enthalpy of refrigerant at point $1, B t u / 1 b m$

The amount of heat rejected to the rejection space/lbm of refrigerant flowing is

$q_{r}=q_{c}+w_{c}$

$q_{r}=h_{2}-h_{3}$

where

$\mathrm{q}_{\mathrm{r}}=$ Ideal heat rejected by refrigerant, Btu/lbm

$h_{3}=h_{4}$ since process $(3-4)$ is an ideal adiabatic expansion, Btu/lbm

The mass flow rate of the refrigerant controls the specific amount of heat removed from the cooled space.

An adapted measure of the performance of a complete cooling system is the coefficient of performance (COP). The definition of $C O P$ is the ratio of heat removed from 
the cooled space to the work expended. From Eqns, 4-1 and 4-2 and Figure 4-2, the ideal COP of a basic vapor compression system is given by (see Fig. 4-3)

$\operatorname{COP}=\frac{h_{1}-h_{4}}{h_{2}-h_{1}}$

where

$\mathrm{COP}=\mathrm{EER} / 3.413$ unitless

Looking at the T-s diagram (see Fig. 4-4) in more detail, observations can be made to see what happends to the cooling (unavailable energy) and work (available energy) of the basic vapor compression system when the ambient temperature is increased. From Fig. 4-4 the following relationships can be obtained for determining the performance of the system when the ambient temperature is increased. At $I_{\mathrm{AMB}}$

$$
\begin{aligned}
& \text { WORK }=W+\text { WORK* } \\
& \text { COOLING }=C+\text { COOLING* }
\end{aligned}
$$

At $\mathrm{T}_{\mathrm{AMB}}^{\prime}$

$$
\begin{aligned}
& \text { WORK' }=W^{\prime}+\text { WORK }^{*} \\
& \text { COOLING' }=\text { COOLING }
\end{aligned}
$$

where

$$
\begin{aligned}
& \mathrm{W}^{\prime}>\mathrm{W} . \\
& \mathrm{T}_{\mathrm{AMB}}^{\prime}>\mathrm{T}_{\mathrm{AMB}}
\end{aligned}
$$

Due to the practical need for a finite $\Delta \mathrm{T}\left(15-25^{\circ} \mathrm{F}\right)$ across the condenser coil (similarly for the evaporator coil), $\mathrm{T}_{3}>\mathrm{T}_{\mathrm{AMB}}$ and $\mathrm{T}_{3}^{\prime}>\mathrm{T}_{\mathrm{AMB}}^{\prime}$. From Eqns. 4-6 to 4-9 the 


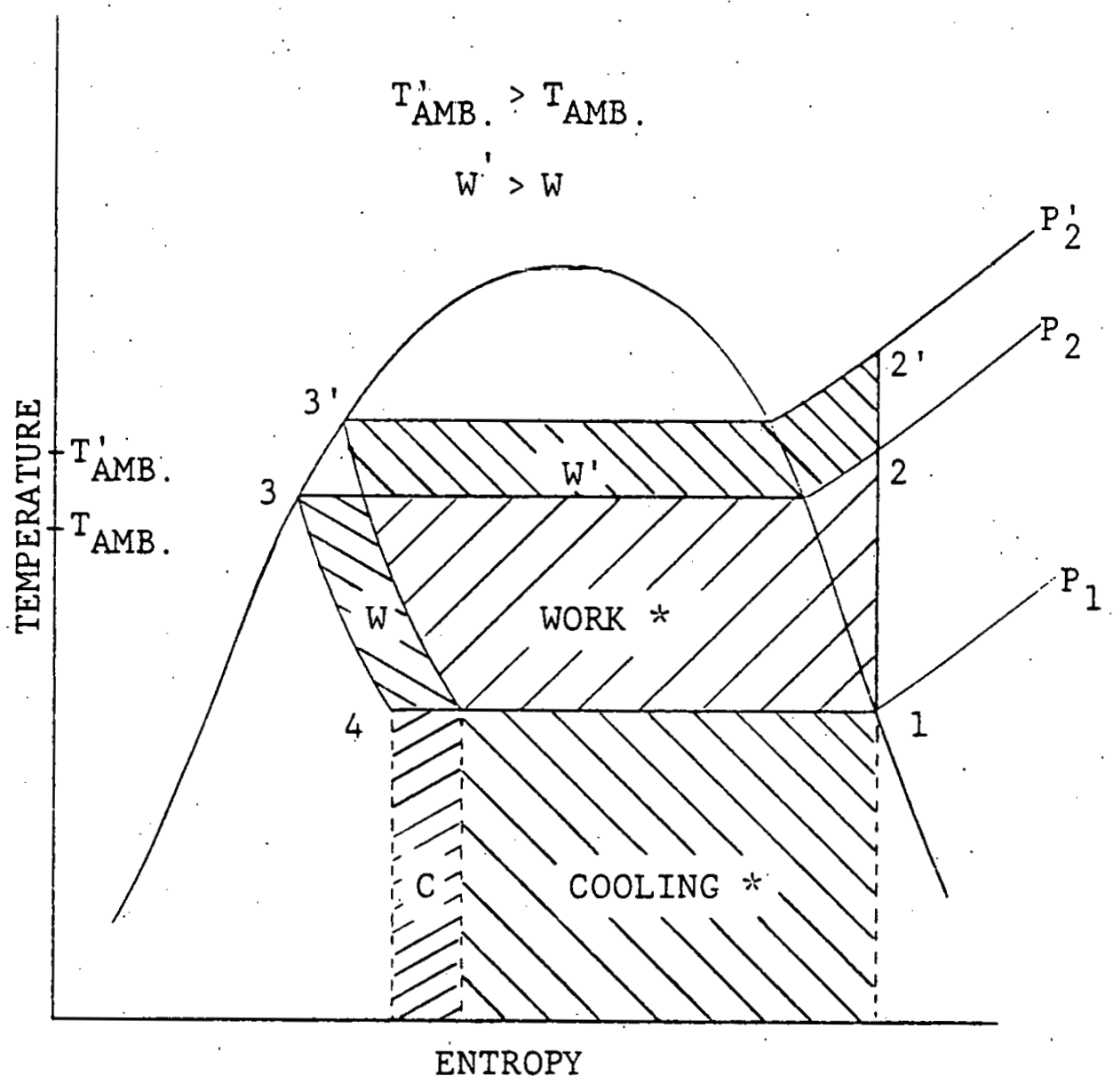

Figure 4-4 Detailed Look at Temperature - Entropy Diagram for Basic Vapor Compression System. 
energy efficiency ratios are calculated

$\mathrm{EER}_{\mathrm{B}}=\frac{\text { COOLING* }+\mathrm{C}}{\text { WORK }^{*}+W} \quad \mathrm{CT}_{\mathrm{AMB}}$

$\mathrm{EER}_{\mathrm{A}}=\frac{\mathrm{COOLING}^{*}}{\mathrm{WORK}^{*}+\mathrm{W}^{\top}} \quad \mathrm{CT}_{\mathrm{AMB}}^{\prime}$

where

$$
\mathrm{W}^{\prime}>\mathrm{W}
$$

Hence, using Eqns. 4-10 and 4-11 the following ratio is obtained

$$
\frac{\operatorname{EER}_{A}}{\operatorname{EER}_{B}}=\frac{1}{1+\underbrace{\frac{C}{\operatorname{COOIING*}}}_{\alpha<1}} \cdot \frac{1+\frac{W}{W O R K^{*}}}{1+\frac{W^{\prime}}{W O R K^{*}}}
$$

therefore, noting that $\alpha$ and $\beta$ are both less than one

$$
\frac{E E R_{A}}{E_{B}}=\alpha \cdot \beta<1 .
$$

Thus, Eqn. 4-13 gives the first indication that the ratio of the steady state EERs is less than one. Next, it is useful to determine the approximate value of this ratio. This is accomplished by considering the theoretical efficiency of the ideal Carnot cycle.

The maximum theoretical efficiency is given by the Carnot cycle

$$
E E R=3.413\left[\frac{\mathrm{T}_{\mathrm{SOR}}}{\left(\mathrm{T}_{\mathrm{SIN}}-\mathrm{T}_{\mathrm{SOR}}\right)}\right]
$$

where

$$
\begin{aligned}
& \mathrm{T}_{\mathrm{SOR}}=\text { absolute temperature of heat source } \\
& \mathrm{T}_{\mathrm{SIN}}=\text { absolute temperature of heat sink }
\end{aligned}
$$


The factor 3.413 converts from dimensionless coefficient of performance (COP.) to Btu/W-h.

Due to temperature differentials in practical application, the practical theoretical EER is limited to

$E E R=3.413\left[\frac{\left(460+T_{E V A P}\right)}{\left(460+T_{C O N D}\right)-\left(460+T_{E V A P}\right)}\right]$

Typical CAC's with EER's of 6 have condensing temperatures of $130^{\circ} \mathrm{F}\left(54.4^{\circ} \mathrm{C}\right)$ and evaporator temperatures of $45^{\circ} \mathrm{F}$ $\left(7.2^{\circ} \mathrm{C}\right)$ during heavy load conditions (29). Theoretically increased efficiency could be achieved by reducing the condenser temperature closer to ambient and increasing the evaporator temperature. Presently high-efficiency designs have condensing temperatures of $120^{\circ} \mathrm{F}\left(48.9^{\circ} \mathrm{C}\right)$ and evaporator temperatures of $49^{\circ} \mathrm{F}\left(9.4^{\circ} \mathrm{C}\right)(29)$. The practical limits for the condenser and evaporator are $105^{\circ} \mathrm{F}\left(40.6^{\circ} \mathrm{C}\right)$ and $60^{\circ} \mathrm{F}$ $\left(15.6^{\circ} \mathrm{C}\right)$ respectively. However, $60^{\circ} \mathrm{F}\left(15.6^{\circ} \mathrm{C}\right)$ is approximately the dew point of the evaporator test ambient, and no dehumidification would occur. Thus, a temperature of about $50^{\circ} \mathrm{F}\left(10^{\circ} \mathrm{C}\right)$ is the best that can be achieved when dehumidification is considered.

Whenever the CAC system is called into operation the condensing temperature is principally determined by the existing ambient temperature as shown in Figure 4-5, wherein, the solid line shows typical response with a conventional constant displacement compressor and an evaporator and condenser with constant air flow. CAC systems with thermostatic expansion valves or those with capillary control can not respond over such a wide range of condensing temperatures without such problems as frosted evaporators, and hence "low ambient" kits are normally supplied which force the condenser temperature along the dashed line of Figure 4-5 ( 9 ). For light load conditions the condenser temperature may be $15^{\circ} \mathrm{F}\left(8.3^{\circ} \mathrm{C}\right)$ lower (i.e., $\mathrm{T}_{\text {COND }}=115^{\circ} \mathrm{F}$ e $32^{\circ} \mathrm{F}$ ambient) and evaporator temperature $5^{\circ} \mathrm{F}\left(2.8^{\circ} \mathrm{C}\right)$ higher than 
at heavy loads (29). Thus, assuming a linear relationship between the evaporator and ambient temperatures (see Figure 4-6), the practical theoretical EER for test $A$ and $B$ can be calculated. Using Eqn. 4-15 and Figures 4-5 and 4-6, the following is obtained

$\mathrm{EER}_{\mathrm{A}} \cong 3.413\left[\frac{(460+46.4)}{(460+125)-(460+46.4)}\right]$ (Q9 $95^{\circ} \mathrm{F}$

$\mathrm{EER}_{\mathrm{A}}=21.98 \mathrm{Btu} / \mathrm{W}-\mathrm{h}$

similarly,

$\mathrm{EER}_{\mathrm{B}} \cong 3.413\left[\frac{(460+50)}{(460+115)-(460+50)}\right]$
$@ 82^{\circ} \mathrm{F}$

$\mathrm{EER}_{\mathrm{B}}=26.78 \quad \mathrm{Btu} / \mathrm{W}-\mathrm{h}$

The results in Eqns. 4-17 and 4-19 are rather high. In reality the theoretical EER's are smaller due to losses in:

mechanical elements, electrical motors, fans, heat transfer and deviation from the Carnot cycle. Hence, assuming the percentage in losses are the same in both cases, then using Eqns. 4-17 and 4-19 the ratio of the EER's become

$\frac{E_{A E R}}{E_{B}}=0.82$

which compares to the experimentally obtained average ratio (Eqn. 2-17) of approximately 0.88 .

The generalized plots for steady state conditions in Fig. 4-7 represent the general trend in todays design of central air conditioners. In general, central air conditioners cooling capacity decreases with increasing ambient temperatures and power consumption increases slightly with 


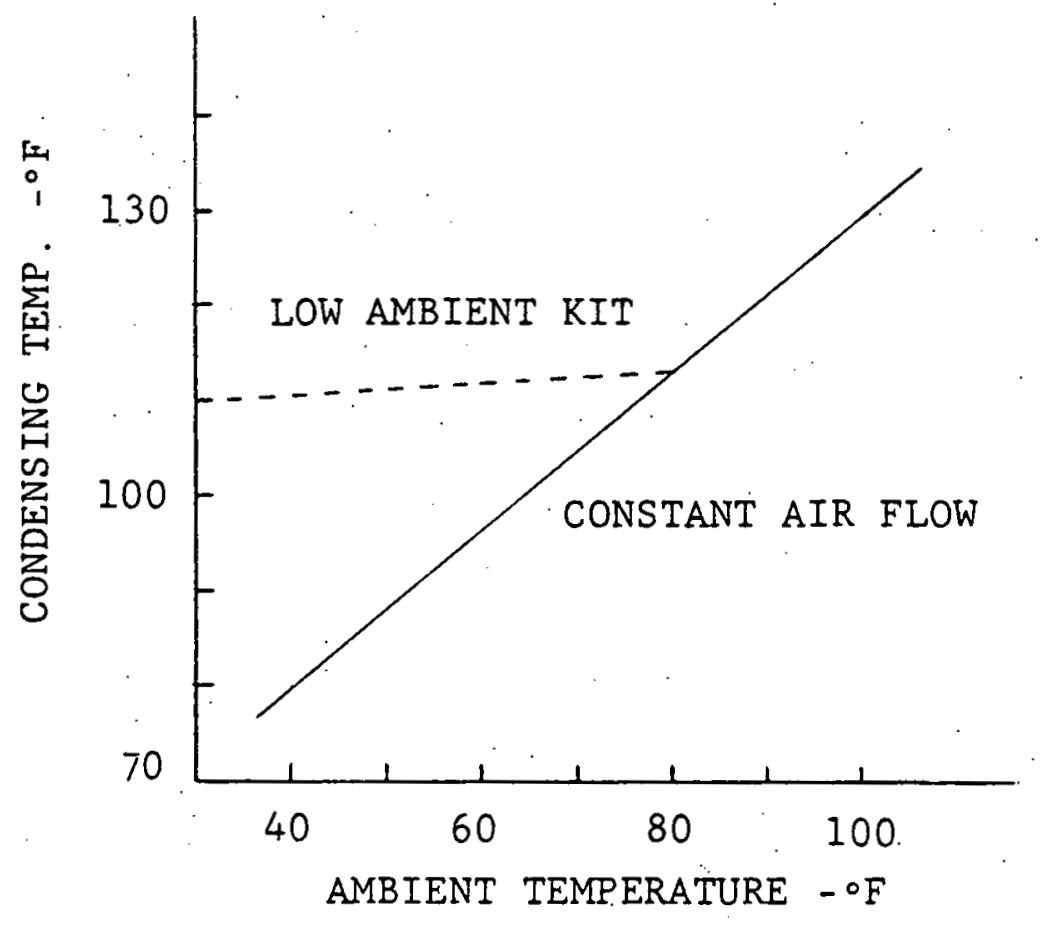

Figure 4-5 Typical Response of Condensing Temperature to Ambient Temperature (9).

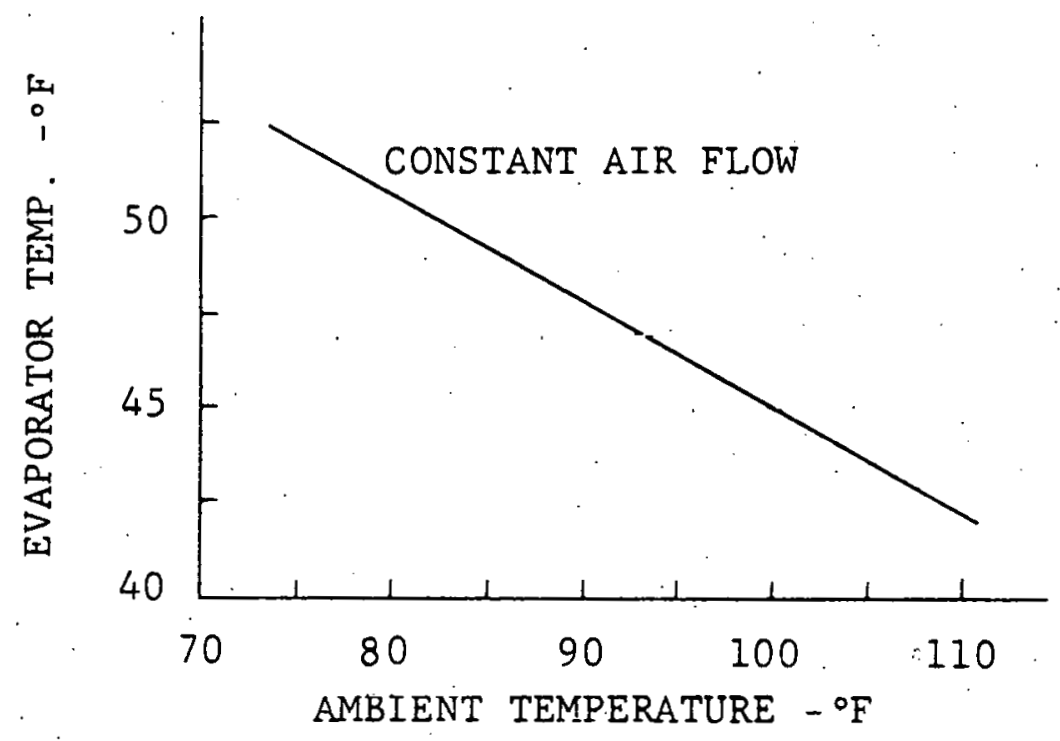

Figure 4-6 Evaporator Temperature vs. Ambient Temperature. 

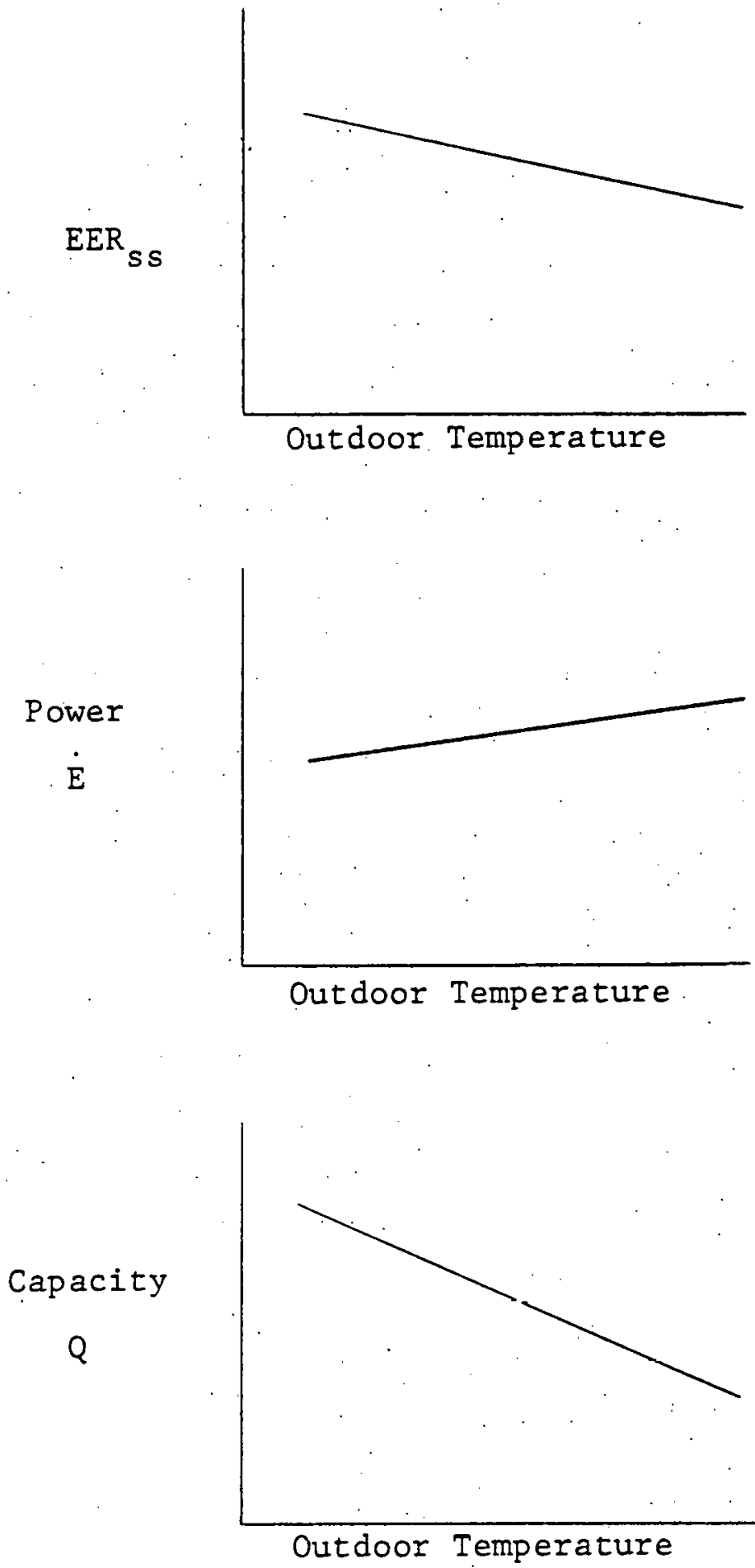

Figure 4-7 Typical Performance of Most Central Air Conditioners (Steady State Conditions). 
increasing ambient temperatures. The net result is, the steady state EER decreases with increasing ambient temperatures. Thus; in general, the steady state EER ratio at a higher ambient temperature to that at a lower ambient temperature will be less than one.

From this analysis it is possible to see why the steady state EER ratio is less than unity. By looking at the system in more detail, the EER ratio could possibly be better explained.

\section{B) Semi-Empirical Analysis of Cyclic EER Ratio}

From the evaporator coil temperature vs. time plots and a few other assumptions, a mathematical (empirical model) was developed in Chapter 3. The semi-empirical equations developed in Chapter 3 will be used here to determine an approximate value for the cyclic EER ratio (i.e. $E_{E R} / E E R_{C}$ ).

The cooling capacities $\dot{Q}_{S S}\left(95^{\circ} \mathrm{F}\right)$ from test $A, \dot{Q}_{S S}\left(82^{\circ} \mathrm{F}\right)$ from test $B$ and $\dot{Q}_{S S}$, dry from test $C$ are calculated using the equations specified in section 3.7 of ASHRAE Standard 37-69 ( 3 ). The total cooling, $Q_{c y c}$, dry from test $D$, is calculated using Eqn. 3-4. The sensible cooling capacity is determined by

$\dot{Q}_{\mathrm{SEN}}=\frac{60 \hat{\mathrm{V}} \mathrm{c}_{\mathrm{pa}}\left(\mathrm{T}_{\mathrm{a} 1}-\mathrm{T}_{\mathrm{a} 2}\right)}{\left[\mathrm{V}_{\mathrm{n}}^{1}\left(1+\mathrm{W}_{\mathrm{n}}\right)\right]}$

where

$$
\begin{aligned}
& \dot{\mathrm{Q}}_{\text {SEN }}=\text { sensible cooling capacity }(\mathrm{Btu} / \mathrm{h}) \\
& \mathrm{T}_{\mathrm{al}}=\text { temperature of air entering } \mathrm{CAC}\left({ }^{\circ} \mathrm{F}\right) \\
& \mathrm{T}_{\mathrm{a} 2}=\text { temperature of air leaving CAC }\left({ }^{\circ} \mathrm{F}\right)
\end{aligned}
$$

and the other values are defined in Chapter 3. Since test $\mathrm{C}$ is run with a dry coil, there is no (very little) latent cooling, thus 
$\dot{\mathrm{Q}}_{S s, \mathrm{dry}}=\dot{\mathrm{Q}}_{\mathrm{SEN}}$

For test D, Eqn. 3-4 is used in conjunction with Eqn. 3-5. Since tests $C$ and $D$ are both run at identical test conditions (see Table 2-1), then the assumption (i.e., Eqn. 3-6)

$$
\frac{60 \dot{\bar{V}} c_{p a}}{\left[V_{n}^{1}\left(1+w_{n}\right)\right]}=k
$$

where

$$
\mathrm{K}=\text { constant, with units of } \mathrm{Btu} / \mathrm{h}-{ }^{\circ} \mathrm{F} \text {, }
$$

is a logical choice.

Substituting this assumption into Eqns. 4-22 and 3-4, the following is obtained:

$$
\begin{aligned}
& \dot{Q}_{s s, d r y}=\mathrm{K} \Delta \mathrm{T}_{s s} \quad(B t u / h) \\
& \mathrm{Q}_{c y c, d r y}=\mathrm{K} \int_{0}^{\mathrm{t}} \text { on } \Delta \mathrm{T}(\mathrm{t}) \mathrm{dt} \quad(B t u)
\end{aligned}
$$

where

$$
\Delta \mathrm{T}_{\mathrm{ss}}=\mathrm{T}_{\mathrm{al}}-\mathrm{T}_{\mathrm{a} 2}
$$

Energy efficiency ratio from test $C, E E R_{C}$, is calculated as the ratio of the total cooling capacity in Btu/h to the total electrical power input in watts and the energy efficiency ratio from test $D, E E R_{D}$, is calculated as the ratio of the total cooling in Btu to the total electrical energy usage in watt-hours. Therefore, using Eqns. 4-23 and 4-24, the energy efficiency ratios become (see Eqns. 3-12\&3-13)

$$
\begin{aligned}
& \operatorname{EER}_{C}=\frac{\mathrm{K}}{\dot{\mathrm{E}}_{C}} \Delta \mathrm{T}_{S S} \\
& \operatorname{EER}_{D}=\frac{\mathrm{K}}{\dot{\mathrm{E}}_{D} \cdot \mathrm{t}_{\text {on }}} \int_{0}^{t_{\text {on }}} \Delta \mathrm{T}(\mathrm{t}) \mathrm{dt}
\end{aligned}
$$


Now assuming that the electrical power input for test $C$ and $D$ are equal (see Fig. 4-8), since test $C$ and $D$ are run at the same test conditions and the rate of power consumed is such a weak function of time that it can be considered constant during an on-time, the following cyclic EER ratio can be calculated:

$\frac{E E R_{D}}{E_{C E R_{C}}}=\frac{\int_{0}^{t_{\text {on }}} \Delta T(t) d t}{\Delta T_{S S} \cdot t_{\text {on }}}$

Figure 4-9 shows what Eqn. 4-27 is descriptive of an ideal response of the evaporator coil with time. Hence the cyclic EER ratio can be thought as the ratio of two different areas obtained by running the steady state and cyclic dry coil tests. From Fig. 4-9 the area for the cyclic test will always be smaller than the steady state. This will be true due to the response of the central air conditioner not being able to reach $\Delta T_{S S}$ at the instant the unit is turned on. Thus, the ratio $E E R_{D} / E E R_{C}$ will be less than unity.

The preceding reflects from an ideal situation where certain basic assumptions have been made (i.e., $K, \dot{\mathrm{E}}_{C}=\overline{\mathrm{E}}_{\mathrm{D}}$. ideal response). Generally these assumptions will not be exact due to experimental deviations from theoretical calculations. Thus, the result may not be precise, but does give insight to what is happening.

From Chapter 3, it was found that in general, the capacity response of the central air conditioner follows a first order type response. For heat pumps, it has been found that an exponential function provides a reasonably accurate mathematical model for heat output rate with time (33).. From Chapter 3 the temperature drop across the evaporator coil can be approximated to follow an exponential response generalized by

$\Delta T(t)=\Delta T_{s S}\left[1-C_{1} \exp (-t / \tau)\right]$ 


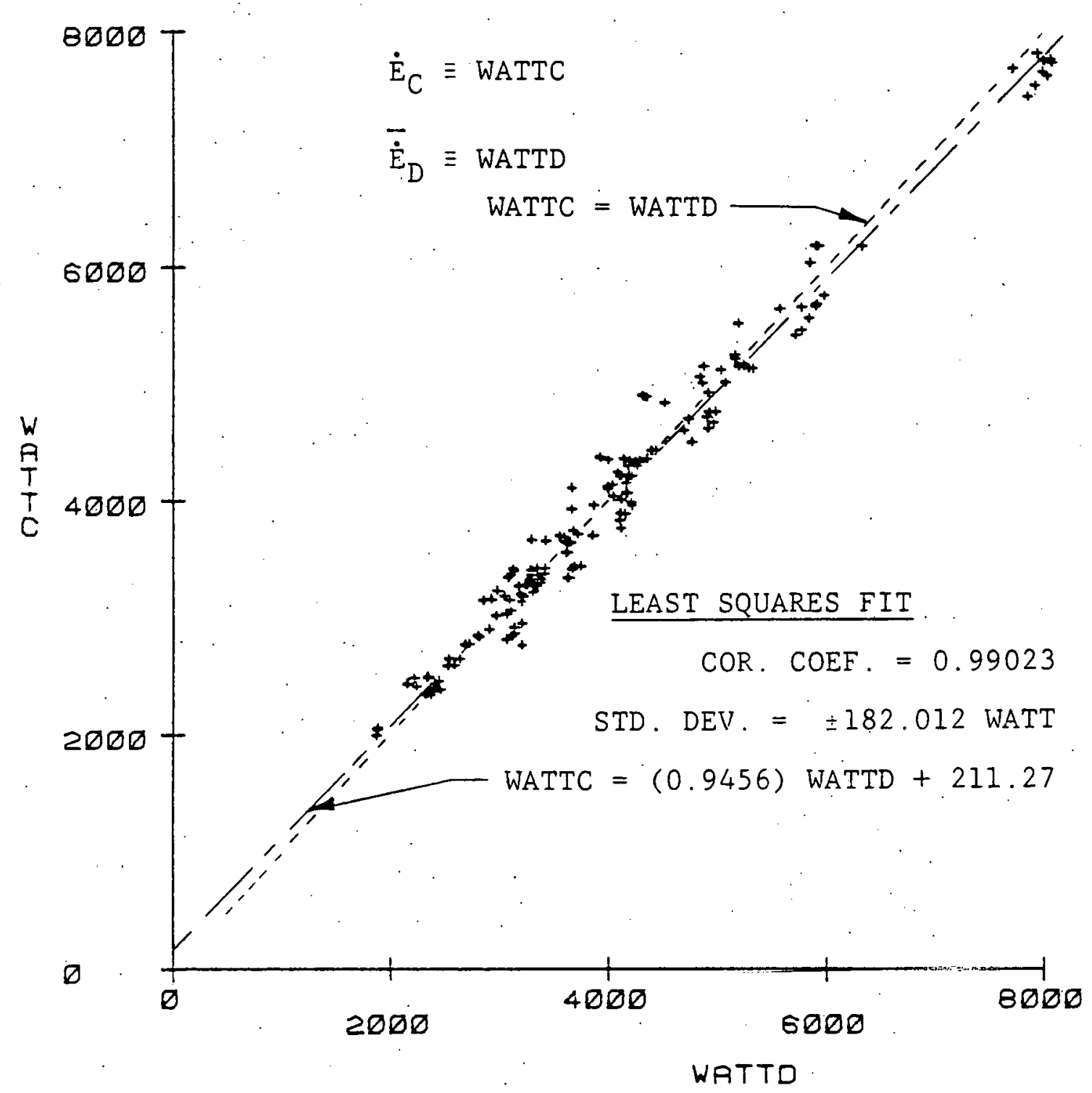

Figure 4-8 Total Power Input for the Same Ambient Conditions for Test $C$ vs. Test $D$. 




Figure 4-9 Ideal Resporse of $\Delta \mathrm{T}$ Across Evaporator Coil as a Function of Time. 
where

$$
\begin{aligned}
C_{1} & =1-\frac{\Delta T_{0}}{\Delta T_{s s}} \\
\tau & =\text { time constant }
\end{aligned}
$$

Thus, by substituting Eqn. 4-28 into Eqri. 4-27 and performing the necessary operations or from Eqn. 3-14 with appropriate assumptions, the cyclic EER ratio becomes, where it is assumed $\Delta T_{0}=0$

$\frac{E E R_{D}}{E_{C E R}}=1-\frac{\tau}{t_{\text {on }}}\left[1-\exp \left(-t_{\text {on }} / \tau\right)\right]$.

For sufficiently large on-times (i.e., $t_{\text {on }} / \tau>1$ ), Eqn. 4-29 can be approximated by

$$
\frac{E E R_{D}}{E_{C}} \cong 1-\frac{\tau}{t_{\text {on }}}
$$

For the DOE test $t_{\text {on }}$ is six minutes and time constants of central air conditioners vary from approximately 0.5 to 1.5 minutes. Therefore, Eqn. 4-30 becomes

$\frac{E E R_{D}}{E E R_{C}} \cong 0.75$ to 0.92

From the experimental data it was found that the average time constant, $\bar{\tau}$, was close to 0.6 minutes. Hence, the average cyclic EER ratio is

$\left.\frac{E E R_{D}}{E E R_{C}}\right|_{\bar{\tau}} \cong 0.9$

in good agreement with the measured value. (Eqns. 2-2 and $2-3)$ of 0.88 . 
From both of these analyses the EER ratios (Eqns. 4-20 and 4-32) are shown to be less than unity and to approximate close to the same value. Future data may show that this does not hold true for all units, but is true for those units reported. This relationship deserves further study.

It is envisioned that if a central air conditioner performed in the described manner; then a much simpler test could be run to determine the transient performance of the central air conditioners. This would involve the justification and use of the time constant $\tau$. This idea also warrants further research. 
CHAPTER 5

ERROR ANALYSIS

\section{A) Introduction}

Experimental test methods have been developed to relate the cycling and steady state performance of a central air conditioner to a typical seasonal efficiency rating (SEER). These test procedures are based solely on experimental results. It is imperative when developing test procedures that an error be performed to show an estimate of the expected accuracy of the results. A development of the error in. PLF and $C_{D}$ is made because PLF is an explicit term in the calculation of SEER, and $C_{D}$ is the criterion based on which a test may or may not be performed.

The following error analysis will be mainly concerned with the propagation of allowable measured errors in the test procedure and the inherent inaccuracy of the test instrumentation.

\section{B) Propagation of Allowable Measured Errors}

The allowable measured error is the test operating tolorancc specified in the test procedures. The total observed tolerance range for tests $A, B$ and $C$ are listed in Table 5-1, and Table 5-2 lists the range for test $D$.

Starting the error analysis with the response time error due to the thermocouple time constant, since it creates the effect of having the measured capacity lag the actual. capacity. The size of the time constant and the response of the system will determine the influence on the integrated cooling. The limiting case is when the time constant is zero, indicating the measured and actual capacities are identical. The DOE test specifies a maximum 
Table 5-1 Test Operating Tolerances for Steady State Wet and Dry-Coil Tests A,B \& C (20).

Readings, Remarks

All Air Temperatures; ${ }^{\circ} \mathrm{F}$

Outdoor dry-bulb:

entering

leaving

Outdoor wet-bulb:

entering

leaving

Indoor dry-bulb:

entering

leaving

Indoor wet-bulb:

entering

leaving

Condenser cooling water

temperatures, ${ }^{\circ} \mathrm{F}$

Saturated refrigerant

suction temperature, ${ }^{\circ} \underline{F}$

Iiquid temperatures not

otherwise specified, ${ }^{\circ} \mathrm{F}$

External resistance to

air flow, in.water.

Electrical voltage, $\%$

Fluid flow rates, $\%$

Nozzle pressure drops,

$\%$ of reading
Test Operating Tolerance (Total Observed Range)

Cooling and Non-Frost Heating

2.0

2.0

1.0

1.0

2.0

2.0

1.0

1.0

0.5

3.0

0.5

0.05

2

2

2.0 
Table 5-2 Test Operating Tolerances for Cyclic Dry-Coil Test D (20).

Readings, Remarks

Al1 Air Temperatures, ${ }^{\circ} \mathrm{F}$

outdoor dry-bulb

entering

Indoor dry-bulb

entering

Indoor wet-bulb

entering

After the first 30 s after

compressor startup:

External resistance to

airflow, in. water

Nozzle pressure drops,

$\%$ of reading.

Electrical voltage inputs

to the test unit, $\%$
Test Operating Tolerance

(Total Observed Range) 
time constant of 2.5 seconds. Another important factor is the location of the thermocouples. Murphy and Goldschmidt (23) looked at these effects using a computer (mathematical) model to simulate the evaporator section. In their study, they used a 30 second evaporator coil time constant and varied the thermocouple time constant $(0,3,5 \mathrm{sec})$ and the distance $(0,6 \mathrm{~m})$ from the blower exit. Table 5-3. shows the percent deviations obtained when applying these variations.

Table 5-3 Percent Deviation of $\mathrm{CPLF}^{1}$ with Variation of Thermocouple Response Rate

Percent Deviation Between Different Thermocouple

\begin{tabular}{|c|c|c|c|}
\hline Thermocouple Time Constant & $0-3 \mathrm{sec}$. & & $0-5 \mathrm{sec}$ \\
\hline At Blower Exit & $0.641 \%$ & & $1.07 \%$ \\
\hline At Duct Exit $(6 \mathrm{~m})$ & $0.435 \%$ & & $0.652 \%$ \\
\hline Thermocouple Time Constant & 0 sec. & 3 sec. & $5 \mathrm{sec}$ \\
\hline $\begin{array}{l}\text { Percent Deviation Between } \\
\text { Blower Exit and Duct Exit }\end{array}$ & $1.71 \%$ & $1.51 \%$ & $1.30 \%$ \\
\hline
\end{tabular}

${ }^{1}$ CPLF - Cooling Part Load Factor defined as the ratio of integrated cyclic cooling to integrated steady state cooling.

Thomas, Tree and Goldschmidt (30) showed the error due to only thermal lag of the thermocouple to be on the order of $0.7 \%$. Since the error is small it will be neglected in the following analysis.

Beginning with the PLF equation

PLF $=\frac{E E R_{D}}{E E R_{C}}=\frac{Q_{D}}{\dot{Q}_{C}} \frac{\dot{E}_{C}}{E_{D}}$

the relations between the uncertainties ( $\delta^{\prime} s$ ) may be developed. from elementary statistics as 


$$
\left(\frac{\delta P L F}{P L F}\right)^{2}=\left(\frac{\delta E E R_{D}}{E E R_{D}}\right)^{2}+\left(\frac{\delta E E R_{C}}{E E R_{C}}\right)^{2}
$$

where

$$
\left(\frac{\delta E E R_{C}}{E_{C} R_{C}}\right)^{2}=\left(\frac{\delta \dot{Q}_{C}}{\dot{Q}_{C}}\right)^{2}+\left(\frac{\delta \dot{\mathrm{E}}_{C}}{\dot{\mathrm{E}}_{\mathrm{C}}}\right)^{2}
$$

and

$$
\left(\frac{\delta \dot{Q}_{\mathrm{C}}}{\dot{\mathrm{Q}}_{\mathrm{C}}}\right)^{2}=\left(\frac{\delta \dot{\bar{V}}}{\dot{\bar{V}}}\right)^{2}+\left(\frac{\delta \mathrm{C}_{\mathrm{pa}}}{\mathrm{C}_{\mathrm{pa}}}\right)^{2}+\left(\frac{\delta \Delta \mathrm{T}}{\Delta \mathrm{T}}\right)^{2}+\left(\frac{\delta \mathrm{V}_{\mathrm{n}}^{2}}{\mathrm{~V}_{\mathrm{n}}^{1}}\right)^{2}+\left(\frac{\delta \dot{W}_{\mathrm{n}}}{\mathrm{W}_{\mathrm{n}}}\right)^{2}
$$

To obtain the maximum possible error in the PLF, Eqn.

5-2 would change as follows

$\left|\frac{\delta P L F}{P L F}\right|_{M A X}=\left|\frac{\delta E E R_{D}}{E E R_{D}}\right|+\left|\frac{\delta E E R_{C}}{E E R_{C}}\right|$

The other required equations would change similarly. The maximum possible error is only an upper bound, since the probability of all errors weighting the result in one direction is very small.

To work with Eqn. 5-4, other equations are needed to determine the dependance of each variable. From ASHRAE Standard 37-69 ( 3 ) the following equations are obtained

$$
\begin{aligned}
& \mathrm{C}_{\mathrm{pa}}=0.24+0.444 \mathrm{~W}_{\mathrm{n}} \\
& \dot{\overline{\mathrm{V}}}=1096 \mathrm{CA}_{\mathrm{n}}\left(\mathrm{P}_{\mathrm{v}} \mathrm{V}_{\mathrm{n}}^{1}\right)^{0.5} \\
& \mathrm{~V}_{\mathrm{n}}^{1}=29.92 \mathrm{v}_{\mathrm{n}} / \mathrm{P}_{\mathrm{n}}\left(1+\mathrm{W}_{\mathrm{n}}\right)
\end{aligned}
$$

where

$$
\begin{aligned}
c_{p a} & =\text { specific heat of air (Btu/lb }{ }^{\circ} \mathrm{F} \text { of dry air) } \\
W_{n} & =\text { humidity ratio at nozzle (los moisture/lb dry air) } \\
\dot{\nabla} & =\text { indoor air flow rate }\left(\mathrm{ft}^{3} / \mathrm{min}\right)
\end{aligned}
$$




$$
\begin{aligned}
C= & \text { coefficient of discharge at nozzle } \\
A_{n}= & \text { area of nozzle }\left(f^{2}\right) \\
P_{v}= & \text { velocity pressure at nozzle throat or static } \\
& \text { pressure difference across nozzle (in. } \mathrm{H}_{2} \text { ) } \\
\mathrm{V}_{\mathrm{n}}^{1}= & \text { specific volume of air at nozzle ( } \mathrm{ft}^{3} \text {. Ib of air- } \\
& \text { water mixture) } \\
\mathrm{v}_{\mathrm{n}}= & \text { specific volume of air at dry and wet bulb tempera- } \\
& \text { ture conditions existing at nozzle but at standard } \\
& \text { barometric pressure (ft } / \mathrm{lb} \text { of dry air) } \\
\mathrm{P}_{\mathrm{n}}= & \text { pressure at nozzle throat (in. Hg absolute) }
\end{aligned}
$$

Substituting Eqns. 5-6, 5-7 and 5-8 into Eqn. 5-4, the uncertainties become

$$
\begin{aligned}
\left(\frac{\delta \dot{Q}_{C}}{\dot{Q}_{C}}\right)^{2}=\left(\frac{\delta C}{C}\right)^{2} & +\left(\frac{\delta A_{n}}{A_{n}}\right)^{2}+\left(\frac{\delta W_{n}}{W_{n}}\right)^{2}+\left(\frac{\delta \Delta T_{1-2}}{\Delta T_{1-2}}\right)^{2}+\left(\frac{1}{2} \frac{\delta v_{n}}{v_{n}}\right)^{2} \\
& +\left(\frac{1}{2} \frac{\delta W_{n}}{W_{n}}\right)^{2}+\left(\frac{1}{2} \frac{\delta P_{v}}{P_{v}}\right)^{2}+\left(\frac{1}{2} \frac{\delta P_{n}}{P_{n}}\right)^{2}
\end{aligned}
$$

letting

$\frac{\delta X}{X}=e_{X}=$ per unit error in $X$

and simplifying

$$
\begin{gathered}
e_{Q_{C}}^{2}=e_{C}^{2}+e_{A_{n}}^{2}+\left(\frac{\sqrt{5}}{2} e_{W_{n}}\right)^{2}+e_{\Delta T}^{2}+\left(\frac{e_{v}}{2}\right)^{2}+\left(\frac{e_{V}}{2}\right)^{2} \\
+\left(\frac{e_{P_{n}}}{2}\right)^{2}
\end{gathered}
$$

The error in the cyclic test will tend to be more due to the transients of the test. Since all test conditions in test $D$ are exactly the same as in test $C$, the only difference in Eqn. 5-10 will be in the $\Delta \mathrm{T}$ term. Using Eqn. 3-8, the uncertainty in $\Gamma$ can be calculated 
$e_{\Gamma}^{2}=e_{\Delta T_{S S}}^{2}+e_{\Delta T_{o}}^{2}+e_{t_{\text {on }}}^{2}+e_{\tau}^{2}$

Applying the theory in determining the uncertainty in $\Gamma(17)$, and using

$$
\begin{aligned}
\Delta \mathrm{T}_{\text {SS }} & =17^{\circ} \mathrm{F} \\
\Delta \mathrm{T}_{0} & =0 \\
\mathrm{t}_{\text {On }} & =6 \mathrm{~min} . \\
\tau & =1 \mathrm{~min} .
\end{aligned}
$$

the error in $\Gamma$ is approximately equal to the following

$e_{\Gamma}=0.027$

The uncertainty in determining the temperature drop across the evaporator coil is interpreted from the Federal Registar (31), section 4.1.2.

Tables 5-1 and 5-2 give the test operating tolerances for the four tests $(A, B, C, \& D)$. The various measurements that are required for these four tests will contain error which are expected to be within the limits permitted by the test procedures. These limits of error are intended to be those of two standard deviations. This means $95 \%$ of the readings will have errors less than specified, and $68 \%$ of the readings will have errors, less than one-half of the specified errors. Listed below are the allowable measurement errors, and some of the considerations for their limits:

(1) The flow coefficient is expected to be accurate within $1.2 \%$. This is a major source of fan testing error but is based on extensive work (6):

$$
e_{c}=0.012
$$


(2) The area at the flow measuring station will be within $0.5 \%$, when the diameter measurements are within $0.2 \%$. This error will have a small effect on overall accuracy:

$$
e_{A_{n}}=0.005
$$

(3) The humidity ratio will be within $1.3 \%$, when the indoor dry-bulb $\left(80 \pm 1^{\circ} \mathrm{F}\right)$ and wet-bulb $\left(67 \pm 0.5^{\circ} \mathrm{F}\right)$ temperatures are correct:

$$
\mathrm{e}_{\mathrm{W}_{\mathrm{n}}}=0.013
$$

(4) It can be demonstrated that a temperature difference of $17^{\circ} \mathrm{F}$ between air entering and leaving the indoor side will be known within $2.5 \%$ when the dry-bulb temperatures are correct to $\pm 0.3^{\circ} \mathrm{F}$ :

$$
e_{\Delta T}=0.025
$$

(5) Using the ideal gas law one can show that the specific volume of air will be within $2.4 \%$. This is based on the errors in measuring temperature and pressure :

$$
\dot{e}_{v_{n}}=0.024
$$

(6) The static or velocity pressures should be within instrument accuracy (see Table 5-4):

$$
\mathrm{e}_{\mathrm{p}}=0.01
$$

(7) Similarly the pressure at the nozzle throat should be within instrument accuracy: 


$$
e_{p_{n}}=0.02
$$

Substituting these representative error values into Eqn. 5-10 $e_{Q_{C}}^{2}$ becomes

$$
\begin{aligned}
e_{Q_{C}}^{2}=(0.012)^{2} & +(0.005)^{2}+\left(\frac{\sqrt{5}}{2} 0.013\right)^{2}+(0.025)^{2} \\
& +\left(\frac{0.024}{2}\right)^{2}+\left(\frac{0.01}{2}\right)^{2}+\left(\frac{0.02}{2}\right)^{2}
\end{aligned}
$$

$\mathrm{e}_{\mathrm{Q}_{\mathrm{C}}}^{2}=1.27 \times 10^{-3}$

Since the uncertainty in $e_{\Gamma}$ and $e_{\Delta T}$ (see Eqns.. 5-1la and 5-15) are nearly equal, then it will be assumed that the uncertainties in the cyclic and steady tests ( $\& D$ ) are approximately the same, then

$\left(\frac{\delta Q_{D}}{Q_{D}}\right)^{2}=\left(\frac{\delta \dot{Q}_{C}}{\dot{Q}_{C}}\right)^{2}=e_{Q}^{2}$

Using the accuracy of the electrical measuring device from Table 5-1 and Eqn. 5-3, the uncertainty in the energy efficiency ratio can be obtained as

$$
\begin{aligned}
\left(\frac{\delta E E R_{C}}{E_{C}}\right)^{2} & =(0.036)^{2}+(0.02)^{2} \\
& =1.67 \times 10^{-3}
\end{aligned}
$$

Therefore, from Eqns. 5-2 and 5-22 the possible error in PLF due to the test tolerances is

$$
\begin{aligned}
100 \times \frac{\delta \mathrm{PLF}}{\mathrm{PLF}} & =\left(1.67 \times 10^{-3}+1.67 \times 10^{-3}\right) 1 / 2 \times 100 \\
& =5.8 \%
\end{aligned}
$$


Table 5-4 Accuracy of Instruments (20).

$\begin{array}{ll}\quad \text { Measurement } & \text { Accuracy } \\ \text { Pressure } & \pm 2 \% \text { absolute } \\ \text { Static or velocity pressures } & \pm 1 \% \\ \text { Diameter of nozzles } & \pm 0.2 \% \\ \text { Electrical } & \pm 0.5 \% \\ \begin{array}{l}\text { (fan motors, compressor } \\ \text { motors, equipment acces- }\end{array} & \\ \text { sories) } & \\ \text { Temperature (across coil, } & \\ \text { indoor dry-bulb air } & \\ \text { entering and leaving) } & \end{array}$

This result reflects the propagation of allowable measured errors. Since the errors will occur randomly, the uncertainty result in PLF is the likely error that will occur from test tolerances. In calculating the uncertainty in PLF, it was assumed that the error in the steady state energy efficiency ratio was the same as in the cyclic energy efficiency ratio. In general, the error in the cyclic test will actually be greater than in the steady state test. Thus, the uncertainty calculated for PLF is expected to be a lower bound.

To determine the error resulting in the degradation coefficient $C_{D}$, Eqn. $3-11$ is expanded into uncertainty form

$$
\left(\frac{\delta C_{D}}{C_{D}}\right)^{2}=\left(\frac{\delta P L F}{P L F}\right)^{2}+\left(\frac{\delta C L F}{C L F}\right)^{2}
$$

Hence, assuming the error in CLF is a sum of the errors in determining the cooling capacities of $Q_{D}$ and $Q_{C}$, the uncertainty in $C_{D}$ becomes 
$100 \times \frac{\delta C_{D}}{C_{D}}=7.7 \%$

Calculating the maximum possible errors for PLF and $C_{D}$, the following results are obtained

$\left.P L F\right|_{\max }=20.7 \%$

$\left.C_{D}\right|_{\max }=37.4 \%$

Again it should be noted that this is an unrealistic value, since many errors will tend to cancel each other.

C) Probable Error

Data distribution has a marked effect upon probable error. For instance, if a large proportion of the data are such that they have small deviations, they are said to be more reliable. As a general practical term, probable error $p$ is defined as that deviation which in the algebraic plusand-minus sense, encloses exactly 50 percent of the total test points or reading population (2) (28). It may be stated that the chance that a given reading will have a deviation greater than $\mathrm{p}$, is the same as that it will have one' less than $p$.

The value of $p$ may be expressed in terms of the standard deviation as follows (2):

$\mathrm{p}=0.675 \mathrm{~s}$

Now taking the incertainty of PLF to be the standard deviation of PLF, the probable error can be calculated from the test tolerances. Hence the following is obtained 
$\left.\mathrm{p}\right|_{\mathrm{PLF}}=0.675(5.8 \%)$

$\left.\mathrm{P}\right|_{\mathrm{PLF}}=3.9 \%$

Similarly for $C_{D}$

$\left.P\right|_{C_{D}}=5.2 \%$

Thus, the statistical most probable errors in PLF and $C_{D}$ due to test tolerances are $3.9 \%$ and $5.2 \%$ respectively. Stating again, this is the deviation that encloses $50 \%$ of all the distribution.

D) Error Resulting from Room Dependence

The inside and outside temperature variations will

have an effect on the cooling capacity and power consumption (see Fig. 4-7). This room dependence on temperature will then create possible variations in PLF, CLF, $C_{D}$ and finally SEER.

The test tolerance for the inside and outside temperature (dry-bulb) variation is $\pm 1 \circ \mathrm{F}$. This variation from the set point will be analyzed.

From Eqn. 2-1, the variation of steady state EER to outdoor temperature can be determined. With a $\pm 1^{\circ} \mathrm{F}$ change in outdoor temperature there will be approximately a $1 \%$ change in steady state EER. Thus, this value will be used for variations of EER with outdoor temperature.

Similarly, the variation of EER with indoor temperature will assume to be of the same order, assuming the size of the two coils are of the same order of magnitude.

Combining both of these temperature variations, it is then assumed the total variation in EER with temperature (inside and outside) will be $2 \%$ for each change of $\pm 1^{\circ} \mathrm{F}$. 
Using Eqn: 5-2 the change in PLF with respect to room dependence on temperature will be

$\left.\left.\frac{\delta P L F}{\text { PLF }}\right|_{\substack{\text { ROOMENDENCE } \\ \text { DEPEND }}}=\left[(0.02)^{2}+(0.02)^{2}\right]\right]^{1 / 2}$

$\left.\frac{\delta P L F}{P L F}\right|_{R D}=0.028$

and using Eqn: 5-24 for $C_{D}$

$\left.\frac{\delta C_{D}}{C_{D}}\right|_{R D}=\left[(0.028)^{2}+(0.02)^{2}+(0.02)^{2}\right]^{1 / 2}$

$\left.\frac{\delta C_{D}}{C_{D}}\right|_{R D}=0.04$

Since capacity is more dependent on temperature than power, the error for $Q_{D}$ and $Q_{C}$ was taken to be the same as. in EER. Table 5-5 summarizes the results from this chapter. The room dependence error added to the allowable measured error, gives the overall error that may result when performing the required test procedure.

From this analysis it appears the overall error resulting when performing the requircd tcst, is in good engineering accuracy. The probable error in PLF and $C_{D}$ will be around $6 \%$ and $8 \%$ respectively. 
Table 5-5 Summary of Error Analysis

\begin{tabular}{|c|c|c|}
\hline Variable & & $\begin{array}{l}\text { for With } \\
\text { or Occurrence., \% }\end{array}$ \\
\hline Possible Errorl & $\begin{array}{r}\text { PLF } \\
C_{D}\end{array}$ & $\begin{array}{r}8.6 \\
11.7\end{array}$ \\
\hline & SEER $^{2}$ & 9.5 \\
\hline Probable Error? & $\begin{array}{r}P L F \\
C_{D}\end{array}$ & $\begin{array}{l}5.8 \\
7.9\end{array}$ \\
\hline & SEER ${ }^{2}$ & 6.4 \\
\hline
\end{tabular}

1. Based on random errors and including room variations tolerable.

2. $\frac{\delta \text { SEER }}{\text { SEER }}=\left[\left(\frac{\delta E E R_{B}}{\text { EER }_{B}}\right)^{2}+\left(\frac{\delta P L F}{P L F}\right)^{2}\right] 1 / 2$

$$
\text { where } \frac{\delta E E R_{B}}{E E R_{B}}=\frac{\delta E E R_{C}}{E_{C E R_{C}}}
$$


CHAPTER 6

DIFFERENT METHODS OF COMPUTING

SEASONAL ENERGY EFFICIEINCY RATIO FROM

TESTS $A, B, C$ AND D

\section{A) Introduction and Methods Used}

In reference (20) it is stated that the effect of varying weather conditions through the United States, for single compressor, constant speed units, has less than $10 \%$ effect on the calculated value of seasonal energy efficiency ratio. Thus, a national weather bin can be used. This bin was obtained in such a way that the average outdoor temperature was $82^{\circ} \mathrm{F}\left(27.8^{\circ} \mathrm{C}\right)$. The average temperature $\left(82^{\circ} \mathrm{F}\right)$ was weighted with respect to the number of units in each region. Reference (20) further states that for single compressor, constant speed units, a further simplification can be made in estimating the SEER. "The SEER is taken to be equal to the energy efficiency ratio of a cooling unit operating cyclically at a cooling load factor, CLF equal to 0.5 and at an outdoor temperature of $82^{\circ} \mathrm{F}\left(27.8^{\circ} \mathrm{C}\right) . "$ As suming these two statements are true, it does indeed reduce the amount of compulation necessary, but does not reduce the amount of testing necessary.

The comparison of seasonal energy efficiency ratio will be concerned with the varying cycle-time obtained from the ideal thermostat demand cycle. The test procedure considers the $20 \%$ on-time at a cycle rate of $2 \mathrm{CPH}$, which 
corresponds to 6 minutes on $/ 24$ minutes off. * It is imperative that this analysis be made with the on-time and cycletime varying, so that it represents a real life situation. In this new analysis, certain basic assumptions will be made. One assumption is that the initial temperature drop $\Delta \mathrm{T}_{0}=0$ for all units. This will simplify Eqn. 3-14 to

$\operatorname{PLF}=1-\frac{\tau}{t_{\text {on }}}\left[1-\exp \left(-t_{\text {on }} / \tau\right)\right] \frac{\dot{\mathrm{E}}_{\mathrm{C}}}{\dot{\bar{E}}_{\mathrm{D}}}$

Another important assumption needs to be made about the power consumption ratio. Since no experimental data has been received to show how this ratio varies with percent on-time, two different assumptions will be used and analyzed. From Fig. 4-8, it is noted that the power consumption ratios of all the units are approximately equal to one. Hence, the power consumption ratio will be assumed to equal one for all percent on-times in the first analysis. Table F-1 shows the actual power consumption ratio (WATTCD) for the experimental data.

A different assumption will be made about the power consumption ratio in the second analysis. It will be assumed that the power consumption ratio varies linearly with percent on-time. Hence, the power consumption ratio will approach one in the limit, as the value of the percent on-time approaches one. The slope of the line is determined from the experimental data at $20 \%$ on-time. Thus, the general equation is

* It should be noted that although $6 / 30$ is $20 \%$ on-time, the thermostat demand cycle with $\mathrm{CPH}=3$, predicts the following percent on-times: 1) $6.34 / 30=21.1 \%$ 2) $6 / 36=16.67 \%$ 3) $5.25 / 31.25=20 \%$. 
$\frac{\overline{\dot{E}}_{D}}{\dot{\mathrm{E}}_{C}}=1-\operatorname{SLOPE}\left[1-\frac{t_{\text {on }}}{\bar{t}_{\text {cyc }}}\right]$

where

SLOPE $=1-\frac{\overline{\dot{E}}_{D}(20)}{\dot{E}_{C}(20)} / 0.8$

$\frac{\bar{E}_{D}(20)}{\dot{E}_{C}(20)}=$ experimental power ratio at $20 \%$ on-time.

From the analysis in Chapter 3 , it was shown that the variation in CLF with percent on-time for a variable cycle-time tends to be linear (see Fig. 3-7). Thus, the semi-empirical equation for CLF and the experimental data can be used to predict an approximate time constant $\tau$ for each unit. Assuming the time constant $\tau$ for each unit is constant, then this result can be used in the semi-empirical equations to perform the further analysis as needed.

In order to determine the SEER using a weather ( $\mathrm{Na}$ tional) bin method and the semi-empirical equations, a relationship between outdoor temperature and cycle-time must be determined. One appropriate model is obtained from reference ( 8 ). Figure 6-1 shows the cycling rate characteristice for cooling as a funcliun of outdoor temperature. Using the appropriate equations in reference (20) it can be shown using a $10 \%$ over design of cooling capacity and the building cooling load, that at an outdoor temperature of $82^{\circ} \mathrm{F}\left(27.8^{\circ} \mathrm{C}\right)$ the steady-state cooling capacity ratio $\dot{\mathrm{Q}}_{\mathrm{B}} / \dot{\mathrm{Q}}_{\mathrm{A}}$ must be equal to 1.04 for the cooling load factor to be 


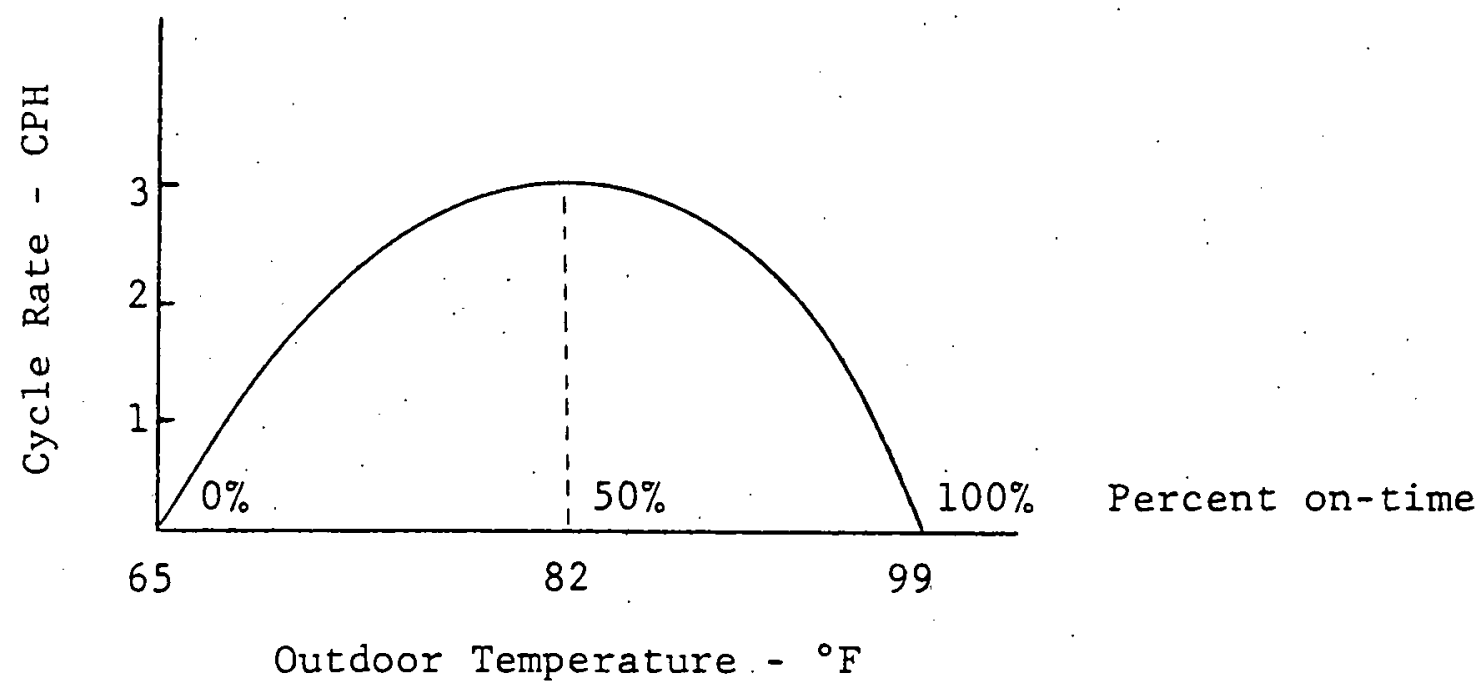

Figure 6-1 Heat Pump in Cooling Mode ( 8 )

equal to 0.50 . This will help insure that at $82^{\circ} \mathrm{F}\left(27.8^{\circ} \mathrm{C}\right)$ the percent on-time is approximately $50 \%$. In analyzing the experimental data it was found that $95 \%$ of the $\dot{Q}_{B} / \dot{Q}_{A}$ ratios satisfied the condition where the cooling load factor was equal to $0.50 \pm 0.02$ at an outdoor temperature of $82^{\circ} \mathrm{F}$ $\left(27.8^{\circ} \mathrm{C}\right)$. Thus, the percent on-time at $82^{\circ} \mathrm{F}\left(27.8^{\circ} \mathrm{C}\right)$ will be approximately $50 \%$ for most all of the units analyzed. Applying the same analysis as before, the following equation is obtained

$t_{c y c}=\frac{60 \mathrm{~min} .}{\frac{-3}{\left(17^{\circ} \mathrm{F}\right)^{2}}\left(\mathrm{~T}-82^{\circ} \mathrm{F}\right)^{2}+3}$

where $\mathrm{T}=$ outdoor temperature $\left({ }^{\circ} \mathrm{F}\right)$

With Eqn. 6-4, the cycle-time can be predicted at an outdoor temperature and use this cycle-time to predict the ontime. This equation will be used in the weather bin method to help calculate the seasonal energy efficiency ratio.

Using the ideal thermostat demand cycle to predict the cycle and on-times and the semi-empirical equations with the time constant $\tau$ for each unit, the seasonal energy 
efficiency will be calculated in several different methods as discussed below. All six methods will be calculated using both assumptions concerning the power consumption ratio.

For the 166 units that will be compared it will be assumed:

1. The seasonal energy efficiency ratio can be obtained by taking the experimentally determined 20\% load and extrapolating to a $50 \%$ load at an outdoor temperature of $82^{\circ} \mathrm{F}\left(27.8^{\circ} \mathrm{C}\right)$. This is the present DOE test procedure for single compressor, constant speed units. It contains all assumptions of this procedure. It is labeled SEER(DOE).

2. The seasonal energy efficiency ratio can be obtained by using the time constant $\tau$ in combination with the semi-empirical equations to predict the PLF and CLF at $20 \%$ on-time. With these results the same procedure can be applied as specified in method 1 to obtain comparable results. This result is labeled $\operatorname{SEER}(20)$.

3. The seasonal energy efficiency ratio is obtained by using the semi-empirical equation to predict the $50 \%$ on-time at an outdoor temperature of $82^{\circ} \mathrm{F}$ $\left(27.8^{\circ} \mathrm{C}\right)$. Using the PLF at this point similar procedures can be applied as before to determine the seasonal energy efficiency based on the $50 \%$ on-time. It is labeled $\operatorname{SEER}(50)$.

4. The seasonal energy efficiency ratio is obtained by using the semi-empirical equations to predict PLF and CLF at $20 \%$ on-time and then calculate $C_{D}$ at this point. The PLF at $50 \%$ on-time is obtained by extrapolating with slope $C_{D}$. This method then uses the same procedure in method 3 . This result is labeled SEER2(50). 
5. The seasonal energy efficiency ratio is obtained by using the national weather bin and calculating $C_{D}$ at $20 \%$ on-time from the experimental data. A linear relation between cooling capacity and energy consumption vs. outdoor temperature is assumed. This is the present DOE test method for multispeed compressor units or multi-compressor units except that it has been modified for single compressor, constant speed units. It contains the same design point and oversizing as the test procedure. This is the method which reference (20) says can be replaced by method 1 above. It is labeled SEER(BLD).

6. The seasonal energy efficiency ratio can be obtained using the national weather bin, but assuming that $C_{D}$ is not constant. The thermostat demand cycle, time constant $\tau$ and semi-empirical equations are used to predict PLF and CLF at each temperature bin. This is labeled SEER(EMP).

\section{B) Results from SEER Comparisons}

Table F-2 in Appendix $F$ lists the seasonal energy efficiency ratio for the 166 units calculated using methods 1-6 and using the assumption that $\dot{\mathrm{E}}_{C} / \dot{\mathrm{E}}_{\mathrm{D}} \neq 1$ for all percent on-times. The unit number is given in the table to make comparisons easier.

Each method was further analyzed by comparing values of all 166 units with the seasonal energy efficiency ratio as obtained by the modified DOE test procedure SEER(BLD). The percent difference was obtained by subtracting SEER(BLD) from each value, multiplying by 100 and then dividing by $\operatorname{SEER}(B L D)$. The results of this study are summarized in Table F-3. Included in Table $F-3$ is the percent difference between the semi-empirically determined SEER(2) and experimentally determined SEER(DOE), remembering that SEER(DOE) 
is the present DOE shortcut test procedure for single compressor, constant speed units. From Table F-3, the following conclusions can be drawn:

1) Assuming that all conditions of the present DOE test procedure are going to be used (i.e., $20 \%$ ontime to find $C_{D}, 10 \%$ oversizing, etc.) then all of the methods give to within approximately $\pm 2.5 \%$ for all 166 units tested the same seasonal energy efficiency ratio as the national weather bin method.

2) Both semi-empirically determined seasonal energy efficiency ratios SEER(20) and SEER(EMP) give to within $\pm 2.5 \%$ of the experimentally determined seasonal energy efficiency ratios SEER(DOE) and SEER(BLD) respectively for the 166 units .

3) Using the empirical equations to determine the seasonal energy efficiency ratio, $100 \%$ of the SEER(20) are within $1.0 \%$ of the respective SEER (DOE).

4) For the empirical weather bin method tested SEER (EMP), $97.6 \%$ had percent differences within $\pm 1 \%$ of SEER(BLD). It should be noted here that there have been questions raised as to the validity of some of the data. This could possibly explain the $2.4 \%$ deviation in this result.

5) From Table F-2 the following trends can be observed

$$
\begin{aligned}
& \operatorname{SEER}(50)>\operatorname{SEER} 2(50) \\
& \operatorname{SEER}(50)>\operatorname{SEER}(\operatorname{EMP}) \\
& \operatorname{SEER}(20)>\operatorname{SEER}(\operatorname{EMP})
\end{aligned}
$$

The first inequality is expected since the slope of $C_{D}$ at the $50 \%$ on-time is smaller than at $20 \%$ on-time. The last two inequalities show that these two methods overestimate the seasonal energy efficiency ratio when calculated using the national 
weather bin method and a variable $C_{D}$. However, one should note that the difference between any of the methods is very small.

Table F-4 lists the seasonal energy efficiency ratio for the 166 units using the six different rating methods and using the assumption that $\dot{\mathrm{E}}_{C} / \dot{\vec{E}}_{D}=1$ for all percent ontimes. Similarly as before, each method was further analyzed by comparing each method to the modified DOE test procedure SEER(BLD). The percent difference of each method is listed in Table F-5. Table F-5 is similar to Table F-3 except for the assumption concerning the power consumption ratio used in the semi-empirical equations. Figure 6-2 summarizes the deviation of SEER(EMP) from SEER(BLD) when using this assumption. Hence, $90 \%$ of the units have the empirical SEER(EMP) within $\pm 5 \%$ of the experimental SEER(BLD) and $99.4 \%$ are within $\pm 8 \%$. The same general trend can be obtained when analyzing the other methods.

In conclusion, by including the ideal thermostat demand cycle with the semi-empirical equations, the comparisons of the empirical results to the DOE method are very good. The best results are obtained when the power consumption ratio is taken into consideration. From this analysis, the linearity assumption of $C_{D}$ appears to be justifiable when considering the thermostat response. Since air conditioning systems respond to thermostats, it is logical that the preceding analysis confirms the approximate linearity of $C_{D}$ over the range of cooling loads from 0.1 to 1 .

It should be noted here that in reference (30), the analysis considered the variation in SEER when using different weather-bin data. The previous analysis used only the average national weather. Thus, for further comparisons of SEER with weather dependence, see reference (30). 


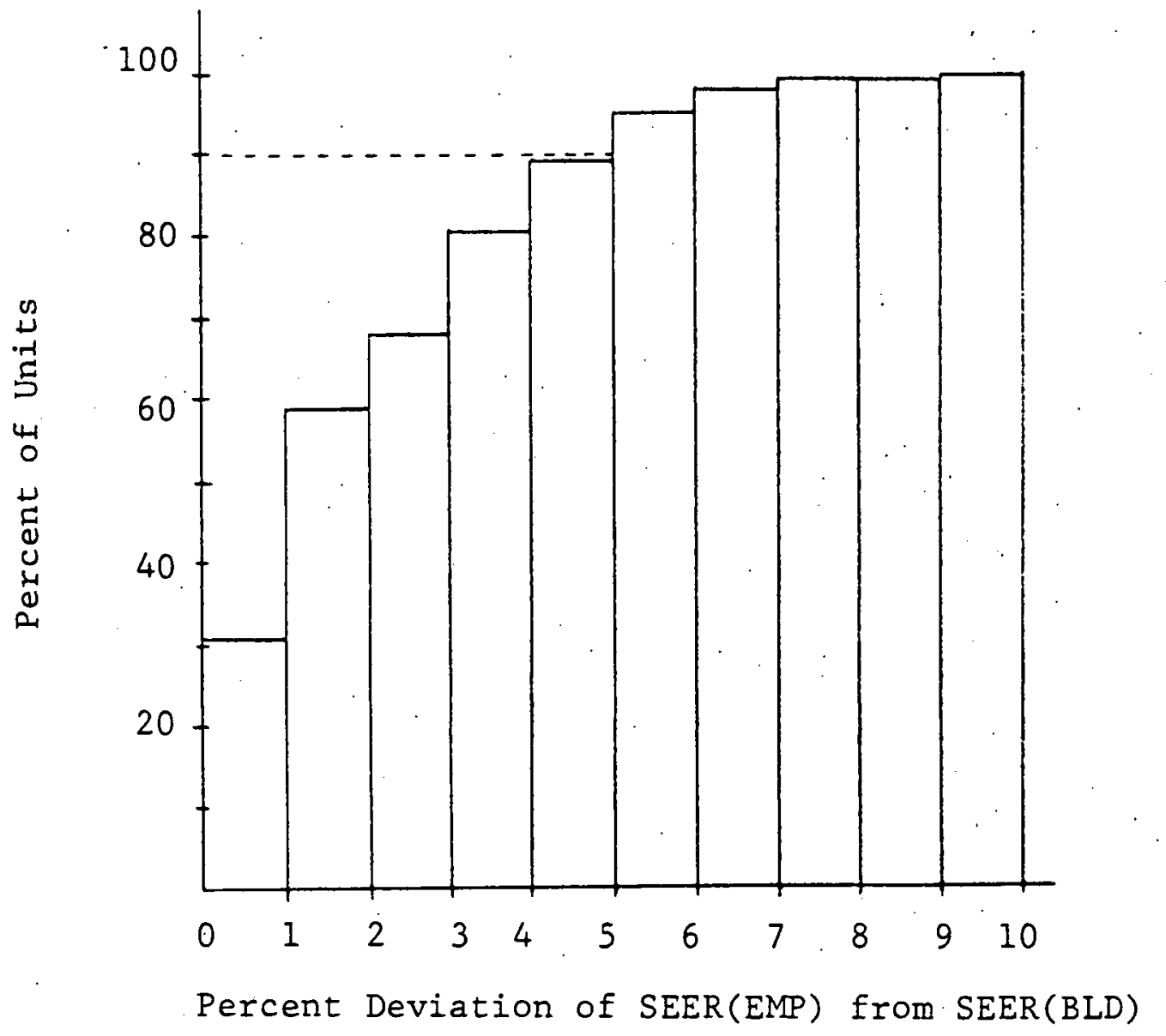

Figure 6-2 Percent Deviation of SEER(EMP) from SEER(BID) when the Power Consumption Ratio is Unity for all Percent On-Times 
CHAPTER 7

\section{CONCLUSIONS AND RECOMMENDATIONS}

From the results presented in this work, several conclusions may be drawn conceming the seasonal performance test procedures for central air-conditioners and the corresponding semi-empirical model. These results also suggest several recommendations for future research. It should be noted that all conclusions apply only to the experimental test data received by the Ray $W$. Herrick Laboratories.

A) Conclusions

This study has analyzed the test procedure for determining the seasonal energy efficiency ratio for central air-conditioners and heat pumps in the cooling mode. Considering all the possible rating procedures that could have been developed and considering the time constraint placed upon the Department of Energy and the National Bureau of Standards, they did a commendable job of developing a rating procedure. It appears from the test data received and manufacturers' responses, that problems resulted in interpretation of the DOE test procedure, lack of adequate facilities and lack of experience. It is expected that with time and experience these problems could be overcome.

From this work it appears that the semi-empirical equations combined with the thermostat demand cycle and power consumption ratio could be a promising model in determining the seasonal efficiency of a CAC. The foundation of this model requires more research into the validity and constancy of the time constant $\tau$ of the CAC. A transient test to determine the time constant $t$ for a CAC may be an adequate replacement for the dry-coil tests $C$ and $D$. 
The semi-empirical model developed showed that the degradation coefficient is not constant, but the variation in its value was rather small, thus confirming the linearity of $C_{D}$ in the range of CLF equal to 0.1 to 1 .

From the error analysis on the test procedures, it was determined that the most probable errors in obtaining PLF and $C_{D}$ are $4.0 \%$ and $5.3 \%$ respectively.

B) Recommendations

1. The fact that for nearly all units tested, $E E R_{D} / E E R_{C} \cong$ $E_{A E R} / E E R_{B}$, may lead to a simplification of the testing required. This method needs further investigation. It may not be universally true, but for families of units, the two ratios may be related by a simple constant. It is recommended that further study be done in this area.

2. If the analysis of Chapters 3 and 6 are true for all units, a simple test could be done to determine a time constant $\tau$ and could be substituted for the dry coil tests $C$ and $D$. An SEER could be obtained from the measured time constant $\tau$ without making some of the assumptions now existing in the DOE test procedure. The author envisions a much simpler test than the cyclic tests and therefore, strongly recommends more work in this area. The validity and constancy of the time constant $\tau$ needs further work.

Further work includes the need for an analysis of the shape of the $\Delta T$ curve and determination of how the power consumption ratio $\dot{\mathrm{E}}_{C} / \overline{\mathrm{E}}_{\mathrm{D}}$ varies with percent on-time.

3. Further work is recommended in determining the optimum thermostat demand cycle which produces the maximum seasonal energy efficiency. Constant and variable cycletime will create different demand cycles, thus producing different seasonal energy efficiencies. Further work in this area is needed. 
4. The parameter SEER is used to determine a seasonal rating value for an air conditioning unit. Needed to determine the SEER of a unit, is a relationship between PLF and CLF. This determines how the unit performs under part-load conditions at any load. The degradation coefficient $C_{D}$ is the slope of the line for PLF vs. CLF, determined at an experimental operating condition $(20 \%$ ontime). Since $C_{D}$ is a slope of a line, it is fairly sensitive to little changes. Generally, this change has less of an influence on SEER, since SEER is really a function of PLF. Therefore, error in determining $C_{D}$ may be larger than PLF, it is really the error in determining PLF that influences SEER. Thus, PLF is the characterizing parameter in determining a SEER.

5. It should be noted that even though SEER is a seasonal rating value, the actual field practice will generally be different. Parameters such as different oversizing, building interactions, weather variations and occupancy patterns will greatiy affect the seasonal performance of a unit. Since all the parameters that affect the seasonal performance of a unit:could not be included in the test procedure, the SEER value should be used as a rating value for comparison.

The bin method should be used since it can take into consideration different oversizing and weather variations. 


\section{BIBLIOGRAPHY}




\section{BIBLIOGRAPHY}

1. Air-Conditioning and Refrigeration Institute (ARI), "Standard for Unitary Air-Conditioning Equipment," Standard 210, 1979.

2. Ambrosius, Edgare; Fellows, Robert D. and Brickman, Arthur D., Mechanical Measurement and Instrumentation, The Ronald Press Company, New York, 1966, pp. 43-56.

3. American Society of Heating, Refrigerating and Air-Conditioning Engineers (ASHRAE), "Methods of Testing for Rating Unitary Air Conditioning and Heat Pump Equipment". Standard 37-69, 1969.

4. Appelbaum, B.; Hesse, M.; Kapner, R.S. and Lannus, A., "On the Transient Performance of Unitary Heat Pump Equipment", Proceedings of the Documentation and Analysis of Improvements in Efficiency and Performance of HVAC Equipment and Systems, Purdue University, 1978.

5. Berg, Charles A., "A Technical Basis for Energy Conservation", Mechanical Engineering, Vol. 96, May 1974, pp. 30-42.

6. Bohanon, Hoy R., "Laboratory Fan Test: Error Analysis", ASHRAE Transactions, 1975, part 1, pp. 83-92.

7. Bonne, Ulrich and Patani, Amin, "Modeling the Influence of Heat Pump Sizing, Climate, and Test Conditions on Seasonal Efficiency (COP)", Proceedings of the Documentation and Analysis of Improvements in Efficiency and Performance of HVAC Equipment and Systems, Purdue University, 1978.

8. Bullock, Charles E. and Reedy, Wayne R., "Heat Pump Cyclic Performance and its Influence on Seasonal Operation", 3rd Annual Heat Pump Technology Conference, Okla. State University, April 1978.

9. Cohen, R.; Hamilton, J.F., and Pearson, J.T., "Possible Energy Conservation Thru Use of Variable Capacity Compressors", Proceedings of the Conference on Improving Efficiency in HVAC Equipment and Components for Residential and Small Commercial Buildings, Oct 7-8, 1974. 


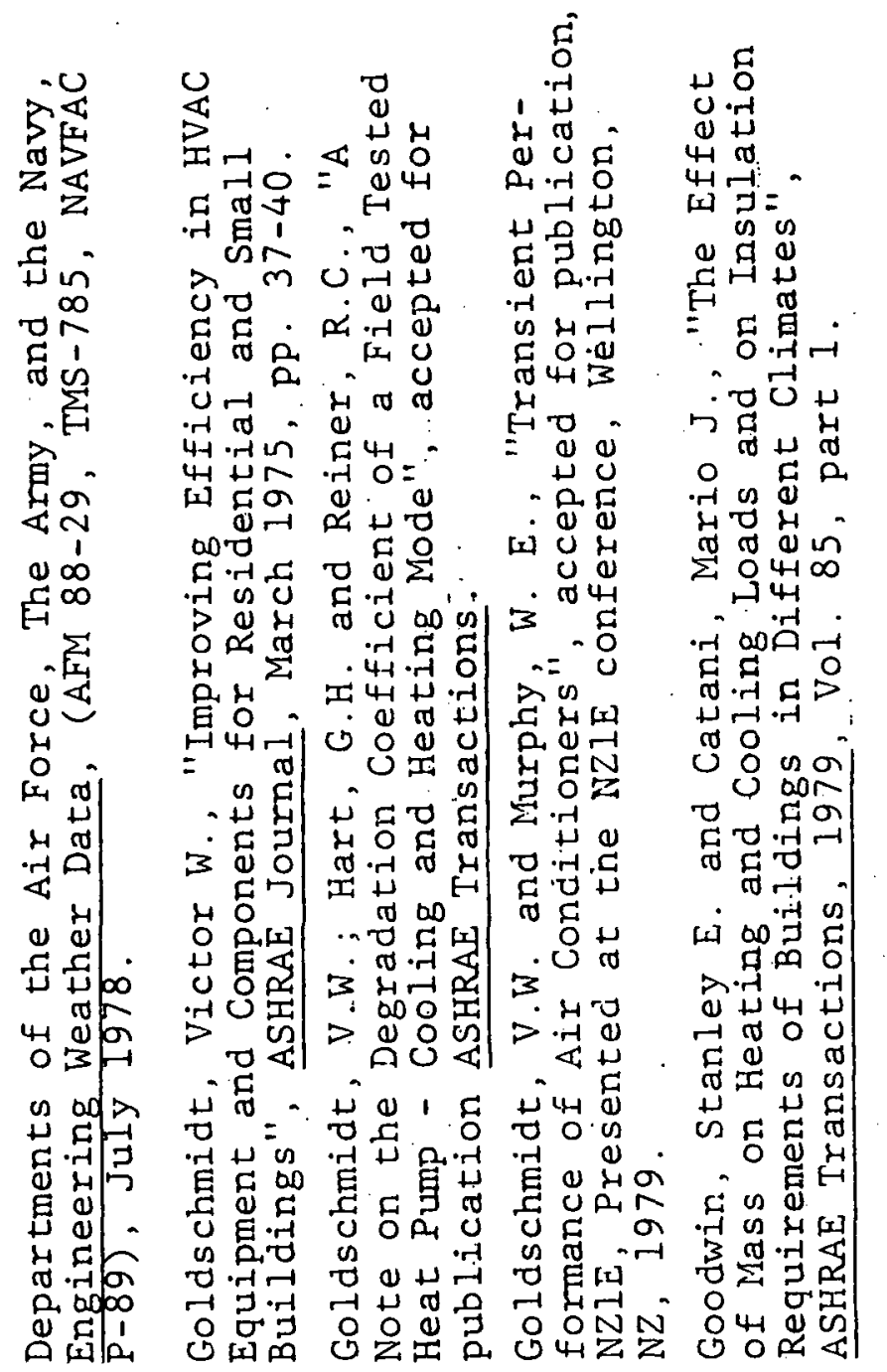

욱 $\ddot{7}$ $\underset{7}{-1}$ m.

ป

in

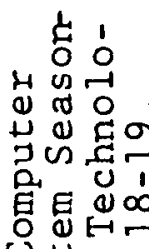
U 《会合

ค

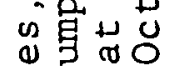
मم ฮึ ป 正苨 凶y 是 苍寻告至 ${ }_{1} \cos 0$ न' की व

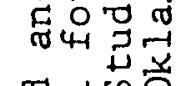
ग ชै 0 U원 ज吉点

\section{ن. ․ㅓㅇ}

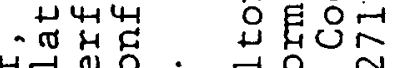

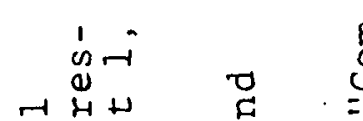
记 ค. सिम - OR $\therefore \pi$

世 0 जि

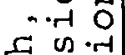
至 \& $\infty 0_{\pi}^{0}$ ○兒 至 दिभ क्ष 용 is on

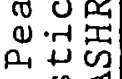
or ग्न क्ष 0

- U $E$

मा क स

is

ते 대-1 呬它 คथ - 0 -

工

I $=\frac{d}{0,0}$

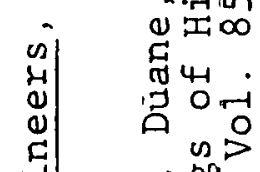
i) म. तुo प्रुत्त न 口. $\begin{array}{lll}0 & 0 & 0 \\ 0 & 0 & 0 \\ & 0 & 0\end{array}$

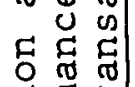

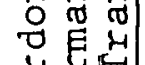
त्ञ O 0

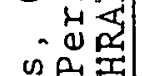
क म O 峁苨 . द् $=$

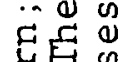
造 $>\Phi$ ज 00 范



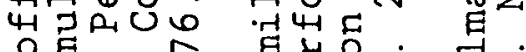
車舟 क्षेत्र मु.

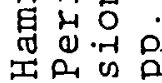
贡 我满

E

O

द年

क्ष

ه 언

० 14

त्व

घ त

0. म्न 000

a 5 त्-

웡

ه.न픔 Q 的苏 ते

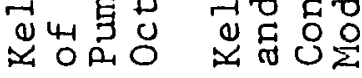

उ它䆵台 a $\pi$ Q एक W पथ का IIN $\rightarrow+1$ द on न का

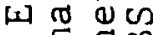
. 0 z

$\stackrel{2}{\sim}$ 우 
21. Kelnhofer, W.J., "Energy Usage of Installed Residential Air Conditioning Equipment", Proceedings of the Documentation and Analysis of Improvements in Efficiency and Performance of HVAC Equipment and Systems, Purdue University, 1978.

22. Lipson, Charles and Sheth, Nasendra J., "Statistical Design and Analysis of Engineering Experiments, McGrawHill, New York, 1973, PP. 345-382.

23. Murphy, W.E. and Goldschmidt, V.W., "Analysis of Measurement Procedure", Ray W. Herrick Laboratories, HL $79-4$.

24. Murphy, William E. and Goldschmidt, Victor W., "The Degradation Coefficient of a Field-Tested Self-Contained 3-Ton Air Conditioner", ASHRAE Transactions, 1979, Vol. 85 , part 2 .

25. National Electrical Manufactures Association (NEMA), "Residential Controls - Low Voltage Room Thermostats". Pub. No. DC3-1972.

26. Parken, Walter H.; Beausoliel, Robert W. and Kelly, George. E., "Factor Affecting The Performance of a Residential Air-to-Air Heat Pump", ASHRAE Transactions, 1977, Vol. 83, part 1, pp. 839-849.

27. Rudoy, William and Dougal1, Richard S. "Effects of the Thermal Mass on Heating and Cooling Load in Residences", ASHRAE Transactions, 1979, Vol. 85, part 1.

28. Schenck, Hilbert, Theories of Engineering Experimentation, 3rd Ed., McGraw-Hill, New York, 1979, pp. 27-34, 53-64, 234-245.

29. Science Applications, Inc., "Energy Efficiency Program for Room Air Conditioners, Central Air Conditioners, Dehumidifiers, and Heat Pumps", La Jolla, Ca; March, 1978.

30. Thomas, Steven B.; Tree, David R. and Goldschmidt, Victor W., "Compilation of Data and Analysis of Test Procedure for SEER", Ray W. Herrick Laboratories Report No. HL 79-2, Purdue University, 1979.

31. U.S. Federal Register, "Test Procedures for Central Air Conditioners, Including Heat Pumps", Vol. 44, No. 249, Thursday, December 27, 1979, pP 76700-76723. 
32. Wark, Kenneth, Thermodynamics, McGraw-Hill Book Co., New York, 3rd ed., 1977, pp. 765.

33. Wildin. M.W.; Fong, Albert; Nakos, James and Nakos, John, "Analysis of Performances of Installed Air-toAir Heat Pumps Using a Simple Method for Predicting the Effects of Cycling on Heating Performance in an Arid Climate", Proceedings of the Documentation and Analysis of Improvements in Efficiency and Performance of HVAC Equipment and Systems, Purdue University, 1978.

34. Wrench, James C., "Factors Affecting RAC Efficiency", ASHRAE Journal, February 1975, PP 42-43.

35. Zaleski, Robert H., "Probable Errors in Field Performance Measurements of Fan Systems", ASHRAE Transactions, 1976, part 1, pp. 883-887. 


\section{APPENDICES}


APPENDIX A

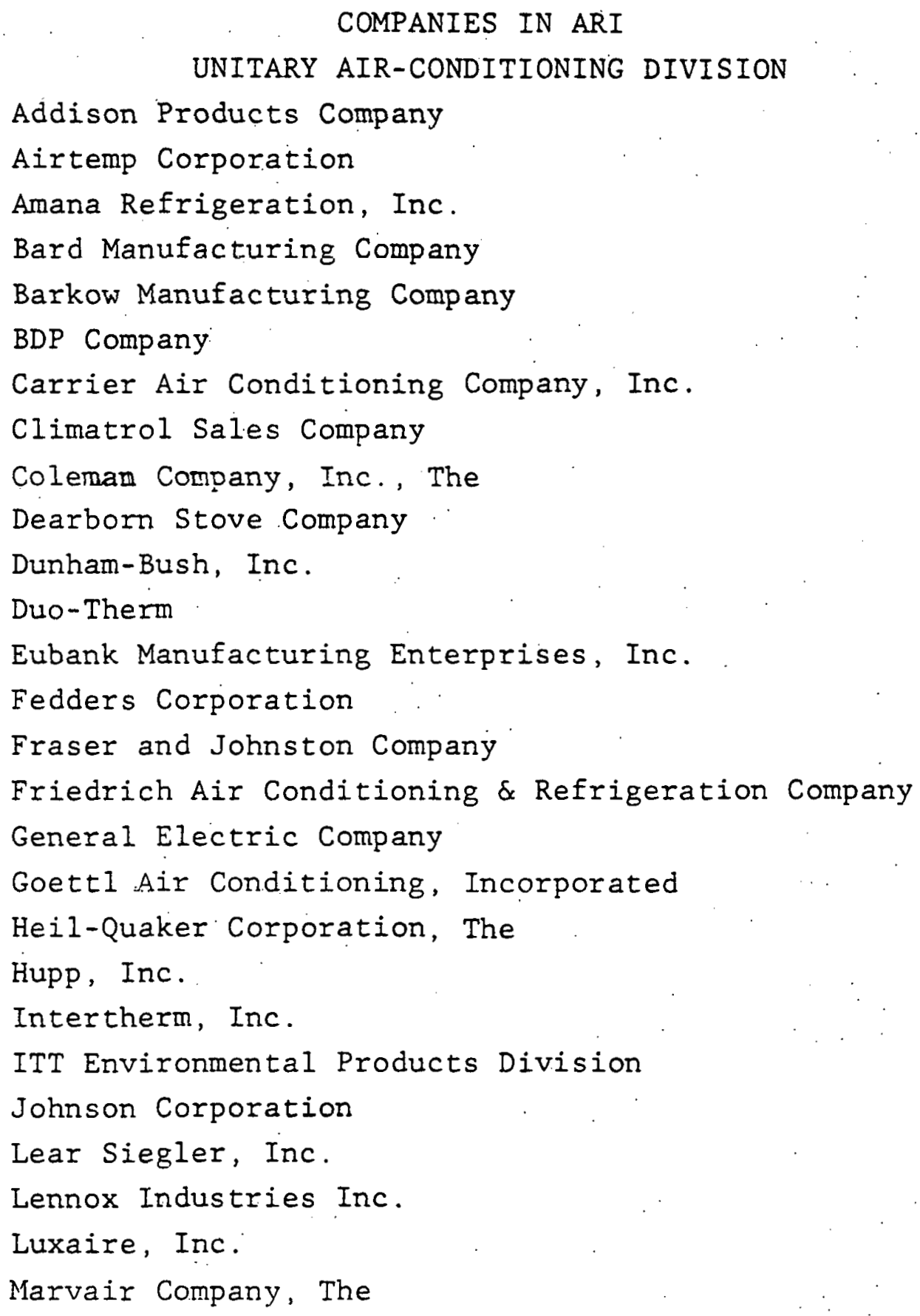


McGraw-Edison Company

McQuay Group

Northrup, Inc.

Rheem Manufacturing Company

Singer Company, The

Southwest Manufacturing

Sterling Radiator Division

Square D Company. The

Tappan Company

Trane Company: Trie

Westinghouse Electric Corporation

Villiamson Company, The

York 


\author{
APPENDIX B \\ QUESTIONNAIRE \\ DOE TESTS FOR CENTRAL AIR CONDITIONERS
}

Return to: David R. Tree

Ray $W$. Herrick Laboratories

Purdue University

West Lafayette, Indiana 47907

\title{
BACKGROUND
}

1. Company Name

2. Person's Name Preparing the Questionnaire

3. Have you attempted successfully or unsuccessfully to make the following measurements according to the DOE Standard?

$\begin{array}{ll}\text { Type A } & \text { Yes } \\ \text { Type Bo } & \text { Yes } \\ \text { Type C } & \text { No }- \\ \text { Type D } & \text { Yes }=\text { No }=\end{array}$

4. Do you now have facilities that can make according to DOE Standards the following tests?

Type A

Type $B$

Type $C$

Type D

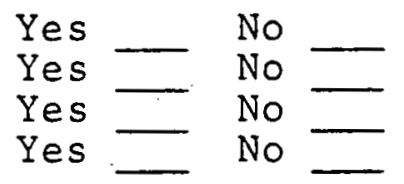

IF ANSWER TO ANY PART OF QUESTION 4 IS NO

5. Do you think present facilities can be modified to accomplish all four tests? Yes _ No _ 
6. Do you have plans to modify present facilities?

Yes _ No _

IF PRESENT FACILITIES CAN NOT BE MODIFIED TO CONDUCT ALL OF DOE TESTS OR IF YOU DO NOT HAVE ENOUGH FACILITIES

7. Do you have plans to construct new test facilities?

Yes _ No

8. If yes, expected date of completion.

$\overline{\text { Month Year }}$

IF ANSWER TO ANY PART OF QUESTION 4 IS YES

9. Have you made according to DOE Standards any of the following measurements?

Type A Yes _ No _., If yes no. units tested

Type B Yes - No - If yes no. units tested

Type C Yes — No - If yes no. units tested

Type D Yes - No - If yes no. units tested

IF FACILITIES ARE AVAILABLE OR ARE TO BECOME AVAILABLE

10. Do you plan to make before December 1, 1978 any more of the following tests?

Type A Yes _ No _. If yes approx. no. units

Type $B$ Yes $\longrightarrow$ No $\longrightarrow$, If yes approx. no. units

Type $C$ Yes - No - , If yes approx. no. units

Type D Yes - No - If yes approx. no. units

IF YOU HAVE ATTEMPTED TO MAKE SUCCESSFULLY OR UNSUCCESSFULLY ANY MEASUREMENTS ACCORDING TO DOE STANDARDS HAVE YOU HAD ANY OF THE FOLLOWING PROBLEMS?

11. Obtaining set point for either room. Yes _ No If yes, explain (type test A, B, C, D, problem)

12. Holding temperatures as outlined. Yes No If yes., explain (type test, problem) 
13. Holding Relativity Humidity. Yes _ No _ If yes, explain (type test, problem)

14. Any other problems.

IF YOU HAVE MADE ANY MEASUREMENTS ACCORDING TO DOE TEST STANDARDS,

15. Approximately how long does it take to make a complete run?
a) Set up plus $A$ and $B$ only (time)
b) Set up plus A, B, C, and D (time)

16. How many units are needed to meet the confidency level?
a) $A$ and $B$ type tests (number)
b) C and D type tests (number)

17. Have you submitted data taken to Herrick Laboratories?

Yes No

If no, do you plan to submit data?

Yes No

If. yes, by (date)

18. If and when it becomes mandatory to report SEER, how do you plan to obtain SEER?
a) Measure all data necessary
b) Measure only $A$ and $B$ and use $C_{D}=0.25$
C) Other (explain) 
APPENDIX $C$ TEST ROOM CONFIGURATIONS FROM ASHRAE STANDARD 37-69 


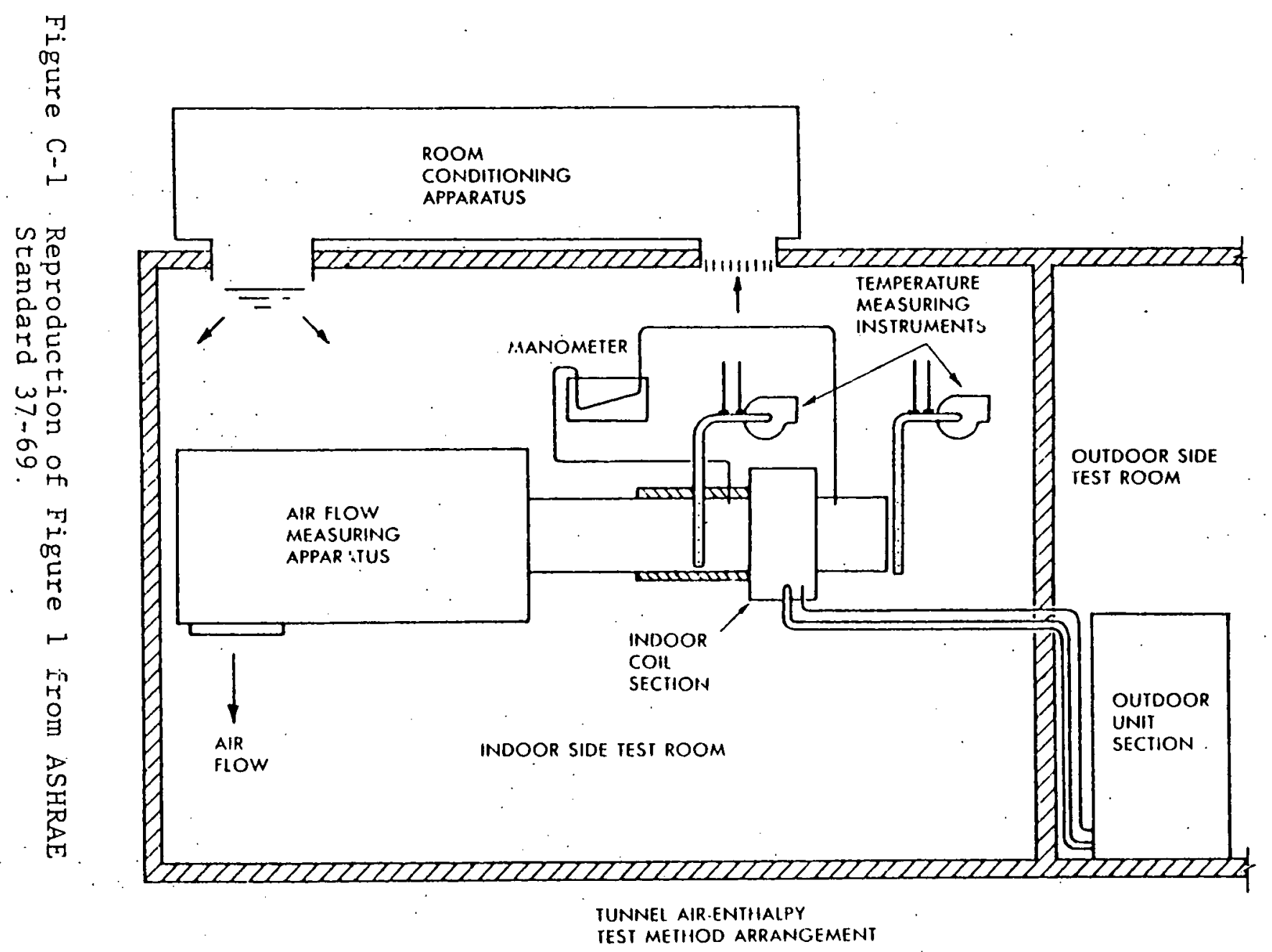




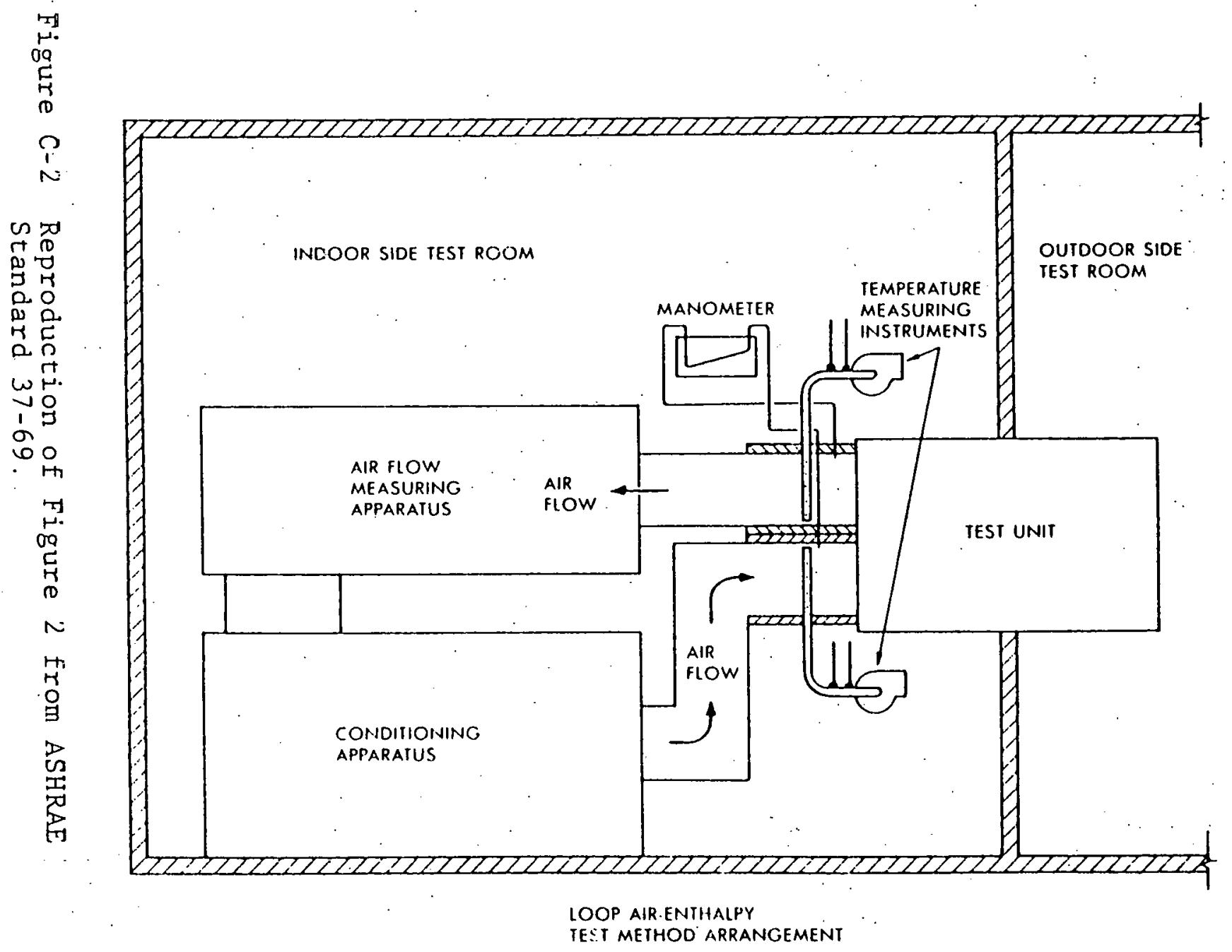




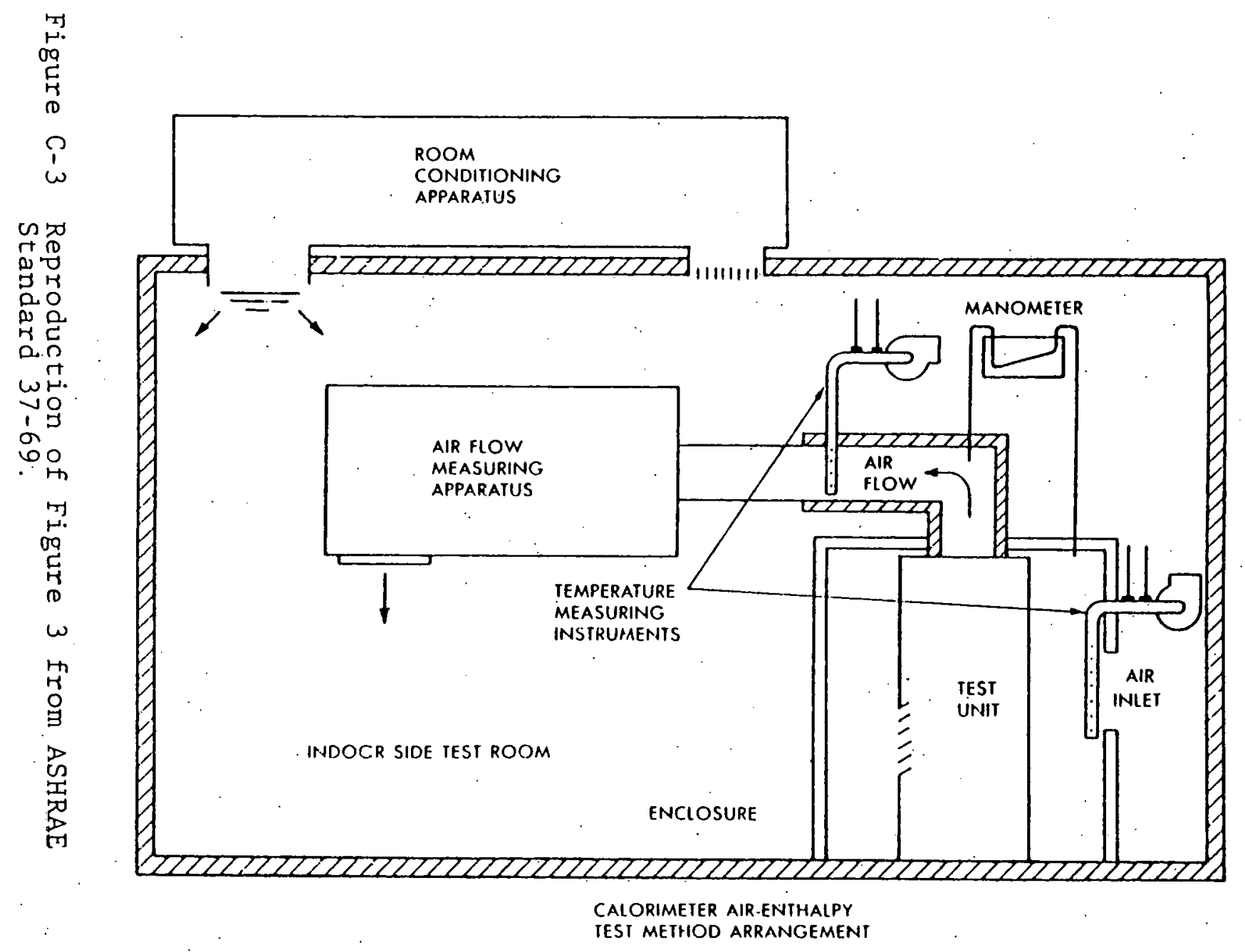




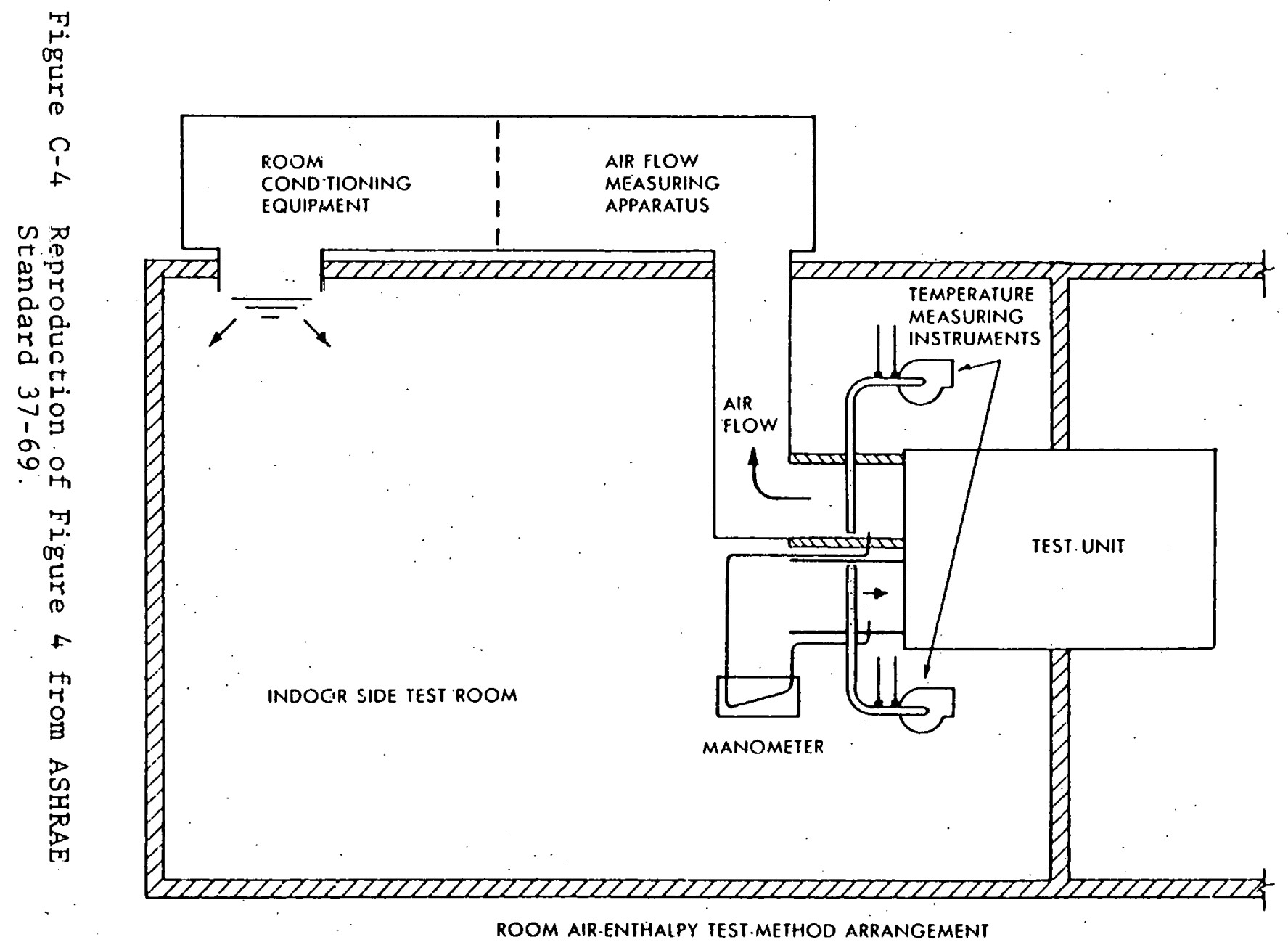


APPENDIX D

EXPERIMENTAL DATA 
Table D-1 Experimental Data

\begin{tabular}{|c|c|c|c|c|c|c|c|}
\hline & EERPA & EERB & EERC & EERD & SEER & $C D$ & $P L F(0.5)$ \\
\hline 1: & 7.26 & 8.02 & 7.21 & 6.63 & 7.63 & .10 & .95 \\
\hline 2: & 6.30 & 7.35 & 6.65 & 5.83 & 6.81 & .15 & .93 \\
\hline 3: & 6.43 & 7.36 & 6.82 & 5.75 & 6.67 & .19 & .91 \\
\hline 4: & 6.51 & 7.32 & 6.86 & 5.03 & 6.79 & .14 & .53 \\
\hline 5: & 6.53 & 7.31 & 6.73 & 5.11 & 6.91 & .11 & .94 \\
\hline 6: & 6.77 & 7.84 & 7.58 & 6.47 & 7.10 & .19 & .91 \\
\hline 7: & 7.01 & 7.90 & 7.36 & 6.19 & 7.14 & .19 & .90 \\
\hline 8: & 6.54 & 7.39 & 6.79 & 6.24 & 7.03 & .10 & .95 \\
\hline 9: & 6.11 & 6.94 & 6.32 & 5.93 & 6.68 & .07 & .96 \\
\hline 10: & 5.09 & 5.95 & 6.31 & 6.04 & 6.78 & .05 & .97 \\
\hline 11: & 7.12 & 7.92 & 7.14 & 6.73 & 7.64 & .07 & .97 \\
\hline 12: & 7.09 & 7.89 & 7.24 & 5.66 & 7.51 & .10 & .95 \\
\hline 13: & 6.16 & 7.05 & 5.47 & 5.05 & 6.80 & .07 & .96 \\
\hline $14:$ & 7.32 & 8.12 & 7.32 & 5.28 & 7.43 & .17 & .91 \\
\hline 15: & 8.48 & 9.16 & 8.54 & 7.60 & 8.56 & .13 & .93 \\
\hline 16: & 8.20 & 9.04 & 8.17 & 7.16 & 8.38 & .15 & .83 \\
\hline 17: & 8.99 & 9.95 & 9.00 & 7.70 & 9.10 & .17 & .91 \\
\hline 18: & 7.56 & 8.22 & 7.33 & 6.88 & 7.92 & .07 & .96 \\
\hline 19: & 8.68 & 9.49 & 8.80 & 7.54 & 8.68 & .17 & .91 \\
\hline $20:$ & 7.19 & 8.02 & 7.46 & 5.75 & 7.56 & .11 & .94 \\
\hline 21: & 7.04 & 8.02 & 7.32 & 6.41 & 7.43 & .15 & .93 \\
\hline ट2: & 7.08 & 8.20 & 7.50 & 5.57 & 6.95 & .30 & .85 \\
\hline ट3: & 6.83 & 8.70 & 5.98 & 5.63 & 6.81 & .23 & .88 \\
\hline 24: & 6.65 & .7 .64 & 7.00 & 5,57 & 8.71 & .24 & .88 \\
\hline 25: & 6.55 & 7.38 & 6.74 & 5.07 & 6.94 & .12 & .94 \\
\hline 26: & 7.09 & 8.14 & 7.26 & 5.81 . & 7.84 & .07 & .95 \\
\hline
\end{tabular}




\begin{tabular}{|c|c|c|c|c|c|c|c|}
\hline $27:$ & 6.19 & 7.09 & 6.57 & 6.00 & 6.72 & .10 & .95 \\
\hline 28: & 7.10 & 8.03 & 7.46 & 7.13 & 7.81 & .05 & .97 \\
\hline 29: & 8.51 & 3.48 & 8.77 & 8.02 & 9.00 & .10 & \\
\hline $30:$ & 7.89 & 8.76 & 7.73 & 7.41 & 8.54 & .05 & 9 \\
\hline 31: & 8.78 & 9.84 & 9.12 & 8.23 & 9.27 & .12 & .9 \\
\hline 32: & 8.27 & 9.41 & 8.68 & 8.19 & 9.09 & .07 & \\
\hline 33: & 7.44 & 8.04 & 7.60 & 5.78 & 6.91 & .28 & .8 \\
\hline 34: & 7.52 & 8.47 & 7.26 & 5.94 & 7.54 & .22 & .8 \\
\hline 35: & 7.47 & 8.30 & 7.23 & 5.93 & 7.40 & .22 & \\
\hline 36: & 7.36 & 8.19 & 7.23 & 5.84 & 7.24 & .23 & .88 \\
\hline 37: & 7.16 & 8.13 & 6.72 & 5.69 & $? .3 ?$ & .19 & 9. \\
\hline 38: & 7.34 & 8.34 & 6.96 & 5.80 & 7.50 & .20 & .96 \\
\hline 39: & 7.11 & 8.22 & 6.62 & 5.68 & 7.51 & .17 & .9 \\
\hline 40: & 7.50 & 8.17 & P.22 & 5.85 & 7.24 & .23 & .8 \\
\hline 41: & 7.39 & 8.14 & 7.15 & 6.04 & 7.37 & .19 & .91 \\
\hline 42: & 7.45 & 8.23 & 7.43 & 5.99 & 7.27 & .23 & .88 \\
\hline 43: & 7.56 & 8.56 & 7.07 & 6.12 & 7.85 & .16 & .92 \\
\hline 44: & 7.46 & 8.40 & 6.85 & 5.82 & 7.63 & .18 & .91 \\
\hline 45: & 7.62 & 8.67 & 7.53 & 6.20 & 7.74 & .21 & .89 \\
\hline 46: & 6.56 & 7.28 & 6.55 & 5.54 & 6.60 & .19 & .91 \\
\hline 47: & 6.61 & 7.37 & 6.66 & 5.64 & 6.68 & .19 & .91 \\
\hline 48: & 6.53 & 7.34 & 6.57 & 5.53 & 6.64 & .19 & .90 \\
\hline 49: & 6.38 & 7.28 & 6.42 & 5.46 & 6.62 & .18 & 91 \\
\hline 50: & 6.52 & 7.39 & 6.41 & 5.54 & 6.78 & .17 & - Se \\
\hline 51: & 6.51 & 7.31 & 6.40 & 5.49 & 6.68 & .17 & 91 \\
\hline 52: & 7.75 & 8.76 & 8.00 & 6.90 & 8.02 & .17 & 52 \\
\hline 53: & 7.97 & 8.91 & 8.05 & 5.78 & 8.06 & .19 & .9 \\
\hline
\end{tabular}




\begin{tabular}{|c|c|c|c|c|c|c|c|}
\hline 54: & 7.91 & 8.86 & 8.09 & 6.82 & 8.01 & .19 & .90 \\
\hline 55: & 7.44 & 8.67 & 7.40 & 5.84 & 7.57 & .25 & .87 \\
\hline 56: & 7.39 & 8.55 & 7.94 & 5.91 & 7.23 & .31 & .85 \\
\hline 57: & 7.53 & 8.85 & 7.69 & 6.06 & 7.72 & .26 & .87 \\
\hline 58: & 7.78 & 8.87 & 7.71 & 6.61 & 8.09 & .17 & .91 \\
\hline 59: & 7.90 & 8.96. & 7.71 & 6.59 & 8.16 & .18 & .91 \\
\hline 60: & 7.80 & 8.85 & 7.88 & 6.57 & 7.95 & .20 & .90 \\
\hline 61: & $? .46$ & 8.43 & 7.62 & 5.98 & 7.33 & .26 & .87 \\
\hline 62: & 7.48 & 8.62 & 7.52 & 5.80 & 7.43 & .28 & .86 \\
\hline 63: & 7.79 & 8.78 & 7.78 & 6.09 & 7.63 & .26 & .87 \\
\hline 64: & 8.11 & 8.98 & 7.85 & 6.34 & 7.94 & .23 & .88 \\
\hline 65: & 7.86 & 8.74 & 7.93 & 6.37 & 7.70 & .24 & .88 \\
\hline 66: & 7.78 & 8.69 & 7.75 & 6.15 & 7.61 & .25 & .88 \\
\hline 67: & 7.77 & 8.95 & 7.77 & 6.15 & 7.83 & .25 & .87 \\
\hline 68: & 7.89 & 8.98 & 7.81 & 6.32 & 7.94 & .23 & .88 \\
\hline E9: & 7.82 & 8.82 & $? .45$ & 6.04 & 7.81 & .23 & .89 \\
\hline $70:$ & 6.45 & 7.24 & 6.53 & 5.97 & 6.86 & .11 & .95 \\
\hline 71: & 7.39 & 8.50 & 7.37 & 6.74 & 8.06 & .10 & .95 \\
\hline 72: & 7.12 & 8.15 & 7.24 & .6 .24 & 7.47 & .17 & .92 \\
\hline $.73:$ & 7.13 & 8.02 & 7.14 & 6.33 & 7.47 & .14 & .93 \\
\hline $741^{\circ}$ & E.P1 & P. 48 & 6.96 & 6.52 & 7.19 & .08 & .96 \\
\hline 75: & 6.71 & 7.60 & 6.90 & 6.35 & 7.23 & .10 & .95 \\
\hline 76: & 6.55 & 8.12 & 6.73 & 6.39 & 7.87 & .06 & .97 \\
\hline 77: & 6.82 & 7.87 & 7.01 & 6.79 & 7.72 & .04 & .98 \\
\hline 78: & 6.98 & 7.89 & 7.16 & 6.78 & 7.63 & .07 & .97 \\
\hline 79: & 7.13 & 7.96 & 7.18 & 6.74 & 7.66 & .08 & .96 \\
\hline 30: & 7.00 & 7.92 & $7: 40$ & 6.86 & 7.57 & .09 & .96 \\
\hline 31: & 6.46. & 7.00 & 6.43 & 5.92 & 6.66 & .10 & .95 \\
\hline
\end{tabular}




\begin{tabular}{|c|c|c|c|c|c|c|c|}
\hline 82: & 6.03 & 6.74 & 6.15 & 5.84 & 6.53 & .08 & .97 \\
\hline 83: & 5.99 & 6.60 & 6.12 & 5.7 .3 & 5.34 & .08 & .95 \\
\hline 84: & 6.03 & 6.96 & 6.34 & 5.86 & 5.64 & .09 & .95 \\
\hline 85: & 5.14 & 6.96 & 6.17 & 5.85 & 6.75 & .06 & .97 \\
\hline 85: & 6.43 & P.02. & 6.44 & 5.82 & 6.61 & .12 & .94 \\
\hline 87: & 6.60 & 7.17 & 6.59 & 5.95 & 6.75 & .12 & .94 \\
\hline 88: & 6.14 & $6 . .95$ & 6.23 & 5.52 & 6.47 & .14 & .93 \\
\hline 89: & 6.10 & 5.94 & 6.17 & 5.51 & 6.49 & .13 & .93 \\
\hline 90: & 6.33 & 6.99 & 6.34 & 5.94 & 6.72 & .08 & .96 \\
\hline 91: & 6.37 & 7.14 & 6.40 & 5.99 & 6.86 & .08 & .96 \\
\hline SE: & 5.21 & 6.90 & 6.31 & 5.76 & 5.53 & .11 & .95 \\
\hline 93: & 6.29 & 7.01 & 6.44 & 6.15 & 6.82 & .06 & .97 \\
\hline 94: & 6.40 & 7.31 & 6.36 & 6.07 & 7.10 & .06 & $.9 ?$ \\
\hline 95: & 6.42 & 7.21 & 6.46 & 6.08 & 6.95 & .07 & .96 \\
\hline 96: & 8.99 & 9.75 & 9.15 & $8.0 ?$ & 9.05 & .14 & .93 \\
\hline 97: & 9.12 & 9.78 & 9.21 & 8.08 & 9.05 & .15 & .93 \\
\hline 98: & 8.06 & 9.41 & 8.50 & 7.36 & 8.65 & .16 & .92 \\
\hline 99: & 7.97 & 9.47 & 8.35 & 7.25 & 8.70 & .16 & .92 \\
\hline 100: & 8.11 & 9.38 & 8.42 & 7.71 & 8.90 & .10 & .95 \\
\hline 101: & 8.37 & 9.17 & 8.49 & 7.92 & 8.79 & .00 & .98 \\
\hline 102: & 7.77 & 8.48 & 8.13 & 7.39 & 8.01 & .11 & .94 \\
\hline 103: & 8.06 & 8.89 & 8.41 & 7.85 & 8.53 & .08 & .96 \\
\hline 104: & 7.71 & 8.80 & 7.99 & 7.54 & 8.50 & .07 & .97 \\
\hline 105: & 7.76 & 8.83 & 8.03 & 7.52 & 8.49 & .08 & .96 \\
\hline 106: & 8.72 & 9.38 & 8.97 & 8.28 & 8.94 & .09 & .95 \\
\hline 107: & 8.80 & 9.71 & 8.77 & 7.67 & 8.97 & .15 & .92 \\
\hline 108: & 8.40 & 9.68 & 9.07 & 8.35 & 9.21 & .10 & .95 \\
\hline
\end{tabular}




\begin{tabular}{|c|c|c|c|c|c|c|c|}
\hline 109: & 8.85 & 9.63 & 9.15 & 8.09 & 8.95 & .14 & .93 \\
\hline 110: & 8.86 & 9.92 & 9.33 & 8.50 & 9.38 & .11 & .9 \\
\hline 111: & 9.09 & 9.99 & 3.36 & 8.36 & 9.34 & .13 & $\cdot 9$ \\
\hline 112: & 8.77 & 9.70 & 9.22 & 8.11 & 8.99 & .15 & .5 \\
\hline 113: & 8.43 & 9.58 & 8.66 & 8.33 & 9.36 & .05 & .5 \\
\hline 114: & 8.51 & 9.30 & 8.72 & 7.90 & 8.77 & .11 & .9 \\
\hline 115: & 8.40 & 9.68 & 9.15 & 7.80 & 8.82 & .18 & .9 \\
\hline 116: & 8.80 & 9.71 & 9.29 & 7.80 & 8.77 & .19 & .9 \\
\hline 117: & 8.72 & 9.38 & 9.08 & 7.80 & 8.58 & .17 & .5 \\
\hline 118: & 6.35 & $7.37^{\circ}$ & 6.79 & 6.16 & 5.95 & .11 & .9 \\
\hline 119: & 6.29 & 7.29 & 6.76 & 5.29 & 6.38 & .09 & .9 \\
\hline 120: & 6.83 & 7.44 & 5.90 & 5.26 & 7.02 & .11 & .9 \\
\hline 121: & 6.65 & 7.39 & 6.82 & 5.02 & 6.86 & .14 & .9 \\
\hline 122: & 6.53 & 7.28 & 6.71 & 6.14 & 6.90 & .10 & .0 \\
\hline 123: & 6.15 & 7.07 & 6.38 & 5.68 & 6.60 & .13 & .93 \\
\hline 124: & 6.10 & 7.12 & 6.35 & 5.36 & 6.45 & .19 & .91 \\
\hline 125: & 6.11 & 7.05 & 6.28 & 5.35 & 6.42 & .18 & .91 \\
\hline 126: & 5.95 & 7.00 & 6.61 & 6.04 & 6.63 & .10 & .95 \\
\hline 127: & 6.10 & 6.88 & 6.39 & $5: 71$ & 6.43 & .13 & .93 \\
\hline 128: & 6.10 & 6.85 & 6.42 & 8.31 & 6.78 & .02 & .99 \\
\hline 129: & 6.18 & 7.00 & 6.53 & 5.95 & 6.62 & .11 & .95 \\
\hline 130: & $6: 34$ & 7.08 & 6.66 & 6.29 & 6.84 & .07 & .97 \\
\hline 131: & 7.72 & 8.73 & 8.0 & 6.79 & 7.92 & .19 & .91 \\
\hline 132: & 7.73 & 8.97 & 8.28 & 6.85 & 8.04 & .21 & .90 \\
\hline 135: & 1.77 & 7.99 & 7.99 & 6.80 & 7.27 & .18 & .91 \\
\hline 134: & 7.94 & 8.85 & $8.5 C$ & 7.13 & 7.95 & .20̊ &.$y 0$ \\
\hline 135: & 7.82 & 9.13 & 8.18 & 7.15 & 8.43 & .15 & .92 \\
\hline 136: & 8.00 & 9.56 & 8.41 & 7.78 & 9.12 & .09 & .95 \\
\hline
\end{tabular}




\begin{tabular}{|c|c|c|c|c|c|c|c|}
\hline 137: & 7.90 & 9.02 & 8.08 & 5.71 & $8: 10$ & .20 & .90 \\
\hline 138: & 7.76 & 8.58 & 8.16 & 7.32 & 8.04 & .13 & .94 \\
\hline 139: & 7.68 & 8.47 & 6.91 & 6.33 & 8.04 & .10 & \\
\hline 140: & 7.60 & 9.01 & 8.18 & 7.60 & 8.62 & .09 & .9 \\
\hline 141: & 7.71 & 9.10 & 8.03 & 7.39 & 8.66 & .10 & \\
\hline 142: & 6.85 & 8.34 & 7.18 & 6.64 & 7.95 & .09 & .9 \\
\hline 143: & 7.30 & 8.44 & 7.49 & 6.48 & 7.75 & .16 & .9 \\
\hline 144: & 7.15 & 8.34 & 7.52 & 6.57 & 7.64 & .17 & \\
\hline 45: & 7.24 & 8.16 & 7.53 & 7.08 & 7.85 & .07 & \\
\hline 146: & 7.30 & 7.94 & 7.78 & 7.19 & 7.57 & .09 & .9 \\
\hline 147: & 6.74 & 8.45 & 7.33 & 6.69 & 8.01 & .11 & .5 \\
\hline 148: & $6 . E 9$ & 8.34 & 7.35 & 6.70 & 7.89 & .11 & \\
\hline 49: & 6.65 & 8.12 & 7.07 & 6.26 & 7.56 & .14 & .9 \\
\hline 150: & 7.16 & 8.67 & 7.59 & 6.52 & 7.93 & .17 & .91 \\
\hline 151: & 6.97 & 8.36 & 7.27 & 5.93 & 7.44 & .22 & .89 \\
\hline 152: & $7.0 ?$ & 8.37 & 7.14 & 6.01 & 7.57 & .19 & .90 \\
\hline 153: & 6.57 & 8.07 & 7.33 & 6.15 & 7.30 & .19 & .90 \\
\hline 154: & 6.38 & 7.44 & 6.65 & 5.92 & 5.94 & .13 & .93 \\
\hline 155: & 6.26 & 7.34 & 6.43 & 6.10 & 7.11 & .06 & .97 \\
\hline 156: & 7.31 & 8.42 & 7.60 & 0.83 & $\vec{P} \cdot 30$ & .12 & .94 \\
\hline 157: & 7.17 & 8.37 & 7.69 & 6.85 & 7.81 & .13 & .93 \\
\hline 158: & 6.71 & 7.71 & 7.02 & 6.22 & 7.17 & .14 & .93 \\
\hline 159: & 7.09 & 8.19 & 6.65 & 6.25 & 7.89 & .07 & .96 \\
\hline 150: & ร. 5.9 & 7.89 & $7: 18$ & 6.72 & 7.58 & .00 & .96 \\
\hline 161: & 7.02 & 8.13 & 7.36 & 5.41 & 7.49 & .16 & \\
\hline 162: & 7.05 & 7.95 & 7.18 & 6.89 & 7.75 & .05 & \\
\hline 163: & 7.22 & 8.40 & 7.49 & 5.55 & 8.03 & .09 & \\
\hline
\end{tabular}




$\begin{array}{lllllll}164: 6.67 & 7.90 & 7.27 & 5.72 & 7.54 & .09 & .95 \\ 165: 5.16 . & 7.77 & 6.37 & 6.00 & 7.49 & .07 & .95 \\ 166: 5.91 & 7.73 & 6.73 & 5.96 & 7.20 & .14 & .93\end{array}$


APPENDIX E

DERIVATION OF LEAST SQUARES METHOD FOR THE DEGRADATION COEFFICIENT $C_{D}$

The equations for fitting a straight line to the data points without any restrictions can be found in almost any elementry statistical analysis book. To obtain the "best fit" that will go through $(1,1)$, the theory of least squares has to be applied to the line

$y=(1-b)+b x+\varepsilon$

where

$$
\begin{aligned}
b & =\text { slope } \\
\varepsilon & =\text { deviation }
\end{aligned}
$$

According to the method of least squares, the total sum of squares of deviation $E$ is given by

$E=\sum_{i=1}^{n} \varepsilon_{i}^{2}=\sum_{i=1}^{n}\left[y_{i}-b x_{i}-(1-b)\right]^{2}$

where

$$
\left(x_{i}, y_{i}\right) \text { are the data points. }
$$

Taking the derivative with respect to the slope and setting equal to zero, and writing $\sum y$ for $\sum_{i=1} y_{i}$, $\sum x y$ for $\sum_{i=1} x_{i} y_{i}$; etc., the following is obtained after simplifying

$b=\frac{\Sigma y x-\sum y-\sum x+n}{\Sigma x^{2}-2 \sum x+n}$ 
where

$$
\begin{array}{ll}
\mathrm{y} \equiv \mathrm{PLF} & \mathrm{b} \equiv \mathrm{C}_{\mathrm{D}} \\
\mathrm{x} \equiv \mathrm{CLF} . & \mathrm{n}=\text { total number of points }
\end{array}
$$

Hence, Eqn. E-3 can be applied to obtain the best possible slope (i.e., degradation coefficient) when PLF is plotted against CLF. 


\section{APPENDIX $F$ \\ RESULTS OF SEER AND DEVA ANALYSIS \\ FOR 166 UNITS}

The following definitions will be helpful:

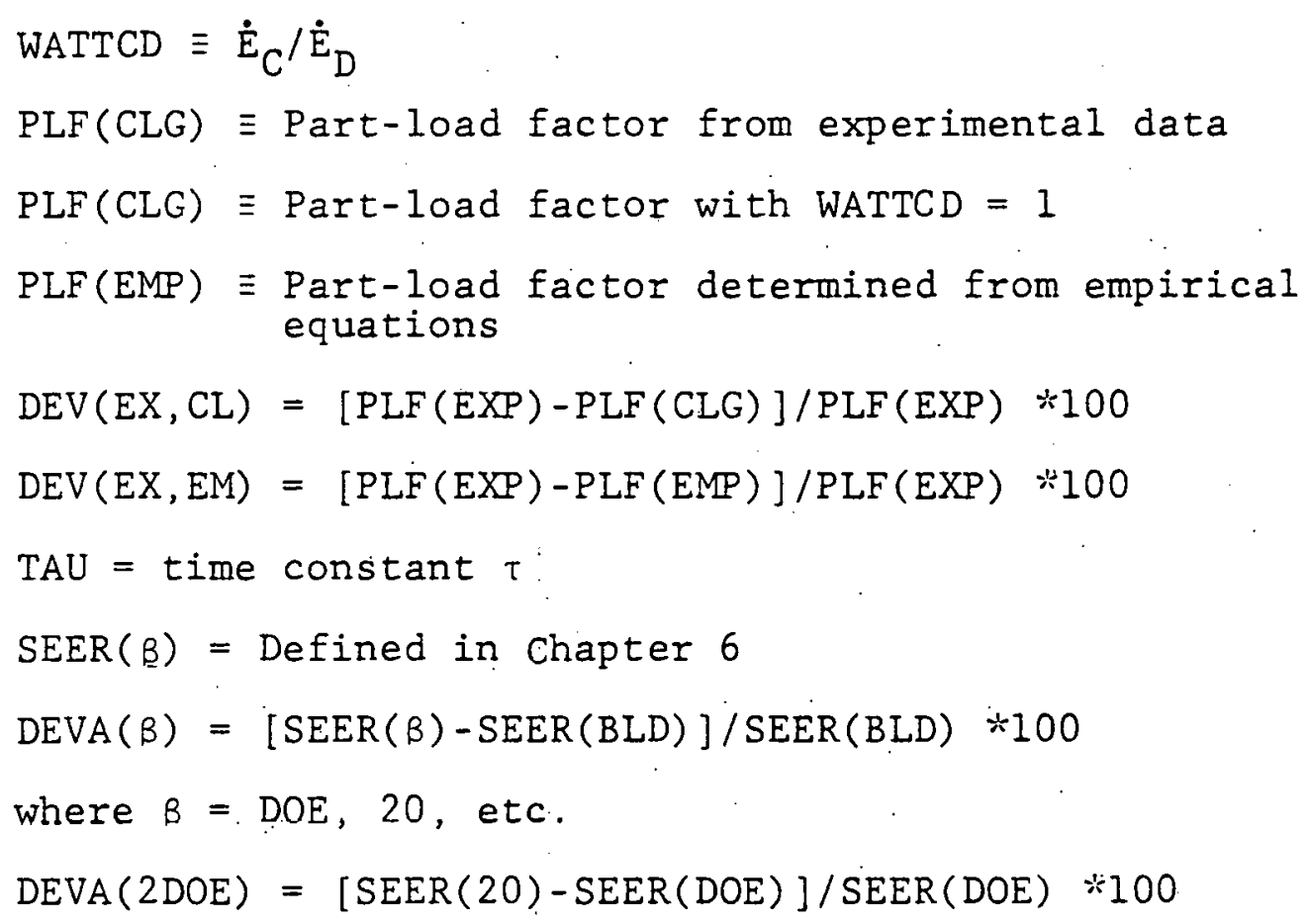


Table F-1 Power Consumption Ratio

\begin{tabular}{|c|c|c|c|c|c|c|c|}
\hline & WATTCD & $P L F(E X P)$ & PLF(CLG) & $\operatorname{PLF}(E M P)$ & $\mathrm{DEU}(E X, C L)$ & $D E U(E X, E M)$ & TAU \\
\hline 1: & 1.0144 & .9197 & .9066 & .9197 & 1.4225 & -.0002 & .5606 \\
\hline $2:$ & 1.0446 & .8771 & .8400 & .8774 & 4.2303 & -.0373 & .5619 \\
\hline 3: & 1.0302 & .8442 & .8201 & .3449 & 2.8481 & -.0867 & 1.0834 \\
\hline 4: & 1.0733 & .8790 & .8197 & .8798 & 6.7438 & -.0880 & 1.0859 \\
\hline 5: & 1.0843 & .9046 & .8347 & .9051 & 7.7334 & -.0476 & .9943 \\
\hline 6: & 1.0169 & .8434 & .8299 & .8439 & 1.6033 & -.0586 & 1.0236 \\
\hline 7: & .9497 & .8415 & .8860 & .8415 & -5.2931 & -.0020 & .9840 \\
\hline 8: & 1.0715 & .9193 & .8581 & .9194 & 6.6559 & -.0145 & .9522 \\
\hline 9: & 1.0857 & .9387 & .8647 & .9388 & 7.8818 & -.0097 & .8124 \\
\hline 10: & 1.0954 & .9574 & .8740 & .9575 & 8.7065 & -.0052 & .7550 \\
\hline 11: & 1.0881 & .9434 & .8671 & .9435 & 8.0919 & -.0083 & .7979 \\
\hline 12: & 1.0825 & .9201 & .8502 & .9203 & 7.5995 & -.0225 & .9001 \\
\hline 13: & 1.0828 & .9409 & .8691 & .9410 & 7.6356 & -.0073 & .7859 \\
\hline 14: & 1.0225 & .8578 & .8393 & .3582 & 2.1601 & -.0385 & .9561 \\
\hline 15: & 1.1370 & .8892 & .7842 & .3917 & 11.3028 & -.2837 & 1.3073 \\
\hline 16: & 1.1236 & .8764 & .7823 & .8790 & 10.7343 & -.2995 & 1.3201 \\
\hline 17: & 1.1050 & .8555 & .7769 & .8584 & 9.1857 & -.3481 & 1.3549 \\
\hline 18: & 1.1166 & .9380 & .8403 & .9383 & 10.4103 & -.0368 & .9600 \\
\hline 19: & 1.0705 & .8564 & .8013 & .8579 & 6.4314 & -.1685 & 1.2000 \\
\hline $20:$ & 1.0721 & .9049 & .8443 & .3052 & 6.7005 & -.0304 & .9355 \\
\hline 21: & 1.0870 & .8761 & .8071 & .8773 & 7.8721 & -.1390 & 1.1640 \\
\hline 22: & .9713 & .7427 & .7681 & .7460 & -3.4094 & -.4390 & 1.4118 \\
\hline 23: & .9957 & .8065 & .8110 & .3075 & -.5551 & -.121 .5 & 1.1400 \\
\hline 24: & .9849 & .7954 & .8087 & .7964 & -1.6693 & -.1318 & 1.1544 \\
\hline 25: & 1.0688 & .9004 & .8428 & .9007 & 6.4065 & -.0327 & .9451 \\
\hline 26: & 1.0996 & .9382 & .8534 & .9384 & 9.0418 & $=.0 .189$ & .2808 \\
\hline 27: & 1.0869 & .9136 & .8409 & .9140 & 7.9598 & -.0357 &.$\$ 563$ \\
\hline
\end{tabular}




\begin{tabular}{|c|c|c|c|c|c|c|c|}
\hline 28: & 1.0900 & .9560 & .8771 & $.9561^{\circ}$ & 8.2518 & -.0041 & .7374 \\
\hline 29: & 1.1184 & .9149 & .8188 & .9157 & 10.5088 & -.0914 & 1.0919 \\
\hline 30: & 1.1265 & .9575 & .8502 & .9578 & 11.2109 & -.0225 & .9000 \\
\hline $31:$ & 1.1256 & .9026 & .8032 & .9040 & 11.0140 & -.1586 & 1.1886 \\
\hline 32: & 1.1379 & .9429 & .8291 & .9434 & 12.0668 & -.0805 & 1.0284 \\
\hline 33: & 1.0133 & .7600 & .7546 & .7646 & .7068 & -.6104 & 1.4999 \\
\hline 34: & .9610 & .8192 & .8526 & .8193 & -4.0841 & -.0197 & .8852 \\
\hline $35:$ & .9654 & .8197 & .8493 & .8159 & -3.6049 & -.0235 & .9054 \\
\hline 36: & .9549 & .8080 & .8464 & .8082 & -4.7540 & -.0273 & .9230 \\
\hline $37:$ & .9398 & .8466 & .9009 & .8466 & -6.4068 & -.0005 & .5948 \\
\hline 38: & .9396 & .8330 & .8866 & .8331 & -6.4312 & -.0019 & .5804 \\
\hline 39: & .9451 & .8579 & .9078 & .8579 & -5.8084 & -.0002 & .5534 \\
\hline $40:$ & .9600 & .8097 & .8437 & .8100 & -4.1592 & -.0312 & .9392 \\
\hline 41: & .9613 & .8449 & .8789 & .8449 & -4.0276 & -.0036 & .7265 \\
\hline $42:$ & .9594 & .8067 & .8412 & .8070 & -4.2667 & -.0353 & .9548 \\
\hline 43: & .9481 & .8657 & .9130 & .8657 & -5.4696 & -.0001 & . 5220 \\
\hline 44: & .9448 & .8502 & .8998 & .8502 & -5.8393 & -.0005 & .6013 \\
\hline 45: & .9512 & .8234 & .8657 & .8235 & -5.1387 & -.0091 & .8062 \\
\hline 46: & .9695 & .8451 & .8718 & .3452 & -3.1540 & -.0061 & .7697 \\
\hline 47: & .9591 & .8477 & .8839 & .3477 & -4.2679 & -.0024 & .5 .970 \\
\hline 48: & .9636 & .8409 & .8727 & .8409 & -3.7856 & -.0057 & .7539 \\
\hline $49:$ & .9595 & .8504 & .8863 & .8504 & -4.2230 & -.0019 & .6821 \\
\hline 50: & .9497 & .8632 & .9089 & .8632 & -5.2918 & -.0002 & .5467 \\
\hline 51: & .9526 & .8571 & .3998 & .8571 & -4.9751 & -.0005 & .6015 \\
\hline 52: & .9493 & .8628 & .9089 & .8628 & -5.3437 & -.0002 & .5467 \\
\hline 53: & .9495 & $.84 こ 2$ & .8870 & .8422 & -5.3200 & -.0018 & .5782 \\
\hline 54: & .9393 & .8435 & .8980 & .8435 & -5.4655 & -.0006 & .6119 \\
\hline
\end{tabular}




\begin{tabular}{|c|c|c|c|c|c|c|c|}
\hline 55: & .9204 & .7894 & .8578 & .7895 & -8.6666 & -.0148 & .6541 \\
\hline 56: & .8621 & .7442 & .8633 & .7443 & -16.0040 & -.0105 & .8206 \\
\hline 57: & .9274 & .7887 & .8506 & .7888 & -7.8565 & -.0220 & .8974 \\
\hline 58: & .9350 & .8583 & .9180 & .8583 & -6.9561 & -.0000 & .4918 \\
\hline 59: & .9334 & .8552 & .9152 & .8552 & -7.1335 & -.0001 & .5030 \\
\hline 60: & .9148 & .8339 & .9116 & .8339 & -9.3119 & -.0001 & .5305 \\
\hline 61: & .9140 & .7849 & .8589 & .7850 & $-9.4 \approx 36$ &.-.0139 & .8476 \\
\hline 62: & .9115 & .7713 & .8464 & .7715 & -9.7422 & -.0273 & .5230 \\
\hline 63: & .9177 & .7823 & .8526 & .7324 & -8.5935 & -.0197 & .8854 \\
\hline 64: & .9315 & .8075 & .8670 & .8076 & -7.3637 & -.0084 & .7986 \\
\hline 65: & .9317 & .8032 & .8622 & .8032 & -7.3467 & -.0114 & .3275 \\
\hline 66: & .9171 & .7930 & .8647 & .7931 & -9.0476 & -.0097 & .8120 \\
\hline 67: & .9171 & .7932 & .8550 & .7933 & -3.0474 & -.0095 & .8107 \\
\hline 68: & .9213 & .8094 & .8786 & .8095 & -8.5405 & -.0037 & .7287 \\
\hline 69: & .9188 & .8098 & .8815 & .8098 & -8.8446 & -.0029 & .7114 \\
\hline $70:$ & .9784 & .9148 & .9351 & $.9 ! 48$ & -2.2125 & -.0000 &.$\unlhd 397$ \\
\hline $71:$ & .9996 & .9145 & .9149 & .9145 & -.0353 & -.0001 & .5108 \\
\hline $72:$ & .9873 & .8625 & .8736 & .8625 & -1.2883 & -.0053 & .7586 \\
\hline 73: & .9852 & .8871 & .9004 & .8871 & -1.5030 & -.0005 & .5975 \\
\hline 74: & 1.0272 & .9367 & .9119 & .9367 & 2.6474 & -.0001 & .5288 \\
\hline $75:$ & 1.0197 & .9202 & .9025 & .9202 & 1.9285 & -.0004 &.$\Xi 052$ \\
\hline 76: & 1.0261 & .9493 & .9252 & .9493 & 2.5391 & -.0000 & .4486 \\
\hline $77:$ & 1.0000 & .9688 & .9688 & .9688 & .0000 & .0000 & .1874 \\
\hline 78: & 1.0088 & .9461 & .9378 & .9461 & .8700 & -.0000 & $.37 \approx 9$ \\
\hline 79: & 1.0028 & .9381 & .9355 & .9381 & .2789 & -.0000 & .3873 \\
\hline 80: & 1.0375 & .9264 & .8929 & .9264 & 3.6163 & -.0011 & .5425 \\
\hline 81: & 1.0258 & .9201 & .8969 & .9201 & 2.5122 & -.0007 & .5184 \\
\hline 82: & 1.0215 & .9492 & .9292 & .9492 & 2.1077 & -.0000 & 19 \\
\hline
\end{tabular}




\begin{tabular}{|c|c|c|c|c|c|c|c|}
\hline 83: & 1.0140 & .9362 & .9233 & .9362 & 1.3788 & -.0000 & .4601 \\
\hline 84: & 1.0098 & .9238 & .9148 & .3238 & .9708 & -.0001 & .5112 \\
\hline 85: & 1.0163 & .9490 & .9338 & .9490 & 1.6014 & -.0000 & .3974 \\
\hline 86: & 1.0131 & .9026 & .8909 & .9026 & 1.2903 & -.0013 & .6545 \\
\hline 87: & 1.0145 & .9030 & .8901 & .9030 & 1.4290 & -.0014 & .6597 \\
\hline 88: & .9837 & .8867 & .9014 & .8867 & -1.6614 & -.0004 & .5914 \\
\hline 89: & .9829 & .8924 & .9079 & .8924 & -1.7436 & -.0002 & .5525 \\
\hline 90: & 1.0284 & .9360 & .9102 & .9360 & 2.7612 & -.0001 & .5390 \\
\hline 91: & 1.0102 & .9360 & .9265 & .9360 & 1.0134 & -.0000 & .4410 \\
\hline 92: & 1.0000 & .9136 & .9136 & .9136 & -.0001 & -.0001 & .5184 \\
\hline 93: & 1.0269 & .9552 & .9301 & .9552 & 2.6208 & -.0000 & .4192 \\
\hline 94: & 1.0169 & .9548 & .9389 & .9548 & 1.5620 & -.0000 & .3666 \\
\hline 95: & .9908 & .9418 & .9505 & .9418 & -.9247 & -.0000 & .2972 \\
\hline 96: & 1.0150 & .8822 & .8692 & .8822 & 1.4686 & -.0072 & .7851 \\
\hline 97: & 1.0137 & .8763 & .8646 & .8764 & 1.3435 & -.0098 & .3131 \\
\hline 98: & .9970 & .8657 & .8684 & .8658 & -.3054 & -.0076 & .7902 \\
\hline 99: & .9728 & .8678 & .8921 & .8679 & -2.7969 & -.0011 & .6474 \\
\hline 100: & 1.0082 & .9146 & .9072 & .9146 & .8082 & -.0002 & .5565 \\
\hline 101: & 1.0140 & .9324 & .9196 & .9324 & 1.3782 & -.0000 & .4825 \\
\hline 102: & 1.0048 & .9090 & .9047 & .9090 & .4767 & -.0003 & .5719 \\
\hline 103: & 1.0480 & .9337 & .8909 & .9337 & 4.5777 & -.0013 & .6545 \\
\hline 104: & 1.0323 & .9444 & .9149 & .9444 & 3.1303 & -.0001 & .5108 \\
\hline 105: & 1.0262 & .9365 & .9126 & .9365 & 2.5527 & -.0001 & .5243 \\
\hline 106: & 1.0062 & .9231 & .9174 & .9231 & .6141 & -.0000 & .4954 \\
\hline 107: & .9599 & .8754 & .9119 & .8754 & -4.1782 & -.0001 & . ت283 \\
\hline 108: & .9981 & .9209 & .9227 & .9209 & -.1954 & -.0000 & .4640 \\
\hline 109: & 1.0091 & .8844 & .8764 & .8844 & .8966 & -.0043 & .7416 \\
\hline
\end{tabular}




\begin{tabular}{|c|c|c|c|c|c|c|c|}
\hline 110: & 1.0211 & .9111 & .8923 & .3111 & 2.0608 & -.0011 & .6462 \\
\hline 111: & 1.0328 & .8929 & .8646 & .8930 & 3.1587 & -.0097 & .8127 \\
\hline 112: & 1.0164 & .8796 & .8655 & .8797 & 1.6057 & -.0092 & .8076 \\
\hline 113: & 1.0410 & .9623 & .9244 & .9623 & 3.9361 & -.0000 & .4536 \\
\hline 114: & 1.0008 & .9058 & .9050 & .9058 & .0818 & -.0003 & .5698 \\
\hline 115: & .9981 & .8528 & .8546 & .8530 & -.2130 & -.0176 & .8731 \\
\hline 116: & .9599 & .8395 & .8746 & .8396 & -4.1833 & -.0045 & .7524 \\
\hline 117: & 1.0062 & .8590 & .8539 & .8532 & .5959 & -.0184 & .8774 \\
\hline 118: & 1.0056 & .9056 & .9006 & .9056 & .5520 & -.0005 & .5962 \\
\hline 119: & 1.0272 & .9835 & .9575 & .9835 & 2.6514 & -.0000 & .2553 \\
\hline 120: & .9787 & .9072 & .9269 & .9072 & -2.1803 & -.0000 & .4384 \\
\hline 121: & .9924 & .8831 & .8899 & .8831 & -.7692 & -.0014 & .6606 \\
\hline 122: & .9895 & .9144 & .9241 & .9144 & -1.0587 & -.0000 & .4552 \\
\hline 123: & .9766 & .8910 & .9123 & .8910 & -2.3977 & -.0001 & .5260 \\
\hline 124: & .9742 & .8432 & .8656 & .8433 & -2.5568 & -.0092 & .3069 \\
\hline 125: & .9760 & .8516 & .8726 & .8517 & -2.4597 & -.0057 & .7648 \\
\hline 126: & 1.0396 & .9136 & .8789 & .9136 & 3.8013 & -.0036 & .7270 \\
\hline 127: & .9633 & .8931 & .9272 & .8931 & -3.8090 & -.0000 & .4370 \\
\hline 128: & 1.0570 & .9823 & .9294 & .9823 & 5.3895 & -.0000 & .4236 \\
\hline 129: & .9982 & .9118 & .9227 & .9118 & -1.1917 & -.0000 & .4641 \\
\hline 130: & 1.0027 & .945 & .9426 & .9452 &.$\approx 673$ & -.0000 & .3442 \\
\hline 131: & 1.0043 & .8447 & .8414 & .8450 & .3926 & -.0349 & .9532 \\
\hline 132: & .9904 & .8273 & .8357 & .8277 & -1.0116 & -.0455 & .9881 \\
\hline 133: & .9906 & .8514 & .8596 & .8515 & -.9666 & -.0132 & .8429 \\
\hline 134: & .9705 & .8338 & .8593 & .8340 & -3.0518 & -.0135 & .8450 \\
\hline 135: & 1.0015 & .8870 & .8856 & .8370 & .1497 & -.0021 &.$\$ 863$ \\
\hline 136: & .9856 & .9255 & .9390 & .9255 & -1.4628 & -.0000 & .3658 \\
\hline 137: & .9741 & .8304 & .8526 & .8305 & -2.6818 & -.0197 & $.885 i$ \\
\hline
\end{tabular}




\begin{tabular}{|c|c|c|c|c|c|c|c|}
\hline 138: & .9987 & .8955 & .8966 & .8955 & -.1265 & -.0007 & .6203 \\
\hline 139: & 1.0739 & .9156 & .8527 & .9158 & 6.8623 & -.0196 & .3845 \\
\hline 140: & 1.0071 & .9143 & .9078 & .9143 & .7050 & -.0002 & .5532 \\
\hline 41: & 1.0162 & .9360 & .9210 & .9360 & 1.5980 & -.0000 & .4740 \\
\hline 42: & .9869 & .9243 & .9366 & .9243 & -1.3309 & -.0000 & .3802 \\
\hline 43: & .9759 & .8638 & .8852 & .8638 & -2.4713 & -.0021 & .5891 \\
\hline 44: & .9819 & .8624 & .8783 & .8624 & -1.8443 & -.0038 & .7305 \\
\hline 45: & 1.0525 & .9396 & .8928 & .5396 & 4.9827 & -.0011 & .5433 \\
\hline 46: & 1.0277 & .9241 & .8992 & .9241 & 2.6970 & -.0006 & .6048 \\
\hline 147: & 1.0074 & .9129 & .9062 & .9129 & .7336 & -.0002 & .5630 \\
\hline 148: & 1.0482 & .9101 & .8684 & .9102 & 4.5891 & -.0075 & .7501 \\
\hline 149: & 1.0296 & .8854 & .8601 & .8856 & 2.8607 & -.0129 & .8400 \\
\hline 150: & 1.0029 & .8600 & .8576 & .8601 & .2719 & -.0149 & .8549 \\
\hline 51: & .9966 & .8161 & .8196 & .2168 & -.4314 & -.0885 & 1.0867 \\
\hline 152: & 1.0075 & .8423 & .8364 & .8427 & .7031 & -.0440 & .9838 \\
\hline 53: & 1.0280 & .8405 & .8183 & .8412 & 2.6324 & -.0929 & 1.0945 \\
\hline 54: & .9859 & .8907 & .9035 & .8907 & -1.4298 & -.0003 & .5 \\
\hline 155: & .9832 & .9485 & .9647 & .9485 & -1.7082 & -.0000 & .2119 \\
\hline 156: & .9814 & .8991 & .9161 & .8991 & -1.5927 & -.0001 & .5036 \\
\hline 157: & .9916 & .8913 & $.8988^{\circ}$ & .8913 & -.8427 & -.0006 & .6072 \\
\hline 58: & .9786 & .8861 & .9055 & .8861 & -2.1835 & -.0003 & .5673 \\
\hline 9: & 1.0122 & .9406 & .9293 & .9406 & 1.2014 & -.0000 & .4242 \\
\hline 50: & 1.0632 & .9351 & .8795 & .9351 & 5.9374 & -.0034 & .7230 \\
\hline 161: & .9750 & .8705 & .8928 & .8705 & -2.5694 & -.0011 & .6430 \\
\hline 2: & 1.0417 & .9607 & . .2222 & .9607 & 4.0065 & -.0000 & .4669 \\
\hline 3: & 1.0318 & •9283 & .8997 & • 9283 & 3.0795 & -.0005 & .6017 \\
\hline & 1.0473 & .9238 & .8821 & . 9238 & 4.5101 & -.0028 & \\
\hline
\end{tabular}




\begin{tabular}{|c|c|c|c|c|c|}
\hline 165: 1.0039 & .9412 & .9376 & .9412 & .3866 & -.0000 \\
\hline 56: 1.0238 & .8851 & .8646 & .8852 & 2.3133 & -.0097 \\
\hline
\end{tabular}


Table F-2 Seasonal Energy Efficiency Ratio Calculated Using $\dot{E}_{C} / \overline{\dot{E}}_{D} \neq 1$ for all
Percent On-Times.

\begin{tabular}{|c|c|c|c|c|c|c|}
\hline SEER (DOE) & $\operatorname{SEER}(20)$ & $\operatorname{SEER}(50)$ & SEER2 $(50)$ & $\operatorname{SEER}(B L D)$ & $\operatorname{SESR}(E M P)$ & TAU \\
\hline $1: 7.626$ & 7.644 & 7.638 & 7.623 & $7 . \varepsilon 28$ & 7.629 & .5606 \\
\hline $2: 6.805^{\circ}$ & 6.835 & 6.823 & 6.785 & 6.763 & 6.797 & .9619 \\
\hline 3: 5.672 & 6.706 & 6.683 & 6.536 & 6.652 & 6.665 & 1.0834 \\
\hline 4: 0.794 & 6.830 & 6.820 & 6.777 & 6.779 & 6.800 & 1.0859 \\
\hline 5: 6.392 & 6.925 & 6.920 & 6.886 & 6.870 & 6.899 & .9943 \\
\hline $6: 7.100$ & 7.134 & 7.108 & 7.062 & 7.056 & 7.084 & 1.0236 \\
\hline $7: 7.142$ & 7.162 & 7.127 & 7.111 & 7.123 & 7.120 & .5840 \\
\hline $8: 7.028$ & $? .055$ & 7.053 & 7.027 & 7.025 & 7.034 & .8522 \\
\hline $9: 6.687$ & 6.712 & 6.712 & 6.693 & 6.678 & 6.691 & .8124 \\
\hline $10: 6.785$ & 6.808 & 6.809 & 6.797 & 6.771 & 6.786 & .7550 \\
\hline $11: 7.646$ & 7.673 & 7.673 & 7.554 & 7.645 & 7.654. & .7979 \\
\hline $12: 7.515$ & 7.546 & 7.543 & 7.514 & 7.516 & 7.525 & .9001 \\
\hline $13: 6.797$ & 6.821 & 6.821 & 6.803 & 6.785 & 6.799 & .7859 \\
\hline $14: 7.424$ & 7.456 & 7.435 & 7.392 & 7.432 & 7.425 & .9661 \\
\hline 15: 8.561 & 8.625 & 8.614 & 8.554 & 8.596 & 8.603 & 1.3079 \\
\hline $16: 8.376$ & 8.438 & 8.424 & 8.359 & 8.413 & 8.411 & 1.3201 \\
\hline $17: 9.097$ & 9.168 & 9.143 & 9.062 & 9.138 & 9.131 & 1.3549 \\
\hline $18: 7.912$ & 7.948 & 7.949 & 7.922 & 7.907 & 7.930 & .9600 \\
\hline $19: 8.679$ & 8.732 & 8.710 & 8.641 & 8.705 & 8.700 & 1.2000 \\
\hline $20: 7.559$ & 7.592 & 7.586 & 7.552 & 7.549 & 7.567 & .9359 \\
\hline $21: 7.429$ & 7.473 & 7.461 & 7.409 & 7.411 & 7.436 & 1.1640 \\
\hline 22: 6.955 & 7.009 & 6.916 & 6.841 & 6.937 & 6.909 & 1.4118 \\
\hline 23: 6.810 & $6.847^{\circ}$ & 8.803 & 6.750 & 6.800 & 6.792 & 1.1400 \\
\hline 24: 6.712 & 6.748 & 6.698 & 6.645 & 6.687 & 6.685 & 1.1544 \\
\hline
\end{tabular}




\begin{tabular}{|c|c|c|c|c|c|c|c|}
\hline 25: & 6.942 & 6.972 & 6.967 & 6.933 & 6.941 & 6.949 & .9451 \\
\hline 2E: & 7.835 & 7.867 & 7.867 & 7.843 & 7.812 & 7.837 & .8808 \\
\hline $27:$ & 6.725 & 6.755 & 6.752 & 6.723 & 6.717 & 6.729 & .9563 \\
\hline 28: & 7.816 & 7.842 & 7.843 & 7.828 & 7.807 & 7.819 & .7374 \\
\hline 29: & 9.001 & 9.050 & 9.046 & 9.002 & 9.014 & 9.021 & 1.0019 \\
\hline 30: & 8.532 & 8.568 & 8.569 & 8.551 & 8.522 & 8.543 & .9000 \\
\hline 31: & 9.271 & .9 .329 & 9.323 & 9.268 & 9.280 & 9.294 & 1.1886 \\
\hline $32:$ & 9.036 & 9.132 & 9.133 & 9.104 & 9.077 & 9.096 & 1.0284 \\
\hline 33: & 6.901 & 6.963 & 6.888 & 6.802 & 6.936 & 6.899 & 1.4999 \\
\hline $34:$ & 7.543 & 7.571 & 7.525 & 7.492 & 7.531 & 7.518 & .8852 \\
\hline 35: & 7.401 & 7.430 & 7.386 & 7.351 & 7.400 & 7.381 & .9054 \\
\hline 36: & 7.244 & 7.272 & 7.221 & 7.188 & 7.240 & 7.217 & .9230 \\
\hline 37: & 7.366 . & 7.384 & 7.349 & 7.340 & 7.332 & 7.340 & .5948 \\
\hline 38: & 7.491 & 7.512 & 7.470 & 7.456 & 7.455 & 7.460 & .6804 \\
\hline 39: & 7.509 & 7.525 & 7.495 & 7.487 & 7.460 & 7.483 & .5534 \\
\hline $40:$ & 7.238 & 7.257: & 7.218 & 7.182 & 7.259 & 7.221 & .9392 \\
\hline 41: & 7.377 & 7.399 & 7.366 & 7.345 & 7.403 & 7.369 & .7265 \\
\hline 42: & 7.277 & 7.307 & 7.256 & 7.219 & 7.299 & 7.258 & .9548 \\
\hline 43: & 7.858 & 7.875 & 7.847 & 7.839 & 7.846 & 7.842 & .5220 \\
\hline 44: & 7.631 & 7.650 & 7.616 & 7.605 & 7.606 & 7.608 & .6013 \\
\hline $45:$ & 7.748 & 7.774 & 7.728 & 7.702 & 7.716 & 7.717 & $.806 \mathrm{C}$ \\
\hline 46: & 6.600 & 6.621. & 6.592 & 6.570 & 6.598 & 6.588 & .7697 \\
\hline 47: & 6.692 & 6.711 & .6 .682 & 6.665 & 6.691 & 6.679 & .6970 \\
\hline 48: & 6.637 & 6.658 & 6.627 & 6.606 & 6.624 & 6.620 & .7639 \\
\hline 49: & 6.623 & 6.641 & 6.613 & 6.597 & 6.589 & 6.602 & .6821 \\
\hline 50: & 6.771 & 5.786 & 6.761 & 6.753 & 6.740 & 6.752 & .5467 \\
\hline 51: & 6.675 & 6.691 & 6.665 & 6.654 & 6.644 & 6.656 & .6015 \\
\hline 52: & 8.023 & 8.041 & 8.011 & 8.002 & 8.013 & 8.006 & .5467 \\
\hline
\end{tabular}




\begin{tabular}{|c|c|c|c|c|c|c|c|}
\hline 53: & 8.059 & 8.082 & 8.043 & 3.025 & 8.051 & 8.038 & .5782 \\
\hline 54: & 8.014 & 8.034 & 7.994 & 7.984 & 8.021 & 7.995 & .6119 \\
\hline 55: & 7.556 & 7.592 & 7.521 & 7.501 & 7.505 & 7.509 & .8541 \\
\hline 56: & 7.232 & 7.255 & 7.139 & 7.149 & 7.176 & 7.138 & .8206 \\
\hline 57: & 7.720 & 7.748 & 7.676 & 7.650 & 7.653 & 7.661 & .8974 \\
\hline 58: & 8.104 & 8.120 & 8.086 & 8.083 & 8.074 & 8.080 & .4918 \\
\hline 59: & 8.170 & 8.186 & 8.150 & 8.147 & 8.137 & 8.143 & .5030 \\
\hline 60: & 7.947 & 7.964 & 7.915 & 7.917 & 7.919 & 7.912 & .5305 \\
\hline 61: & 7.335 & 7.360 & 7.287 & 7.270 & 7.291 & 7.279 & .8476 \\
\hline 62: & 7.430 & 7.458 & 7.373 & 7.351 & 7.361 & 7.350 & .5230 \\
\hline 63: & 7.627 & 7.654 & 7.577 & 7.555 & 7.586 & 7.569 & .8854 \\
\hline 64: & 7.934 & 7.960 & 7.900 & 7.879 & 7.940 & 7.901 & .7986 \\
\hline 65: & 7.700 & 7.727 & 7.665 & 7.643 & 7.701 & 7.655 & .8276 \\
\hline 66: & 7.605 & 7.630 & 7.560 & 7.544 & 7.595 & 7.560 & .5120 \\
\hline 67: & 7.831 & 7.856 & 7.784 & 7.768 & 7.787 & 7.777 & .8107 \\
\hline 68: & 7.939 & 7.963 & 7.901 & 7.889 & 7.897 & 7.893 & .7287 \\
\hline 69: & 7.798 & 7.821 & 7.760 & 7.750 & 7.767 & 7.754 & .7114 \\
\hline $70:$ & 6.860 & 6.871 & 6.862 & 6.857 & 6.860 & 6.858 & .3897 \\
\hline $71:$ & 8.055 & 8.073 & 8.064 & 8.051 & 8.033 & 8.050 & .5103 \\
\hline $.72:$ & 7.488 & 7.512 & 7.488 & 7.462 & 7.471 & 7.476 & .7586 \\
\hline 73: & 7.468 & 7.487 & 7.471 & 7.455 & 7.454 & 7.461 & .5975 \\
\hline $74:$ & 7.191 & 7.207 & 7.204 & 7.192 & 7.185 & 7.193 & .5288 \\
\hline 75: & 7.232 & 7.250 & 7.244 & $\cdot 7.229$ & 7.215 & 7.230 & .5852 \\
\hline 75: & 7.865 & 7.880 & 7.878 & 7.869 & 7.823 & 7.853 & .4436 \\
\hline $77:$ & $7.7 \geq 2$ & 7.728 & 7.727 & 7.725 & 7.688 & 7.716 & .1874 \\
\hline 78: & 7. Б̄E? & 7.639 & 7.63̈6 & 7.530 & 7.607 & T.625 & \\
\hline 79: & 7.657 & 7.669 & 7.685 & 7.658 & 7.644 & 7.655 & .3 \\
\hline
\end{tabular}




\begin{tabular}{|c|c|c|c|c|c|c|c|}
\hline $80:$ & 7.568 & 7.589 & 7.585 & 7.568 & 7.547 & 7.568 & .6426 \\
\hline 81: & 6.660 & 6.678 & 6.673 & 6.558 & 6.569 & 6.667 & .5184 \\
\hline 82: & 6.528 & 6.540 & 6.538 & 6.532 & 6.515 & 6.528 & .4249 \\
\hline 83: & 6.342 & 6.354 & 6.351 & 6.343 & 6.339 & 6.343 & .4601 \\
\hline 84: & 6.639 & 6.653 & 6.648 & 6.637 & 6.605 & 6.633 & .5112 \\
\hline 85: & 6.739 & 6.750 & 6.748 & 6.742 & 6.719 & 6.736 & .3974 \\
\hline 86: & 6.606 & 6.624 & 6.616 & 6.598 & 6.607 & 6.609 & .6545 \\
\hline 87: & 6.743 & 6.762 & 6.753 & 6.735 & 6.753 & 6.748 & .6597 \\
\hline 88: & 6.467 & 6.483 & 6.469 & 6.456 & 6.454 & 6.461 & .5914 \\
\hline 89: & 6.479 & 6.494 & 6.482 & 6.470 & 6.461 & 6.472 & .5525 \\
\hline 90: & 6.719 & 6.735 & 6.732 & 6.721 & 6.710 & 6.721. & .5390 \\
\hline 91: & 6.856 & 6.868 & 6.865 & 6.857 & 6.841 & 6.854 & .4410 \\
\hline 92: & 6.535 & 6.550 & 6.542 & 6.531 & 6.526 & 5.534 & .5184 \\
\hline 93: & 6.819 & 6.831 & 6.830 & 6.824 & 5.808 & 6.819 & .4192 \\
\hline 94: & 7.111 & 7.122 & $7.1 \geq 1$ & 7.115 & 7.083 & 7.107 & .3666 \\
\hline 95: & 5.949 & 6.957 & 6.954 & 6.950 & 6.934 & 6.946. & .2972 \\
\hline 96: & 9.055 & 9.085 & 9.068 & 9.033 & 9.086 & 9.055 & .7851 \\
\hline 97: & 9.047 & 9.079 & 9.060 & 9.022 & 9.090 & 9.061 & $.8 ! 31$ \\
\hline 98: & 8.649 & 8.678 & 8.654 & 8.620 & 8.609 & 8.633 & .7902 \\
\hline 95: & 8.706 & 8.729 & 8.702 & 8.681 & 8.648 & 8.683 & .6474 \\
\hline 100: & 8.891 & 8.912 & 8.903 & 8.886 & 8.862 & 8.885 & .5565 \\
\hline 101: & 8.794 & 8.812 & 8.807 & 8.795 & 8.804 & 8.800 & .4825 \\
\hline 102: & 8.011 & 8.030 & 8.021 & 8.004 & 8.031 & 8.017 & .5719 \\
\hline 103: & 8.534 & 8.559 & 8.556 & 8.537 & 8.540 & 8.542 & .6545 \\
\hline 104: & 8.498 & 8.517 & 8.515 & 8.503 & 8.480 & 8.497 & .5108 \\
\hline 105: & 8.490 & 8.509 & 8.505 & 8.492 & 8.473 & 8.488 & .5243 \\
\hline 106: & 8.935 & 8.953 & 8.946 & 8.932 & 8.960 & 8.944 & .4954 \\
\hline 107: & 8.970 & 8.989 & 8.963 & 8.951 & 8.992 & 8.984 & .5283 \\
\hline
\end{tabular}




\begin{tabular}{|c|c|c|c|c|c|c|c|}
\hline 108: & 9.213 & 9.23! & 9.222 & 9.210 & 9.199 & 9.209 & .4640 \\
\hline 109: & 8.959 & 8.987 & 8.970 & 8.939 & 8.993 & 8.968 & .7416 \\
\hline 110: & 9.381 & 9.407 & 9.398 & 9.374 & 9.395 & 9.386 & .6462 \\
\hline 111: & 9.573 & 9.607 & 9.594 & 9.556 & 9.586 & 9.578 & .3127 \\
\hline 112: & 8.998 & 9.030 & 9.012 & 8.975 & 9.013 & 9.002 & .8076 \\
\hline 113: & 9.355 & 9.373 & 9.373 & 9.364 & 9.338 & 9.353 & .4536 \\
\hline 114: & 8.764 & 8.786 & 8.774 & 8.756 & 8.790 & 8.772 & .5698 \\
\hline 115: & 8.824 & 8.857 & 8.827 & 8.785 & 8.815 & 8.811 & .8731 \\
\hline 116: & 8.766 & 8.793 & 8.751 & 8.724 & 8.791 & 8.753 & .7524 \\
\hline 117: & 8.579 & 8.612 & 8.586 & 8.545 & 8.618 & 8.588 & .8774 \\
\hline 118: & 6.943 & 6.561 & 6.952 & 6.936 & 6.897 & 6.934 & .5552 \\
\hline 119: & 7.218 & 7.226 & 7.226 & 7.224 & 7.175 & 7.211 & .2553 \\
\hline 120: & 7.020 & 7.033 & 7.022 & 7.015 & 7.023 & 7.019 & .4384 \\
\hline 121: & 6.862 & 6.881 & 6.867 & 6.848 & 6.858 & 6.859 & .5606 \\
\hline 122: & 6.898 & 6.911 & 6.903 & 6.894 & 6.892 & 6.896 & .4532 \\
\hline 123: & 6.594 & 6.609 & 6.595 & 6.585 & 6.564 & 6.584 & .5260 \\
\hline $124:$ & 6.441 & 6.463 & 6.435 & 6.410 & 6.398 & 6.419 & .8069 \\
\hline 125: & 6.418 & 6.439 & 6.414 & 6.392 & 6.388 & 6.401 & .7648 \\
\hline 126: & 6.632 & 6.653 & 6.648 & 6.627 & 6.581 & 6.624 & $.7 \geq 70$ \\
\hline 127: & 6.430 & 6.442 & 6.428 & 6.422 & 6.417 & 6.422 & .4370 \\
\hline 128: & 6.777 & 6.790 & 6.790 & 5.787 & 6.763 & 6.779 & .4235 \\
\hline 129: & 6.625 & 6.638 & 6.629 & 6.521 & 6.613 & 6.621 & .4641 \\
\hline 130: & 6.837 & 6.847 & 6.844 & 6.839 & 6.829 & 6.836 & .3442 \\
\hline 131： & 7.912 & 7.946 & 7.916 & 7.871 & 7.901 & 7.902 & .9532 \\
\hline 132: & 8.039 & 8.074 & 8.034 & 7.586 & 8.004 & 8.015 & .9881 \\
\hline 133: & 8.038 & 8.067 & 8.038 & 8.003 & 8.010 & 8.022 & .2429 \\
\hline 134: & 7.955 & 7.993 & 7.354 & 7.921 & 7.983 & 7.952 & .8450 \\
\hline
\end{tabular}




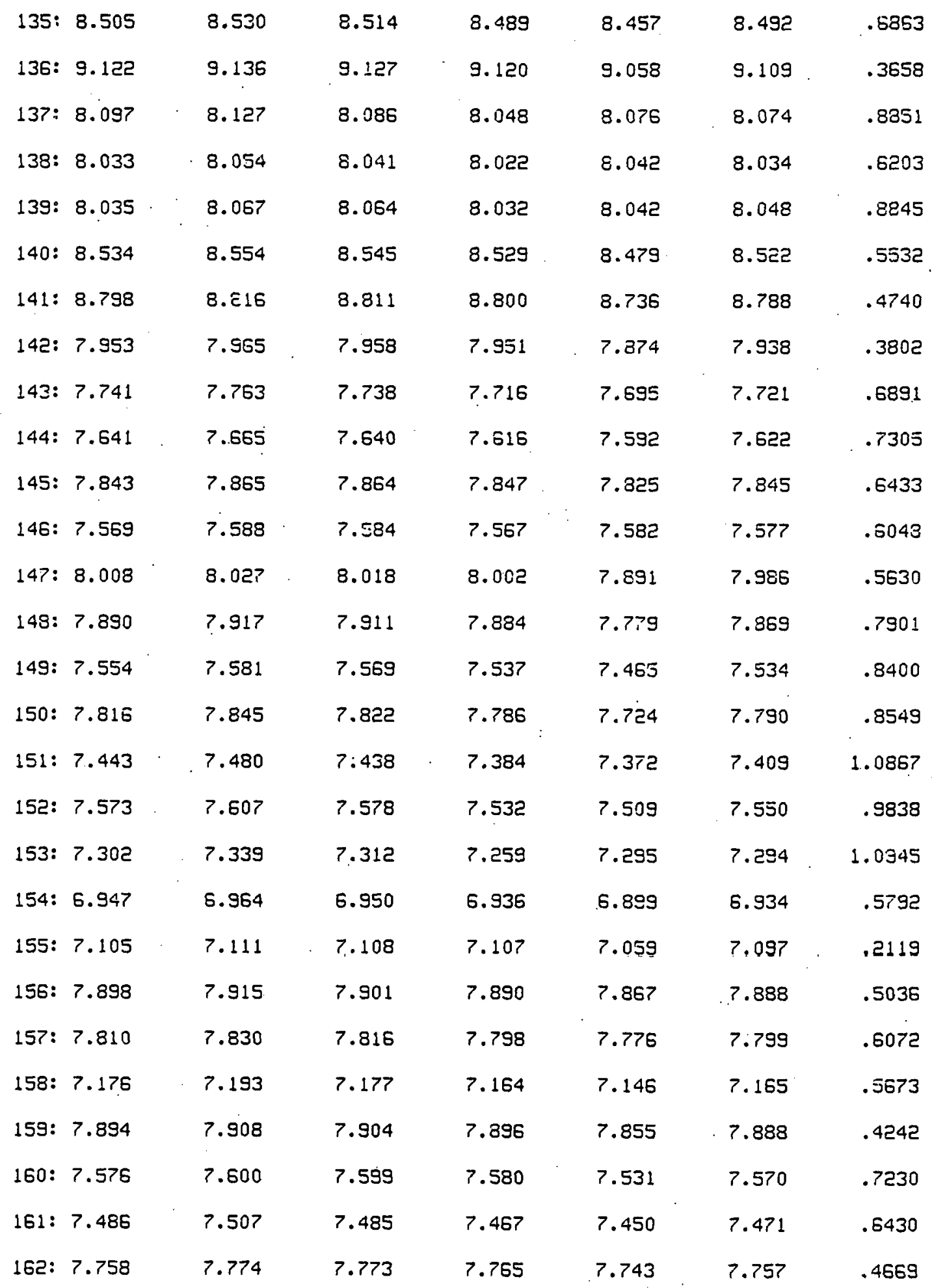




$\begin{array}{lllllllll}163: 8.036 & 8.056 & 8.052 & 8.036 & 7.996 & 8.030 & .0017 \\ 164: 7.536 & 7.559 & 7.556 & 7.535 & 7.482 & 7.528 & .7074 \\ 165: 7.494 & 7.506 & 7.502 & 7.496 & 7.385 & 7.478 & .3746 \\ 168: 7.194 & 7.219 & 7.207 & 7.178 & 7.042 & 7.162 & .8127\end{array}$


Table F-3 Deviations of the. Different Methods from SEER(BLD) when Using $\dot{\mathrm{E}}_{C} / \dot{\mathrm{E}}_{D} \neq 1$ :

deva(dOE) deva(20) deva(50) deviaz(50) deva(emp) deva(2Doe) tau

\begin{tabular}{|c|c|c|c|c|c|c|}
\hline $1:-.020$ & .219 & .136 & -.056 & .018 & .239 & .5606 \\
\hline .622 & 1.063 & .885 & .333 & .505 & .438 & .5619 \\
\hline .311 & .822 & .476 & -.239 & .201 & .509 & 1.0834 \\
\hline .234 & .750 & .610 & -.031 & .313 & .525 & 1.0859 \\
\hline .329 & .799 & .735 & .240 . & .420 & .469 & .5943 \\
\hline. . EES & 1.096 & .729 & .077 & .400 & .467 & 1.0235 \\
\hline $.264^{\circ}$ & .545 & .054 & -.167 & -.042 & .280 & .5840 \\
\hline .053 & .438 & .399 & .035 &.$: 33$ & .386 & .8522 \\
\hline .148 & .517 & .512 & .234 & .200 & .369 & .8124 \\
\hline .211 & .555 & .565 & .380 & .222 & .343 & .7560 \\
\hline .006 & .367 & .368 & .114 & .119 & .352 & .7979 \\
\hline $2:-.018$ & .396 & .363 & -.022 & .119 & .414 & .9001 \\
\hline .172 & .527 & .523 & .263 & .201 & .355 & .7859 \\
\hline$:-.112$ & .322 & .039 & -.538 & -.088 & .434 & .9661 \\
\hline$:-.400$ & .337 & .215 & -.482 & .087 & .740 & 1.3079 \\
\hline$:-.442$ & .302 & .136 & -.637 & -.029 & .747 & 1.3201 \\
\hline $7:-.449$ & .325 & .062 & -.831 & -.079 & .877 & 1.3549 \\
\hline .061 & .518 & .520 & .190 & .283 & .457 & .9600 \\
\hline : -.295 & .315 & .063 & -.730 & -.050 & .612 & 1.2000 \\
\hline .132 & .563 & .494 & .035 & .236 & .431 & .3359 \\
\hline .253 & .843 & .685 & -.019 & .337 & .588 & 1.1640 \\
\hline .269 & 1.041 & -.297 & -1.383 & -.398 & .770 & 1.4118 \\
\hline .150 & .887 & .045 & $-.74 \overline{2}$ & -.125 & .536 & $1 . i 400$ \\
\hline .370 & .915 & .163 & -.532 & -.038 & .543 & 1.1544 \\
\hline
\end{tabular}




\begin{tabular}{|c|c|c|c|c|c|c|c|}
\hline 25: & .016 & .451 & .368 & -.109 & .113 & .435 & .9451 \\
\hline 26: & .300 & .709 & .708 & .403 & .330 & .407 & .8803 \\
\hline 27: & .115 & .562 & .520 & .081 & .183 & .447 & .9563 \\
\hline 28: & .114 & .447 & .455 & .269 & .155 & .333 & .7374 \\
\hline 29: & -.147 & .396 & . 362 & -.129 & .084 & .544 & 1.0919 \\
\hline 30: & .118 & .543 & .558 & .345 & .248 & .424 & .5000 \\
\hline 31: & -.097 & .525 & .457 & -.132 & .147 & .622 & 1.1886 \\
\hline 32: & .100 & .606 & $.61 \mathrm{i}$ & .293 & .207 & .506 & 1.0284 \\
\hline 33: & -.511 & .387 & -.695 & -1.929 & -.539 & .902 & 1.4999 \\
\hline 34: & .166 & .541 & -.070 & -.510 & -.170 & .374 & .8852 \\
\hline 35: & .010 & .396 & -.201 & -.672 & -.264 & .386 & .9054 \\
\hline 36: & .057 & .448 & -.257 & -.722 & -.312 & .392 & .9230 \\
\hline 37: & .470 & .712 & .232 & .110 & .113 & .241 & .5948 \\
\hline 38: & .486 & .764 & .198 & .011 & .070 & .277 & .6304 \\
\hline 39: & .657 & .884 & .476 & .367 & .317 & .225 & .5534 \\
\hline 40: & -.281 & .119 & -.560 & -1.054 & -.523 & .401 & .9392 \\
\hline 41: & -.353 & -.052 & -.498 & -.782 & -.465 & .301 & .7265 \\
\hline 42: & -.294 & .114 & -.589 & -1.098 & -.559 & .409 & .9548 \\
\hline 43: & .152 & .375 & .015 & -.082 & -.046 & .212 & .5220 \\
\hline 44: & .331 & .577 & .127 & -.015 & .029 & .245 & .6013 \\
\hline 45: & .415 & .751 & .146 & -.150 & .005 & .334 & .8062 \\
\hline 46: & .025 & .347 & -.083 & -.425 & -.157 & . 322 & .7697 \\
\hline 47: & .019 & .307 & -.129 & -.384 & -.184 & .288 & .6970 \\
\hline 48: & .190 & .509 & .042 & -.283 & -.066 & .318 & .7639 \\
\hline 49: & .505 & .789 & .367 & .122 & .199 & .282 & .6821 \\
\hline 50: & .464 & .E88 & .317 & .199 & .187 & .223 & .5467 \\
\hline 51: & .470 & .717 & .319 & .155 & .177 & .246 & .6015 \\
\hline 52: & .125 & .349 & -.023 & -.139 & -.080 & .223 & .5467 \\
\hline
\end{tabular}




\begin{tabular}{|c|c|c|c|c|c|c|c|}
\hline 53: & .108 & .386 & -.101 & -.316 & -.150 & .278 & .6782 \\
\hline 54: & -.083 & .165 & -.333 & -.465 & -.328 & .248 & .6119 \\
\hline 55: & .810 & 1.161 & .210 & -.063 & .044 & .348 &.$E 541$ \\
\hline 56: & .782 & 1.102 & -.517 & -.385 & -.528 & .317 & .8206 \\
\hline 57: & .872 & 1.246 & .306 & -.041 & .111 & .371 & .8974 \\
\hline 58: & .373 & .572 & .150 & .113 & .072 & .198 & .4918 \\
\hline 59: & .402 & .605 & .163 & .124 & .078 & .202 & .5030 \\
\hline 60: & .356 & .568 & -.044 & -.023 & -.086 & .211 & .5305 \\
\hline 81: & .609 & .954 & -.054 & -.289 & -.168 & .344 & .8476 \\
\hline $62:$ & .935 & 1.317 & . 166 & -.135 & -.016 & .373 & .9230 \\
\hline 63: & .535 & .900 & -.122 & -.413 & -.226 & .362 & .8854 \\
\hline 64: & -.069 & .257 & -.506 & -.769 & -.488 & .326 & .7986 \\
\hline 65: & -.009 & .330 & -.468 & -.759 & -.465 & .339 & .8276 \\
\hline 66: & .139 & .468 & -.454 & -.668 & -.459 & .328 & .8120 \\
\hline 67: & .558 & .887 & -.036 & -.251 & -.137 & .328 & .8107 \\
\hline 68: & .539 & .834 & .056 & -.102 & -.051 & .293 & .7287 \\
\hline 69: & .410 & .696 & -.084 & -.216 & -.158 & .285 & .7114 \\
\hline 70: & -.006 & .156 & .028 & -.053 & -.040 & .162 & .3997 \\
\hline $71:$ & .282 & .498 & .389 & .226 & .214 & .215 & .5108 \\
\hline 72: & .219 & .541 & .229 & -.126 & .062 & .321 & .7586 \\
\hline 73: & .189 & .440 & .228 & .013 & .096 & .250 & .5975 \\
\hline $74:$ & .075 & .302 & .251 & .101 & $: 103$ & .227 & .5288 \\
\hline 75: & .226 & .477 & .399 & .192 & .207 & .251 & .5852 \\
\hline 76: & .538 & .732 & .707 & .596 & .385 & .192 & .4485 \\
\hline 77: & .439 & .518 & .504 & .482 & .356 & .078 & .1874 \\
\hline 78: & .263 & .421 & .383 & .299 & .228 & .158 & .3729 \\
\hline 79: & .162 & .326 & .271 & .178 & .145 & .163 & .3873 \\
\hline
\end{tabular}




\begin{tabular}{|c|c|c|c|c|c|c|c|}
\hline 80: & .276 & .556 & .505 & .272 & .273 & .279 & .6426 \\
\hline 81: & -.137 & .129 & .057 & -.171 & -.032 & .265 & .6184 \\
\hline $8 \bar{c}:$ & .202 & .383 & .356 & .254 & .197 & .181 &.$\simeq \cong 49$ \\
\hline 83: & .049 & .245 & .194 & .066 & .076 & .196 & .4601 \\
\hline 84: & .511 & .729 & .651 & .489 & .425 & .217 & .5112 \\
\hline 85: & .288 & .458 & : 428 & .335 & .255 & .169 & .3974 \\
\hline 86: & -.028 & .252 & .124 & -.142 & .019 & .250 & .5545 \\
\hline 87: & -.157 & .125 & -.000 & -.270 & -.076 & .233 & .3597 \\
\hline 88: & .204 & .452 & .236 & .027 & .102 & .247 & .5914 \\
\hline 89: & .281 & .512 & .316 & .135 & .171 & .231 & .5525 \\
\hline 90: & .136 & .368 & .327 & .151 & .169 & .232 & .5390 \\
\hline 91: & .221 & .408 & .354 & .236 & .202 & .187 & .4410 \\
\hline $92:$ & .147 & .366 & $.2 \equiv 5$ & .088 & .126 & .219 & .5184 \\
\hline 93: & .156 & .336 & .318 & .225 & .161 & .179 & .4192 \\
\hline 94: & .392 & .548 & .526 & .449 & .338 & .156 & .3666 \\
\hline 95: & .218 & .342 & .286 & .234 &.$i 75$ & .124 & .2972 \\
\hline 96: & -.346 & -.008 & -.198 & -.582 & -.233 & .340 & .7851 \\
\hline $97:$ & -.474 & -.122 & -.336 & -.748 & -.220 & .353 & .8131 \\
\hline 98: & .470 & .810 & .527 & .135 & .278 & .338 & ז'902 \\
\hline 99: & .671 & .942 & .631 & .390 & .406 & .269 & .6474 \\
\hline 100: & .335 & .572 & .471 & .278 & .265 & .236 & .5565 \\
\hline 101: & -.112 & .093 & .036 & -.105 & -.052 & .205 & .4825 \\
\hline 102: & -.250 & -.008 & -.127 & -.330 & -.175 & .242 & .5719 \\
\hline 103: & -.074 & .212 & .180 & -.045 & .021 & .286 & .6545 \\
\hline 104: & .217 & .438 & .411 & .269 & .200 & .220 & .5108 \\
\hline 105: & .192 & .417 & .375 & .217 & .179 & .225 & .5243 \\
\hline 108: &.- .279 & -.070 & -.152 & -.303 & -.178 & .210 & .4954 \\
\hline 107: & -.246 & -.029 & -.324 & -.453 & -.312 & $.2 \mathrm{i} 7$ & . \\
\hline
\end{tabular}




\begin{tabular}{|c|c|c|c|c|c|c|c|}
\hline 108: & .152 & .348 & .253 & .120 & .104 & .195 & .4540 \\
\hline 109: & -.385 & -.068 & -.258 & -.502 & -.278 & .318 & .7416 \\
\hline 110: & -.148 & .129 & .032 & -.2222 & -.095 & .278 & .6462 \\
\hline 111: & -.134 & .223. & .088 & -.310 & -.076 & .357 & .8127 \\
\hline 112: & -.165 & .135 & -.014 & -.420 & -.118 & .351 & .8075 \\
\hline 113: & .177 & .373 & .367 & .274 & .158 & .196 & .4536 \\
\hline 114: & -.287 & -.046 & -.178 & -.379 & -.201 & .241 & .5698 \\
\hline 115: & .100 & .479 & .138 & -.339 & -.038 & .378 & .8731 \\
\hline 116: & -.292 & .020 & -.460 & -.765 & -.440 & .312 & .7524 \\
\hline 117: & -.448 & -.067 & -.364 & -.845 & -.346 & .383 & .8774 \\
\hline 118: & .662 & .916 & .788 & .565 & .527 & .253 & .5962 \\
\hline 119: & .604 & .7 .13 & .713 & .690 & .508 & .109 & .2553 \\
\hline $120:$ & -.043 & .139 & -.012 & -.118 & -.060 & .182 & .4384 \\
\hline 121: & .059 & .338 & .121 & -.150 & .009 & .279 & .6606 \\
\hline 122: & .081 & .271 & .152 & .028 & .053 & .190 & .4552 \\
\hline 123: & .468 & .688 & .479 & .322 & .308 & .219 & .5260 \\
\hline 124: & .663 & 1.005 & .570 & .182 & .325 & .340 & .8069 \\
\hline 125: & .479 & .802 & .416 & .068 & .214 & .322 & .7648 \\
\hline 126: & .763 & 1.084 & 1.008 & .702 & .546 & .318 & .7270 \\
\hline 127: & .211 & .391 & .174 & .091 & .086 & .179 & .4370 \\
\hline 128: & .205 & .390 & .334 & . 352 & .234 & .185 & .4236 \\
\hline 129: & .185 & .379 & .252 & .122 & .126 & .194 & .4641 \\
\hline 130: & .116 & .261 & .219 & .146 & .103 & .145 & .3442 \\
\hline 131: & .142 & .565 & .190 & -.378 & .012 & .422 & .9532 \\
\hline 132: & .436 & .875 & .373 & -.229 & .134 & .437 & .9881 \\
\hline 13ว: & .353 &.$? 16$ & .355 & -.087 & .154 & .361 & .8429 \\
\hline 134: & -.222 & .135 & -.359 & -.775 & -.381 & .357 & .8450 \\
\hline
\end{tabular}




\begin{tabular}{|c|c|c|c|c|c|c|c|}
\hline 135: & .558 & .861 & .663 & .372 & .410 & .292 & .6863 \\
\hline 136: & .708 & .262 & .757 & .590 & .565 & .152 & .3658 \\
\hline 137: & . Eó &.$E 40$ & .129 & -.337 & -.025 & .378 & .8851 \\
\hline 138: & -.111 & .151 & -.014 & -.254 & -.096 & .252 & .6203 \\
\hline 139: & -.091 & .312 & .267 & -.126 & .070 & .403 & .3845 \\
\hline 140: & .643 & .880 & .776 & .585 & .511 & .235 & . \\
\hline 141: & .714 & .917 & .867 & .732 & .593 & .202 & .4740 \\
\hline 142: & 1.000 & 1.160 & 1.054 & .979 & .815 & .158 & .3802 \\
\hline 143: & .592 & .882 & .556 & .276 & .340 & .288 & .5891 \\
\hline 144: & .651 & .960 & .638 & .313 & .391 & .307 & .7305 \\
\hline 145: & .230 & .512 & .491 & .284 & .257 & .282 & .5433 \\
\hline 146: & -.181 & .079 & .016 & -.198 & -.072 & .261 & .6048 \\
\hline 147: & 1.476 & 1.719 & 1.511 & 1.412 & 1.204 & .239 & .5630 \\
\hline 148: & 1.422 & 1.777 & 1.701 & 1.344 & 1.157 & .349 & .7901 \\
\hline 149: & 1.189 & 1.563 & 1.399 & .963 & .925 & .370 & .8400 \\
\hline 150: & 1.190 & 1.565 & $1.263^{\circ}$ & .799 & .847 & .370 & .8549 \\
\hline 151: & .953 & 1.458 & .885 & .157 & .495 & .500 & 1.0867 \\
\hline 152: & .850 & 1.294 & .908 & .301 & .534 & .440 &.$\Xi 338$ \\
\hline 153: & .095 & .611 & .243 & -.487 & -.004 & .516 & 1.0545 \\
\hline 154: & .685 & .929 & .730 & .526 & .454 & .243 & .5792 \\
\hline $155:$ & .650 & .738 & .690 & .669 & .535 & .088 & .2119 \\
\hline 15E: & .399 & .610 & .435 & .287 & .271 & .210 & .5036 \\
\hline 157: & .447 & .704 & .515 & .286 & .306 & .256 & .6072 \\
\hline 158: & .419 & .656 & .431 & .244 & .261 & .236 & .5673 \\
\hline 159: & .458 & .669 & .625 & .516 & .413 & .180 & .4242 \\
\hline 160: & .593 & .915 & .894 & .540 & .516 & .321 & .7230 \\
\hline 161: & .484 & .753 & .457 & .217 & .269 & $.2 \overline{6 ̈} \bar{\varepsilon}$ & .5430 \\
\hline 16E: & .196 & .359 & .392 & .293 & .190 & .202 & .4669 \\
\hline
\end{tabular}




\begin{tabular}{|c|c|c|c|c|c|c|c|}
\hline 163: & .493 & .754 & .702 & .494 & .424 & .260 & .5017 \\
\hline 164: & .720 & 1.033 & $.984^{\circ}$ & .709 & .612 & .310 & .7074 \\
\hline 165: & 1.481 & 1.641 & 1.592 & 1.504 & 1.255 & $\therefore 158$ & .3746 \\
\hline 166: & 2.149 & $2.5 i 2$ & 2.338 & 1.922 & 1.698 & 355 & 127 \\
\hline
\end{tabular}


Table F-4 Seasonal Energy Efficiency Ratio Calculation Using $\dot{\mathrm{E}}_{C} / \dot{\mathrm{E}}_{\mathrm{D}}=1$ for all Percent On-Times.

\begin{tabular}{|c|c|c|c|c|c|c|}
\hline SEER (DOE) & SEER(20) & SEER $(50)$ & SEER2 $(50)$ & SEER (BLD) & SEER (EMP) & TAU \\
\hline 1: 7.625 & 7.580 & 7.570 & $? .555$ & 7.628 & 7.563 & .5606 \\
\hline 2: 6.805 & 6.668 & 6.641 & 6.603 & 6.763 & 5.520 & .9613 \\
\hline 3: 6.672 & 6.596 & 6.561 & 6.514 & 6.652 & 6.546 & 1.0834 \\
\hline $4: 6.794$ & 6.564 & 6.529 & 6.482 & 6.779 & 6.516 & 1.0859 \\
\hline $5: 6.892$ & 6.513 & 6.584 & 6.544 & 6.870 & 6.559 & .9943 \\
\hline $6: 7.100$ & 7.067 & 7.034 & 6.988 & 7.056 & 7.012 & 1.0235 \\
\hline $7: 7.142$ & 7.377 & 7.362 & 7.341 & 7.123 & 7.350 & .6840 \\
\hline $8: 7.028$ & 6.780 & 6.759 & 6.728 & $7.0 \varepsilon 5$ & 6.750 & .8522 \\
\hline $9: 6.637$ & 6.399 & 6.381 & 6.354 & 6.578 & 6.371 & .9124 \\
\hline $10: 6.785$ & 6.454 & 6.438 & 6.415 & 6.771 & 6.428 & .7560 \\
\hline $11: 7.646$ & 7.305 & 7.285 & $? .256$ & 7.645 & 7.278 & .7979 \\
\hline $12: 7.515$ & 7.209 & $7 .: 84$ & $7: 148$ & 7.516 & 7.177 & .9001 \\
\hline $13: 6.797$ & 6.512 & 6.495 & 6.470 & 6.785 & 5.484 & .7859 \\
\hline $14: 7.424$ & 7.363 & 7.333 & $P .290$ & $? .432$ & 7.326 &. $\operatorname{se} 61$ \\
\hline $15: 8.561$ & 8.033 & 7.965 & 7.386 & 8.596 & 7.976 & 1.3079 \\
\hline $16: 8.376$ & 7.914 & 7.845 & 7.766 & 8.413 & 7.853 & 1.3201 \\
\hline 17: 9.097 & 8.681 & 3.601 & 8.510. & 9.138 & 8.608 & 1.3549 \\
\hline 18: 7.912 & 7.160 & $\bar{T} .430$ & 7.387 & 7.907 & 7.422 & .9500 \\
\hline $19: 8.679$ & 8.409 & 8.351 & 8. 279 & 8.705 & 8.352 & 1.2000 \\
\hline $20: 7.559$ & 7.295 & 7.267 & 7.228 & 7.549 & 7.256 & .9359 \\
\hline $21: 7.429$ & 7.134 & 7.088 & 7.030 & .7 .411 & 7.073 & $1 .: 640$ \\
\hline $22: 6.955$ & 7.117 & 7.044 & 6.364 & 6.937 & 7.032 & 1.4118 \\
\hline $23: 6.810$ & 6.863 & 6.822 & 6.758 & $E .800$ & 0.810 & 1.1400 \\
\hline $24: 6.712$ & $6.805^{\circ}$ & 6.752 & 6.708 & 6.687 & 6.747 & 1.1544 \\
\hline
\end{tabular}




\begin{tabular}{|c|c|c|c|c|c|c|c|}
\hline 25: & 6.942 & 6.713 & 6.686 & 6.549 & 8.941 & 5.678 & .9451 \\
\hline 26: & .7 .835 & 7.447 & 7.422 & 7.386 & 7.812 & 7.406 & .3808 \\
\hline 27: & 6.725 & 6.441 & 6.415 & 6.378 & 6.717 & 6.404 & .9563 \\
\hline 28: & 7.816 & 7.455 & 7.438 & 7.413 & 7.807 & 7.428 & .7374 \\
\hline 29: & 9.001 & 8.494 & 8.448 & 8.386 & 9.014 & 8.444 & 1.0919 \\
\hline 30: & 8.532 & 7.996 & 7.968 & 7.928 & 8.522 & 7.958 & .9000 \\
\hline 31: & 9.271 & 8.731 & 8.673 & 8.599 & 9.280 & 8.667 & 1.1886 \\
\hline $3 \varepsilon:$ & 9.086 & 8.481 & 8.441 & 8.386 & 9.077 & 8.429 & 1.0284 \\
\hline 33: & 6.901 & 6.915 & 6.831 & 6.747 & 6.936 & 6.844 & 1.4999 \\
\hline 34: & 7.543 & 7.743 & 7.717 & 7.679 & 7.531 & 7.704 & .8852 \\
\hline 35: & 7.401 & 7.578 & 7.551 & 7.512 & 7.400 & 7.542 & .9054 \\
\hline 36: & 7.244 & $7.46 ?$ & 7.435 & 7.395 & 7.240 & 7.425 & .9230 \\
\hline 37: & 7.366 & 7.654 & 7.643 & 7.626 & 7.332 & 7.629 & .5948 \\
\hline 38: & 7.491 & 7.785 & 7.770 & 7.748 & 7.455 & 7.754 & .6804 \\
\hline $39:$ & 7.509 & 7.777 & $? .767$ & 7.752 & 7.460 & 7.749 & .5534 \\
\hline 40: & 7.238 & 7.435 & 7.406 & 7.365 & 7.259 & 7.404 & .9392 \\
\hline 41: & 7.377 & 7.568 & 7.552 & 7.527 & 7.403 & 7.548 & .7 \\
\hline 42: & 7.277 & 7.478 & 7.448 & 7.405 & 7.259 & 7.444 & .0548 \\
\hline 43: & 7.858 & 8.124 & 8.115 & 8.101 & 7.846 & 8.103 & .5220 \\
\hline 44: & 7.631 & 7.905 & 7.894 & 7.876 & 7.606 & 7.880 & .5013 \\
\hline 45: & 7.748 & 7.997 & 7.975 & 7.943 & 7.716 & 7.958 & .8062 \\
\hline 46: & 6.500 & 6.739 & 6.722 & 6.697 & 5.598 & 6.714 & .7597 \\
\hline 47: & 6.692 & 6.874 & 6.860 & 6.340 & 6.6 .91 & 6.852 & .6970 \\
\hline 48: & 6.637 & 8.800 & 6.784 & 6.759 & 6.624 & 6.773 & .7639 \\
\hline 49: & 6.623 & 6.801 & 6.788 & 6.768 & 6.589 & 6.773 & .6821 \\
\hline 50: & 6.771 & 6.993 & 5.985 & 6.972 & 5.740 & 6.972 & .5467 \\
\hline 51: & 6.675 & 6.883 & 5.872 & 5.857 & 6.644 & 6.859 & .6015 \\
\hline 52: & 8.023 & 8.289 & 8.279 & 8.253 & 8.013 & 8.267 & \\
\hline
\end{tabular}




\begin{tabular}{|c|c|c|c|c|c|c|c|}
\hline 53: & 8.059 & 8.326 & 8.310 & 8.286 & 8.051 & 8. E99 & .6782 \\
\hline 54: & 8.014 & 8.330 & 8.317 & 8.258 & 8.021 & 8.308 & .6119 \\
\hline 55: & 7.566 & 7.952 & 7.928 & 7.891 & 7.505 & 7.905 & .8541 \\
\hline 56: & 7.232 & 7.875 & .7 .853 & 7.820 & 7.176 & 7.834 & .8206 \\
\hline 57: & 7.720 & 8.080 & 8.052 & 8.012 & 7.653 & 8.027 & .8974 \\
\hline 58: & 8.104 & 8.446 & 8.438 & 8.425 & 8.074 & 8.423 & .4918 \\
\hline 59: & 8.170 & 8.522 & 8.514 & 8.500 & 8.137 & 8.499 & .5030 \\
\hline 60: & 7.947 & 8.386 & 8.376 & 8.361 & 7.919 & 8.362 & .5305 \\
\hline 61: & 7.335 & 7.739 & 7.715 & 7.681 & 7.291 & 7.698 & .8476 \\
\hline 62: & 7.430 & 7.850 & 7.820 & 7.779 & 7.361 & 7.798 & .9230 \\
\hline 63: & 7.627 & 8.029 & 8.001 & 7.962 & 7.586 & 7.985 & .8854 \\
\hline 64: & 7.934 & 8.285 & 8.253 & 8.230 & 7.940 & 8.255 & .7986 \\
\hline 65: & 7.700 & 8.040 & 8.017 & 7.982 & 7.701 & 8.008 & .8275 \\
\hline $6 \epsilon:$ & 7.605 & 8.010 & 7.987 & 7.954 & 7.595 & 7.976 & .8120 \\
\hline 67: & 7.831 & 8.247 & 8.224 & 8.190 & 7.887 & 8.205 & .8107 \\
\hline 68: & 7.939 & 8.342 & 8.323 & 8.295 & 7.897 & 8.305 & .7287 \\
\hline 69: & 7.798 & 8.206 & 8.189 & 8.163 & 7.767 & 8.174 & .7114 \\
\hline $70:$ & 6.860 & 6.961 & 6.957 & 6.951 & 6.860 & 6.950 & .3897 \\
\hline $71:$ & 8.055 & 8.075 & 8.066 & 8.053 & 8.033 & 8.052 & .5108 \\
\hline 72: & 7.488 & $? .567$ & 7.548 & 7.521 & 7.471 & 7.534 & .7586 \\
\hline 73: & 7.468 & 7.552 & 7.541 & 7.524 & 7.454 & 7.530 & .5975 \\
\hline 74: & 7.191 & 7.093 & 7.085 & 7.072 & 7.185 & 7.077 & .5288 \\
\hline 75: & .7 .232 & 7.167 & 7.157 & 7.142 & 7.215 & 7.145 & .5852 \\
\hline 76: & 7.865 & 7.759 & 7.753 & 7.743 & 7.823 & 7.734 & .4486 \\
\hline $77:$ & 7.722 & 7.728 & 7.727 & 7.725 & 7.688 & 7.716 & .1874 \\
\hline 78: & 7.627 & 7.599 & 7.595 & 7.588 & 7.607 & 7.584 & .3729 \\
\hline 79: & 7.657 & 7.656 & 7.651 & 7.644 & 7.644 & 7.642 & .3873 \\
\hline
\end{tabular}




\begin{tabular}{|c|c|c|c|c|c|c|c|}
\hline 80: & 7.558 & ז.427 & 7.414 & 7.395 & 7.547 & 7.401 & .6425 \\
\hline 81: & 6.660 & 6.578 & 6.568 & 6.552 & 6.669 & 6.565 & .6184 \\
\hline 82: & 5.528 & 6.457 & 6.452 & 6.445 & 6.515 & 6.444 & .4249 \\
\hline 83: & 6.342 & 6.302 & 6.296 & 6.288 & 6.339 & 6.290 & .4601 \\
\hline 84: & 6.639 & 6.615 & 6.507 & 6.597 & 6.605 & 6.593 & .5112 \\
\hline 85: & 6.739 & 6.685 & 6.580 & 6.574 & 6.719 & 6.670 & .3974 \\
\hline 86: & 6.606 & 6.574 & 6.5602 & 6.545 & 6.607 & 6.557 & .6545 \\
\hline 87: & 6.743 & 6.705 & 6.693 & 6.675 & 6.753 & 6.689 & .6597 \\
\hline 88: & 6.467 & 6.546 & 6.537 & 6.522 & 6.454 & 6.526 & .5914 \\
\hline 89: & 6.479 & 6.561 & 6.552 & 6.540 & 6.461 & 6.541 & .5525 \\
\hline 90: & 6.719 & 6.624 & 6.616 & 5.604 & 6.710 & 6.608 & .5390 \\
\hline 91: & 6.856 & 6.827 & 6.821 & 6.813 & 6.841 & 6.812 & .4410 \\
\hline 92: & 6.535 & 6.550 & 6.542 & 6.531 & 6.526 & 6.534 & .5184 \\
\hline 93: & 6.819 & 6.723 & 6.718 & 6.711 & 6.808 & 6.710 & .4192 \\
\hline 94: & 7.111 & 7.051 & 7.047 & 7.041 & 7.083 & 7.035 & .3666 \\
\hline 95: & 6.549 & 5.996 & 6.994 & 6.990 & 6.934 & 6.985 & .2972 \\
\hline 96: & 9.055 & 9.008 & 8.984 & 8.950 & 9.086 & 8.584 & .7851 \\
\hline 97: & 9.047 & 9.008 & 8.983 & 8.946 & 9.090 & 8.987 & .8131 \\
\hline 98: & 8.649 & 8.693 & 8.670 & 8.636 & 8.509 & 8.648 & .7902 \\
\hline 99: & 8.706 & 8.870 & 8.854 & 8.831 & 8.648 & 8.830 & .6474 \\
\hline 100: & 8.891 & 8.870 & 0.058 & 8.841 & 8.862 & 8.841 & .5565 \\
\hline 101: & 8.794 & 8.740 & 8.731 & 8.719 & 8.804 & 8.726 & .4825 \\
\hline 102: & 8.011 & 8.007 & 7.997 & .7 .980 & 8.031 & 7.993 & .5719 \\
\hline 103: & 8.534 & 8.326 & 8.311 & 8.289 & 8.540 & 8.305 & .6545 \\
\hline 104: & 8.498 & 8.357 & 8.348 & 8.335 & 8.480 & 8.335 & .5108 \\
\hline 105: & 8.490 & 8.379 & 8.369 & 8.355 & 8.473 & 8.357 & .5243 \\
\hline 106: & 8.935 & 8.921 & 8.912 & 8.898 & 8.560. & 8.910 & .4954 \\
\hline 107: & 8.970 & 9.208 & 9.197 & 9.181 & 8.992 & 9.191 & 283 \\
\hline
\end{tabular}




\begin{tabular}{|c|c|c|c|c|c|c|c|}
\hline 108: & 9.213 & 9.242 & 9.234 & 9.221 & 9.199 & 9.220 & .4640 \\
\hline 109: & 8.959 & 8.940 & 8.919 & 8.889 & 8.993 & 8.919 & .7410 \\
\hline $110:$ & 9.381 & 9.293 & 9.277 & 9.252 & 9.395 & 9.269 & .6482 \\
\hline 111: & 9.573 & 9.430 & 9.403 & 9.364 & 9.586 & 9.394 & .8127 \\
\hline 112: & 8.998 & 8.946 & 8.921 & 8.884 & 9.013 & 8.914 & $: 8076$ \\
\hline 113: & 9.355 & 9.150 & 9.142 & 3.131 & 9.338 & 9.130 & .4536 \\
\hline 114: & 8.764 & 8.781 & 8.770 & 8.752 & 8.790 & 8.768 & .5698 \\
\hline 115: & 8.824 & 8.867 & 8.838 & 8.795 & 8.815 & 8.822 & .8731 \\
\hline 116: & 8.766 & 9.001 & 8.979 & 8.948 & 8.791 & 8.974 & .7524 \\
\hline 117: & 8.579 & 8.582 & 8.554 & 8.512 & 8.618 & 8.556 & .8774 \\
\hline 118: & 6.943 & 6.938 & 6.528 & 6.912 & 6.897 & 6.910 & .5962 \\
\hline 119: & 7.218 & 7.108 & 7.106 & 7.104 & $? .175$ & 7.094 & .2553 \\
\hline 120: & 7.020 & 7.124 & 7.113 & 7.110 & 7.023 & 7.112 & .4384 \\
\hline 121: & 6.862 & 6.912 & 6.900 & 6.881 & 6.858 & 6.891 & .6006 \\
\hline e2: & 6.898 & 6.954 & 6.548 & 6.939 & 6.892 & 6.940 & .4552 \\
\hline 123: & 6.594 & 6.701 & 6.634 & 6.682 & 6.564 & 6.680 &.$\Xi 260$ \\
\hline 124: & 6.441 & 6.560 & 6.541 & 6.515 & 5.398 & 6.523 & .8069 \\
\hline 125: & 6.418 & 6.529 & 6.513 & 6.489 & 6.388 & 6.497 & .7648 \\
\hline 126: & 6.632 & 6.504 & 6.490 & 6.468 & 6.581 & 6.469 & .7270 \\
\hline 127: & 6.430 & 6.586 & 6.581 & 6.573 & $6: 417$ & 6.571 & .4370 \\
\hline $128:$ & 6.777 & 6.566 & 6.561 & 6.554 & 6.P63 & 6.554 & .4236 \\
\hline 129: & 6.625 & 6.685 & 6.679 & 6.670 & 6.613 & 6.669 & .4641 \\
\hline 130: & 6.837 & 6.836 & 6.833 & 6.828 & 6.829 & 6.825 & .3442 \\
\hline 131: & 7.912 & 7.926 & 7.895 & 7.850 & 7.901 & 7.881 & .9532 \\
\hline 132: & 8.039 & 8.117 & 8.082 & 8.033 & 8.004 & 8.062 & .5881 \\
\hline 33: & 8.038 & 8.111 & 8.086 & 8.050 & 8.010 & 8.069 & .8429 \\
\hline 134: & 7.965 & 8.130 & 8.105 & 8.069 & 7.983 & 8.098 & .8450 \\
\hline
\end{tabular}




\begin{tabular}{|c|c|c|c|c|c|c|c|}
\hline 135: & 8.505 & 8.522 & 8.506 & 8.481 & 8.457 & 8.484 & .6863 \\
\hline 136: & 9.122 & 9.216 & 9.211 & 9.203 & 9.058 & 9.190 & .3658 \\
\hline 137: & 8.097 & 8.249 & 8.221 & 8.180 & 8.076 & 8.204 & .8851 \\
\hline 138: & 8.033 & 8.060 & 8.047 & 8.0ट8. & 3.042 & 8.040 & .6203 \\
\hline 139: & 8.035 & $7: 743$ & 7.717 & 7.679 & 8.042 & 7.712 & .8845 \\
\hline 140: & 8.534 & .8 .518 & 8.507 & 8.491 & 8.479 & 8.486 & .5532 \\
\hline 141: & 8.798 & 8.732 & 8.723 & 8.711 & 8.736 & 8.702 & .4740 \\
\hline 142: & 7.953 & 8.029 & 8.024 & 8.017 & 7.874 & 8.002 & .3802 \\
\hline 143: & 7.741 & 7.873 & 7.857 & 7.834 & 7.695 & 7.838 & .6891 \\
\hline 144: & 7.641 & 7.746 & 7.728 & 7.702 & 7.592 & 7.707 & .7305 \\
\hline 145: & 7.843 & 7.632 & 7.619 & 7.599 & 7.825 & 7.606 & .6433 \\
\hline 146: & 7.569 & 7.467 & 7.456 & 7.439 & 7.582 & 7.453 & .6048 \\
\hline 147: & 8.008 & 7.992 & 7.981 & 7.966 & 7.891 & 7.950 & .5530 \\
\hline 148: & 7.890 & 7.705 & 7.684 & 7.654 & 7.779 & 7.648 & .7901 \\
\hline 149: & 7.554 & 7.456 & 7.433 & 7.400 & 7.465 & 7.402 & .8400 \\
\hline 150: & 7.816 & 7.832 & 7.808 & 7.772 & 7.724 & 7.776 & .8549 \\
\hline 151: & 7.443 & 7.494 & 7.454 & 7.400 & 7.372 & 7.424 & 1.0867 \\
\hline 152: & 7.573 & 7.575 & 7.542 & 7.497 & 7.509 & 7.515 & .9838 \\
\hline 153: & 7.302 & 7.228 & 7.188 & 7.135 & 7.295 & 7.175 & 1.0945 \\
\hline 154: & 6.947 & 7.022 & 7.012 & 6.997 & 6.899 & 6.994 & .5792 \\
\hline 155: & 7.105 & 7.185 & 7.184 & 7.182 & 7.059 & 7.171 & .2119 \\
\hline 156: & 7.898 & 8.003 & 7.995 & 7.982 & 7.967 & 7.979 & .5036 \\
\hline 157: & 7.810 & 7.869 & 7.857 & 7.839 & 7.776 & 7.839 & .6072 \\
\hline 158: & 7.176 & 7.285 & 7.275 & 7.261 & 7.146 & 7.260 & .5673 \\
\hline 155: & 7.894 & 7.851 & 7.845 & 7.836 & 7.855 & 7.830 & .4242 \\
\hline 160: & 7.576 & 7.333 & 7.317 & ᄀ. 233 & P. 931 . & 7.295 & .7230 \\
\hline 161: & 7.486 & 7.618 & 7.605 & 7.585 & 7.450 & 7.588 & .6430 \\
\hline 162: & 7.758 & 7.585 & 7.578 & 7.568 & 7.743 & 7.568 & .4669 \\
\hline
\end{tabular}




$\begin{array}{lllllll}163: 8.036 & 7.909 & 7.897 & 7.879 & 7.996 & 7.879 & .6017 \\ 164: 7.536 & 7.358 & 7.343 & 7.320 & 7.482 & 7.320 & .7074 \\ 165: 7.494 & 7.489 & 7.494 & 7.478 & 7.385 & 7.460 & .3746 \\ 166: 7.194 & 7.122 & 7.102 & 7.073 & 7.042 & 7.060 & .8127 .\end{array}$


Table F-5 Deviations of the Different Methods from $\operatorname{SEER}\left(B L D\right.$ ) when Using $\dot{\mathrm{E}}_{C} / \overline{\mathrm{E}}_{D}=1$.

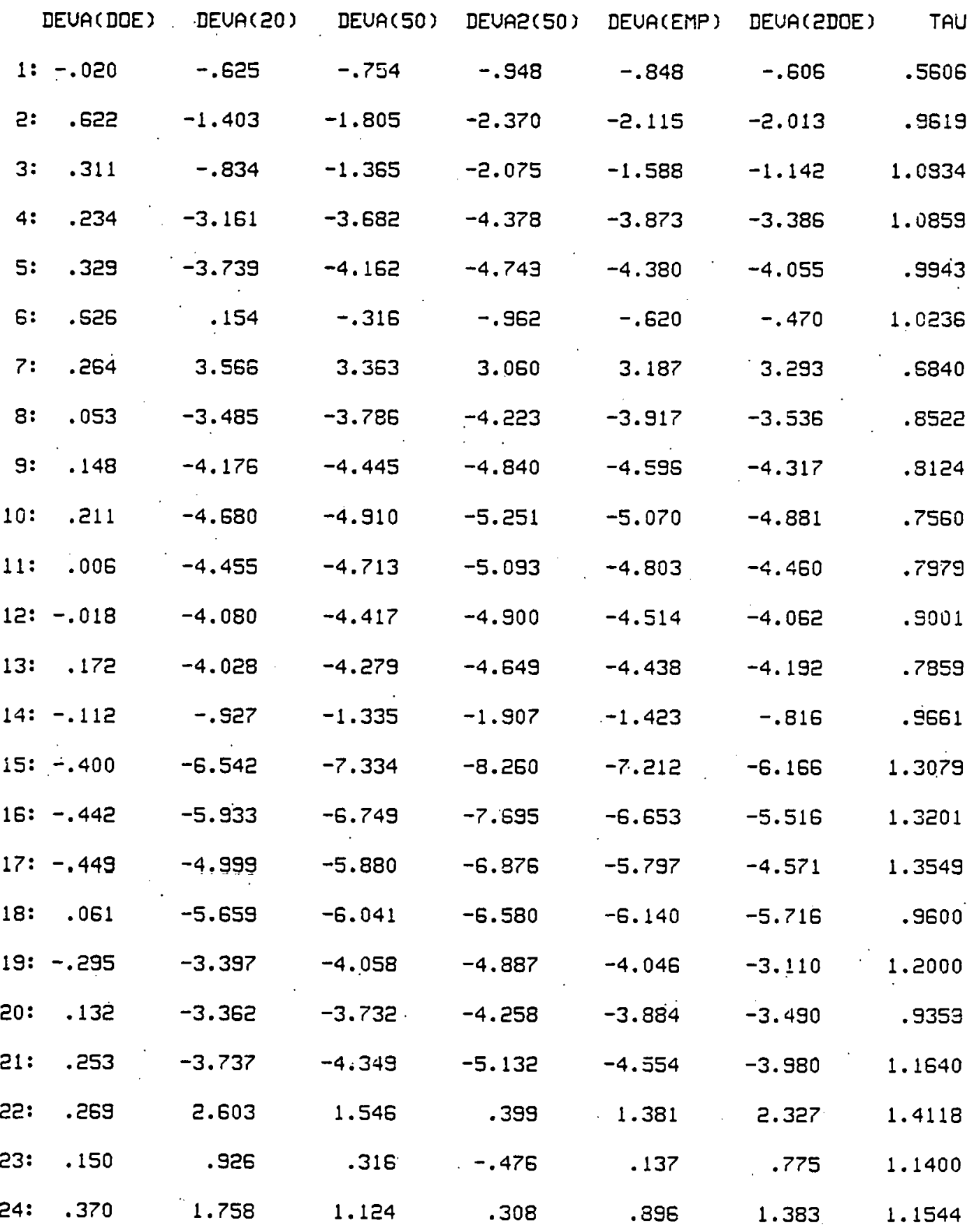




\begin{tabular}{|c|c|c|c|c|c|c|c|}
\hline 25: & .016 & -3.291 & -3.670 & -4.205 & -3.7 .94 & -3.306 & .9451 \\
\hline $26:$ & .300 & -4.675 & -4.994 & -5.455 & -5.199 & -4.960 & .8808 \\
\hline $27:$ & .115 & -4.116 & -4.502 & -5.045 & -4.663 & -4.227 & .9563 \\
\hline 28: & .114 & -4.509 & -4.728 & -5.052 & -4.853 & -4.618 & .7374 \\
\hline 29: & -.147 & -5.767 & -6.281 & -6.965 & -6.323 & -5.629 & 1.0919 \\
\hline 30: & .118 & -6.171 & -6.500 & -6.974 & -6.620 & -6.282 & .9000 \\
\hline 31: & -.097 & -5.918 & -6.547 & -7.341 & -6.611 & -5.827 & 1.1886 \\
\hline 32: & .100 & -6.567 & -7.010 & -7.017 & -7.141 & -6.660 & 1.0284 \\
\hline 33: & -.511 & -.306 & -1.507 & -2.726 & -1.329 & .206 & 1.4999 \\
\hline 34: & .166 & 2.816 & 2.468 & 1.966 & 2.301 & 2.645 & .8852 \\
\hline $35:$ & .010 & 2.397 & 2.032 & 1.510 & 1.911 & 2.386 & .9054 \\
\hline $36:$ & .057 & 3.071 & 2.689 & 2.143 & 2.558 & 3.013 & .9230 \\
\hline $37:$ & .470 & 4.398 & 4.245 & 4.015 & 4.044 & 3.910 & .5948 \\
\hline 35: & .486 & 4.427 & 4.225 & 3.923 & 4.011 & 3.922 & .5804 \\
\hline 39: & .657 & 4.256 & 4.124 & 3.925 & 3.887 & 3.575 & .5534 \\
\hline $40:$ & -.281 & 2.425 & 2.030 & 1.469 & 1.997 & 2.714 & .9392 \\
\hline 41: & -.353 & 2.232 & 2.004 & 1.867 & 1.958 & 2.553 & .7265 \\
\hline 42: & -.294 & 2.450 & 2.040 & 1.461 & 1.989 & 2.752 & .9548 \\
\hline 43: & .162 & 3.550 & 3.433 & 3.259 & 3.281 & 3.383 & .5220 \\
\hline 44: & .331 & 3.937 & 3.781 & 3.547 & 3.605 & 3.594 & .5013 \\
\hline 45: & .415 & 3.644 & 3.357 & 2.936 & 3.138 & 3.215 & .8052 \\
\hline 46: & .025 & 2.138 & 1.882 & 1.504 & 1.759 & 2.113 & .7697 \\
\hline 47: & .019 & .2 .743 & 2.533 & 2.222 & 2.408 & 2.723 & .6970 \\
\hline 48: & .190 & 2.658 & 2.405 & 2.031 & 2.239 & 2.464. & .7539 \\
\hline 49: & .505 & 3.215 & 3.014 & 2.715 & 2.789 & 2.696 &.$E 821$ \\
\hline 50: & .464 & 3.763 & 3.635 & 3.442 & 3.440 & 3.284 & .5467 \\
\hline 51: & .470 & 3.597 & 3.438 & 3.205 & 3.243 & 3.110 & .6015 \\
\hline 52: & .126 & 3.444 & 3.316 & 3.124 & 3.168 & 3.313 & .5467 \\
\hline
\end{tabular}




\begin{tabular}{|c|c|c|c|c|c|c|c|}
\hline 53: & .108 & 3.419 & $3.2=0$ & 2.923 & 3.078 & 3.308 & .6782 \\
\hline 54: & -.083 & 3.856 & 3.694 & 3.452 & 3.581 & 3.942 & .6119 \\
\hline 55: & .810 & 5.950 & 5.628 & .5 .146 & 5.327 & 5.108 & .8541 \\
\hline 56: & .732 & 9.744 & 9.429 & 8.567 & 9.164 & 8.893 & .8206 \\
\hline 57: & .872 & 5.585 & 5.217 & 4.688 & 4.892 & 4.673 & .8974 \\
\hline 58: & .373 & 4.609 & 4.504 & 4.348 & 4.324 & 4.220 & .4918 \\
\hline 59: & .402 & 4.738 & 4.628 & 4.464 & 4.447 & 4.319 & .5030 \\
\hline 60: & .356 & 5.897 & 5.774 & 5.589 & 5.596 & 5.521 & .5305 \\
\hline 61: & .609 & 6.150 & 5.823 & 5.347 & 5.589 & 5.508 & .8478 \\
\hline 62: & .935 & 6.642 & 6.246 & 5.581 & $5 . \$ 36$ & 5.654 & .9230 \\
\hline 63: & .535 & 5.837 & 5.478 & 4.961 & 5.256 & 5.273 & .8354 \\
\hline 64: & -.069 & 4.350 & 4.067 & 3.651 & 3.954 & 4.422 & .7986 \\
\hline 65: & -.009 & 4.401 & 4.095 & 3.645 & 3.978 & 4.410 & .8276 \\
\hline 66: & .139 & 5.465 & 5.169 & 4.735 & 5.024 & 5.318 & .8120 \\
\hline 67: & .558 & 5.906 & 5.610 & 5.175 & 5.364 & 5.319 & .8107 \\
\hline 68: & .539 & 5.631 & 5.395 & 5.044 & 5.170 & 5.054 & .7287 \\
\hline 69: & .410 & 5.662 & 5.438 & 5.104 & 5.243 & 5.231 & .7114 \\
\hline $70:$ & -.006 & 1.474 & 1.411 & 1.316 & 1.301 & 1.480 & .3897 \\
\hline $71:$ & .282 & .519 & .411 & .248 & .236 & .236 & .5108 \\
\hline 72: & .219 & 1.279 & 1.033 & .668 & .842 & 1.058 & .7586 \\
\hline 73: & .189 & 1.319 & 1.159 & .544 & 1.015 & 1.128 & .5975 \\
\hline 74: & .075 & -1.284 & -1.398 & -1.569 & -1.510 & -1.358 & .5288 \\
\hline $75:$ & .226 & -.670 & -.811 & -1.022 & -.972 & -.894 & .5852 \\
\hline $76:$ & .538 & -.809 & -.891 & -1.014 & -1.134 & -1.340 & .4486 \\
\hline 77: & .439 & .518 & .504 & .482 & .356 & .078 & .1874 \\
\hline 78: & .263 & -.106 & -.163 & -.248 & -.304 & -.368 & .3729 \\
\hline 79: & .162 & .157 & .096 & .004 & -.026 & -.005 & .3873 \\
\hline
\end{tabular}




\begin{tabular}{|c|c|c|c|c|c|c|c|}
\hline 80: & .276 & -1.598 & -1.767 & -2.021 & -1.943 & -1.869 & .6426 \\
\hline 81: & -.137 & -1.358 & -1.515 & -1.750 & -1.562 & -1.223 & .6184 \\
\hline 82: & .202 & -.892 & -.966 & -1.076 & -1.094 & -1.092 & .4249 \\
\hline 83: & .049 & -.583 & -.669 & -.799 & -.767 & -.632 & .4601 \\
\hline 84: & .511 & $\therefore 148$ & .040 & -.122 & -.172 & -.361 & .5112 \\
\hline 85: & .288 & -.513 & -.577 & -.674 & -.726 & -.799 & .3974 \\
\hline 86: & -.028 & -.506 & -.684 & -.950 & -.771 & -.478 & .6545 \\
\hline 87: & -.157 & -.714 & -.894 & -1.164 & -.946 & -.557 & .6597 \\
\hline 88: & .204 & 1.424 & 1.277 & 1.056 & 1.115 & 1.218 & .5914 \\
\hline 89: & .231 & 1.537 & 1.409 & 1.217 & 1.237 & 1.253 &.$\Xi 525$ \\
\hline 90: & .136 & -1.286 & -1.405 & -1.583 & -1.525 & -1.420 & .5390 \\
\hline 91: & .221 & -.202 & -.281 & -.401 & -.419 & -.421 & .4410 \\
\hline 92: & .147 & .356 & .255 & .088 & .126 & .219 & $.5: 84$ \\
\hline 93: & .156 & -1.254 & -1.325 & -1.432 & -1.442 & -1.408 & .4192 \\
\hline 94: & .392 &.- .464 & -.518 & $\therefore .601$ & -.682 & -.852 & .3666 \\
\hline 95: & .218 & .902 & .866 & .811 & .741 & .683 & .2972 \\
\hline SE: & -.346 & -.859 & -1.119 & -1.500 & -1.125 & -.515 & .7851 \\
\hline $97:$ & -.474 & -.899 & -1.179 & -1.588 & -1.137 & -.428 & .8131 \\
\hline 98: & .470 & .982 & .715 & .321 & .461 & .510 & .7902 \\
\hline 99: & .671 & 2.568 & 2.389 & 2.121 & 2.112 & 1.385 & .6474 \\
\hline 100: & .335 & .092 & -.037 & -.229 & -.228 & -.243 & .5565 \\
\hline 101: & -.112 & -.731 & -.826 & -.969 & -.889 & -.620 & .4825 \\
\hline 102: & -.250 & -.239 & -.424 & -.627 & -.463 & -.039 & .5719 \\
\hline 103: & -.074 & -2.513 & -2.687 & -2.947 & -2.758 & -2.440 & .6545 \\
\hline 104: & .217 & -1.448 & -1.554 & -1.713 & -1.706 & -1.662 & .5108 \\
\hline 105: & .152 & -1.114 & -1.226 & -1.395 & -1.375 & -1.303 & .5243 \\
\hline 106: & -.279 & -.435 & -.535 & -.686 & -.550 & -.156 & .4954 \\
\hline 107: & -.246 & 2.397 & 2.279 & 2.102 & 2.211 & 2.650 & .5283 \\
\hline
\end{tabular}




\begin{tabular}{|c|c|c|c|c|c|c|c|}
\hline 108: & .152 & .464 & .375 & .242 & .222 & .312 & .4640 \\
\hline 10s: & -.385 & -.589 & -.820 & -1.161 & -.820 & -.205 & .7416 \\
\hline 110: & -.148 & -1.085 & -1.257 & -1.515 & -1.339 & -.938 & .5462 \\
\hline 111: & -.134 & -1.623 & -1.900 & -2.306 & -1.594 & -1.491 & .8127 \\
\hline 112: & -.165 & -.748 & -1.023 & -1.428 & -1.097 & -.583 & .8076 \\
\hline 113: & .177 & -2.019 & -2.102 & -2.226 & $-2: 233$ & -2.192 & .4530 \\
\hline 114: & -.287 & -.095 & $-.2 \Sigma 9$ & -.431 & -.251 & .192 & .5698 \\
\hline 115: & .100 & .590 & .260 & -.218 & .080 & .489 & .8731 \\
\hline 116: & -.292 & 2.384 & 2.139 & 1.777 & 2.081 & 2.683 & .7524 \\
\hline 117: & -.448 & -.416 & -.747 & -1.225 & -.717 & .032 & .8774 \\
\hline 118: & .662 & .589 & .440 & .218 & .186 & -.072 & .5952 \\
\hline 119: & .604 & -.929 & -.956 & -.995 & -1.130 & -1.524 & .2553 \\
\hline 120: & -.043 & 1.431 & 1.351 & 1.231 & 1.272 & 1.474 & .4384 \\
\hline 121: & .059 & .785 & .601 & .327 & .477 & .725 & .6606 \\
\hline 122: & .081 & .001 & .815 & .686 & .699 & .820 & .4552 \\
\hline 123: & .468 & 2.101 & 1.984 & 1.809 & 1.780 & 1.625 & .5260 \\
\hline 124: & .663 & 2.518 & 2.234 & 1.817 & 1.947 & 1.843 & .3069 \\
\hline 125: & .479 & 2.209 & 1.956 & 1.583 & 1.715 & 1.722 & .7548 \\
\hline 126: & .763 & -1.174 & -1.394 & -1.720 & -1.702 & -1.922 & .7270 \\
\hline 127: & .211 & 2.639 & 2.559 & 2.438 & 2.413 & 2.423 & .4370 \\
\hline 128: & .205 & -2.916 & -2.987 & -3.095 & -3.098 & -3.115 & .4236 \\
\hline 129: & .185 & 1.088 & .998 & .864 & .852 & .901 & .7641 \\
\hline 130: & .116 & .100 & .051 & -.021 & -.060 & -.017 & .3442 \\
\hline 131: & .142 & .323 & -.078 & -.643 & -.248 & .180 & .9532 \\
\hline 132: & .436 & 1.418 & .979 & .367 & .722 & .978 & .9881 \\
\hline 133: & .353 & 1.261 & .952 & .503 & .738 & .904 & .8429 \\
\hline 134: & -.222 & 1.845 & 1.533 & 1.079 & 1.451 & 2.071 & .5450 \\
\hline
\end{tabular}




\begin{tabular}{|c|c|c|c|c|c|c|c|}
\hline 135: & .568 & .772 & .574 & .277 & .317 & .203 & .6863 \\
\hline 136: & .708 & 1.744 & 1.688 & 1.505 & 1.460 & 1.029 & .3658 \\
\hline 137: & $.251^{\circ}$ & 2.140 & 1.794 & 1.296 & 1.593 & 1.874 & .8851 \\
\hline 138: &.$- i 11$ & .225 & .054 & -.176 & -.020 & $.33 E$ & .6203 \\
\hline 135: & -.091 & -3.719 & -4.045 & -4.514 & -4.113 & -3.632 & .8845 \\
\hline $140:$ & .643 & .457 & .330 & .139 & .076 & -.185 & .5532 \\
\hline 141: & .714 & -.048 & -.140 & -.279 & -.388 & -.756 & .4740 \\
\hline 142: & 1.000 & 1.965 & 1.904 & 1.814 & $1.634^{\circ}$ & .955 & .3802 \\
\hline 143: & .592 & 2.312 & 2.108 & 1.805 & 1.856 & 1.710 & .5891 \\
\hline 144: & .651 & 2.025 & 1.796 & 1.455 & 1.521 & 1.365 & .7305 \\
\hline 145: & .230 & -2.471 & -2.639 & -2.351 & -2.797 & -2.695 & .6433 \\
\hline 146: & -.181 & -1.521 & -1.670 & -1.894 & -1.709 & -1.342 & .6048 \\
\hline 147: & 1.476 & 1.278 & 1.145 & .946 & .750 & -.195 & .5630 \\
\hline 148: & 1.422 & -.958 & -1.221 & -1.607 & -1.685 & -2.347 & .7901 \\
\hline 149: & 1.189 & -.120 & -.422 & -.362 & -.847 & -1.294 & .8400 \\
\hline 150: & 1.190 & 1.399 & 1.081 & .619 & .669 & .207 & .8549 \\
\hline 151: & .953 & 1.650 & 1.101 & .370 & .704 & .690 & 1.0867 \\
\hline 152: & .850 & .869 & .437 & -.166 & .076 & .019 & .9838 \\
\hline 153: & .095 & -.920 & -1.463 & -2.185 & -1.647 & -1.013 & 1.0945 \\
\hline 154: & .685 & 1.771 & 1.630 & 1.418 & 1.374 & 1.079 & .5792 \\
\hline 155: & .650 & 1.783 & 1.765 & 1.737 & 1.587 & 1.127 & .2119 \\
\hline 15E: & .399 & 1.729 & 1.623 & 1.463 & 1.429 & 1.325 & .5036 \\
\hline 157: & .447 & 1.199 & 1.044 & .811 & .820 & .748 & .6072 \\
\hline 158: & .419 & 1.937 & 1.801 & 1.598 & 1.597 & 1.512 & .5673 \\
\hline 159: & .488 & -.057 & -.131 & -.242 & -.324 & -.543 & .4242 \\
\hline 160: & .593 & -2.638 & -2.852 & -3.169 & -3.123 & -3.211 & .7230 \\
\hline 161: & .484 & 2.246 & 2.070 & 1.806 & 1.341 & 1.754 & .8430 \\
\hline 162: & .196 & -2.034 & -2.122 & -2.254 & -2.254 & -2.226 & .4669 \\
\hline
\end{tabular}




\begin{tabular}{|c|c|c|c|c|c|c|c|}
\hline 163: & .493 & -1.088 & -1.236 & -1.459 & $-1.4 E 3$ & -1.573 & .6017 \\
\hline 164: & .720 & -1.658 & -1.864 & -2.172 & -2.162 & -2.361 & .7074 \\
\hline 165: & 1.481 & 1.405 & 1.345 & 1.259 & 1.016 & -.075 & .3746 \\
\hline 166: & 2.149 & 1.137 & .852 & .435 & .257 & -.991 & .8127 \\
\hline
\end{tabular}

